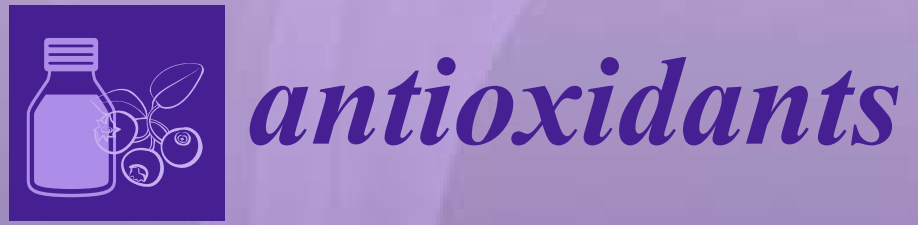

\title{
Peroxiredoxin 6 as a Unique Member of the Peroxiredoxin Family
}

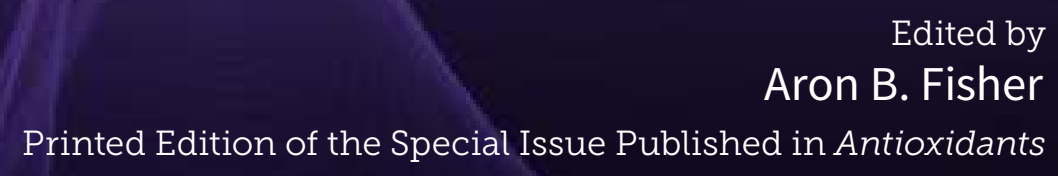


Peroxiredoxin 6 as a Unique Member of the Peroxiredoxin Family 



\section{Peroxiredoxin 6 as a Unique Member of the Peroxiredoxin Family}

Special Issue Editor Aron B. Fisher 
Special Issue Editor

Aron B. Fisher

University of Pennsylvania

USA

Editorial Office

MDPI

St. Alban-Anlage 66

4052 Basel, Switzerland

This is a reprint of articles from the Special Issue published online in the open access journal Antioxidants (ISSN 2076-3921) from 2018 to 2019 (available at: https://www.mdpi.com/journal/ antioxidants/special_issues/Peroxiredoxin)

For citation purposes, cite each article independently as indicated on the article page online and as indicated below:

LastName, A.A.; LastName, B.B.; LastName, C.C. Article Title. Journal Name Year, Article Number, Page Range.

ISBN 978-3-03897-934-0 (Pbk)

ISBN 978-3-03897-935-7 (PDF)

(C) 2019 by the authors. Articles in this book are Open Access and distributed under the Creative Commons Attribution (CC BY) license, which allows users to download, copy and build upon published articles, as long as the author and publisher are properly credited, which ensures maximum dissemination and a wider impact of our publications.

The book as a whole is distributed by MDPI under the terms and conditions of the Creative Commons license CC BY-NC-ND. 


\section{Contents}

About the Special Issue Editor $\ldots \ldots \ldots \ldots \ldots \ldots \ldots$ vii

\section{Aron B. Fisher}

Antioxidants Special Issue: Peroxiredoxin 6 as a Unique Member of the Peroxiredoxin Family

Reprinted from: Antioxidants 2019, 8, 107, doi:10.3390/antiox8040107 . . . . . . . . . . 1

Sheldon I. Feinstein

Mouse Models of Genetically Altered Peroxiredoxin 6

Reprinted from: Antioxidants 2019, 8,77, doi:10.3390/antiox8040077 . . . . . . . . . . . 6

Renata Bannitz-Fernandes, Rogério Aleixo-Silva, João Paulo Silva, Chandra Dodia,

Jose Pablo Vazquez-Medina, Jian-Qin Tao, Aron Fisher and Luis Netto

Non-Mammalian Prdx6 Enzymes (Proteins with 1-Cys Prdx Mechanism) Display PLA 2 Activity

Similar to the Human Orthologue

Reprinted from: Antioxidants 2019, 8, 52, doi:10.3390/antiox8030052 . . . . . . . . . . 16

Sharifun Shahnaj, Rimpy Kaur Chowhan, Potshangbam Angamba Meetei, Pushpa

Kakchingtabam, Khundrakpam Herojit Singh, Laishram Rajendrakumar Singh,

Potshangbam Nongdam, Aron B. Fisher and Hamidur Rahaman

Hyperoxidation of Peroxiredoxin 6 Induces Alteration from Dimeric to Oligomeric State

Reprinted from: Antioxidants 2019, 8, 33, doi:10.3390/antiox8020033 . . . . . . . . . . . 33

Suiping Zhou, Chandra Dodia, Sheldon I. Feinstein, Sandra Harper, Henry J. Forman,

David W. Speicher and Aron B. Fisher

Oxidation of Peroxiredoxin 6 in the Presence of GSH Increases its Phospholipase $A_{2}$ Activity at

Cytoplasmic $\mathrm{pH}$

Reprinted from: Antioxidants 2019, 8, 4, doi:10.3390/antiox8010004 . . . . . . . . . . . 47

José A. Arevalo and José Pablo Vázquez-Medina

The Role of Peroxiredoxin 6 in Cell Signaling

Reprinted from: Antioxidants 2018, 7, 172, doi:10.3390/antiox7120172 . . . . . . . . . . 61

Aron B. Fisher, Chandra Dodia and Sheldon I. Feinstein

Identification of Small Peptides that Inhibit NADPH Oxidase (Nox2) Activation

Reprinted from: Antioxidants 2018, 7, 181, doi:10.3390/antiox7120181 _ . . . . . . . . . 73

Priyal Patel and Shampa Chatterjee

Peroxiredoxin6 in Endothelial Signaling

Reprinted from: Antioxidants 2019, 8, 63, doi:10.3390/antiox8030063 . . . . . . . . . . . 86

Matthew Lovatt, Khadijah Adnan, Gary S. L. Peh and Jodhbir S. Mehta

Regulation of Oxidative Stress in Corneal Endothelial Cells by Prdx6

Reprinted from: Antioxidants 2018, 7, 180, doi:10.3390/antiox7120180 _ . . . . . . . . 98

Mars G. Sharapov, Vladimir I. Novoselov and Sergey V. Gudkov

Radioprotective Role of Peroxiredoxin 6

Reprinted from: Antioxidants 2019, 8, 15, doi:10.3390/antiox8010015 . . . . . . . . . . . 110

Cristian O'Flaherty

Peroxiredoxin 6: The Protector of Male Fertility

Reprinted from: Antioxidants 2018, 7, 173, doi:10.3390/antiox7120173 . . . . . . . . . . . 133 



\section{About the Special Issue Editor}

Aron B. Fisher received an MD degree from the University of Pennsylvania School of Medicine followed by post-doctoral training in internal medicine and pulmonary physiology at the University Hospitals of Cleveland, the Hospital of the University of Pennsylvania, and the University of Pennsylvania School of Medicine. He was appointed to the University of Pennsylvania School of Medicine faculty in 1968 and was promoted through the ranks to Professor of Physiology and Medicine in 1980. Five years later, he was re-appointed as Professor of Physiology and Environmental Medicine and Director of The Institute for Environmental Medicine. His research interests have been focused on the cell biology of the lung, with a special interest in oxidative stress and antioxidant defense, lung endothelial mechano-transduction, and lung surfactant phospholipid turnover. He has been continuously supported for the past 45 years by the National Heart Lung and Blood Institute (USA) and has published over 250 articles of peer-reviewed research. He has served on the editorial boards of Experimental Lung Research, the American Review of Respiratory Diseases (currently called the American Journal of Respiratory and Critical Care Medicine), the Journal of Applied Physiology, the American Journal of Physiology: Lung Cellular and Molecular Physiology, Antioxidants and Redox Signaling, and Current Respiratory Medicine Reviews. He served as co-editor of the section on The Respiratory System in the Handbook of Physiology (1980-85) published by the American Physiological Society. He has also served as the editor of forums on Lung Surfactant Active Proteins (Experimental Lung Research), Mechanotransduction: Forces, Sensors and Redox Signaling (Antioxidants and Redox Signaling), Extension of Oxygen Tolerance (Experimental Lung Research), and Oxidants and Antioxidants (American J. Respiratory and Critical Care Medicine). 



\title{
Antioxidants Special Issue: Peroxiredoxin 6 as a Unique Member of the Peroxiredoxin Family
}

\author{
Aron B. Fisher \\ Department of Physiology and the Institute for Environmental Medicine, University of Pennsylvania, \\ Philadelphia, PA 19104, USA; abf@upenn.edu
}

Received: 15 April 2019; Accepted: 17 April 2019; Published: 19 April 2019

check for updates

The peroxiredoxins, first discovered about 30 years ago, are the most recently described family of ubiquitously expressed antioxidant enzymes [1,2]. These proteins have been classified into six groups (PRX1, PRX5, PRX6, PRXQ, TPx, and ahpE) that include both vertebrate and non-vertebrate forms [3]. A mammalian-only classification also recognizes six groups by expanding the PRX1 group into four closely related sub-groups (PRX1-4) plus PRX5 and PRX6. PRX6 is frequently abbreviated Prdx6, as is used in this Special Issue. Prdx6, first isolated about 25 years ago, was the last of the mammalian family of peroxiredoxins to be described and its molecular sequence was published shortly afterwards [4-6]. In the older literature, this enzyme also has been called 1-cys peroxiredoxin, nonselenium glutathione peroxidase (GPx), acidic $\mathrm{Ca}^{2+}$-independent phospholipase $\mathrm{A}_{2}($ aiPLA 2$)$, antioxidant protein 2 (AOP2), Clara cell protein 26 (CC26), and protein p29 [7]. While Prdx6 shows sequence homology with the other PRX forms and like them functions to reduce $\mathrm{H}_{2} \mathrm{O}_{2}$, short chain hydroperoxides, and peroxinitrite $[1,8]$, it also shows some important distinguishing characteristics.

The special characteristics that differentiate Prdx6 from the other PRXs include:

(1) Catalytic mechanism: All peroxiredoxins express a conserved cysteine (Cys) residue, called the peroxidatic Cys, that is oxidized by interaction with $\mathrm{H}_{2} \mathrm{O}_{2}$ or other oxidant substrate. The PRX 1-5 family members express a second (resolving) Cys that, in conjunction with thioredoxin, reduces the peroxidatic Cys and restores the physiologically active form. Prdx6, however, expresses only a single conserved Cys and uses glutathione (GSH) plus GSH S-transferase (GST) for reduction and resolution of its oxidized peroxidatic Cys [9];

(2) Substrate binding: Unlike other PRXs, Prdx6 can bind to phospholipids [10]. This is important for several enzymatic activities of Prdx6 (described next) that are not present in other members of the PRX family of enzymes.

(3) Phospholipid hydroperoxide reductase activity: Prdx6 is able to bind and to reduce phospholipid hydroperoxides that may be produced as a result of oxidative stress [11]. This phospholipid hydroperoxide reductase activity is analogous to the enzymatic activity of GSH peroxidase, type 4 (GPx4); the protein with the dominant reductase activity in any given tissue appears to vary with cell type [12].

(4) Phospholipid hydrolysis: Phospholipids bound to Prdx6 can be hydrolyzed at the sn-2 position indicating a phospholipase $\mathrm{A}_{2}\left(\mathrm{PLA}_{2}\right)$ activity [13];

(5) Lysophosphosphatidylcholine acyltransferase (LPCAT) activity: Prdx6 is able to acylate lysophospholipids (lysophosphatidylcholine is the primary substrate) by a transferase reaction to generate a phospholipid (phosphatidylcholine) [14].The coupling of the PLA 2 and LPCAT activities of Prdx6 represents a major mechanism for phospholipid remodeling through hydrolysis followed by re-acylation at the $s n-2$ position $[7,12]$.

(6) Subcellular localization: Like several other PRXs, Prdx6 is localized primarily to cytosol, but it is also the only member of the PRX family to be present in both lysosomes and lysosomal related 
organelles such as the lung lamellar bodies that are a site for synthesis and storage of the lung surfactant [15].

These six special characteristics of Prdx6 allow this protein to play specific and important roles in normal physiology and pathobiology including the scavenging of oxidants, the repair of peroxidized cell membranes, the turnover of lung surfactant phospholipids, and cellular signaling as mediated by reactive oxygen and nitrogen species (ROS/RNS) [12,16-18]. These functions of Prdx6 are postulated as important in various disease states including inflammation, acute lung injury, cancer, chronic diseases of the CNS, type II diabetes, and male infertility among others. Many of these topics are explored in depth in this special issue that includes five review articles and five articles reporting original research.

The first article in this special issue is a review by Feinstein that reports on currently available mouse models to evaluate the physiological and pathophysiological roles of Prdx6 [19]. Of special interest are the models to identify the specific roles of the GSH peroxidase vs. the $\mathrm{PLA}_{2}$ activities of Prdx6 using mice with C47S-Prdx6 and D140A-Prdx6 mutations. The second article by Bannitz-Fernandes et al. describes original research that, for the first time, shows the presence of PLA 2 activity in several non-mammalian Prdx6 enzymes [20]. The original research by Shahnaj et al. in the third article of this FORUM used recombinant mammalian Prdx6 to demonstrate that hyperoxidation of the protein results in the formation of multimers [21], similar to that shown for other members of the peroxiredoxin family [22]. The fourth article, original research by Zhou et al., shows that the presence of GSH can lead to hyperoxidation of the protein in vitro, resulting in the loss of peroxidase activity but a significant increase in $\mathrm{PLA}_{2}$ activity at cytosolic $\mathrm{pH}$; this effect was unrelated to the formation of multimers [23]. The fifth article by Allervajo and Vazquez-Medina reviews the role of Prdx6 in cell signaling with special emphasis on superoxide anion $\left(\mathrm{O}_{2} \bullet-\right)$ generation by NADPH oxidase (NOX2) and its important role in cellular communication [24]. Prdx6 generates lysophosphatidylcholine through its $\mathrm{PLA}_{2}$ activity, that results in the downstream activation of Rac, a required co-factor for the activation of NOX2. The following original research article by Fisher et al. identifies several peptides derived from the naturally occurring protein surfactant protein A (SP-A) that can inhibit the PLA 2 activity of Prdx6 and prevent the activation of NOX2 [25]. The seventh article by Patel and Chatterjee reviews cellular signaling with focus on the endothelium [26]. The authors present evidence that the regulation of Prdx6 expression and activity is crucial to endothelial cellular homeostasis and discuss the role of Prdx6 in mediating various pathologies. One of those pathologies, Fuchs endothelial corneal dystrophy (FECD), is a leading indication for corneal endothelial transplantation as described in the subsequent article by Lovatt et al.; this report of original research is focused on the role of Prdx6 in the preservation of corneal endothelial cellular integrity [27]. The ninth article by Sharapov et al. reviews the ability of Prdx6 to protect against X-irradiation-induced injury such as that used for treatment of cancer [28]. Both exogenous Prdx6 as well as increased expression of endogenous Prdx6 provide radioprotection. The tenth and final contribution to the special issue is a review by O'Flaherty that focuses on male fertility [29]. This review postulates that Prdx6 is the primary antioxidant enzyme that protects spermatozoa from oxidative stress-associated damage. Thus, the 5 articles of new research along with the 5 review articles cover a broad spectrum of Prdx6 function in physiology and pathophysiology and will serve as a base for continued studies of this important protein.

Despite the considerable increase during the past 25 years in our knowledge of Prdx6, there remain large gaps in our understanding of its structure-function relationships and (patho)physiological roles. Although a structural mechanism to account for its ability to bind phospholipids was proposed some time ago [30], there has not been definitive confirmation of this scheme (nor an acceptable alternative proposed) despite two publications using X-ray crystallographic analysis [31,32] and another using a zero length crosslinking technique [33]. Likewise, there has not been identification of the mechanism for the marked increase in $\mathrm{PLA}_{2}$ activity following phosphorylation of the protein, although the Thr177 amino acid in Prdx6 has been identified as the phosphorylation site [34] and a change in protein confirmation has been shown to be required for the increased activity [35]. Another intriguing question relates to the roles of the enzymatic activities of Prdx6 in cellular function. None of the activities of 
Prdx6 is unique and a variety of other dedicated enzymes also can reduce $\mathrm{H}_{2} \mathrm{O}_{2}$, hydroperoxides, and peroxynitrite, hydrolyze phospholipids ( $\mathrm{PLA}_{2}$ activity), and transfer acyl groups. In many cases, the impact of Prdx6 may relate to its specific tissue expression as seems to be the explanation for the predominant role of Prdx6 to reduce phospholipid hydroperoxides in the lung [12]. But, the determinants for expression of a particular enzyme in particular cells (as opposed to expression of another enzyme with similar activity) is largely unknown. With respect to the role of Prdx6 in pathophysiology, altered expression of the protein has been shown with many types of human cancers and expression levels have been shown to alter cancer growth rates as well as metastatic potential (reviewed in [13]). Altered Prdx6 expression also has been demonstrated in many types of neurodegenerative disease (reviewed in [13]). However, no reasonable mechanism has been proposed or studied related to these pathophysiologic effects of altered expression. So, the basic unresolved issues discussed above, as well as other issues that undoubtedly will be identified by future studies, indicate the need for considerable additional work to explore the structure-function relationships and the (patho)physiologic roles of this intriguing enzyme.

Funding: Original research by the author of this editorial was supported in part by grant R01-HL102016 (P.I, A.B.F.) from the National Institutes of Health of the United States.

Conflicts of Interest: A.B.F. and S.I.F. have a patent application pending for peptide inhibitors of peroxiredoxin 6 $\mathrm{PLA}_{2}$ activity and have part ownership of a start-up company (Peroxitech) to promote their clinical use.

\section{References}

1. Rhee, S.G. Overview on Peroxiredoxin. Mol. Cells 2016, 39, 1-5. [PubMed]

2. Perkins, A.; Nelson, K.J.; Parsonage, D.; Poole, L.B.; Karplus, P.A. Peroxiredoxins: Guardians against oxidative stress and modulators of peroxide signaling. Trends Biochem. Sci. 2015, 40, 435-445. [CrossRef]

3. Nelson, K.J.; Knutson, S.T.; Soito, L.; Klomsiri, C.; Poole, L.B.; Fetrow, J.S. Analysis of the peroxiredoxin family: Using active-site structure and sequence information for global classification and residue analysis. Proteins 2011, 79, 947-964. [CrossRef] [PubMed]

4. Chae, H.Z.; Robison, K.; Poole, L.B.; Church, G.; Storz, G.; Rhee, S.G. Cloning and sequencing of thiol-specific antioxidant from mammalian brain: Alkyl hydroperoxide reductase and thiol-specific antioxidant define a large family of antioxidant enzymes. Proc. Natl. Acad. Sci. USA 1994, 91, 7017-7021. [CrossRef] [PubMed]

5. Kim, T.S.; Sundaresh, C.S.; Feinstein, S.I.; Dodia, C.; Skach, W.R.; Jain, M.K.; Nagase, T.; Seki, N.; Ishikawa, K.; Nomura, N.; et al. Identification of a human cDNA clone for lysosomal type $\mathrm{Ca}^{2+}$-independent phospholipase $\mathrm{A}_{2}$ and properties of the expressed protein. J. Biol. Chem. 1997, 272, 2542-2550. [CrossRef] [PubMed]

6. Lee, T.H.; Yu, S.L.; Kim, S.U.; Kim, Y.M.; Choi, I.; Kang, S.W.; Rhee, S.G.; Yu, D.Y. Characterization of the murine gene encoding 1-Cys peroxiredoxin and identification of highly homologous genes. Gene 1999, 234, 337-344. [CrossRef]

7. Fisher, A.B. Peroxiredoxin 6: A bifunctional enzyme with glutathione peroxidase and phospholipase $\mathrm{A}_{2}$ activities. Antioxid. Redox Signal. 2011, 15, 831-844. [CrossRef]

8. Diet, A.; Abbas, K.; Bouton, C.; Guillon, B.; Tomasello, F.; Fourquet, S.; Toledano, M.B.; Drapier, J.C. Regulation of peroxiredoxins by nitric oxide in immunostimulated macrophages. J. Biol. Chem. 2007, 282, 36199-36205. [CrossRef]

9. Zhou, S.; Sorokina, E.; Harper, S.; Ralat, L.; Dodia, C.; Speicher, D.; Feinstein, S.I.; Fisher, A. Peroxiredoxin 6 homodimerization and heterodimerization with glutathione $\mathrm{S}$-transferase pi are required for its peroxidase but not phospholipase $\mathrm{A}_{2}$ activity. Free Radic. Biol. Med. 2016, 94, 145-156. [CrossRef]

10. Manevich, Y.; Shuvaeva, T.; Dodia, C.; Kazi, A.; Feinstein, S.I.; Fisher, A.B. Binding of peroxiredoxin 6 to substrate determines differential phospholipid hydroperoxide peroxidase and phospholipase A2 activities. Arch. Biochem. Biophys. 2009, 485, 139-149. [CrossRef]

11. Fisher, A.B.; Dodia, C.; Manevich, Y.; Chen, J.W.; Feinstein, S.I. Phospholipid hydroperoxides are substrates for non-selenium glutathione peroxidase. J. Biol. Chem. 1999, 274, 21326-21334. [CrossRef] [PubMed]

12. Fisher, A.B. Peroxiredoxin 6 in the repair of peroxidized cell membranes and cell signaling. Arch. Biochem. Biophys. 2017, 617, 68-83. [CrossRef] [PubMed] 
13. Fisher, A.B. The Phospholipase A2 Activity of Peroxiredoxin 6. J. Lipid Res. 2018, 59, 1132-1147. [CrossRef] [PubMed]

14. Fisher, A.B.; Dodia, C.; Sorokina, E.M.; Li, H.; Zhou, S.; Raabe, T.; Feinstein, S.I. A novel lysoPhosphatidylcholine acyl transferase activity is expressed by peroxiredoxin 6. J. Lipid Res. 2016, 57, 587-596. [CrossRef] [PubMed]

15. Sorokina, E.M.; Dodia, C.; Zhou, S.; Tao, J.Q.; Gao, L.; Raabe, T.; Feinstein, S.I.; Fisher, A.B. Mutation of serine 32 to threonine in peroxiredoxin 6 preserves its structure and enzymatic function but abolishes its trafficking to lamellar bodies. J. Biol. Chem. 2016, 291, 9268-9280. [CrossRef] [PubMed]

16. Vazquez-Medina, J.P.; Dodia, C.; Weng, L.; Mesaros, C.; Blair, I.; Feinstein, S.I.; Chatterjee, C.; Fisher, A. The phospholipase $\mathrm{A}_{2}$ activity of peroxiredoxin 6 modulates NADPH oxidase 2 activation via lysophosphatidic acid receptor signaling in the pulmonary endothelium and alveolar macrophages. FASEB J. 2016, 30, 2885-2898. [CrossRef]

17. Fisher, A.B.; Dodia, C.; Feinstein, S.I.; Ho, Y.S. Altered lung phospholipid metabolism in mice with targeted deletion of lysosomal-type phospholipase A2. J. Lipid Res. 2005, 46, 1248-1256. [CrossRef] [PubMed]

18. Fisher, A.B.; Dodia, C.; Yu, K.; Manevich, Y.; Feinstein, S.I. Lung phospholipid metabolism in transgenic mice overexpressing peroxiredoxin 6. Biochim. Biophys. Acta 2006, 1761, 785-792. [CrossRef]

19. Feinstein, S.I. Mouse Models of Genetically Altered Peroxiredoxin 6. Antioxidants 2019, 8, 77. [CrossRef]

20. Bannitz-Fernandes, R.; Aleixo-Silva, R.; Silva, J.P.; Dodia, C.; Vazquez-Medina, J.P.; Tao, J.Q.; Fisher, A.; Netto, L. Non-Mammalian Prdx6 Enzymes (Proteins with 1-Cys Prdx Mechanism) Display PLA(2) Activity Similar to the Human Orthologue. Antioxidants 2019, 8, 52. [CrossRef]

21. Shahnaj, S.; Chowhan, R.K.; Meetei, P.A.; Kakchingtabam, P.; Herojit Singh, K.; Rajendrakumar Singh, L.; Nongdam, P.; Fisher, A.B.; Rahaman, H. Hyperoxidation of Peroxiredoxin 6 Induces Alteration from Dimeric to Oligomeric State. Antioxidants 2019, 8, 33. [CrossRef] [PubMed]

22. Lim, J.C.; Choi, H.I.; Park, Y.S.; Nam, H.W.; Woo, H.A.; Kwon, K.S.; Kim, Y.S.; Rhee, S.G.; Kim, K.; Chae, H.Z. Irreversible oxidation of the active-site cysteine of peroxiredoxin to cysteine sulfonic acid for enhanced molecular chaperone activity. J. Biol. Chem. 2008, 283, 28873-28880. [CrossRef] [PubMed]

23. Zhou, S.; Dodia, C.; Feinstein, S.I.; Harper, S.; Forman, H.J.; Speicher, D.W.; Fisher, A.B. Oxidation of Peroxiredoxin 6 in the Presence of GSH Increases its Phospholipase A2 Activity at Cytoplasmic pH. Antioxidants 2018, 8, 4. [CrossRef] [PubMed]

24. Arevalo, J.A.; Vazquez-Medina, J.P. The Role of Peroxiredoxin 6 in Cell Signaling. Antioxidants 2018, 7, 172. [CrossRef]

25. Fisher, A.B.; Dodia, C.; Feinstein, S.I. Identification of Small Peptides that Inhibit NADPH Oxidase (Nox2) Activation. Antioxidants 2018, 7, 181. [CrossRef]

26. Patel, P.; Chatterjee, S. Peroxiredoxin6 in Endothelial Signaling. Antioxidants 2019, 8, 63. [CrossRef]

27. Lovatt, M.; Adnan, K.; Peh, G.S.L.; Mehta, J.S. Regulation of Oxidative Stress in Corneal Endothelial Cells by Prdx6. Antioxidants 2018, 7, 180. [CrossRef]

28. Sharapov, M.G.; Novoselov, V.I.; Gudkov, S.V. Radioprotective Role of Peroxiredoxin 6. Antioxidants 2019, 8, 15. [CrossRef]

29. O'Flaherty, C. Peroxiredoxin 6: The Protector of Male Fertility. Antioxidants 2018, 7, 173. [CrossRef]

30. Manevich, Y.; Reddy, K.S.; Shuvaeva, T.; Feinstein, S.I.; Fisher, A.B. Structure and phospholipase function of peroxiredoxin 6: Identification of the catalytic triad and its role in phospholipid substrate binding. J. Lipid Res. 2007, 48, 2306-2318. [CrossRef] [PubMed]

31. Choi, H.J.; Kang, S.W.; Yang, C.H.; Rhee, S.G.; Ryu, S.E. Crystal structure of a novel human peroxidase enzyme at 2.0 A resolution. Nat. Struct. Biol. 1998, 5, 400-406. [CrossRef] [PubMed]

32. Kim, K.H.; Lee, W.; Kim, E.E. Crystal structures of human peroxiredoxin 6 in different oxidation states. Biochem. Biophys. Res. Commun. 2016, 477, 717-722. [CrossRef] [PubMed]

33. Rivera-Santiago, R.F.; Harper, S.L.; Zhou, S.; Sriswasdi, S.; Feinstein, S.I.; Fisher, A.B.; Speicher, D.W. Solution structure of the reduced form of human peroxiredoxin- 6 elucidated using zero-length chemical cross-linking and homology modelling. Biochem. J. 2015, 468, 87-98. [CrossRef] [PubMed] 
34. Wu, Y.; Feinstein, S.I.; Manevich, Y.; Chowdhury, I.; Pak, J.H.; Kazi, A.; Dodia, C.; Speicher, D.W.; Fisher, A.B. Mitogen-activated protein kinase-mediated phosphorylation of peroxiredoxin 6 regulates its phospholipase A2 activity. Biochem. J. 2009, 419, 669-679. [CrossRef]

35. Rahaman, H.; Zhou, S.; Dodia, C.; Feinstein, S.I.; Huang, S.; Speicher, D.; Fisher, A.B. Increased phospholipase A2 activity with phosphorylation of peroxiredoxin 6 requires a conformational change in the protein. Biochemistry 2012, 51, 5521-5530. [CrossRef] [PubMed]

(C) 2019 by the author. Licensee MDPI, Basel, Switzerland. This article is an open access article distributed under the terms and conditions of the Creative Commons Attribution (CC BY) license (http://creativecommons.org/licenses/by/4.0/). 


\title{
Mouse Models of Genetically Altered Peroxiredoxin 6
}

\author{
Sheldon I. Feinstein ${ }^{1,2}$ \\ 1 Institute for Environmental Medicine, University of Pennsylvania Perelman School of Medicine, \\ Philadelphia, PA 19104, USA; sif@pennmedicine.upenn.edu \\ 2 Peroxitech, Ltd., Philadelphia, PA 19104, USA
}

Received: 18 January 2019; Accepted: 20 March 2019; Published: 27 March 2019

\begin{abstract}
Peroxiredoxin 6 (Prdx6) has been shown to have three enzymatic activities: peroxidase, phospholipase $\mathrm{A}_{2}\left(\mathrm{PLA}_{2}\right)$ and acyl transferase. The peroxidase activity is unusual, as it is capable of reducing phospholipid hydroperoxides (as well as hydrogen peroxide and short chain organic peroxides). Knockout and overexpressing mice have been produced that demonstrate the effect that eliminating or overproducing Prdx6 has on the animals' physiology. In addition, mutations in various amino acids of Prdx6 have been identified that interfere with different enzymatic functions as well as protein transport. These mutations were originally characterized biochemically; subsequently, several knock-in mouse strains have been produced, each containing one mutation. These mice include the S32T knock-in that affects protein transport, the C47S knock-in that inactivates the peroxidase enzymatic activity, the D140A knock-in that inactivates the $\mathrm{PLA}_{2}$ enzymatic activity and the H26A knock-in that inactivates the peroxidase and blocks binding to phospholipids. This review summarizes the properties of these mice based upon studies conducted with the knockout, overexpressing and knock-in mice and the effect of the genetic changes on the biochemistry and physiology of these mice. The availability of these mice is also briefly discussed.
\end{abstract}

Keywords: peroxidase; phospholipase $\mathrm{A}_{2}$; lipid peroxidation; phospholipid hydroperoxide; knockout mouse; knock-in mouse; membrane repair

\section{Introduction}

Peroxiredoxin $6(\operatorname{Prdx} 6)$ is a multifunctional enzyme with several different enzymatic activities [1,2] and has been implicated as a factor in a wide variety of diseases [3]. The molecular properties of the enzyme have been intensely studied and mutations affecting each of the activities of Prdx6 have been identified. The effects of many of these mutations, as well as the effect of deleting Prdx6 completely or of overexpressing it, have been studied in various models, including, knock-out, over-expressing and knock-in mice.

The primary purpose of this article is to review the information about Prdx6 that has emerged from studies of genetically altered mice. The mouse studies described here have, in general, been compatible with the results obtained in biochemical and in cell culture studies. However, live mice do often provide information about the role of Prdx6 that is not possible to deduce from other types of studies.

\section{Background: Enzymatic Activities of Prdx6 and Critical Amino Acids for Enzymatic Activities}

Prdx6 has several enzymatic activities. It can reduce peroxides [4] including fatty acid peroxides and phospholipid hydroperoxides. The product of this reaction is a secondary alcohol [5]. The reaction is equally efficient for hydrogen peroxide, tert-butyl hydroperoxide, fatty acid hydroperoxides and phospholipid hydroperoxides. The only other enzyme in mammalian cells that can reduce phospholipid hydroperoxides is glutathione peroxidase 4 (GPX4), also known as phospholipid 
hydroperoxide glutathione peroxidase [6]. Other peroxiredoxins reduce peroxides using an active cysteine which is then partially reduced by a second conserved cysteine, forming a disulfide bond that is, in turn, restored to the thiol form by interaction with reductants thioredoxin or glutaredoxin. However, Prdx6 has a single active cysteine, at position 47 in the amino acid sequence $[7,8]$, which is reduced by pi glutathione-s-transferase. It occurs in a consensus sequence, PVCTT, although the effect of mutating this consensus, other than the cysteine, on Prdx6 peroxidase activity, has not been tested. The ability to reduce phospholipid hydroperoxides [5] suggests that Prdx6 is important in the repair of damage to cell lipids, such as lipids in the cell membrane. Overexpression of Prdx6 in cells protected against membrane damage [9] while blocking expression of Prdx6 in a lung epithelial cell line increased lipid peroxidation [10].

Prdx6 also has a phospholipase $\mathrm{A}_{2}\left(\mathrm{PLA}_{2}\right)$ activity, which cleaves phospholipids at the sn2 acyl bond, releasing the headgroup, e.g., lysophosphatidylcholine from the fatty acid moiety. The preferred substrate is phosphatidylcholine (PC), followed by phophatidylethanolamine and phosphatidylglycerol. Activity is low on other substrates such as phosphatidylinositol and phosphatidyl serine $[7,11,12]$. The PLA $_{2}$ catalytic activity requires a catalytic triad that includes the histidine at position 26 (H26), the serine at position 32 (S32) and the aspartate at position 140 (D140). Our studies have shown that all three residues are necessary for $\mathrm{PLA}_{2}$ catalytic activity and that the $\mathrm{H} 26$ and S32 are required for binding of the Prdx6 enzyme to its phospholipid substrate [13]. Thus, mutation of either of these two residues not only blocks the PLA $\mathrm{P}_{2}$ activity, but also the ability to reduce phospholipid hydroperoxides. However, it has no effect on the reduction of other peroxides, both inorganic and short chain organic [13]. Since mutation of $\mathrm{S} 32$ or $\mathrm{H} 26$ gives a mixed result, mutation of D140 is the most reliable way to differentiate the effect of PLA $\mathrm{P}_{2}$ from the other activities of Prdx6. In addition, Prdx6 has recently been shown to have acyl transferase activity [2]. This activity can synthesize dipalmitoylphosphatidylcholine (DPPC) from lysophosphatidyl choline and palmitoyl coA. Other lyso compounds such as lysophosphatidylethanolamine, lysophosphatidylglycerol, lysophosphatidylinositol and lysophosphatidylserine as well as other fatty acyl coA molecules such as stearoyl, oleoyl and arachidonoyl coAs were much less efficiently incorporated by the enzyme. Mutational analysis in our laboratory showed that mutation of the aspartate at position 31 [D31], blocks the activity. However, the acyltransferase activity is unaffected by mutations that block the other two activities. Even mutations that prevent binding to the phospholipid substrate apparently do not block the ability to bind to the lysophosphatidylcholine (LPC) substrate. The PLA 2 and acyl transferase activities could cooperate in the repair of membrane phospholipids via the remodeling pathway in which generation of DPPC occurs via deacylation/reacylation of sn2 unsaturated PC. They are likely to also be important in the metabolism of the lipid components of pulmonary surfactant.

\section{Prdx6 Knockout and Overexpressing Mouse Models}

The Prdx6 gene is located on mouse chromosome 1 [14]. Two strains of Prdx6 null mice are available. One was produced by Wang et al. [15] and the other by our laboratory and collaborators [16]. The former mouse has a deletion in Exon III of the Pdrx6 gene, while the mouse from our laboratory has a deletion in Exon II. Both mice are anatomically normal, viable and capable of reproduction, although male null mice from our laboratory have been found to be less fertile than wild-type mice due to oxidative damage of the spermatozoa [17-19] as reviewed in this FORUM [20]. This has not been tested in the other Prdx6 mouse model. In general, null mice or cells derived from these mice exhibited increased sensitivity to oxidative stress, with lower survival rates, increased tissue damage and higher oxidation levels for lipids and protein [21-24].

Other studies with Prdx6 null mice have also been published. The Prdx6 null mice from our laboratory showed a deficiency in phospholipid catabolism, so that the mice accumulated phospholipids in their lungs as they aged. The levels of PC and disaturated phosphatidylcholine (DSPC) in the lungs (normalized to body wt) increased by about $300 \%$ in the first year of life and 
continued to increase thereafter. Wild- type mice had stable levels of PC and DSPC, normalized to body weight, throughout life [25].

A comparison of GPX1 null mice with Prdx6 null mice showed that, despite GPX1 accounting for approximately nine-fold as much GSH-dependent peroxidase activity compared to Prdx6, the Prdx6 null mice are significantly more sensitive to oxidative stress [26]. The most likely explanation is that Prdx6 can reduce phospholipid hydroperoxides while GPX1 cannot. In fact, lungs from Prdx6 null mice do not exhibit any detectable enzymatic activity for reduction of phospholipid hydroperoxides, suggesting that the lungs of these mice do not contain GPX4; this was confirmed on a Western blot showing relatively abundant GPX4 in testis, but nothing in lung [26].

We have also found [27] that the $\mathrm{PLA}_{2}$ activity of Prdx6 triggers superoxide production by activating the reduced form of nicotinamide adenine dinucleotide phosphate (NADPH) oxidase 2 (Nox2) so that the Prdx6 null mice do not activate Nox2. This lack of Nox2 activation might be expected to result in reduced damage to tissues of Prdx6 null mice in some conditions associated with increased oxidant stress, which would mitigate their reduced repair capacity, due to a lack of Prdx6.

Our laboratory also used the Prdx6 null mice as a source for cells that do not have Prdx6. Mouse pulmonary microvascular endothelial cells (MPMVECs) were obtained from the null mice and used in transfection or infection studies in which various expression constructs of wild-type or mutant Prdx6 could be introduced into the cells and their effects studied. These were used to show the role of Prdx6 in superoxide generation [27] and in protection of cells against lipid peroxidation [24].

A Prdx6 overexpressing mouse model was produced by introducing a mouse Prdx6 gene, as a transgene, into wild-type mice. Mice with multiple copies of the gene were analyzed and a line was chosen whose expression level of Prdx6 was more than an order of magnitude higher in the aorta than the wild-type mice [28]. These mice were subsequently shown to have increased resistance to oxygen toxicity as compared to wild-type mice [29] and also an increased turnover rate for lung DPPC, supporting a role for Prdx6 in surfactant metabolism [30].

\section{Mouse Knock-in Models for Prdx6 Mutations}

Knock-in mice are transgenic mice in which a gene of interest has been replaced by a copy of the same gene with a different sequence. The change can be as small as a mutation consisting of a single nucleotide difference. The knock-in mice described here were prepared by the method known as "recombineering" which relies on cloning using homologous recombination, generally performed in E. coli [31]. Initially, the mutation is introduced into a cloned copy of the mouse gene in a plasmid that contains a neomycin resistance cassette flanked by two flippase recombinase targetFRT sites. Subsequently, the mutation is introduced into mouse embryonic stem (ES) cells from the mouse strain of interest by selecting for neomycin resistance. The neomycin resistant cells are mixed into mouse embryos from mice with a different coat color. Mice born from these chimeric embryos that exhibited evidence of the coat color contributed by the embryonic stem cells are tested for germline transmission of the coat color and subsequently, the mutation. Mutant mice are bred to homozygosity and the neomycin cassette can be removed by mating with mice containing the Flippase gene which is itself removed by further breeding.

It should be noted that the generation of the mice described here was completed several years ago; today, it is possible to generate mice much more rapidly and easily using clustered regularly interspaced short palindromic repeats (CRISPR)/CRISPR associated protein 9 (Cas9) technology in which rodent embryos can be electroporated directly, eliminating the need for using ES cells [32].

The knock-in mice described below were generated by the Gene Targeting Core and Laboratory and the Transgenic and Chimeric Mouse Facility of the University of Pennsylvania (Philadelphia, PA, USA). 


\subsection{Directing Prdx6 to Lamellar Bodies and Lysosomes: The S32T Mutation}

A portion of Prdx6 protein in the lung is found in lamellar bodies and lysosomes; presumably, it is also found in lysosomes in other organs as well although that has not been evaluated. Our laboratory set out to study the mechanism for this targeting. Deletion analysis was performed on a Prdx6 mammalian expression plasmid that was fused with a gene coding for green fluorescent protein GFP on the N-terminus. The mutant plasmids were transfected into cell lines and the GFP fluorescence was examined for co-localization with a stain for lamellar bodies (Nile Red) or lysosomes (Lysotracker Red). The results of these studies identified a region of Prdx6, amino acids 31-40, that was responsible for the targeting. This region includes the Serine 32 that is the part of the catalytic site of the $\mathrm{PLA}_{2}$ activity. Site-directed mutagenesis studies showed that mutating the Serine 32 to Alanine or the Glycine 34 to Leucine prevented the targeting [33]. Subsequently, it was shown that the chaperone protein 14-3-3-epsilon, after its activation by mitogen-activated protein kinases (MAPK kinases): ERK or P38, plays a role in the targeting process [34].

Further studies indicated that, unlike the Serine 32 to Alanine (S32A) mutation, the Serine 32 to Threonine (S32T) mutation did not abolish the $\mathrm{PLA}_{2}$ activity of the Prdx6 in recombinant protein produced in E. coli nor in recombinant protein produced in mammalian cells by infection with lentiviral constructs. The S32A mutation also prevented the Prdx6 from binding to phospholipids, however, this was not the case for the S32T mutation. Thus, in contrast to the S32A mutation the S32T mutation did not interfere with the ability of the Prdx6 to cleave phospholipids. However, mammalian cells did not transport the S32T mutant protein to lamellar bodies as they did for wild-type [35].

A knock-in mouse was constructed in which the Serine 32 was mutated to threonine. Studies with these mice showed that the mutation had no effect on the PLA $\mathrm{A}_{2}$ enzymatic activity of the protein. However, unlike the wild-type, the Prdx6 was not transported to lamellar bodies. This was apparent both using immunohistochemical studies and also analysis of purified lamellar body fractions. Studies showed that the 14-3-3-Epsilon chaperone protein could not bind to the S32T protein, suggesting a possible mechanism for the defect in transport [35]. Thus, the data from the S32T mouse indicates that $\mathrm{T}$ can substitute for $\mathrm{S}$ at position 32 for preservation of the physical structure of Prdx6 and the ability of the enzyme to bind to and cleave phospholipids, but not for the trafficking of the protein to lamellar bodies.

\subsection{Abolishing the Ability of Prdx6 to Reduce Peroxides: The C47S Mutation}

Studies on recombinant protein had indicated that the phospholipase $\mathrm{A}_{2}$ activity and the phospholipid reductase activity were located in different parts of the protein and had different active centers. The cysteine at position 47 in the amino acid sequence of Prdx6 was shown to be the active site for the reduction of the phospholipid hydroperoxide. This cysteine (shown in bold) occurs in a consensus amino acid sequence for peroxidase activity, PVCTT. Mutating this cysteine to serine abolished the ability of the protein to reduce any hydroperoxide. However, this mutation had no effect on the PLA $\mathrm{P}_{2}$ activity of the Prdx6 enzyme [7] except that it did prevent the increase in PLA $\mathrm{A}_{2}$ activity associated with oxidation of the Prdx6 protein [36,37]. Plasmids containing the Prdx6 with the C47S mutation were able to restore $\mathrm{PLA}_{2}$ activity, but not peroxidase activity, when transfected into Prdx6 null cells. Nevertheless, these mutant plasmids were able to partially rescue the ability of the cells to recover from oxidative stress [24]. We developed knock-in mice containing the C47S mutation [38]. When the lungs of these mice were isolated and analyzed biochemically, there was no GSH-dependent lipid peroxidase activity, indicating that GPx4 (phospholipid hydroperoxide GSH peroxidase), the other major enzyme capable of reducing phospholipid hydroperoxides [6], is not active in mouse lungs. The recovery of the C47S mouse lungs from oxidative stress brought on by hyperoxia in vivo, monitored by reduction of membrane lipids, as indicated by quantitative assays of lipid peroxide, was slower than the phospholipid hydroperoxide reduction of wild-type mice, but much better than that seen for Prdx6 null mice. Similar results were obtained with perfused lungs from the mutant mice that had been treated with tert-butylhydroperoxide to induce oxidative stress, except that the recovery 
time was much shorter (about ten-fold less ex vivo than in vivo) [38]. This data was also in agreement with rescue experiments in cells [24]. Since the Prdx6 null mice could not recover, but the C47S mutant mice did recover, although more slowly, the data suggested that there is another pathway for cells and lungs to recover from lipid peroxidation brought on by oxidative stress. This pathway is likely to involve the coupled phospholipase $\mathrm{A}_{2}$ /LPCAT activities of Prdx6 which could bring about repair by the deacylation-reacylation pathway.

\subsection{Abolishing the Phospholipase $A_{2}$ Activity of Prdx6: The D140A Mutation}

The catalytic residue for the PLA 2 activity of the Prdx6 enzyme is the serine at position 32 . This serine residue is part of a catalytic triad that also includes the histidine at position 26 and the aspartate at position 140. In the higher order structure of the enzyme, these residues are in proximity to each other and appear to cooperate to form the catalytic triad. Since our data showed that the H26 and the S32 are important for the Prdx6 enzyme to bind to phospholipids but the D140 residue is not, we used a mutation of the aspartate at position 140 to alanine (D140A) to construct a knock-in mouse that lacked the PLA 2 activity of Prdx6 [38].

As predicted, lung extracts from these mice had no PLA 2 activity. The peroxidase activity was unaffected even on phospholipid substrates, indicating that binding to phospholipids was not inhibited. Nevertheless, in experiments examining recovery from injury brought on by oxidative stress, in perfused lung and live mice [38], the data clearly show that the loss of $\mathrm{PLA}_{2}$ activity has a marked effect on recovery, although the effect was slightly less than that of the C47S mutation. This result is in agreement with data that we had obtained previously looking at the ability of a plasmid expressing D140A mutant protein to rescue Prdx6 null cells from damage caused by oxidative stress [24]. Thus, repair of the damage to lungs and lung cells resulting from oxidative stress is repaired exclusively by Prdx6 and can occur by either of two pathways that complement each other: by reducing the oxidized molecules or by excision and repair. The data indicate that the reduction pathway seems slightly more efficient, but that the two pathways are almost equally effective and that both are needed for maximal efficiency.

\subsection{Abolishing Both the Phospholipase $A_{2}$ Activity of Prdx6 and the Ability of Prdx6 to Reduce Phospholipids: The H26A Mutation}

In contrast to the D140 residue, which is necessary for the phospholipase $\mathrm{A}_{2}$ catalytic activity, the other two members of the PLA 2 catalytic triad, $\mathrm{H} 26$ and S32, are also required for Prdx6 binding to phospholipids and thus for reduction of phospholipid hydroperoxides. Therefore, the S32A mutants and the H26A mutants would not be expected to have the acidic, calcium-independent PLA $\mathrm{A}_{2}$ activity $\left(\right.$ aiPLA $A_{2}$ ) nor the ability to repair oxidized phospholipids in membranes, but would still be able to reduce short chain peroxides. It should be noted that some laboratories have used the S32A mutation to inactivate the Prdx6 $\mathrm{PLA}_{2}$, apparently without realizing that they are also affecting the peroxidase activity by preventing the enzyme from reducing phospholipids. For example, Ho et al. [39] concluded that the PLA $\mathrm{P}_{2}$ activity of Prdx6 is necessary for lung cancer cell invasion, by showing that Prdx6 carrying the S32A mutation was much less stimulatory of the invasiveness of transfected A549 cells than wild-type Prdx6 and concluded that this was due to the lack of PLA $\mathrm{A}_{2}$ activity. In fairness, the study also showed that C47S mutation did not have this effect, indicating that the lack of invasiveness was not due to the loss of peroxidase activity. However, in another study looking at cell proliferation, in one cell line (Mel-Ho) the authors conclude that both the peroxidase and $\mathrm{PLA}_{2}$ activities of Prdx6 are necessary for proliferation because neither S32A nor C47S mutant Prdx6 could rescue the decrease in cell proliferation caused by siRNA to Prdx6 [40]. In that case, the inability to restore proliferation could be due to the lack of ability to reduce phospholipid hydroperoxides, as both mutations affect this.

H26A knock-in mice were produced [2] and, as expected, lung homogenate from these mice exhibited very low levels of aiPLA $A_{2}$ activity and lacked the ability to reduce phospholipid hydroperoxides, however, the ability to reduce short chain hydroperoxides or hydrogen peroxide 
was only about $10 \%$ below wild-type. Thus, the H26A mutation would be useful in determining the importance of the ability to reduce short chain peroxides in the overall ability of Prdx6 to protect against oxidative damage. The time course of the ability of these H26A knock-in mice to repair damage was compared with wild-type and knockout mice. In one series of experiments, whole mice were treated with hyperoxia, while in another set of experiments, perfused lungs from the mice were treated with short-chain hydroperoxide [41]. In both experimental sets, the H26A mutation was similar to the Prdx6 knockout in its inability to protect against oxidative stress, indicating that the ability of Prdx6 to reduce inorganic and short chain peroxides, which is retained by the H26A mice, is not enough to confer protection. The results of these experiments also matched experiments in which an H26A mutant construct in a lentiviral vector was introduced into pulmonary microvascular cells from Prdx6 null mice, by infection, and compared with cells infected with wild-type construct or vector alone [41]. It is not surprising that the $\mathrm{H} 26 \mathrm{~A}$ mutation cannot repair the damage to the lungs as this requires either the ability to reduce or cleave phospholipid hydroperoxides and the H26A mutation is unable to fulfill either function.

\section{Conclusions and Future Directions}

Prdx6 is a complicated enzyme, implicated in many physiological processes and diseases, as reviewed in this FORUM [42]. Our understanding of the biochemistry of Prdx6 has been greatly facilitated by mutation of constructs for Prdx6 expression and the examination of the effects of the mutations on enzyme function. However, in order to understand the physiological effects of these mutations, it is necessary to place them in a living organism. We have used genetically altered mice to explore the effects of deleting Prdx6, overexpressing it or mutating it on mouse physiology and metabolism. The results have been helpful in furthering our understanding of the role of Prdx6 and have also shown that our in vitro and cell culture studies give us useful information that is generally borne out by the studies in mice. A summary of the mice described in this review is shown in Table 1.

Table 1. Summary of the description of mice discussed in this review. PLA 2 : Phospholipase $\mathrm{A}_{2}$; MMRRC: Mutant Mouse Resource and Research Center.

\begin{tabular}{|c|c|c|c|c|c|c|}
\hline $\begin{array}{l}\text { Description } \\
\text { of Prdx6 in } \\
\text { Mouse }\end{array}$ & References & $\begin{array}{l}\text { Prdx6 Peroxidase } \\
\text { Activity Against } \\
\text { Inorganic and } \\
\text { Short-Chain } \\
\text { Peroxides }\end{array}$ & $\begin{array}{l}\text { Prdx6 Peroxidase } \\
\text { Activity Against } \\
\text { Phospholipid } \\
\text { Hydroperoxides }\end{array}$ & $\begin{array}{c}\text { PLA }_{2} \\
\text { Activity }\end{array}$ & $\begin{array}{l}\text { Transport to } \\
\text { Lamellar } \\
\text { Bodies }\end{array}$ & $\begin{array}{c}\text { Mice } \\
\text { Available } \\
\text { from: }\end{array}$ \\
\hline Knockout (1) & [15] & No & No & No & $\mathrm{N} / \mathrm{A}$ & Jackson Labs \\
\hline Knockout (2) & [16-27] & No & No & No & $\mathrm{N} / \mathrm{A}$ & MMRRC \\
\hline S32T & [35] & Yes & Yes & Yes & Yes & MMRRC \\
\hline C47S & [38] & No & No & Yes & No & MMRRC \\
\hline D140A & [38] & Yes & Yes & No & Yes & MMRRC \\
\hline $\mathrm{H} 26 \mathrm{~A}$ & [41] & Yes & No & No & Yes & MMRRC \\
\hline
\end{tabular}

N/A: Not applicable.

The mice described here should turn out to be useful in studies of many diseases, as Prdx6 has already been linked to quite a number of them [3]. For example, studies of male fertility have already pointed to the involvement of Prdx6 [18-21]. We have archived all of our mice described here to be available from the MMRRC Repository. Our archived knock-in mice have had the neomycin resistant cassette removed and the Flippase gene bred out. The other Prdx6 knockout mouse and the Prdx6 overexpressing mouse are available from the Jackson Laboratory, Bar Harbor, ME, USA.

Our studies showing that the S32T mouse does not transport Prdx6 to lamellar bodies [33] confirm our cell culture studies in which we identified the region of Prdx6 involved in targeting [33]. It is also 
notable that mutating the serine 32 to a threonine preserves enzyme activity but blocks the transport of the protein [35]. More studies will be needed to determine if the loss of Prdx6 from lamellar bodies has any effect on resistance to oxidative stress and whether the effect of this mutation is similar to the knockout mouse in causing the accumulation of phospholipids in the lung.

Our studies on the D140A and C47S mice have involved mostly repair of oxidative damage. Before these experiments were performed, it seemed likely that the peroxidase activity would be much more important in repair than the $\mathrm{PLA}_{2}$, since it seemed to be a more efficient method of repair. However, it turned out that although the peroxidase activity is more important, the difference is slight and both activities are needed for wild-type repair efficiency [38]. Again, these studies confirmed what had been found in cell culture [24].

The Prdx6 null mouse was much more sensitive to oxidative stress than the GPX1 null mouse, even though there is much more GPX1 protein and activity in the lung than Prdx6 [26]. Our studies with the H26A knock-in mouse [41] support our hypothesis that the reason for this is that Prdx6 can reduce phospholipid hydroperoxides, while GPX1 cannot. The H26A Prdx6 cannot bind to phospholipids and the mouse expressing this mutation is no more protected from oxidative stress than the Prdx6 null mouse.

There are some other potential knock-in mice containing other mutations of Prdx6 that would be useful, however, they have not yet been produced. The improved technology available today would facilitate the production of these mice. It will be interesting to test whether the recently discovered lysophosphatidyl choline acyl transferase activity [2] combines with the PLA 2 activity to perform the repair of membrane phospholipids; these studies would be facilitated by the creation of a knock-in mouse for the D31A mutation which inactivates the acyl transferase. A knock-in mouse model of this mutation would also be useful in evaluating the role of the acyl transferase in the metabolism of pulmonary surfactant.

Prdx6 is phosphorylated by MAP kinases, resulting in an increase in PLA 2 activity of more than an order of magnitude and a broadening of the $\mathrm{pH}$ optimum of the enzyme so that activity at $\mathrm{pH}$ 4 and pH 7.4 is roughly equivalent [43]. However, phosphorylation has no effect on the peroxidase activity. Phosphorylation has been found to take place on the threonine 177 (T177) of the Prdx6 protein. Mutation of the threonine to an alanine (T177A) abolishes the phosphorylation and the increase in activity. Mutation of the threonine to a glutamic acid (T177E) also prevents phosphorylation, but increases the $\mathrm{PLA}_{2}$ activity about two-fold, presumably because the glutamate mimics the charge of the phosphate group (43]. Since the PLA 2 activity of Prdx6 plays roles in surfactant metabolism, membrane repair and activating NADPH oxidase 2 to produce superoxide, it would be interesting to generate T177A (and possibly T177E) knock-in mice and to study the effect of manipulating Prdx6 phosphorylation on these processes.

The active cysteine in Prdx6 is regenerated through heterodimerization with glutathione-S-transferase pi. Mutations at leucine 145 (L145) or leucine 148 (L148] interfere with the heterodimerization and the ability of the Prdx6 to reduce phospholipid hydroperoxides. However, there is no effect on PLA 2 activity. The double mutation (L145A; L148A) essentially eliminates the heterodimerization and the peroxidase activity of the enzyme in vitro [44]. A knock-in mouse model containing the double mutation (L145A; L148A) would be expected to have a phenotype similar to the C47S, although perhaps less severe and this could be tested in models of oxidative stress.

The role of Prdx6 in physiology and disease is complex because of its multiple activities. In some cases, one or another of the enzyme activities has been suggested as a factor in a particular disease. The availability of mouse models in which the effect of the absence of each activity can be studied independently will assist in identifying the role of these mutations in normal physiology and in pathology and may point towards possible targets for drugs directed against these diseases.

Funding: The work on the mouse models in our laboratory was supported by NIH grants: R01 HL65543, R01 HL102016, R01 HL105509 and P01 HL19737 all to Aron B. Fisher. 
Acknowledgments: I thank Aron B. Fisher for helpful discussions. I am grateful to Tobias Raabe and Jean Richa for production of genetically altered mice, to Elena Sorokina for expert mouse genotyping and to Donald Fisher and Jian-Qin Tao for mouse husbandry.

Conflicts of Interest: S.I.F. and A.B.F. have a patent application pending for a peptide inhibitor of peroxiredoxin 6 $\mathrm{PLA}_{2}$ activity and have part ownership of a start-up company to promote clinical use of the peptide inhibitor.

\section{References}

1. Fisher, A.B. Peroxiredoxin 6: A bifunctional enzyme with glutathione peroxidase and phospholipase A(2) activities. Antioxid. Redox Signal. 2011, 15, 831-844. [CrossRef] [PubMed]

2. Fisher, A.B.; Dodia, C.; Sorokina, E.M.; Li, H.; Zhou, S.; Raabe, T.; Feinstein, S.I. A novel lysophosphatidylcholine acyl transferase activity is expressed by peroxiredoxin 6. J. Lipid Res. 2016, 57, 587-596. [CrossRef] [PubMed]

3. Pacifici, F.; Della-Morte, D.; Capuani, B.; Pastore, D.; Bellia, A.; Sbraccia, P.; Di Daniele, N.; Lauro, R.; Lauro, D. Peroxiredoxin6, a Multitask Antioxidant Enzyme Involved in the Pathophysiology of Chronic Noncommunicable Diseases. Antioxid. Redox Signal. 2019, 30, 399-414. [CrossRef] [PubMed]

4. Singh, A.K.; Shichi, H. A novel glutathione peroxidase in bovine eye, sequence analysis, mRNA level and translation. J. Biol. Chem. 1998, 273, 26171-26178. [CrossRef] [PubMed]

5. Fisher, A.B.; Dodia, C.; Manevich, Y.; Chen, J.-W.; Feinstein, S.I. Phospholipid hydroperoxides are substrates for non-selenium glutathione peroxidase. J. Biol. Chem. 1999, 274, 21326-21334. [CrossRef]

6. Imai, H.; Nakagawa, Y. Biological significance of phospholipid hydroperoxide glutathione peroxidase (PHGPx, GPx4) in mammalian cells. Free Radic. Biol. Med. 2003, 34, 145-169. [CrossRef]

7. Chen, J.-W.; Dodia, C.; Feinstein, S.I.; Jain, M.K.; Fisher, A.B. 1-cys peroxiredoxin, a bifunctional enzyme with glutathione peroxidase and phospholipase $\mathrm{A}_{2}$ activities. J. Biol. Chem. 2000, 75, 28421-28427. [CrossRef]

8. Kang, S.W.; Baines, I.C.; Rhee, S.G. Characterization of a mammalian peroxiredoxin that contains one conserved cysteine. J. Biol. Chem. 1998, 273, 6303-6311. [CrossRef] [PubMed]

9. Manevich, Y.; Sweitzer, T.; Pak, J.H.; Feinstein, S.I.; Muzykantov, V.; Fisher, A.B. 1-Cys peroxiredoxin overexpression protects cells against phospholipid peroxidation-mediated membrane damage. Proc. Natl. Acad. Sci. USA 2002, 99, 11599-11604. [CrossRef]

10. Pak, J.H.; Manevich, Y.; Kim, H.S.; Feinstein, S.I.; Fisher, A.B. An antisense oligonucleotide to 1-cys peroxiredoxin causes lipid peroxidation and apoptosis in lung epithelial cells. J. Biol. Chem. 2002, 277, 49927-49934. [CrossRef] [PubMed]

11. Kim, T.S.; Sundaresh, C.S.; Feinstein, S.I.; Dodia, C.; Skach, W.R.; Jain, M.K.; Nagase, T.; Seki, N.; Ishikawa, K.; Nomura, N.; et al. Identification of a human cDNA clone for lysosomal type Ca2+-independent phospholipase $\mathrm{A}_{2}$ and properties of the expressed protein. J. Biol. Chem. 1997, 272, 2542-2550. [CrossRef]

12. Kim, T.S.; Dodia, C.; Chen, X.; Hennigan, B.B.; Jain, M.; Feinstein, S.I.; Fisher, A.B. Cloning and expression of rat lung acidic $\mathrm{Ca}(2+)$-independent $\mathrm{PLA}_{2}$ and its organ distribution. Am. J. Physiol. 1998, 274, L750-L761.

13. Manevich, Y.; Reddy, K.S.; Shuvaeva, T.; Feinstein, S.I.; Fisher, A.B. Structure and phospholipase function of peroxiredoxin 6: Identification of the catalytic triad and is role in phospholipid substrate binding. J. Lip. Res. 2007, 48, 2306-2318. [CrossRef]

14. Phelan, S.A.; Beier, D.R.; Higgins, D.C.; Paigen, B. Confirmation and high resolution mapping of an atherosclerosis susceptibility gene in mice on Chromosome 1. Mamm. Genome 2002, 13, 548-553. [CrossRef]

15. Wang, X.; Phelan, S.A.; Forsman-Semb, K.; Taylor, E.F.; Petros, C.; Brown, A.; Lerner, C.P.; Paigen, B. Mice with targeted mutation of peroxiredoxin 6 develop normally but are susceptible to oxidative stress. J. Biol. Chem. 2003, 278, 25179-25190. [CrossRef] [PubMed]

16. Mo, Y.; Feinstein, S.I.; Manevich, Y.; Zhang, Q.; Lu, L.; Ho, Y.-S.; Fisher, A.B. 1-cys peroxiredoxin knock-out mice express mRNA but not protein for a highly related intronless gene. FEBS Lett. 2003, 555, 192-198. [CrossRef]

17. Ozkosem, B.; Feinstein, S.I.; Fisher, A.B.; O'Flaherty, C. Advancing age increases sperm chromatin damage and impairs fertility in peroxiredoxin 6 null mice. Redox Biol. 2015, 5, 15-23. [CrossRef] [PubMed]

18. Ozkosem, B.; Feinstein, S.I.; Fisher, A.B.; O'Flaherty, C. Absence of peroxiredoxin 6 amplifies the effect of oxidant stress on mobility and SCSA/CMA3 defined chromatin quality and impairs fertilizing ability of mouse spermatozoa. Biol. Reprod. 2016, 94, 1-10. [CrossRef] [PubMed] 
19. Moawad, A.R.; Fernandez, M.C.; Scarlata, E.; Dodia, C.; Feinstein, S.I.; Fisher, A.B.; O'Flaherty, C. Deficiency of peroxiredoxin 6 or inhibition of its phospholipase $A_{2}$ activity impair the in vitro sperm fertilizing competence in mice. Sci. Rep. 2017, 7, 12994. [CrossRef]

20. O'Flaherty, C. Peroxiredoxin 6: The protector of male fertility. Antioxidants 2018, 7, 173. [CrossRef] [PubMed]

21. Wang, Y.; Feinstein, S.I.; Manevich, Y.; Ho, Y.S.; Fisher, A.B. Lung injury and mortality with hyperoxia are increased in peroxiredoxin 6 gene-targeted mice. Free Radic. Biol. Med. 2004, 37, 1736-1743. [CrossRef] [PubMed]

22. Wang, Y.; Feinstein, S.I.; Manevich, Y.; Ho, Y.S.; Fisher, A.B. Peroxiredoxin 6 gene-targeted mice show increased lung injury with paraquat-induced oxidative stress. Antioxid. Redox Signal. 2006, 8, $229-237$. [CrossRef] [PubMed]

23. Wang, Y.; Feinstein, S.I.; Fisher, A.B. Peroxiredoxin 6 as an antioxidant enzyme: Protection of lung alveolar epithelial type II cells from $\mathrm{H}_{2} \mathrm{O}_{2}$-induced oxidative stress. J. Cell. Biochem. 2008, 104, 1274-1285. [CrossRef]

24. Lien, Y.C.; Feinstein, S.I.; Dodia, C.; Fisher, A.B. The roles of peroxidase and phospholipase $\mathrm{A}_{2}$ activities of peroxiredoxin 6 in protecting pulmonary microvascular endothelial cells against peroxidative stress. Antioxid. Redox Signal. 2012, 16, 440-451. [CrossRef]

25. Fisher, A.B.; Dodia, C.; Feinstein, S.I.; Ho, Y.-S. Altered lung phospholipid metabolism with targeted deletion of lysosomal-type phospholipase A 2 . J. Lipid Res. 2005, 46, 1248-1256. [CrossRef]

26. Liu, G.; Feinstein, S.I.; Wang, Y.; Dodia, C.; Fisher, D.; Yu, K.; Ho, Y.-S.; Fisher, A.B. Comparison of glutathione peroxidase I and peroxiredoxin 6 in protection against oxidative stress in the mouse lung. Free Radic. Biol. Med. 2010, 49, 1172-1181. [CrossRef]

27. Chatterjee, S.; Feinstein, S.I.; Dodia, C.; Sorokina, E.; Lien, Y.C.; Nguyen, S.; Debolt, K.; Speicher, D.; Fisher, A.B. Peroxiredoxin 6 phosphorylation and subsequent phospholipase $\mathrm{A}_{2}$ activity are required for agonist-mediated activation of NADPH oxidase in mouse pulmonary microvascular endothelium and alveolar macrophages. J. Biol. Chem. 2011, 286, 11696-11706. [CrossRef] [PubMed]

28. Phelan, S.A.; Wang, X.; Wallbrandt, P.; Forsman-Semb, K.; Paigen, B. Overexpression of Prdx6 reduces $\mathrm{H}_{2} \mathrm{O}_{2}$ but does not prevent diet-induced atherosclerosis in the aortic root. Free Radic. Biol. Med. 2003, 3, 1110-1120. [CrossRef]

29. Wang, Y.; Phelan, S.A.; Manevich, Y.; Feinstein, S.I.; Fisher, A.B. Transgenic mice overexpressing peroxiredoxin 6 show increased resistance to lung injury in hyperoxia. Free Radic. Biol. Med. 2003, 35, 1110-1120. [CrossRef]

30. Fisher, A.B.; Dodia, C.; Yu, K.; Feinstein, S.I. Lung phospholipid metabolism in transgenic mice overexpressing peroxiredoxin 6. Biochim. Biophys. Acta 2006, 1761, 785-792. [CrossRef]

31. Sharan, S.K.; Thomason, L.C.; Kuznetsov, S.G.; Court, D.L. Recombineering: A homologous recombination-based method of genetic engineering. Nat. Protoc. 2009, 4, 206-223. [CrossRef] [PubMed]

32. Kaneko, T.; Mashimo, T. Simple genome editing of rodent intact embryos by electroporation. PLoS ONE 2015, 10, 1371. [CrossRef]

33. Sorokina, E.M.; Feinstein, S.I.; Milovanova, T.N.; Fisher, A.B. Identification of the amino acid sequence that targets peroxiredoxin 6 to lysosome-like structures of lung epithelial cells. Am. J. Physiol. Lung Cell. Mol. Physiol. 2009, 297, 871-880. [CrossRef] [PubMed]

34. Sorokina, E.M.; Feinstein, S.I.; Zhou, S.; Fisher, A.B. Intracellular targeting of peroxiredoxin 6 to lysosomal organelles requires MAPK activity and binding to 14-3-3 epsilon. Am. J. Physiol. Cell Physiol. 2011, 300, C1430-C1441. [CrossRef] [PubMed]

35. Sorokina, E.M.; Dodia, C.; Zhou, S.; Tao, J.Q.; Gao, L.; Raabe, T.; Feinstein, S.I.; Fisher, A.B. Mutation of Serine 32 to Threonine in Peroxiredoxin 6 Preserves Its Structure and Enzymatic Function but Abolishes Its Trafficking to Lamellar Bodies. J. Biol. Chem. 2016, 291, 9268-9280. [CrossRef] [PubMed]

36. Kim, S.Y.; Jo, H.Y.; Kim, M.H.; Cha, Y.Y.; Choi, S.W.; Shim, J.H.; Kim, T.J.; Lee, K.Y. $\mathrm{H}_{2} \mathrm{O}_{2}$-dependent hyperoxidation of peroxiredoxin $6(\operatorname{Prdx} 6)$ plays a role in cellular toxicity via up-regulation of iPLA 2 activity. J. Biol. Chem. 2008, 283, 33563-33568. [CrossRef]

37. Zhou, S.; Dodia, C.; Feinstein, S.I.; Harper, S.; Forman, H.J.; Speicher, D.W.; Fisher, A.B. Oxidation of peroxiredoxin 6 in the presence of GSH increases its phospholipase $\mathrm{A}_{2}$ activity at cytoplasmic $\mathrm{pH}$. Antioxidants 2019, 8, 4. [CrossRef] 
38. Li, H.; Benipal, B.; Zhou, S.; Dodia, C.; Chatterjee, S.; Tao, J.Q.; Sorokina, E.M.; Raabe, T.; Feinstein, S.I.; Fisher, A.B. Critical role of peroxiredoxin 6 in the repair of peroxidized cell membranes following oxidative stress. Free Radic. Biol. Med. 2015, 87, 356-365. [CrossRef]

39. Ho, J.N.; Lee, S.B.; Lee, S.S.; Yoon, S.H.; Kang, G.Y.; Hwang, S.G.; Um, H.D. Phospholipase $A_{2}$ activity of peroxiredoxin 6 promotes invasion and metastasis of lung cancer cells. Mol. Cancer Ther. 2010, 9, 825-832. [CrossRef] [PubMed]

40. Schmitt, A.; Schmitz, W.; Hufnagel, A.; Schartl, M.; Meierjohann, S. Peroxiredoxin 6 triggers melanoma cell growth by increasing arachidonic acid-dependent lipid signalling. Biochem. J. 2015, 471, 267-279. [CrossRef]

41. Fisher, A.B.; Vasquez-Medina, J.P.; Dodia, C.; Sorokina, E.M.; Tao, J.Q.; Feinstein, S.I. Peroxiredoxin 6 phospholipid hydroperoxidase activity in the repair of peroxidized cell membranes. Redox Biol. 2018, 14, 41-46. [CrossRef] [PubMed]

42. Arevalo, J.A.; Vázquez-Medina, J.P. The Role of peroxiredoxin6 in cell signaling. Antioxidants 2018, 7, 172. [CrossRef] [PubMed]

43. Wu, Y.; Feinstein, S.I.; Manevich, Y.; Chowdhury, I.; Pak, J.H.; Kazi, A.; Dodia, C.; Speicher, D.W.; Fisher, A.B. Mitogen-activated protein kinase-mediated phosphorylation of peroxiredoxin 6 regulates its phospholipase A(2) activity. Biochem. J. 2009, 419, 669-679. [CrossRef] [PubMed]

44. Zhou, S.; Sorokina, E.M.; Harper, S.; Li, H.; Ralat, L.; Dodia, C.; Speicher, D.W.; Feinstein, S.I.; Fisher, A.B. Peroxiredoxin 6 homodimerization and heterodimerization with glutathione S-transferase pi are required for its peroxidase but not phospholipase $\mathrm{A}_{2}$ activity. Free Radic. Biol. Med. 2016, 94, 145-156. [CrossRef] [PubMed]

(C) 2019 by the author. Licensee MDPI, Basel, Switzerland. This article is an open access article distributed under the terms and conditions of the Creative Commons Attribution (CC BY) license (http:/ / creativecommons.org/licenses/by/4.0/). 
Article

\title{
Non-Mammalian Prdx6 Enzymes (Proteins with 1-Cys Prdx Mechanism) Display PLA 2 Activity Similar to the Human Orthologue
}

\author{
Renata Bannitz-Fernandes ${ }^{1}$, Rogério Aleixo-Silva ${ }^{1}$, João Paulo Silva ${ }^{1}$, Chandra Dodia ${ }^{2}$, \\ Jose Pablo Vazquez-Medina ${ }^{2,3}$, Jian-Qin Tao ${ }^{2}$, Aron Fisher ${ }^{2}$ and Luis Netto ${ }^{1, *}$ \\ 1 Departamento de Genética e Biologia Evolutiva, Instituto de Biociências, Universidade de São Paulo, \\ São Paulo SP 05508-090, Brazil; bannitzfernandes@gmail.com (R.B.-F.); rlaleixosilva@gmail.com (R.A.-S.); \\ silvajpn7@gmail.com (J.P.S.) \\ 2 Department of Physiology, Institute for Environmental Medicine, Perelman School of Medicine, \\ University of Pennsylvania, Philadelphia, PA 19104, USA; cdodia@pennmedicine.upenn.edu (C.D.); \\ jpv-m@berkeley.edu (J.P.V.-M.); taoj@mail.med.upenn.edu (J.-Q.T.); abf@upenn.edu (A.F.) \\ 3 Department of Integrative Biology, University of California, Berkeley, CA 94720, USA \\ * Correspondence: nettoles@ib.usp.br; Tel.: +55-11-3091-7590
}

Received: 11 January 2019; Accepted: 22 February 2019; Published: 1 March 2019

\begin{abstract}
Mammalian peroxiredoxin class 6 (Prdx6) are bifunctional enzymes. Non-mammalian Prdx6 enzymes display Cys-based peroxidase activity, but to date their putative phospholipase $\mathrm{A}_{2}$ ( $\mathrm{PLA}_{2}$ activities) has not been experimentally investigated. Initially, we observed that five non-mammalian Prdx6 enzymes (enzymes from Arabidopsis thaliana (AtPER1), Triticum aestivum (TaPER1), Pseudomonas aeruginosa (PaLsfA) and Aspergillus fumigatus (AfPrx1 and AfPrxC)) present features compatible with $\mathrm{PLA}_{2}$ activities in mammalian Prdx6 by amino acid sequences alignment and tertiary structure modeling. Employing unilamellar liposomes with tracer amounts of $\left[{ }^{3} \mathrm{H}\right]-1$,2-Dipalmitoyl-sn-glycero-3-phosphocholine (DPPC) and thin layer chromatography, all the tested non-mammalian Prdx6 enzymes displayed PLA $_{2}$ activities, with values ranging from 3.4 to $6.1 \mathrm{nmol} / \mathrm{min} / \mathrm{mg}$ protein. It was previously shown that Thr177 phosphorylation of human Prdx6 increases its $\mathrm{PLA}_{2}$ activity, especially at neutral $\mathrm{pH}$. Therefore, we investigated if human Erk2 kinase could also phosphorylate homologous Thr residues in non-mammalian Prdx6 proteins. We observed phosphorylation of the conserved Thr in three out of the five non-mammalian Prdx enzymes by mass spectrometry. In the case of the mitochondrial Prdx6 from A. fumigatus (AfPrxC), we also observed phosphorylation by western blot, and as a consequence, the PLA 2 activity was increased in acidic and neutral conditions by the human Erk2 kinase treatment. The possible physiological meanings of these PLA 2 activities described open new fields for future research.
\end{abstract}

Keywords: Peroxiredoxin; Prdx6; PLA 2 activity; 1-Cys Prdx

\section{Introduction}

Peroxiredoxins (Prdxs) are ubiquitous enzymes that play prominent roles in regulating peroxide levels within cells. These enzymes are often abundant and are capable of rapidly reducing peroxides [1]. Prdxs are Cys-based peroxidases that contain one or two conserved Cys residues [2]. To date, all characterized Prdxs display the universal motif PxxxT/SxxC and can reduce hydroperoxides efficiently, with rates ranging from $10^{6}$ to $10^{8} \mathrm{M}^{-1} \mathrm{~s}^{-1}$ [3]. In spite of being a heterogeneous family, all Prdxs have this peroxidase activity dependent on $\mathrm{Thr}(\mathrm{Ser})$-Cys-Arg catalytic triad that stabilizes the transition state of the reaction [4]. 
According to the PeroxiRedoxin classification index (PREX) database, Prdxs can be classified into six subfamilies: AhpC/Prx1, Prdx6, Prx5, Tpx, bacterioferritin comigratory protein (BCP)/PrxQ and AhpE, considering sequence and structural characteristics [5]. The Prdx6 subfamily is widespread from Eubacteria and Archaea to higher eukaryotes. It comprises almost exclusively 1-Cys Prdx mechanisms (only one Cys takes part in the catalytic cycle) and forms obligatory antiparallel dimers, and eventually, higher oligomeric states like decamers (pentamer of dimers). The peroxidase activity motif PVCTTE (Pro-Val-Cys-Thr-Thr-Glu) comprises the peroxidatic Cys (Cysp) and is characteristic of Prdx6 enzymes [6].

In addition to the peroxidase activity, mammalian Prdx6 displays a $\mathrm{Ca}^{2+}$-independent phospholipase $\mathrm{A}_{2}\left(\right.$ aiPLA $_{2}$ ) activity [7-9]. The PLA 2 comprise a large family of lipolytic enzymes that hydrolyze the $s n-2$ acyl bond of phospholipids, releasing a free fatty acid and lysophospholipid [10]. The active sites of the peroxidase and aiPLA ${ }_{2}$ activities are spatially and functionally independent and the catalytic triad for human PLA 2 activity is composed of the His26, Ser32 and Asp140 residues [11]. The identification of Ser32 residue in the GxSxG motif [7] as the site of phospholipid hydrolysis involved the use of serine protease inhibitors (e.g., MJ33, 1-hexadecyl-3-trifluoro-ethylglycero-sn-2phosphomethanol), structural analyses and site-direct mutagenesis [12]. Afterwards, the lysosomal targeting signal peptide (GDSWGILFSHP) was determined and it also contains the catalytic Ser (Ser32) [13]. Notably, mutation of Ser32 to Thr abolished targeting human Prdx6 to lysosome-like structures while maintaining its $\mathrm{PLA}_{2}$ activity [14].

This aiPLA ${ }_{2}$ activity is maximum at $\mathrm{pH} 4$, consistent with the subcellular localization of Prdx6 in a lysosome-like organelle. The phosphorylation of Prdx6 at Thr177 by MAP kinase induces a marked increase in $\mathrm{PLA}_{2}$ activity at acid and neutral $\mathrm{pH}$, indicating that the $\mathrm{PLA}_{2}$ activity may also be important in the cytosolic environment [15].

The aiPLA $\mathrm{A}_{2}$ activity is classically involved in pulmonary surfactant metabolism and membrane remodeling [16]. More recently, the Prdx6 PLA 2 activity was also related to NADPH (Nicotinamide Adenine Dinucleotide Phosphate) oxidase 2 (NOX2) activation [17,18], and also with the metastasis and invasiveness of lung cancer cells [19].

So far, $\mathrm{PLA}_{2}$ activity has been identified only in mammalian Prdx6 enzymes. However, Prdx6 enzymes from other taxa also present structural similarities, suggesting that these enzymes might also possess $\mathrm{PLA}_{2}$ activity. Indeed, among $126 \operatorname{Prdx} 6$ sequences analyzed in a previous study, $67 \%$ of the sequences had the lipase motif ( $38 \%$ had the classic lipase motif GxSxG, $11 \%$ had the alternative lipase motif GxSxA and 18\% had variant lipase motifs) [6]. Therefore, we selected 5 non-mammalian Prdx6 enzymes to evaluate their putative PLA 2 activity:

1. TaPER1 from Triticum aestivum: its gene is present as a single copy in the plant genome and is expressed mainly in the cytoplasm and nucleus during the development and germination of wheat seeds [20].

2. AtPER1 from Arabidopsis thaliana: its gene is also a single copy and its expression is induced by abscisic acid and oxidative stress [21]. AtPER1 also presents nuclear and cytoplasm localization [22]. Although knockout mutants for this gene are viable (unpublished data), overexpression or down-regulation of the AtPER1 gene affect seed germination during abiotic stresses [23].

3. AfPrx1 from Aspergillus fumigatus is a cytosolic protein that displays high reactivity for $\mathrm{H} 2 \mathrm{O} 2$ $\left(k=2.28 \times 10^{7} \mathrm{M}^{-1} \mathrm{~s}^{-1}\right)$ [24]. Moreover, the AfPrx1 is essential for the decomposition of exogenously added $\mathrm{H} 2 \mathrm{O} 2$ as shown by the investigation of a knockout strain ( $\triangle$ afprxi) [25]. The strain $\Delta$ afprx 1 is also more sensitive to other stressors' molecules. Additionally, AfPrx1 plays a role in fungus virulence in neutropenic murine models [24].

4. AfPrxC from Aspergillus fumigatus is a mitochondrial protein that also reacts rapidly with $\mathrm{H} 2 \mathrm{O} 2$ $\left(k=2.28 \times 10^{7} \mathrm{M}^{-1} \mathrm{~s}^{-1}\right)[24]$. 
5. PaLsfA from Pseudomonas aeruginosa: PaLsfA is the only 1-Cys Prdx among several antioxidant proteins in P. aeruginosa. PaLsfA expression is induced upon sulfate depletion [26] and it is involved with P. aeruginosa virulence [27].

\section{Materials and Methods}

\subsection{Sequence and Structural Analysis}

All the Prdx6 sequences studied here were obtained from the National Center for Biotechnology Information (NCBI) (https:/ / www.ncbi.nlm.nih.gov/) and confirmed in other curated databases: Phytozome (https:/ / phytozome.jgi.doe.gov) for TaPER1 and AtPER1; AspGD (http:/ / www.aspgd. org) for AfPrx1 and AfPrxC; and Pseudomonas Genome DB (http://www.pseudomonas.com) for PaLsfA. The alignment was performed using Clustal Omega program (https:/ / www.ebi.ac.uk/Tools/ msa/clustalo/) [28], and the software Jalview (University of Dundee, Scotland, UK) [29] was used for visualization.

The structures of non-mammalian Prdx6 were modeled using the human Prdx6 (1PRX) as the template and the SWISS-MODEL tool (https:/ / swissmodel.expasy.org/) [30]. The UCSF (University of California, San Francisco) Chimera program [31] was used to visualize and generate the images. The web based application WebLogo version 2.8.2 (http:/ / weblogo.berkeley.edu, University of California, Berkeley, USA) was used to generate the lysosomal target sequence logo [32].

\subsection{Cloning, Expression and Purification of Recombinant Proteins}

The genes of the corresponding Prdxs were cloned in expression vectors as follows: pET16b/ taper1 (kindly provided by Javier Cejudo) and pET15b/atper1; pET15b/palsfA. To clone into pET expression vectors (Novagen, Madison, USA), the sequences were amplified by polymerase chain reaction (PCR), from $\mathrm{TOPO}^{\mathrm{TM}}$ vector (Invitrogen, Carlsbad, USA) containing each sequence, using the following primers: TaPER1: 5'-ATCATATGCCGGGCCTCACCATCGG- ${ }^{\prime}$ and $5^{\prime}$-ATCTCGAG CTAGACCTTGGTGAAGCG-3', which contained sites for NdeI and XhoI restriction enzymes (bold letters). AtPER1: 5'-ATCATATGCCAGGGATCACACTAGG-3' and 5'-ATGGATCCTCAAGAGACC TCTGTGTGACG-3', which contained sites for NdeI and BamHI restriction enzymes (bold letters). PaLsfA: $5^{\prime}$-CGCATCATATGCTCAGACTCGGCGAC- ${ }^{\prime}$ and $5^{\prime}$-ACGGATCCTCAGCGGTTGGGC TG-3', which contained sites for NdeI and BamHI restriction enzymes (bold letters).

The genes afprx1 and afprxC were codon optimized for Escherichia coli expression and were synthesized by GenScript ${ }^{\circledR}$ (Piscataway, USA). These genes were then cloned into the NdeI (5') and BamHI ( $\left.3^{\prime}\right)$ restriction sites of the pET15b plasmid. All constructions were confirmed by sequencing, using T7 promoter and terminator oligonucleotides (BigDyeTM Terminator v3.1 Cycle Sequencing Kit, Applied Biosystems ${ }^{\circledR}$, Foster City, USA).

\subsubsection{Expression Procedures}

Single colonies of E. coli BL21 (DE3) harboring the respective plasmid (pET16b/taper1, pET15b/atper1, pET15b/afprx1, pET15b/afprxC, pET15b/palsfA) were cultured in Lysogeny broth medium (LB) containing $100 \mu \mathrm{g} / \mathrm{mL}$ ampicillin and grown for $16 \mathrm{~h}\left(37^{\circ} \mathrm{C}\right)$ in an orbital shaker $(250 \mathrm{rpm})$. The cultures were then diluted in $1 \mathrm{~L}$ of $\mathrm{LB}(100 \mu \mathrm{g} / \mathrm{mL}$ ampicillin $)$ and were incubated at $37^{\circ} \mathrm{C}$ until the optical density $\mathrm{OD}_{600 \mathrm{~nm}}$ attained $0.6-0.8$ values. Isopropyl $\beta$-D-1-thiogalactopyranoside (IPTG) was then added at a final concentration of $0.3 \mathrm{mM}$ for AfPrx1, AfPrxC and $1 \mathrm{mM}$ for AtPER1 and TaPER1. Then, each culture was incubated at $37^{\circ} \mathrm{C}$ for an additional $3 \mathrm{~h}(250 \mathrm{rpm})$, with the exception of PaLsfA, in which $1 \mathrm{mM}$ IPTG was added and the culture incubated at $30^{\circ} \mathrm{C}$ for $6 \mathrm{~h}(250 \mathrm{rpm})$. Cells were harvested by centrifugation, and the pellet was washed and resuspended in the start buffer (20 mM sodium phosphate $\mathrm{pH} 7.4 ; 500 \mathrm{mM} \mathrm{NaCl} ; 20 \mathrm{mM}$ imidazole; $625 \mu \mathrm{M}$ phenylmethylsulfonyl fluoride (PMSF). Twenty cycles of $15 \mathrm{~s}$ of sonication (30\% amplitude) following $40 \mathrm{~s}$ in ice were applied to cell suspensions. Cell extracts were kept on ice during treatment with $1 \%$ streptomycin sulfate for 
$15 \mathrm{~min}$ and the suspension was centrifuged at 15,000 rpm for $45 \mathrm{~min}$ to remove nucleic acid precipitates and the insoluble fraction.

\subsubsection{Purification}

Cell extracts were filtered and purified by immobilized metal ion affinity chromatography (IMAC) using the HisTrap ${ }^{\text {TM }}$ FF 5 mL column (GE Healthcare, Chicago, USA), using the ÄKTAFPLC system (GE Healthcare, Chicago, USA). The conditions of protein purification were optimized using the gradient procedure for imidazole concentration as described by the manufacturer. Imidazole was removed from purified proteins by gel filtration using a PD10 column (GE Healthcare, Chicago, US). Purified proteins were stored in the following buffers: AtPER1 and TaPER1 in $20 \mathrm{mM}$ Tris HCl buffer (pH 7.4) containing $500 \mathrm{mM} \mathrm{NaCl}$, AfPrx1 and AfPrxC in $20 \mathrm{mM}$ sodium phosphate buffer (pH 7.4) containing $500 \mathrm{mM} \mathrm{NaCl}$, and PaLsfA in $20 \mathrm{mM}$ HEPES buffer (pH 7.4) containing $150 \mathrm{mM} \mathrm{NaCl}$ and $0.1 \mathrm{mM}$ diethylenetriaminepentaacetic acid (DTPA). Recombinant protein concentrations were determined spectrophotometrically at $280 \mathrm{~nm}$. The extinction coefficients for reduced AtPER1 $\left(\varepsilon_{280 \mathrm{~nm}}\right.$ $\left.=24,013 \mathrm{M}^{-1} \mathrm{~cm}^{-1}\right)$, TaPER1 $\left(\varepsilon_{280 \mathrm{~nm}}=21,555 \mathrm{M}^{-1} \mathrm{~cm}^{-1}\right), \operatorname{AfPrx} 1\left(\varepsilon_{280 \mathrm{~nm}}=20,970 \mathrm{M}^{-1} \mathrm{~cm}^{-1}\right), \operatorname{AfPrxC}$ $\left(\varepsilon_{280 \mathrm{~nm}}=22,460 \mathrm{M}^{-1} \mathrm{~cm}^{-1}\right)$ and PaLsfA $\left(\varepsilon_{280 \mathrm{~nm}}=33,920 \mathrm{M}^{-1} \mathrm{~cm}^{-1}\right)$ were determined using the ProtParam tool (http:/ / www.expasy.ch/tools/protparam.html, Lausanne, Switzerland).

\subsection{Preparation of Unilamellar Liposomes}

The lipids used to make the unilamellar liposomes were: 1,2-Dipalmitoyl-sn-glycero-3phosphocholine (DPPC) (Sigma-Aldrich P0763, Taufkirchen, Germany); L- $\alpha$-Phosphatidylcholine (PC) (Sigma-Aldrich P2772, Taufkirchen, Germany); L- $\alpha$-Phosphatidyl-DL-glycerol ammonium salt (PG) (Sigma-Aldrich P0514, Taufkirchen, Germany); cholesterol (Sigma-Aldrich C8667, Taufkirchen, Germany). The stock solutions were made by diluting the lipids in chloroform.

Unilamellar liposomes were made using DPPC/PC/PG/cholesterol (5:2.5:1:1.5) with tracer amounts of $\left[{ }^{3} \mathrm{H}\right]$ DPPC (American Radiolabeled Chemicals ART 0532, Saint Louis, USA). The lipid solution was evaporated to dryness under $\mathrm{N}_{2}$ and resuspended in isotonic saline. In some cases, the $\mathrm{PLA}_{2}$ inhibitor MJ33 was added $(200 \mu \mathrm{M})$. The solution was repeatedly frozen/thawed by alternating liquid $\mathrm{N}_{2}$ and warm $\mathrm{H}_{2} \mathrm{O}\left(50{ }^{\circ} \mathrm{C}\right)$ (3 times), and then extruded at $50{ }^{\circ} \mathrm{C}$ for 10 cycles through a $200 \mu \mathrm{m}$ pore size membrane to generate unilamellar liposomes using LIPEX ${ }^{\mathrm{TM}}$ (Transferra Nanosciences Inc., Burnaby, Canada). The liposomes were freshly prepared for every use and stored for short times at $4{ }^{\circ} \mathrm{C}[16]$.

\subsection{Evaluation of $\mathrm{PLA} \mathrm{A}_{2}$ Activity}

The PLA $\mathrm{P}_{2}$ activities were determined using unilamellar liposomes (100 $\left.\mu \mathrm{L}\right)$, containing tracer amounts of $\left[{ }^{3} \mathrm{H}\right]$ DPPC. Reaction mixtures contained non-mammalian Prdx6 enzymes $(5,10$ or $50 \mu \mathrm{M})$ in an acid ( $40 \mathrm{mM}$ sodium acetate $\mathrm{pH} 4,5 \mathrm{mM}$ ethylenediaminetetraacetic acid (EDTA)) or neutral $\mathrm{pH}$ buffer (50 mM Tris-Cl pH 7.4, $1 \mathrm{mM}$ ethylene glycol-bis(2-aminoethylether)- $N, N, N^{\prime}, N^{\prime}$-tetraacetic acid (EGTA)), both incubated for $1 \mathrm{~h}$ at $37^{\circ} \mathrm{C}$. The reactions were interrupted by the addition of $3.75 \mathrm{~mL}$ of chloroform/methanol (1:2) for at least $1 \mathrm{~h}$. The lipid extraction was performed by incubating samples with $1.25 \mathrm{~mL}$ of chloroform for $1 \mathrm{~h}$, followed by addition of $1.25 \mathrm{~mL}$ of water and incubation for $1 \mathrm{~h}$. The extracts were centrifuged for $10 \mathrm{~min}$ at $1000 \mathrm{rpm}$. The organic phase was separated and completely dried under $\mathrm{N}_{2}$ flow.

Thin layer chromatography (TLC) was performed in two steps with hexane/diethyl ether/acetic acid ( $1^{\circ}$ step 60:40:10 and $2^{\circ}$ step 90:10:1). After the run and plate drying, samples were stained in an iodine atmosphere chamber. The samples of interest were scrapped from the plate. The free fatty acid spot was quantified after extraction, as follows: $1 \mathrm{~mL}$ of water, $12 \mathrm{~h}$ of repose, addition of $10 \mathrm{~mL}$ of Econo-Safe $^{\mathrm{TM}}$ Biodegradable Counting Cocktail (Research Products International, Mount Prospect, USA) and scintillation reading. The $\mathrm{PLA}_{2}$ activities were determined in counts per minute (cpm) after $1 \mathrm{~h}$ of incubation (subtracting the zero time from control) [16]. Cpm were converted to DPPC 
mass based on the specific activities of the starting material and were expressed as nmol of DPPC hydrolyzed $/ \mathrm{min} / \mathrm{mg}$ protein. Protein contents were measured by Coomassie blue assay, using the Quick Start Bradford Dye reagent (BioRad, Hercules, USA).

\subsection{Phosphorylation Treatments of Non-Mammalian Prdx6}

The human kinase Erk2 (GI: 119554) was selected for the in vitro phosphorylation assays (Merck 14-550, Darmstadt, Germany). Each one of the non-mammalian Prdx6 (150 ng/ $\mu \mathrm{L})$ was incubated in reaction buffer (50 mM Tris-Cl pH 7.5, $20 \mu \mathrm{M}$ EGTA) containing $10 \mathrm{mM} \mathrm{MgCl}_{2}$ and $2 \mathrm{mM}$ ATP in the presence or absence (as control) of active Erk2 kinase $(10 \mathrm{ng} / \mu \mathrm{L}$ ). The reactions were incubated at $30{ }^{\circ} \mathrm{C}$ for $90 \mathrm{~min}$ with slight agitation [33] and then separated for mass spectrometry (MS) analysis or for western blot assay as described below. The Erk2 kinase solution was previously diluted to $80 \mathrm{ng} / \mu \mathrm{L}$, following the manufacturer instructions (50 mM Tris- $\mathrm{Cl} \mathrm{pH} \mathrm{7.5,} 0.1 \mathrm{mM}$ EGTA, with or without $0.1 \mathrm{mM} \mathrm{Na}_{3} \mathrm{VO}_{4}, 0.1 \%$ 2-mercaptoethanol and $1 \mathrm{mg} / \mathrm{mL}$ bovine serum albumin (BSA)).

\subsection{Reduction, Alkylation and Tryptic Digestion for MS}

Samples obtained from the phosphorylation assay (described above) were mixed with $100 \mathrm{mM}$ ammonium bicarbonate buffer $\mathrm{pH} 8$ plus $8 \mathrm{M}$ urea (1:1). Sequentially, samples were reduced with $10 \mu \mathrm{L}$ of $10 \mathrm{mM}$ dithiothreitol (DTT) for $1 \mathrm{~h}$ at $30^{\circ} \mathrm{C}$ and were alkylated in the dark in an Eppendorf ThermoMixer (Eppendorf, Hamburg, Germany) by adding $10 \mu \mathrm{L}$ of $500 \mathrm{mM}$ iodoacetamide for $30 \mathrm{~min}$ at $25^{\circ} \mathrm{C}$ (final volume $140 \mu \mathrm{L}$ ). After incubation, samples were diluted with $540 \mu \mathrm{L}$ of 100 $\mathrm{mM}$ ammonium bicarbonate buffer $\mathrm{pH}$ 8. Finally, protein digestion was started by adding $3 \mu \mathrm{L}$ of Trypsin Gold (Promega, Madison, USA) $40 \mathrm{ng} / \mu \mathrm{L}$ (protein/enzyme ratio of 50:1) for $16 \mathrm{~h}$ at $37^{\circ} \mathrm{C}$. The reaction mixtures were neutralized with $0.1 \%$ trifluoroacetic acid and were completely dried in speed vac. For purification, extracts were resuspended in $0.1 \%$ formic acid solution. Each sample was then concentrated through ZipTip resin (Merck, Darmstadt, Germany) according to the manufacturer's protocol. Subsequently, samples were dried in speed vac and stored at $-20^{\circ} \mathrm{C}$ until use.

\subsection{Evaluation of Thr Phosphorylation by MS}

The resulting peptides were analyzed by liquid chromatography-tandem mass spectrometry (LC-MS/MS) using a nanoACQUITY UPLC system (Waters Corporation, Milford, USA) coupled to a TripleTOF 6600 mass spectrometer (AB SCIEX, Framingham, USA). Analysis was conducted under trap and eluted mode using a nanoACQUITY UPLC-Symmetry (Waters Corporation, Milford, USA) containing a C18 trap column $(20 \mathrm{~mm} \times 180 \mu \mathrm{m} ; 5 \mu \mathrm{m})$ and a separation column $(75 \mu \mathrm{m} \times$ $150 \mathrm{~mm} ; 3.5 \mu \mathrm{m})$. Trapping was done at $10 \mu \mathrm{L} / \mathrm{min}$ with $2 \%$ of solvent B. Peptides were separated with mobile phase $\mathrm{A}(0.1 \%$ formic acid in water) and $\mathrm{B}(0.1 \%$ formic acid in acetonitrile) at a flow rate of $0.4 \mu \mathrm{L} / \mathrm{min}$ using the following gradient: $2-35 \%$ B from 0 to $60 \mathrm{~min} ; 35-85 \%$ B from 60 to $61 \mathrm{~min}$; isocratic elution with $85 \%$ B from 61 to $65 \mathrm{~min} ; 85-2 \%$ B from 65 to $66 \mathrm{~min}$; isocratic elution with $2 \%$ B from 66 to $85 \mathrm{~min}$. Nano-electrospray ion source was operated at $2.2 \mathrm{kV}$ (ion spray voltage floating, ISVF), curtain gas 20, interface heater (IHT) 120, ion source gas 1 (GS1) 3, ion source gas 2 (GS2) zero, declustering potential (DP) $80 \mathrm{~V}$. Time-of-flight mass spectrometry (TOF-MS) and mass spectrometry analyzis (MS/MS) data were acquired using information-dependent acquisition (IDA) mode. For IDA parameters, a $250 \mathrm{~ms}$ survey scan in the $\mathrm{m} / \mathrm{z}$ (mass-to-charge ratio) range of 300-2000 was followed by $25 \mathrm{MS} / \mathrm{MS}$ ions in the $\mathrm{m} / \mathrm{z}$ range of 100-2000 acquired with an accumulation time of $100 \mathrm{~ms}$ (total cycle time $2.8 \mathrm{~s}$ ). Switch criteria included, intensity greater than 150 counts and charge state $2-5$. Former target ions were excluded for $4 \mathrm{~s}$. Software used for acquisition and data processing were Analyst@TF 1.7 (AB SCIEX, Framingham, USA) and PeakView $\AA^{2} 2$ (AB SCIEX, Framingham, USA), respectively. For the analysis of protein modification, MASCOT 2.4 software (Matrix Science Ltd., London, United Kingdom, Redoxoma-FAPESP user license 10.10.1.46/Mascot) was used with mass tolerance of $10 \mathrm{ppm}$ for MS experiments and 0.05 Da for MS/MS experiments. 


\subsection{Evaluation of Prdx Phosphorylation by Western Blot}

After the phosphorylation reaction, samples $(10 \mu \mathrm{L})$ were reduced using DTT $(100 \mathrm{mM})$, then heated $\left(95^{\circ} \mathrm{C}\right)$ for $5 \mathrm{~min}$ and analysed by SDS-PAGE $(12 \%)(50 \mathrm{~min} / 200 \mathrm{~V})$. The gel was transferred to nitrocellulose membranes using NuPAGE®transfer buffer (Thermo Fisher Scientific NP0006, Waltham, US) (90 min/35 V). Ponceau S staining was used to verify the total protein amount. The blocking step was performed with buffer Odyssey (Li-Cor Biosciences 927-40000, Nebraska, USA) at room temperature for $90 \mathrm{~min}$. The membrane was incubated with anti-phosphorylated Prdx6 primary antibody (anti-mouse P-Prdx6 S3091-1, Covance Research Products, Denver, USA) [17], diluted 1:200 in a mix with block buffer: TBS-T (1:4), overnight at $4{ }^{\circ} \mathrm{C}$. TBS-T was used to wash the membrane $(3 \times 10 \mathrm{~min})$. The incubation with secondary antibody anti-rabbit IRDye ${ }^{\circledR} 800 \mathrm{CW}$ (Li-Cor Biosciences 925-32211, Nebraska, USA), diluted 1:5000 in TBS-T, was performed for 45 min at room temperature. The antibody to phosphorylated Prdx6 was generated by Proteintech (Chicago, USA) using a phosphorylated mouse Prdx6 peptide (TGTKPVApTPVDWKKG) that contains the Thr 177 and has been described and validated previously [17].

\section{Results}

\subsection{Conservation of $\mathrm{PLA}_{2}$ Catalytic Triad in Non-Mammalian Prdx6}

Comparing the sequences of Prdx6 from different organisms, we observed that the peroxidase motif (PVCTTE) (Figure 1, light red) and the corresponding catalytic triad (Figure 1, dark red) are fully conserved, with the exception of one single replacement of amino acid with similar physico-chemical properties in Prdx6 from Selaginella moellendorffii (PVCTSE).

In contrast, the PLA 2 motif (Figure 1) is not as conserved among Prdx6 enzymes as the peroxidase motif. The conserved His (His26 in human Prdx6) is present in most sequences (Figure 1, dark green), with few exceptions: a change to Tyr in Plasmodium falciparum, Drosophila melanogaster and Saccharomyces cerevisiae sequences or a change to Asp in the archaeal proteins from Aeropyrum pernix and Pyrococcus horikoshii (Figure 1, dark green). Likewise, Ser (Ser32 in human Prdx6) is conserved in many sequences, presenting a change to Gly in Triticum aestivum, Azotobacter vinelandii and the archaeal proteins, or to Gln or Asn in Caenorhabditis elegans and Neurospora crassa, respectively.

Finally, the last residue of the PLA 2 triad, Asp (Asp140 in human Prdx6) is present in almost all sequences, with the exception of P. falciparum Prdx6, in which a Glu appears, maintaining the acidic properties. Notably, this conserved residue Asp may be located at two slightly distinct positions: in archaea, bacteria and fungus taxa, it is two amino acids backwards compared to other sequences (Figure 1, dark green). Possibly, this conserved Asp occupies similar position in the tertiary structure among distinct Prdx6 enzymes, keeping its function in catalysis.

The Thr residue (Thr177 in human Prdx6) that is subjected to phosphorylation in mammalian enzymes is highly conserved in almost all analyzed sequences. The exceptions are the archaeal ones (Figure 1, gray). It is worth mentioning that the Thr from AfPrx1 is one position backward compared to the other sequences. Although this Thr residue is highly conserved, the surrounding amino acid sequences are quite distinct among non-mammalian Prdx6 enzymes, especially in AfPrx1 and AfPrxC.

In contrast, the lysosomal target sequence exhibits higher variability among Prdx6 enzymes (Figure 1, light green). Notably, the last 5 residues are highly conserved among the analyzed sequences (Leu-Phe/Leu-Ser-His-Pro) (LF/LSHP) (Figure 2). Considering the structural characteristics indicated above, we decided to investigate if other Prdx6 enzymes from non-mammalian organisms display $\mathrm{PLA}_{2}$ activity. 


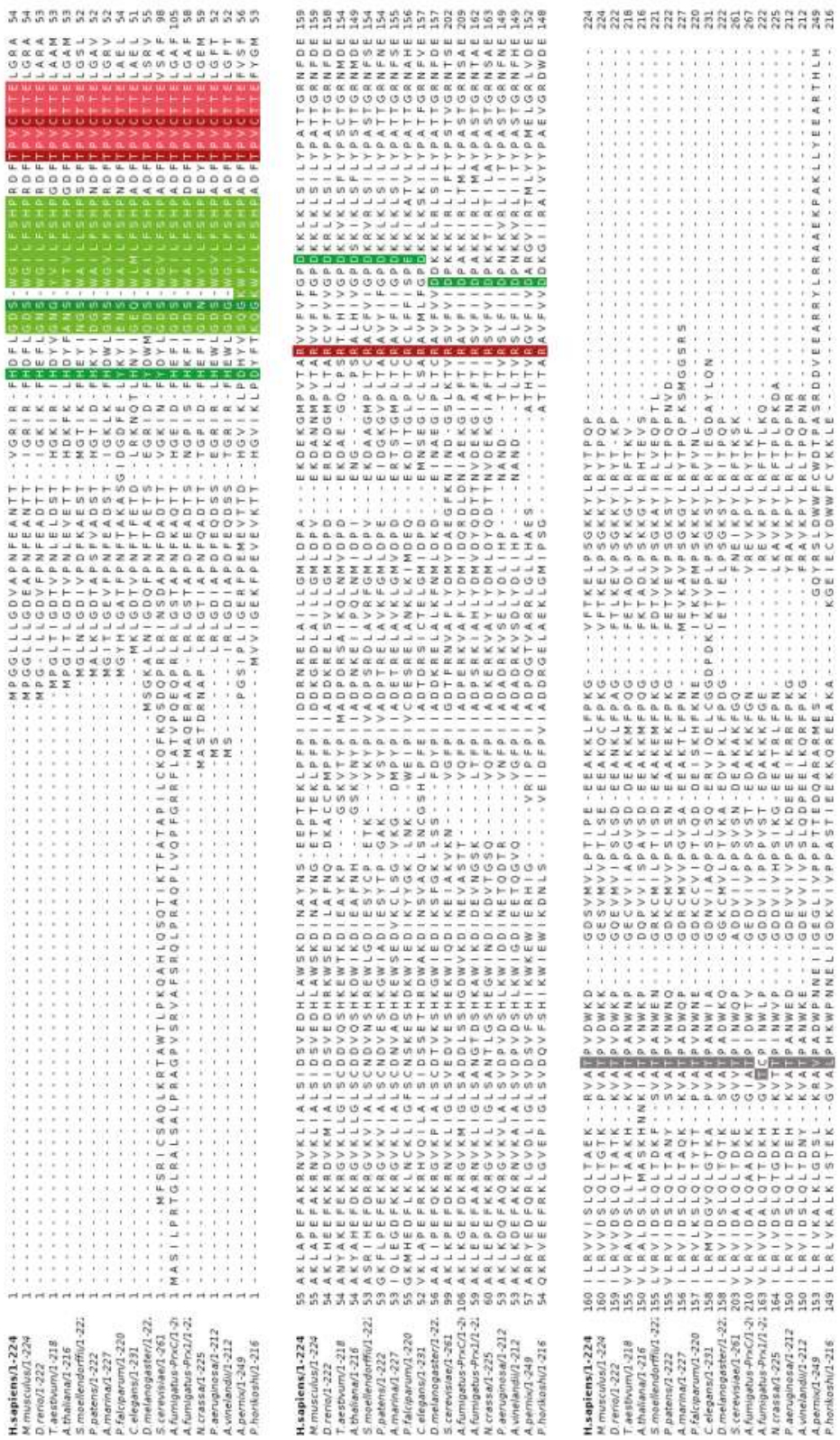

Figure 1. Alignment of representative Peroxiredoxins class $6(\operatorname{Prdx} 6)$ enzymes from organisms that belong to diverse phylogenetic groups. Lysosomal putative target sequence (light green), phospholipase $\mathrm{A}_{2}\left(\mathrm{PLA}_{2}\right.$ ) catalytic triad (dark green), Prdx6 peroxidase motif (light red), peroxidatic catalytic triad (dark red) and the Thr that is putatively subjected to phosphorylation (gray) are highlighted. 


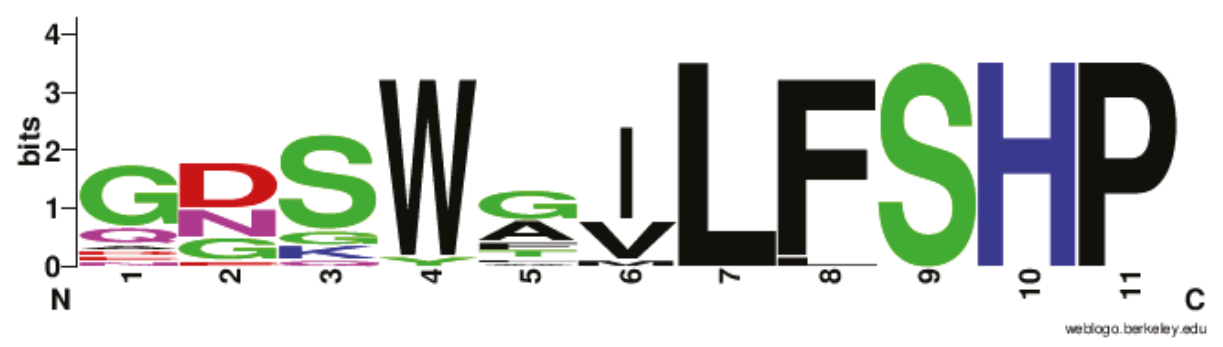

Figure 2. Graphical representation of residue conservation in the putative lysosomal target sequence. The letter size represents the conservation of each residue, while their color represents the chemical property of the corresponding amino acid. Polar amino acids Gly (G), Ser (S), Thr (T), Tyr (Y), Cys (C) are depicted in green; neutral amino acids $G \ln (\mathrm{Q})$ and $A s n(N)$ are in magenta; basic amino acids Leu (L), Arg (R), His (H) are in blue; acidic amino acids Asp (D) and Glu (E) are in red; hydrophobic amino acids Ala (A), Val (V), Leu (L), Ile (I), Pro (P), Trp (W), Phe (F), Met (M) are in black. The logo was generated with the WebLogo application (http://weblogo.berkeley.edu).

\subsection{Structural Conservation of Prdx6 Motifs in TaPER1, AtPER1, AfPrx1, AfPrxC, and PaLsfA}

Next, we investigated the three-dimensional conservation of the PLA 2 catalytic triad by modeling the structures of TaPER1, AtPER1, AfPrx1, AfPrxC, and PaLsfA. The PLA 2 and the peroxidatic active sites are conserved and are located at opposite sides of their thioredoxin fold (Figure 3), as previously described for mammalian Prdx6 [34]. Apparently, in all the predicted structures, the putative substrate (a phospholipid) for the PLA 2 activity would fit in the corresponding cavity (Figure 3). Remarkably, the two distinct positions occupied by the conserved Asp residues in the amino acid sequences are reflected in the predicted three-dimensional structures: (1) the plant orthologues and the human Prdx6 have the Asp in a similar position, whereas (2) the orthologues from fungi and bacteria have the conserved Asp in a backward position (Figure 4). The main difference between non-mammalian Prdx6 and human orthologues is the Ser $\rightarrow$ Gly substitution observed in TaPER1 (Figure 4). The structural similarities among these proteins suggest that they can display $\mathrm{PLA}_{2}$ activity. 


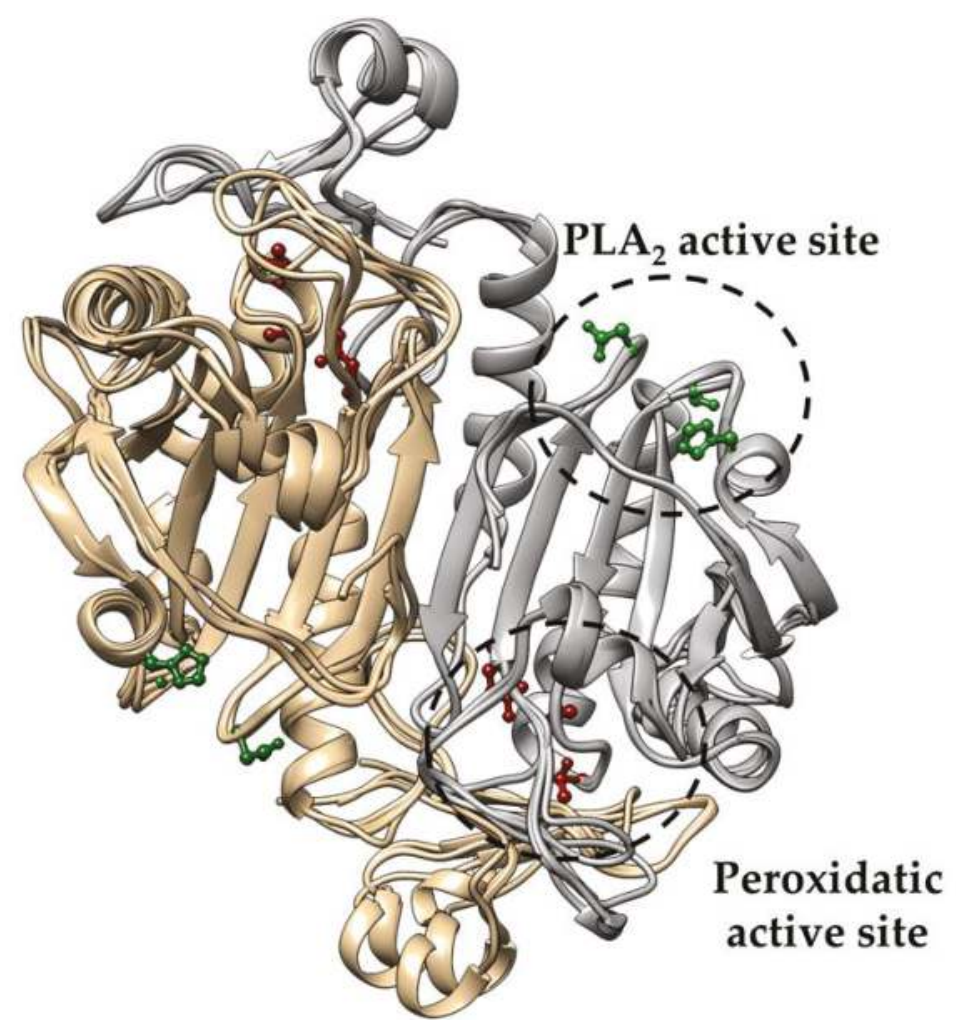

Figure 3. Superposition of the predicted structures of Prdx6 from T. aestivum, A. thaliana, P. aeruginosa, A. fumigatus (AfPrx1 and AfPrxC). One monomer is represented in copper and the other in gray in the antiparallel dimers. The PLA 2 catalytic triad is depicted in green, and the peroxidatic catalytic triad in red. The predicted structures were generated using human Prdx6 as modeled by the SWISS-MODEL tool (https://swissmodel.expasy.org/). 


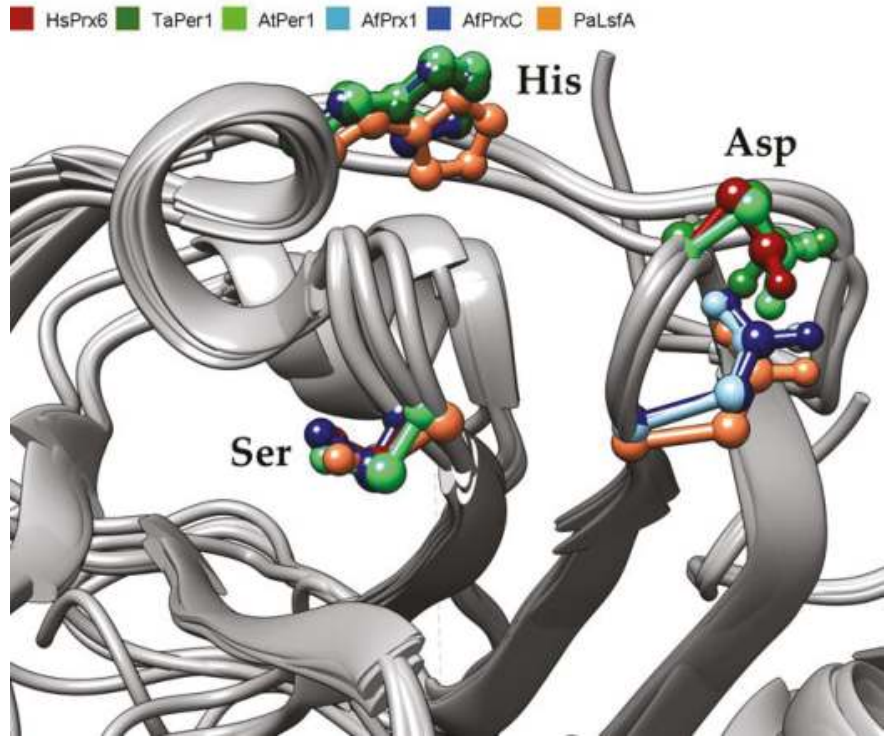

Figure 4. Close view of the PLA 2 catalytic triad of six 1-Cys Prdxs from H. sapiens (red), T. aestivum (dark green), A. thaliana (light green), A. fumigatus (Prx1 in light blue and PrxC in dark blue), and $P$. aeruginosa (orange) superimposed.

\subsection{Acidic, $\mathrm{Ca}^{2+}$-Independent $P L A_{2}\left(\right.$ aiPLA $A_{2}$ ) Activity of Non-Mammalian Prdx6}

Next, we evaluated the PLA 2 activity of four (4) non-mammalian enzymes. All of the analyzed proteins displayed $\mathrm{PLA}_{2}$ activity at acidic conditions ( $\left.\mathrm{pH} 4\right)$ in a $\mathrm{Ca}^{2+}$-independent manner (Table 1), consistent with the so-called acidic $\mathrm{Ca}^{2+}$-independent phospholipase $\mathrm{A}_{2}\left(\right.$ aiPLA $\left.\mathrm{A}_{2}\right)$ described before for the human Prdx6 [34]. In addition, these activities attained similar values, ranging from 3.38 for PaLsfA to 6.09 for AfPrx1 nmol/min/mg protein (Table 1).

Table 1. $\mathrm{PLA}_{2}$ specific activity (nmol/min/mg protein) for non-mammalian Prdx6 at different $\mathrm{pHs}$.

\begin{tabular}{cccc}
\hline \multirow{2}{*}{ Organism } & Protein & \multicolumn{2}{c}{ Activity (nmol/min/mg prot.) } \\
\cline { 2 - 4 } & & $\mathbf{p H ~ 4}$ & $\mathbf{p H ~ 7}$ \\
\hline T. aestivum & TaPER1 & $4.46 \pm 0.1$ & $0.06 \pm 0.01$ \\
A. fumigatus & AfPrx1 & $6.09 \pm 0.1$ & $0.7 \pm 0.2$ \\
P. aeruginosa & AfPrxC & $4.91 \pm 0.2$ & $0.5 \pm 0.1$ \\
\hline
\end{tabular}

\subsection{Phosphorylation at the C-terminal Thr Is Also Conserved Among Non-Mammalian Prdx6}

Thr177 phosphorylation of human Prdx6 increases its PLA $_{2}$ activity, especially at neutral $\mathrm{pH}$ [15]. Therefore, we investigated if human Erk2 could phosphorylate homologous Thr residues in non-mammalian Prdx6 proteins. Several phosphorylation sites were found in the two plant proteins (TaPER1 and AtPER1) and also in the mitochondrial Prdx6 from A. fumigatus (AfPrxC) (data not shown), including the Thr homologous of human Prdx6 Thr177. However, only TaPER1 presented an elevated score (Figure S1). In contrast, AfPrx1 and PaLsfA proteins were not phosphorylated as no phosphorylated peptide was found for either protein by mass spectrometry (Table 2). 
Antioxidants 2019, 8, 52

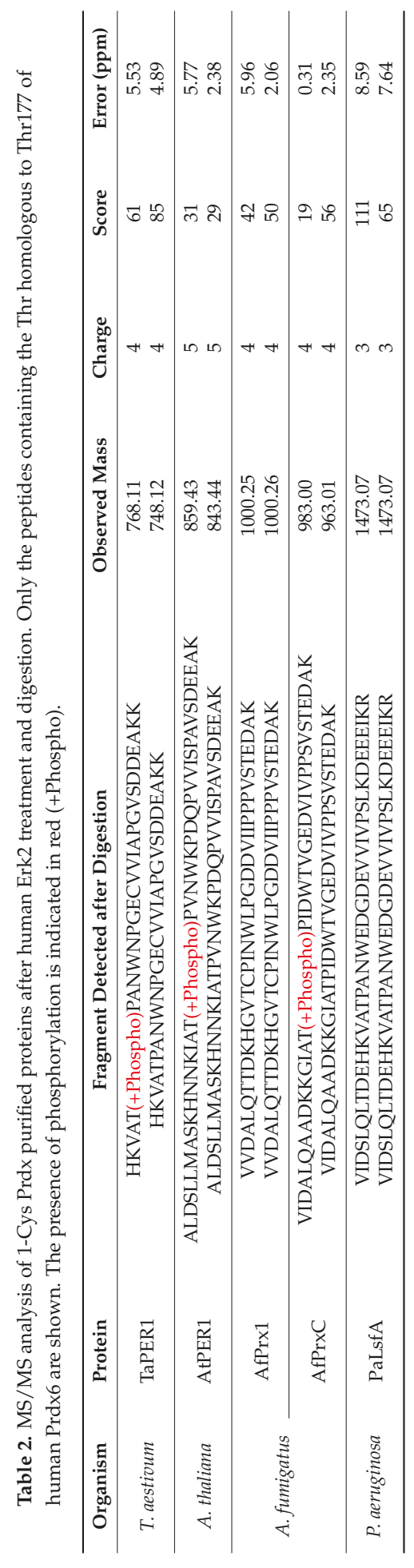


We also verified the possible Thr phosphorylation of AfPrx1 and AfPrxC by western blot using an antibody developed to detect phosphorylated Thr residues in mouse Prdx6 [17]. A band for phosphorylated protein was only observed for AfPrxC (Figure 5), similar to the mass spectrometry results (Table 2 )
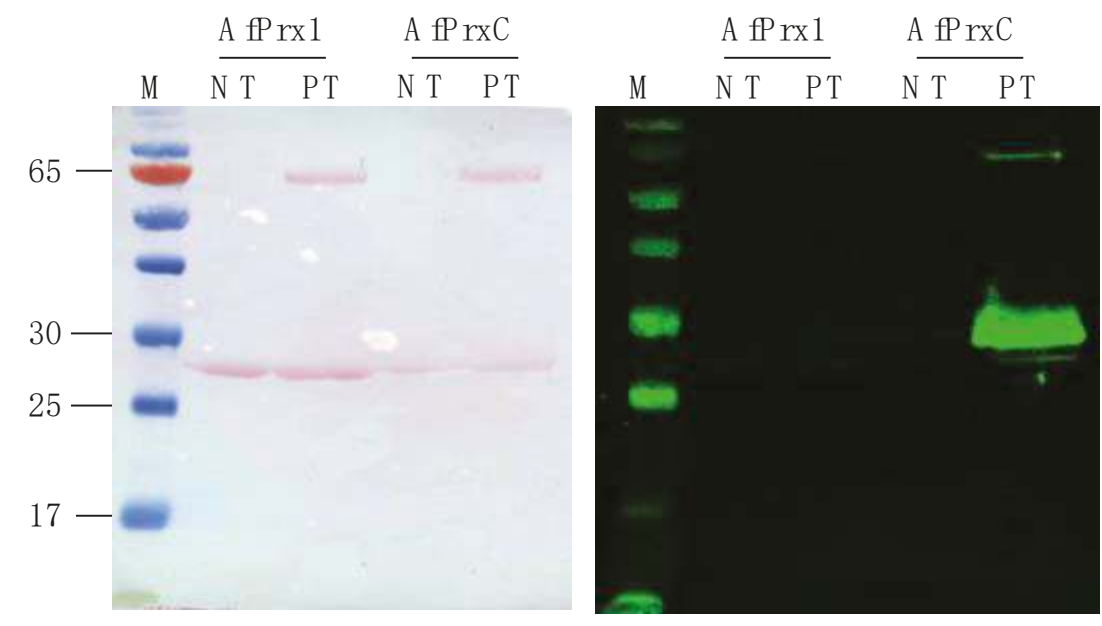

Figure 5. Evaluation of AfPrx1 and AfPrxC phosphorylation. Left panel represents the membrane stained with Ponceau S as the loading control. Right panel represents the Western Blot using the primary antibody for phosphorylated MmPrdx6. Lane 1: molecular ladder, the numbers at the left side represent the molecular weight (kDa); lane 2: non-treated (NT) AfPrx1; lane 3: AfPrx1 after phosphorylation treatment (PT); lane 4: non-treated AfPrxC; lane 5: AfPrxC after phosphorylation treatment. The lower bands represent the Prdx and upper bands represent the kinase Erk2. Phosphorylation treatment is described in the Material and Methods section.

\subsection{Influence of Phosphorylation and Inhibition with MJ33 on PLA 2 Activity of AfPrx1 and AfPrxC}

Then, the effects of the phosphorylation treatment on the PLA 2 activity were determined for AfPrx1 and AfPrxC. Both proteins had their activities increased almost four (4) times after treatment with human Erk2 (Table 3). Next, we evaluated if MJ33, a classical competitive inhibitor of mammalian Prdx6, could inhibit the fungal Prdxs [7]. MJ33 inhibited about $85 \%$ of the aiPLA 2 activities of AfPrx1 and AfPrxC.

Table 3. $\mathrm{PLA}_{2}$ specific activity ( $\mathrm{nmol} / \mathrm{min} / \mathrm{mg}$ protein) for non-mammalian Prdx6 in different $\mathrm{pH}$, phosphorylation treatment with Erk2 and after inhibition with 1-hexadecyl-3-trifluoro-ethylglycerosn-2-phosphomethanol (MJ33). ND: non-determined.

\begin{tabular}{ccccc}
\hline \multirow{2}{*}{ Treatment } & \multicolumn{2}{c}{ AfPrx1 } & \multicolumn{2}{c}{ AfPrxC } \\
\cline { 2 - 5 } & pH 4 & pH 7 & pH 4 & pH 7 \\
\hline No treatment & $6.09 \pm 0.1$ & $0.7 \pm 0.2$ & $4.91 \pm 0.2$ & $0.5 \pm 0.1$ \\
Erk2 & $21.85 \pm 0.5$ & $20.96 \pm 0.3$ & $18.69 \pm 0.2$ & $18.47 \pm 0.1$ \\
MJ33 & $0.85 \pm 0.05$ & ND & $0.89 \pm 0.01$ & ND \\
\hline
\end{tabular}

\section{Discussion}

The aiPLA 2 activity of mammalian Prdx6 was first detected in 1992 in isolated rat lungs [35] and then in epithelial cell cultures [36]. The protein was identified, cloned and enzymatically characterized as a lysosomal type, $\mathrm{Ca}^{2+}$-independent $\mathrm{PLA}_{2}$ [7]. Shortly after that, the Cys-based peroxidase activity of human Prdx6 was described. Then, it was realized that these aiPLA 2 and the human Prdx6 
enzymes shared the same amino acid sequence [7]. Therefore, Prdx6 is a bi-functional enzyme with Cys-based peroxidase and aiPLA ${ }_{2}$ activities. Later, the biological relevance of this aiPLA $A_{2}$ activity was demonstrated, that is, phospholipid turnover, repair of cell membranes; , and NADPH oxidase 2 (NOX2) activation $[16,17,37]$.

Intriguingly, aiPLA $A_{2}$ activity had not yet been evaluated in non-mammalian Prdx6 proteins before this work. Here, we observed that five non-mammalian Prdx6 displayed conserved amino acid sequenced and structural features (Figures 1-4) compatible with enzymes endowed with aiPLA 2 activities. Indeed, the overall structures modeled here were very similar to the human Prdx6. In all cases, accessible active sites were present and the conserved catalytic triads were in the expected position. In mammalian Prdx6, it is proposed that the peroxidized $s n-2$ acyl phospholipid chain enters into the pocket, where the peroxidatic Cys is located on the bottom, and the PLA 2 active site is on the top. Therefore, Prdx6 can reduce and hydrolyze the peroxidized phospholipid [38]. Next, we will consider how each specific featured related to $\mathrm{PLA}_{2}$ activity is conserved among non-mammalian Prdx6 enzymes.

In human Prdx6, His26 is postulated to play roles in phospholipid binding, as the positive charge of this residue can interact with the negative charge of the substrate [12]. In some Prdx6 sequences, a Tyr residue replaces this conserved His (proteins from P. falciparum, D. melanogaster and S. cerevisiae). We did not investigate any of these enzymes here.

Ser32 of human Prdx6 is also important for the interaction of the enzyme with the substrate and for stabilization of protein structure [12]. Almost $70 \%$ of the analyzed sequences possess this residue conserved. However, four homologs, including the TaPER1, possess Gly in the same position. Nevertheless, TaPER1 displayed PLA 2 activity at similar levels to the other Prdx6 analyzed in the present work. Notably, the mutation of catalytic Ser to Asn, Thr, Ala or Asp in human lipoprotein lipase (LPL) abolished the enzymatic activity but when this same Ser residue was mutated to Gly, the activity was maintained [39].

Asp140 of human Prdx6 plays a central role in PLA $_{2}$ catalysis [12] and is the most conserved residue of the catalytic triad. Indeed, the conserved Asp is replaced in only one case (from P. falciparum) by Glu, which is also a negatively charged residue. Notably, the conserved Asp residue can be located at two distinct positions. The proteins analyzed here possess this conserved Asp residue in either one of the two positions (Figure 1; Figure 4) and all of them displayed similar PLA $\mathrm{P}_{2}$ activity (Table 1). Therefore, it is reasonable to assume that these differences in the Asp positioning do not interfere with $\mathrm{PLA}_{2}$ activity.

Thr177 of recombinant human Prdx6 when phosphorylated caused a 30-fold increase in $\mathrm{PLA}_{2}$ activity [40] and is conserved in all sequences, excluding the archaeal proteins. Therefore, we investigated if non-mammalian Prdx6 enzymes could be phosphorylated by human Erk2. Three (TaPER1, AtPER1, AfPrxC) out of the five non-mammalian Prdx6 were phosphorylated at the conserved Thr residue (Table 2). Possibly, this conserved Thr of TaPER1, AtPER1, AfPrxC is phosphorylated by plant and fungal kinases, which could increase their PLA $\mathrm{P}_{2}$ activity. Indeed, AfPrxC treated with human Erk2 had a four-fold increase in its activity (Table 3). Although, we have no experimental evidence that PaLsfA and AfPrx1 are phosphorylated, we cannot exclude the possibility that these peroxidases undergo this post-translational modification in vivo. It is possible that native kinases in $P$. aeruginosa and $A$. fumigatus might phosphorylate these Prdx6 enzymes.

The investigation of the physiological meaning of $\mathrm{PLA}_{2}$ activity in Prdx6 enzymes is complex as these proteins also display peroxidase activity. Indeed, participation of $\mathrm{PLA}_{2}$ activities of mammalian Prdx6 in distinct cellular processes were revealed several years after they were first characterized. For instance, the human alveoli are covered by surfactant, a surface active material able to reduce surface tension at the alveolar air-liquid interface [41]. This function prevents the alveoli from collapsing at end-respiration [42]. Pulmonary surfactant is composed of approximately $90 \%$ lipids and $10 \%$ protein and the major component of surfactant is the amphiphatic phospholipid DPPC (around $40 \%$ total) [43]. This layer is subjected to constant remodeling and the mammalian Prdx6 are 
important in this process of recycling in lamelar bodies (acid organelles) $[13,16,17]$. Since A. fumigatus and $P$. aeruginosa colonize the lungs, starting from alveoli, it is reasonable to speculate that the $\mathrm{PLA}_{2}$ activity of these proteins (AfPrx1, AfPrxC and PaLsfA) might contribute to the colonization process favoring the lung tissue invasion and colonization.

Accordingly, several phospholipases produced by pathogenic bacteria and fungus are virulence factors $[44,45]$. In P. aeruginosa, for example, ExoU is injected directly into the cytoplasm of host cells through the type III secretion system [46] and rapidly destroys the cell membranes of mammalian cells by its $\mathrm{PLA}_{2}$ activity [47]. The presence of ExoU is associated with antibiotic resistance and the severe outcome of many infections [48].

During the infection of mammalian hosts, phospholipase enzymes released by fungi can play important roles in tissue invasion and nutrient acquisition [49,50]. In A. fumigatus, two phospholipase B (plb) genes (Afplb1 and Afplb2) encode two secreted PLB and are upregulated in the presence of the major component of lung surfactant (DPPC) [44,50], substrate analyzed as substrate in the present work. Interestingly, the AfPrx1 was detected in the secretoma of A. fumigatus [51] and can cleave DPPC in the $s n-2$ position (present work).

In plants, PLAs are involved in a wide range of cellular processes, including pollen and seed development, protection against water loss and also during jasmonic acid production, a compound related to signaling during plant defenses to distinct stressful conditions [51]. Interesting, HvPER1 (from Hordeum vulgares) and AtPER1 are highly expressed and accumulated in nucleus from embryos, especially during the final step of seed development, the desiccation step [22,52]. At this stage, the elevated production of reactive oxygen species is associated to the extreme loss of water along with the reduction in metabolism and antioxidant enzymatic defenses $[53,54]$.

\section{Conclusions}

This is the first description of $\mathrm{PLA}_{2}$ activities for non-mammalian Prdx6 enzymes. Notably, the activity of the mammalian $\operatorname{Prdx} 6(\approx 100 \mathrm{nmol} / \mathrm{min} / \mathrm{mg}$ protein $)$ is about 20 times the activity obtained for non-mammalian Prdx6 $(\approx 5 \mathrm{nmol} / \mathrm{min} / \mathrm{mg}$ protein). Possibly, the liposomes used herein were not optimal substrates for non-mammalian Prdx6, as these lipids were designed to mimic human pulmonary surfactants. Indeed, the investigation of the $\mathrm{PLA}_{2}$ activities for the Prdx6 enzymes represents an open field for future research as the roles of lipids in cellular signaling is increasingly recognized.

Supplementary Materials: The following are available online at http:/ / www.mdpi.com/2076-3921/8/3/52/s1, Figure S1: MS/MS fragmentation profile for the non-mammalian Prdx6. The results were obtained using MASCOT 2.4 software (Matrix Science Ltd., London, United Kingdom, Redoxoma-FAPESP user license 10.10.1.46/Mascot).

Author Contributions: Conceptualization, R.B.-F., A.F. and L.N.; methodology, R.B.-F., R.A.-S., J.P.S., C.D., J.P.V.-M., J.-Q.T., A.F. and L.N.; software, R.B.-F., R.A.-S. and J.P.S.; validation, R.B.-F., R.A.-S., J.P.S., C.D., J.P.V.-M., J.-Q.T., A.F. and L.N.; formal analysis, R.B.-F., R.A.-S., J.P.S.; investigation, R.B.-F., R.A.-S., J.P.S., C.D., J.P.V.-M., J.-Q.T.; resources, A.F. and L.N.; data curation, R.B.-F., R.A.-S., J.P.S., C.D., J.P.V.-M., J.-Q.T.; writing-original draft preparation, R.B.-F., R.A.-S., J.P.S., L.N.; writing—review and editing, R.B.-F., R.A.-S., J.P.S., C.D., J.P.V.-M., J.-Q.T., A.F., L.N.; visualization R.B.-F., R.A.-S. and J.P.S.; supervision, C.D., A.F., L.N.; project administration, A.F. and L.N.; funding acquisition, A.F., L.N.

Funding: This work was financially supported by Fundação de Amparo à Pesquisa do Estado de São Paulo (FAPESP) Grants: 2013/07937-8 (Redox Processes in Biomedicine), 2016/12248-5 for Renata Bannitz-Fernandes, Conselho Nacional de Desenvolvimento Científico e Tecnológico (CNPq) Grant 130255/2016-5 for Rogério Aleixo-Silva. Additional support was provided by grant R01-HL102016 (P.I, A.B.F.) from the National Institutes of Health of the United States.

Acknowledgments: We thank Emerson Finco Marques (Instituto de Química, USP) and Dra Giovana de Freitas Lemeszenksi for the proteomic MS/MS analysis. We also thank Thiago Alegria and Elena Sorokina for laboratory technical assistance. We are grateful to Luciana Haddad for kindly providing the EGTA reagent.

Conflicts of Interest: The authors declare no conflict of interest. 


\section{References}

1. Perkins, A.; Poole, L.B.; Karplus, P.A. Tuning of peroxiredoxin catalysis for various physiological roles. Biochemistry 2014, 53, 7693-7705. [CrossRef] [PubMed]

2. Chae, H.Z.; Robison, K.; Poole, L.B.; Church, G.; Storz, G.; Rhee, S.G. Cloning and sequencing of thiol-specific antioxidant from mammalian brain: Alkyl hydroperoxide reductase and thiol-specific antioxidant define a large family of antioxidant enzymes. Proc. Natl. Acad. Sci. USA 1994, 91, 7017-7021. [CrossRef] [PubMed]

3. Flohe, L.; Toppo, S.; Cozza, G.; Ursini, F. A Comparison of Thiol Peroxidase Mechanisms. Antioxid. Redox Signal. 2011, 15, 1-18. [CrossRef] [PubMed]

4. Hall, A.; Parsonage, D.; Poole, L.B.; Karplus, P.A. Structural evidence that peroxiredoxin catalytic power is based on transition-state stabilization. J. Mol. Biol. 2010, 402, 194-209. [CrossRef] [PubMed]

5. Soito, L.; Williamson, C.; Knutson, S.T.; Fetrow, J.S.; Poole, L.B.; Nelson, K.J. PREX: PeroxiRedoxin classification indEX, a database of subfamily assignments across the diverse peroxiredoxin family. Nucleic Acids Res. 2011, 39, D332-D337. [CrossRef] [PubMed]

6. Nevalainen, T.J. 1-Cysteine peroxiredoxin: A dual-function enzyme with peroxidase and acidic $\mathrm{Ca}^{2+}$-independent phospholipase A2 activities. Biochimie 2010, 92, 638-644. [CrossRef] [PubMed]

7. Kim, T.S.; Sundaresh, C.S.; Feinstein, S.I.; Dodia, C.; Skach, W.R.; Jain, M.K.; Nagase, T.; Seki, N.; Ishikawa, K.; Nomura, N.; et al. Identification of a human cDNA clone for lysosomal type $\mathrm{Ca}^{2+}$-independent phospholipase A2 and properties of the expressed protein. J. Biol. Chem. 1997, 272, 2542-2550. [CrossRef] [PubMed]

8. Fisher, A.; Dodia, C.; Manevich, Y.; Chen, J.; Feinstein, S. Phospholipid hydroperoxidase are substrates for non-selenium glutathione peroxidase. J. Biol. Chem. 1999, 274, 21326-21334. [CrossRef] [PubMed]

9. Hiraoka, M.; Abe, A.; Shayman, J.A. Structure and function of lysosomal phospholipase A2: Identification of the catalytic triad and the role of cysteine residues. J. Lipid Res. 2005, 46, 2441-2447. [CrossRef] [PubMed]

10. Burke, J.E.; Dennis, E. A Phospholipase A2 structure/function, mechanism, and signaling. J. Lipid Res. 2009, 50, S237-S242. [CrossRef] [PubMed]

11. Chen, J.W.; Dodia, C.; Feinstein, S.I.; Jain, M.K.; Fisher, A.B. 1-Cys peroxiredoxin, a bifunctional enzyme with glutathione peroxidase and phospholipase A2 activities. J. Biol. Chem. 2000, 275, 28421-28427. [CrossRef] [PubMed]

12. Manevich, Y.; Reddy, K.S.; Shuvaeva, T.; Feinstein, S.I.; Fisher, A.B. Structure and phospholipase function of peroxiredoxin 6: Identification of the catalytic triad and its role in phospholipid substrate binding. J. Lipid Res. 2007, 48, 2306-2318. [CrossRef] [PubMed]

13. Sorokina, E.M.; Feinstein, S.I.; Milovanova, T.N.; Fisher, A.B. Identification of the amino acid sequence that targets peroxiredoxin 6 to lysosome-like structures of lung epithelial cells. Am. J. Physiol. Lung Cell. Mol. Physiol. 2009, 297, L871-L880. [CrossRef] [PubMed]

14. Sorokina, E.M.; Dodia, C.; Zhou, S.; Tao, J.Q.; Gao, L.; Raabe, T.; Feinstein, S.I.; Fisher, A.B. Mutation of serine 32 to threonine in peroxiredoxin 6 preserves its structure and enzymatic function but abolishes its trafficking to lamellar bodies. J. Biol. Chem. 2016, 291, 9268-9280. [CrossRef] [PubMed]

15. Wu, Y.; Feinstein, S.I.; Manevich, Y.; Chowdhury, I.; Pak, J.H.; Kazi, A.; Dodia, C.; Speicher, D.W.; Fisher, A.B. Mitogen-activated protein kinase-mediated phosphorylation of peroxiredoxin 6 regulates its phospholipase A 2 activity. Biochem. J. 2009, 419, 669-679. [CrossRef] [PubMed]

16. Fisher, A.B.; Dodia, C. Lysosomal-type PLA2 and turnover of alveolar DPPC. Am. J. Physiol. Lung Cell. Mol. Physiol. 2001, 280, L748-L754. [CrossRef] [PubMed]

17. Chatterjee, S.; Feinstein, S.I.; Dodia, C.; Sorokina, E.; Lien, Y.-C.; Nguyen, S.; Debolt, K.; Speicher, D.; Fisher, A.B. Peroxiredoxin 6 Phosphorylation and Subsequent Phospholipase A 2 Activity Are Required for Agonist-mediated Activation of NADPH Oxidase in Mouse Pulmonary Microvascular Endothelium and Alveolar Macrophages. J. Biol. Chem. 2011, 286, 11696-11706. [CrossRef] [PubMed]

18. Ambruso, D.R.; Ellison, M.A.; Thurman, G.W.; Leto, T.L. Peroxiredoxin 6 translocates to the plasma membrane during neutrophil activation and is required for optimal NADPH oxidase activity. Biochim. Biophys. Acta Mol. Cell Res. 2012, 1823, 306-315. [CrossRef] [PubMed]

19. Ho, J.-N.; Lee, S.-S.B.; Lee, S.-S.B.; Yoon, S.H.; Kang, G.Y.; Hwang, S.-G.; Um, H.-D. Phospholipase A2 activity of peroxiredoxin 6 promotes invasion and metastasis of lung cancer cells. Mol. Cancer Ther. 2010, 9, 825-832. [CrossRef] [PubMed] 
20. Pulido, P.; Cazalis, R.; Cejudo, F.J. An antioxidant redox system in the nucleus of wheat seed cells suffering oxidative stress. Plant J. 2009, 57, 132-145. [CrossRef] [PubMed]

21. Haslekås, C.; Grini, P.E.; Nordgard, S.H.; Thorstensen, T.; Viken, M.K.; Nygaard, V.; Aalen, R.B. ABI3 mediates expression of the peroxiredoxin antioxidant AtPER1 gene and induction by oxidative stress. Plant Mol. Biol. 2003, 53, 313-326. [CrossRef] [PubMed]

22. Haslekås, C.; Stacy, R.A.; Nygaard, V.; Culiáñez-Macià, F.A.; Aalen, R.B. The expression of a peroxiredoxin antioxidant gene, AtPER1, in Arabidopsis thaliana is seed-specific and related to dormancy. Plant Mol. Biol. 1998, 36, 833-845. [CrossRef] [PubMed]

23. Haslekas, C. Seed 1-Cysteine Peroxiredoxin Antioxidants Are Not Involved in Dormancy, But Contribute to Inhibition of Germination during Stress. PLANT Physiol. 2003, 133, 1148-1157. [CrossRef] [PubMed]

24. Rocha, M.C.; de Godoy, K.F.; Bannitz-Fernandes, R.; Fabri, J.H.T.M.; Barbosa, M.M.F.; de Castro, P.A.; Almeida, F.; Goldman, G.H.; da Cunha, A.F.; Netto, L.E.S.; et al. Analyses of the three 1-Cys Peroxiredoxins from Aspergillus fumigatus reveal that cytosolic Prx1 is central to $\mathrm{H} 2 \mathrm{O} 2$ metabolism and virulence. Sci. Rep. 2018, 8, 1-18. [CrossRef] [PubMed]

25. Santos, C.S.; Bannitz-Fernandes, R.; Lima, A.S.; Tairum, C.A.; Malavazi, I.; Netto, L.E.S.; Bertotti, M. Monitoring $\mathrm{H} 2 \mathrm{O} 2$ inside Aspergillus fumigatus with an integrated microelectrode: The role of peroxiredoxin protein Prx1. Anal. Chem. 2018, 90, 2587-2593. [CrossRef] [PubMed]

26. Hummerjohann, J.; Küttel, E.; Quadroni, M.; Ragaller, J.; Leisinger, T.; Kertesz, M.A. Regulation of the sulfate starvation response in Pseudomonas aeruginosa: Role of cysteine biosynthetic intermediates. Microbiology 1998, 144, 1375-1386. [CrossRef] [PubMed]

27. Kaihami, G.H.; de Almeida, J.R.F.; dos Santos, S.S.; Netto, L.E.S.; de Almeida, S.R.; Baldini, R.L. Involvement of a 1-Cys Peroxiredoxin in Bacterial Virulence. PLoS Pathog. 2014, 10, e1004442. [CrossRef] [PubMed]

28. Sievers, F.; Wilm, A.; Dineen, D.; Gibson, T.J.; Karplus, K.; Li, W.; Lopez, R.; McWilliam, H.; Remmert, M.; Soding, J.; et al. Fast, scalable generation of high-quality protein multiple sequence alignments using Clustal Omega. Mol. Syst. Biol. 2014, 7, 539. [CrossRef] [PubMed]

29. Waterhouse, A.M.; Procter, J.B.; Martin, D.M.A.; Clamp, M.; Barton, G.J. Jalview Version 2-A multiple sequence alignment editor and analysis workbench. Bioinformatics 2009, 25, 1189-1191. [CrossRef] [PubMed]

30. Waterhouse, A.; Bertoni, M.; Bienert, S.; Studer, G.; Tauriello, G.; Gumienny, R.; Heer, F.T.; De Beer, T.A.P.; Rempfer, C.; Bordoli, L.; et al. SWISS-MODEL: Homology modelling of protein structures and complexes. Nucleic Acids Res. 2018, 46, W296-W303. [CrossRef] [PubMed]

31. Pettersen, E.F.; Goddard, T.D.; Huang, C.C.; Couch, G.S.; Greenblatt, D.M.; Meng, E.C.; Ferrin, T.E. UCSF Chimera-A visualization system for exploratory research and analysis. J. Comput. Chem. 2004, 25, 1605-1612. [CrossRef] [PubMed]

32. Crooks, G.E. WebLogo: A Sequence Logo Generator. Genome Res. 2004, 14, 1188-1190. [CrossRef] [PubMed]

33. Marques, E.F.; Medeiros, M.H.G.; Di Mascio, P. Lysozyme oxidation by singlet molecular oxygen: Peptide characterization using $\left[{ }^{18} \mathrm{O}\right]-$ labeling oxygen and nLC-MS/MS. J. Mass Spectrom. 2017, 52, 739-751. [CrossRef] [PubMed]

34. Fisher, A.B. The phospholipase $\mathrm{A}_{2}$ activity of peroxiredoxin 6. J. Lipid Res. 2018, 59, 1132-1147. [CrossRef] [PubMed]

35. Fisher, A.B.; Dodia, C.; Chander, A.; Jain, M. A competitive inhibitor of phospholipase A2 decreases surfactant phosphatidylcholine degradation by the rat lung. Biochem. J. 1992, 288 Pt 2, 407-411. [CrossRef]

36. Fisher, A.B.; Dodia, C. Role of phospholipase A2 enzymes in degradation of dipalmitoylphosphatidylcholine by granular pneumocytes. J. Lipid Res. 1996, 37, 1057-1064. [PubMed]

37. Fisher, A.B.; Vasquez-Medina, J.P.; Dodia, C.; Sorokina, E.M.; Tao, J.Q.; Feinstein, S.I. Peroxiredoxin 6 phospholipid hydroperoxidase activity in the repair of peroxidized cell membranes. Redox Biol. 2018, 14, 41-46. [CrossRef] [PubMed]

38. Fisher, A.B. Peroxiredoxin 6 in the repair of peroxidized cell membranes and cell signaling. Arch. Biochem. Biophys. 2017, 617, 68-83. [CrossRef] [PubMed]

39. Tashiro, J.; Kobayashi, J.; Shirai, K.; Saito, Y.; Fukamachi, I.; Hashimoto, H.; Nishida, T.; Shibui, T.; Morimoto, Y.; Yoshida, S. Effects of substitutions of glycine and asparagine for serine 132 on activity and binding of human lipoprotein lipase to very low density lipoproteins. FEBS Lett. 1992, 298, 36-38. [CrossRef] 
40. Rahaman, H.; Zhou, S.; Dodia, C.; Feinstein, S.I.; Huang, S.; Speicher, D.; Fisher, A.B. Increased Phospholipase A 2 Activity with Phosphorylation of Peroxiredoxin 6 Requires a Conformational Change in the Protein. Biochemistry 2012, 51, 5521-5530. [CrossRef] [PubMed]

41. Schu, S.; Green, F.H.Y.; Bachofen, H.; Tn, A. Formation and structure of surface films: Captive bubble surfactometry. Adsorpt. J. Int. Adsorpt. Soc. 1998, 1408, 180-202.

42. Veldhuizen, E.J.; Haagsman, H.P. Role of pulmonary surfactant components in surface film formation and dynamics. BBA 2000, 1467, 255-270. [CrossRef]

43. Veldhuizen, R.; Nag, K.; Orgeig, S.; Possmayer, F. The role of lipids in pulmonary surfactant. Biochim. Biophys. Acta Mol. Basis Dis. 1998, 1408, 90-108. [CrossRef]

44. Shen, D.K.; Noodeh, A.D.; Kazemi, A.; Grillot, R.; Robson, G.; Brugère, J.F. Characterisation and expression of phospholipases B from the opportunistic fungus Aspergillus fumigatus. FEMS Microbiol. Lett. 2004, 239, 87-93. [CrossRef] [PubMed]

45. Sato, H.; Frank, D.W. ExoU is a potent intracellular phospholipase. Mol. Microbiol. 2004, 53, 1279-1290. [CrossRef] [PubMed]

46. Hauser, A.R. The type III secretion system of Pseudomonas aeruginosa: Infection by injection. Nat. Rev. Microbiol. 2009, 7, 654-665. [CrossRef] [PubMed]

47. Wolfgang, M.C.; Kulasekara, B.R.; Liang, X.; Boyd, D.; Wu, K.; Yang, Q.; Miyada, C.G.; Lory, S. Conservation of genome content and virulence determinants among clinical and environmental isolates of Pseudomonas aeruginosa. Proc. Natl. Acad. Sci. USA 2003, 100, 8484-8489. [CrossRef] [PubMed]

48. Subedi, D.; Vijay, A.K.; Kohli, G.S.; Rice, S.A.; Willcox, M. Association between possession of ExoU and antibiotic resistance in Pseudomonas aeruginosa. PLoS ONE 2018, 13, e204936. [CrossRef] [PubMed]

49. Barman, A.; Gohain, D.; Bora, U.; Tamuli, R. Phospholipases play multiple cellular roles including growth, stress tolerance, sexual development, and virulence in fungi. Microbiol. Res. 2018, 209, 55-69. [CrossRef] [PubMed]

50. Köhler, G.A.; Brenot, A.; Haas-Stapleton, E.; Agabian, N.; Deva, R.; Nigam, S. Phospholipase A2 and phospholipase B activities in fungi. Biochim. Biophys. Acta 2006, 1761, 1391-1399. [CrossRef] [PubMed]

51. Chen, G.; Greer, M.S.; Weselake, R.J. Plant phospholipase A: Advances in molecular biology, biochemistry, and cellular function. Biomol. Concepts 2013, 4, 527-532. [CrossRef] [PubMed]

52. Stacy, R.A.; Nordeng, T.W.; Culiáñez-Macià, F.A.; Aalen, R.B. The dormancy-related peroxiredoxin anti-oxidant, PER1, is localized to the nucleus of barley embryo and aleurone cells. Plant J. 1999, 19, 1-8. [CrossRef] [PubMed]

53. Tommasi, F.; Paciolla, C.; Arrigoni, O. The ascorbate system in recalcitrant and orthodox seeds. Physiol. Plant. 1999, 105, 193-198. [CrossRef]

54. Fait, A.; Angelovici, R.; Less, H.; Ohad, I.; Urbanczyk-Wochniak, E.; Fernie, A.R.; Galili, G. Arabidopsis Seed Development and Germination Is Associated with Temporally Distinct Metabolic Switches. Plant Physiol. 2006, 142, 839-854. [CrossRef] [PubMed]

(C) 2019 by the authors. Licensee MDPI, Basel, Switzerland. This article is an open access article distributed under the terms and conditions of the Creative Commons Attribution (CC BY) license (http:/ / creativecommons.org/licenses/by/4.0/). 


\title{
Hyperoxidation of Peroxiredoxin 6 Induces Alteration from Dimeric to Oligomeric State
}

\author{
Sharifun Shahnaj ${ }^{1}$, Rimpy Kaur Chowhan ${ }^{2}$, Potshangbam Angamba Meetei ${ }^{1}$, \\ Pushpa Kakchingtabam ${ }^{1}$, Khundrakpam Herojit Singh ${ }^{1}$, Laishram Rajendrakumar Singh ${ }^{2}$, \\ Potshangbam Nongdam ${ }^{1}$, Aron B. Fisher ${ }^{3}$ and Hamidur Rahaman ${ }^{1, *}$ \\ 1 Department of Biotechnology, Manipur University, Manipur 795003, India; sharifun15@gmail.com (S.S.); \\ angambameetei@gmail.com (P.A.M.); pushpakakchingtabam@gmail.com (P.K.); \\ herojit009@gmail.com (K.H.S.); purenba@rediffmail.com (P.N.) \\ 2 ACBR, Delhi University, New Delhi, Delhi 110022, India; rimpy_1989@yahoo.co.in (R.K.C.); \\ lairksingh@gmail.com (L.R.S.) \\ 3 Institute for Environmental Medicine, University of Pennsylvania Perelman School of Medicine, \\ Philadelphia, PA 19104-6068, USA; abf@upenn.edu \\ * Correspondence: hamidur2006@gmail.com; Tel.: +91-986-351-8139 or +91-700-540-8775
}

Received: 30 November 2018; Accepted: 29 January 2019; Published: 2 February 2019

\begin{abstract}
Peroxiredoxins(Prdx), the family of non-selenium glutathione peroxidases, are important antioxidant enzymes that defend our system from the toxic reactive oxygen species (ROS). They are thiol-based peroxidases that utilize self-oxidation of their peroxidatic cysteine $\left(C_{p}\right)$ group to reduce peroxides and peroxidized biomolecules. However, because of its high affinity for hydrogen peroxide this peroxidatic cysteine moiety is extremely susceptible to hyperoxidation, forming peroxidase inactive sulfinic acid $\left(\mathrm{Cys}-\mathrm{SO}_{2} \mathrm{H}\right)$ and sulfonic acid $\left(\mathrm{Cys}-\mathrm{SO}_{3} \mathrm{H}\right)$ derivatives. With the exception of peroxiredoxin 6 ( $\operatorname{Prdx} 6$ ), hyperoxidized sulfinic forms of $\operatorname{Prdx}$ can be reversed to restore peroxidase activity by the ATP-dependent enzyme sulfiredoxin. Interestingly, hyperoxidized Prdx6 protein seems to have physiological significance as hyperoxidation has been reported to dramatically upregulate its calcium independent phospholipase $\mathrm{A}_{2}$ activity. Using biochemical studies and molecular dynamic (MD) simulation, we investigated the roles of thermodynamic, structural and internal flexibility of Prdx6 to comprehend the structural alteration of the protein in the oxidized state. We observed the loosening of the hydrophobic core of the enzyme in its secondary and tertiary structures. These changes do not affect the internal dynamics of the protein (as indicated by root-mean-square deviation, RMSD and root mean square fluctuation, RMSF plots). Native-PAGE and dynamic light scattering experiments revealed the formation of higher oligomers of Prdx6 under hyperoxidation. Our study demonstrates that post translational modification (like hyperoxidation) in Prdx6 can result in major alterations of its multimeric status.
\end{abstract}

Keywords: peroxidatic cysteine; thioredoxin fold; sulfonic/sulfinic acid; phospholipase A2 activity; reactive oxygen species

\section{Introduction}

Reactive oxygen species (ROS) are generated as a result of normal cellular metabolism such as aerobic respiration, photosynthesis, and exposure to environmental stimuli [1]. Depending on their concentration in biological systems, ROS can either be harmful or beneficial to living systems [2]. Prolonged presence of these imbalanced reactive oxygen intermediates further initiates a chain reaction where any macromolecule coming into contact with them is oxygenated, thereby exponentially enhancing the ROS concentration and cellular damage. In certain cases, it is very difficult to distinguish whether oxidative stress is the cause or an effect of a disease. 
To combat the exponential growth of ROS, humans are equipped with a robust antioxidant defense system, comprising enzymatic and non-enzymatic antioxidants that work synergistically and interactively to neutralize free radicals. These antioxidants can be both endogenous (reduced glutathione (GSH), superoxide dismutase, peroxiredoxins, etc.), or exogenous (tocopherol, ascorbic acid, flavonoids, etc.) in origin [3-5].

Among all the antioxidant enzymes found in living systems, peroxiredoxins (Prdx) are the most important thiol-dependent selenium and heme-free peroxidases and are ubiquitously found in bacteria, archaea and eukarya domains $[1-3,6,7]$. The high abundance of Prdxs in a wide range of cells and their high catalytic efficiencies in comparison to other peroxidases mean the proteins are responsible for a reduction of $90 \%$ of cellular peroxides such as hydrogen peroxide, peroxinitrite and hydroperoxides [1-3,6-8]. Because of their ROS restricting behavior, Prdxs have been implicated as a mediator in various signaling pathways involved in antioxidant-system regulation, cell proliferation, differentiation, and apoptosis in eukaryotic cells [9].

All Prdxs have a conserved thioredoxin domain at the $\mathrm{N}$-terminal followed by C-terminal residues. These Prdxs belong to thioredoxin (Trx) fold proteins that share a common active site motif with two reactive cysteine residues; $\mathrm{CXXC}$, where $\mathrm{X}$ can be any other amino acid and $\mathrm{C}$ are cysteines residues involved in the catalytic mechanism [10] and their role is to reduce disulfides. The reduced form of some Trx fold proteins contains two free thiol groups at the cysteine residues, whereas the oxidized form contains a disulfide bond between them. In contrast to Trxs, the role of Prdx is to reduce peroxides. However, similar to Trx, Prdxs have a conserved redox-active cysteine residue (the so-called peroxidatic cysteine) $(\mathrm{CpSH})$ but the second catalytic cysteine is present in a different part of the protein. Mammalian Prdxs have been sub-categorized into six isoforms depending on the number of cysteine residues and their mode of involvement in the peroxidatic catalytic mechanism; typical 2-Cys $\operatorname{Prdx}(\operatorname{Prdx} 1-4$ in the other nomenclature), atypical 2-Cys Prdx (Prdx5) and 1-Cys Prdx (Prdx6) [7,9,11]. Peroxiredoxin's catalytic cycle involves three major steps [1]. The first step is peroxidation i.e., reduction of the hydroperoxide substrate leading to oxidation of N-terminal conserved Cys residue of Prdx's

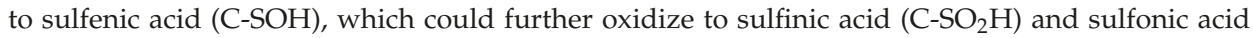
$\left(\mathrm{C}-\mathrm{SO}_{3} \mathrm{H}\right)$. While, $\mathrm{C}-\mathrm{SO}_{3} \mathrm{H}$ is an irreversible oxidized form that causes enzyme inhibition, the $\mathrm{C}-\mathrm{SO}_{2} \mathrm{H}$ of typical 2-Cys Prdx could be reduced with the aid of ATP driven sulfiredoxin catalyzed reaction into $\mathrm{C}-\mathrm{SOH}$. The second step is the resolution which involves the reduction of the sulfenic cys (C-SOH) while the third one is recycling i.e., the regeneration of the reduced cys sufhydryl (C-SH) of the active enzyme.

Typical 2-Cys Prdx have a conserved N-terminal (peroxidatic) and C-terminal (resolving) Cys residues that exist in different subunits in the obligate homodimer. Both Cys residues are involved in the peroxidase catalytic activity. Atypical 2-Cys Prdx only has one conserved N-terminal Cys residue and requires one additional but less conserved Cys residue in the same polypeptide [9]. As the name suggests, 1-Cys Prdx requires only one N-terminal conserved Cys residue for catalysis. However, to accomplish peroxidase activity with just one thiol group, 1-Cys Prdx forms a mixed disulfide with $\pi$-glutathione-s-transferase ( $\pi \mathrm{GST}$ ) which helps it to be glutathionylated, and later regenerated via the conjugated glutathione [12].

Peroxiredoxin 6 (Prdx6), the sole member of the mammalian 1-Cys Prdx subfamily, exists mostly as a dimer, which is aligned so that the two monomers are related not by a disulfide bond but by the hydrogen bonding network formed between two beta-strands of each monomer [13]. Also, it is a multifunctional enzyme having (i) peroxidase activity with $\mathrm{H}_{2} \mathrm{O}_{2}$, short chain hydroperoxides, and phospholipid hydroperoxides as substrates; (ii) calcium independent phospholipase A2 (aiPLA2) activity; and (iii) lysophosphatidylcholine acyl transferase (LPCAT) activity [14]. Interestingly, the dual functions of Prdx6 work in a mutually exclusive fashion at different $\mathrm{pH}$ such that at $\mathrm{pH} 7.4$ (cytosol), it binds only with oxidized phospholipids (supporting its peroxidase activity) while at $\mathrm{pH} 4.0$ (lysosome), it shows substrate specificity for both reduced and oxidized phospholipids (aiPLA $\mathrm{A}_{2}$ activity) [15]. This $\mathrm{pH}$ mediated regulation of the Prdx6 functional switching allows smooth 
functioning of both activities without hampering any other biological process. As Prdx6 has affinity for oxidized substrate both at acidic and neutral $\mathrm{pH}$, it shows aiPLA2 activity at both $\mathrm{pH}$ to play an important role in the repair of peroxidized cell membranes [16-18].

Like 2-cys Prdx, the conserved peroxidatic catalytic residue Cys-47 of Prdx6 is also prone to hyperoxidation forming hyperoxidized forms, $\mathrm{Cys}-\mathrm{SO}_{2} \mathrm{H}$ and $\mathrm{Cys}-\mathrm{SO}_{3} \mathrm{H}$ [19]. It should be noted that hyperoxidized Prdx6 is not a substrate for sulfiredoxin and therefore cannot be regenerated like other Prdxs, even from the $\mathrm{Cys}-\mathrm{SO}_{2} \mathrm{H}$ form, making hyperoxidation irreversible and functional inactivation for Prdx6. Interestingly, it is already reported that $\mathrm{H}_{2} \mathrm{O}_{2}$-mediated hyperoxidation of Prdx6 has been shown to induce cell cycle arrest at the G2/M transition through up-regulation of its aiPLA 2 activity though the hyperoxidized forms do not have peroxidase activity [19]. This effect of hyperoxidation on PLA2 activity is confirmed in a report by Zhou et.al. Our aim is to comprehend the structural alterations that incur due to hyperoxidation of $\operatorname{Prdx6}$ 's peroxidatic cysteine residue. These structural changes could be the mechanism that allows Prdx6 to up-regulate its aiPLA2 activity by accepting reduced phospholipid as its substrate within the cytosol. Until now, to our best knowledge, only a limited number of studies have been conducted to comparatively analyze the hyperoxidized and reduced forms of Prdx6. Here, we used molecular dynamic (MD) simulations along with various spectroscopic methods to investigate the molecular, conformational and thermodynamic studies of the different oxidation states of rat Prdx6. We found that hyperoxidation of Cys47 of Prdx6 induces changes at secondary, and tertiary as well as quaternary levels in the structure of enzyme, which might be responsible for the upregulation of its total cellular aiPLA 2 activity. For the first time, we are reporting the existence of an oligomeric form of Prdx6 enzyme.

\section{Materials and Methods}

\subsection{Materials}

Analytical grade Tris-HCl, Dithiothreitol (DTT), and IPTG samples were purchased from the Sigma-Aldrich Corp. (St. Louis, MO, USA). $\mathrm{H}_{2} \mathrm{O}_{2}$ was obtained from MP Biomedicals (Santa Ana, CA, USA). $\mathrm{NaCl}$ was from Merck (Kenilwort, NJ, USA). This and other chemicals were analytical grade reagents and were used without further purification. 8-Anilinonaphthalene-1-sulfonate (ANS) was also purchased from the Sigma-Aldrich Corp. (St. Louis, MO, USA). Chitin resin beads were purchased from New England Biolabs (NEB) (Ipswich, MA, USA).

\subsection{Preparation of Recombinant Prdx6}

The cloning of the target gene of rat Prdx6 into the pTyB1 vector was done as described previously $[20,21]$. The construct contained Nde1 (at $5^{\prime}$ end) and sap1 (at $3^{\prime}$ end) as restriction sites. The restriction site of Sap1 is not generated after recombinant cloning. Thus, the nucleotide sequence of rPrdx6 is immediately followed by that of an intein tag derived from pTyB1 vector (Figure 1A,B). The recombinant plasmid was constructed to over-express the protein conjugated with an intein tag. During the purification, the protein was eluted by cleaving the intein tag, the cleavage occurred between the last residue of $\mathrm{rPrdx}$ and the Cys residue of the intein tag. The purified protein consists of 224 amino acids, as in the cDNA, without any vector derived residues. The recombinant vector was transformed into the E. coli BL21 (DE3) expression strain. A single colony of transformant was selected and inoculated in luria bertani (LB) medium containing ampicillin (50 $\mu \mathrm{g} / \mathrm{mL})$. Cells were grown at $37^{\circ} \mathrm{C}$ in a shaker incubator overnight. When the optical density (at $600 \mathrm{~nm}$ ) of the growing cells reached $0.6-0.8$, isopropyl- $\beta$-D-thiogalactopyranoside $(0.6 \mathrm{mM})$ was added for its induction. Then, the cells were grown at $20{ }^{\circ} \mathrm{C}$ overnight. After harvesting by centrifugation, the cell pellet was suspended in lysis buffer (20 mM Tris- $\mathrm{HCl}$ pH 7.5, $500 \mathrm{mM} \mathrm{NaCl}$ and $1 \mathrm{mM}$ Ethylenediaminetetraacetic acid (EDTA)) and sonicated on ice (Bandelin sonicator, Bandelin, Germany) with five pulses of $10 \mathrm{~s}$ at an interval of $5 \mathrm{~min}$. The lysate after sonication was centrifuged at 10,000 rpm for $20 \mathrm{~min}$. The supernatant obtained after centrifugation was loaded onto a chitin affinity column equilibrated with $20 \mathrm{mM}$ Tris- $\mathrm{HCl} \mathrm{pH}$ 
$7.5,500 \mathrm{mM} \mathrm{NaCl}$ and $1 \mathrm{mM}$ EDTA. Induction of the on-column cleavage was performed by quickly flushing the column with cleavage buffer containing $20 \mathrm{mM}$ Tris- $\mathrm{HCl} \mathrm{pH} \mathrm{8.5,} 500 \mathrm{mM} \mathrm{NaCl}$ in presence of $80 \mathrm{mM}$ DTT. After $48 \mathrm{~h}$ incubation of the inducted column at room temperature, the target protein was eluted with column buffer ( $20 \mathrm{mM}$ Tris- $\mathrm{HCl} \mathrm{pH} \mathrm{7.5,500} \mathrm{mM} \mathrm{NaCl}$ and $1 \mathrm{mM}$ EDTA). The purified protein was analyzed by running $10 \%$ sodium dodecyl sulfate-polyacrylamide gel electrophoresis (SDS-PAGE) and found to be more than 90\% pure as shown in Figure 1C.

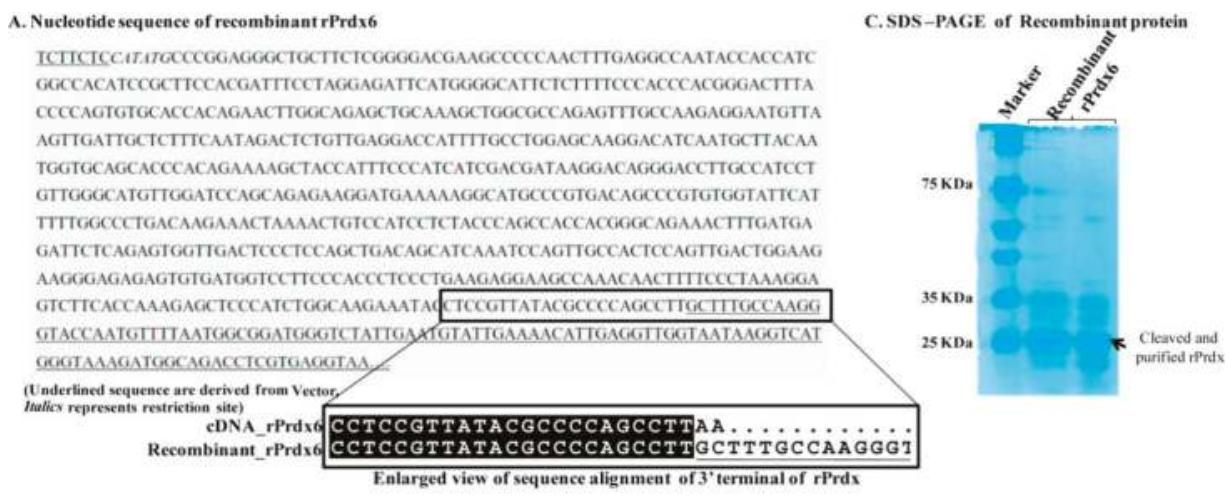

B. Amine acid sequence of Recombinant rPrdx6

MPGGLLLGDEAPNFEANTTIGHIRFHDFLGDSWGILFSHPRDFTPVCTIELGRAAKLAPEFAKRNVKLIALSIDSVED HFAWSKDINAYNGAAPTEKLPFPIIDOKDRDLAILLGMLDPAEKDEKGMPVTARVVFIFGPDKKLKLSIIYPATTGRN FDEILRVVDLLLLTASNPVATPVDWKKGESVMVLPTLPEEEAKQLFPKGVFTKELPSGKKYLRYTPQPCFAKGTNVI MADGSIECIENIEVGNKVMGKDGRPREVIKLPRGRETMYSVVQKSQHRAHKSDSSREVPELL..

(Underlined encodes for-Iatein tag derived frum Vector)

Cleavage site of Intein tag just before Cys

Figure 1. Details of nucleotide sequence of plasmid expressing recombinant rat peroxiredoxin 6 (rPrdx6). The $5^{\prime}$ terminal underlined and italics indicate the derived primer that was used. The $3^{\prime}$ terminal sequence is vector derived nucleotides after recombinant cloning. Inset view shows the different nucleotides of recombinant plasmid to cDNA sequence of $\mathrm{rPrdx} 6$ at $3^{\prime}$ terminal (A). The amino acid sequence of the prepared construct contains an intein tag for purification. Underlined sequence encodes for the vector derived amino acids. The cleavage site of the protein from purification tag is shown with an arrow (B). Sodium dodecyl sulfate polyacrylamide gel electrophoresis (SDS-PAGE) of purified Prdx6 using chitin affinity chromatography. The purity is more than $90 \%$ (C).

\subsection{Preparation of Reduced and Hyperoxidized Prdx6}

The purified protein was used for preparation of reduced Prdx6 by adding $1 \mathrm{mM}$ DTT in standard buffer i.e., $50 \mathrm{mM}$ Tris- $\mathrm{HCl}, 100 \mathrm{mM} \mathrm{NaCl} \mathrm{pH} \mathrm{7.4.} \mathrm{We} \mathrm{incubated} \mathrm{the} \mathrm{protein} \mathrm{with} 500 \mu \mathrm{M} \mathrm{H}_{2} \mathrm{O}_{2}$ to get the hyperoxidized Prdx6 (C47 sulfinic acid or sulfonic acid) at room temperature for $30 \mathrm{~min}$ to $1 \mathrm{~h}$ in the standard buffer. At this concentration of $\mathrm{H}_{2} \mathrm{O}_{2}$ the antibody against the oxidized protein detects both the sulfinic $\left(-\mathrm{SO}_{2} \mathrm{H}\right)$ and sulfonic $\left(-\mathrm{SO}_{3} \mathrm{H}\right)$ states of the protein $[15,19]$.

\subsection{Circular Dichroism (CD) Measurements}

$\mathrm{CD}$ measurements of reduced Prdx6 and hyperoxidized Prdx6 were recorded in $50 \mathrm{mM}$ Tris- $\mathrm{HCl}$, $100 \mathrm{mM} \mathrm{NaCl}, \mathrm{pH} 7.4$ using a Jasco-750 CD Spectropolarimeter. All the measurements were done at $25^{\circ} \mathrm{C}$ in a thermoelectric cell holder, with the temperature being maintained using a Peltier element. Spectra were recorded in the far-ultraviolet region (190-260 nm), with a bandwidth of $1.0 \mathrm{~nm}$, a step size of $1 \mathrm{~nm}$, an integration time of $30 \mathrm{~s}$, and with three repeats. A fused quartz cell with a pathlength of $0.1 \mathrm{~cm}$ was used. The protein concentration was $10 \mu \mathrm{M}$. The results of all the $\mathrm{CD}$ measurements are expressed as mean residue ellipticity $\left([\theta]_{\lambda}\right)$ in $\mathrm{deg} \mathrm{cm}^{2} \mathrm{dmol}^{-1}$ at a given wavelength $\lambda(\mathrm{nm})$ using the relation: $[\theta]_{\lambda}=\theta_{\lambda} \mathrm{M}_{\mathrm{o}} / 10 \mathrm{cl}$, where $\theta_{\lambda}$ is the observed ellipticity in millidegrees at wavelength $\lambda$, 
Mo is the mean residual weight of the protein, $c$ is the protein concentration $\left(\mathrm{mg} / \mathrm{cm}^{3}\right)$, and $l$ is the path length $(\mathrm{cm})$.

\subsection{Fluorescence Measurements}

Fluorescence spectroscopy was performed with a PTI spectrofluorometer (Photon Technology International, Inc., Lawrenceville, NJ, USA) equipped with a single photon counting system for fluorescence intensity detection, dual fluorescence and absorbance channels using excitation and emission slits of $1 \mathrm{~nm}$ each. All measurements were performed at $25^{\circ} \mathrm{C}$ in $50 \mathrm{mM}$ Tris- $\mathrm{HCl}, 100 \mathrm{mM}$ $\mathrm{NaCl}$, pH 7.4 buffer. For tryptophan fluorescence measurements, the emission spectra were recorded in the wavelength range $310-450 \mathrm{~nm}$ after excitation at $295 \mathrm{~nm}$ to avoid tyrosine fluorescence.

8-Anilinonaphthalene-1-sulfonate (ANS) fluorescence spectra of Prdx6 were collected from 400 to $600 \mathrm{~nm}$ after excitation at $360 \mathrm{~nm}$. The protein concentration used for Trp and ANS fluorescence measurements was $1 \mu \mathrm{M}$. The ANS concentration in ANS fluorescence was $16 \mu \mathrm{M}$. All the measurements were done in micro quartz fluorescence cuvettes with pathlength of $0.3 \mathrm{~cm}$ (Sterna).

\subsection{Thermal-Induced Denaturation}

Heat-induced denaturation of Prdx6 was carried out in a Jasco-750 CD Spectropolarimeter equipped with a Peltier-type temperature controller with a heating rate of $1{ }^{\circ} \mathrm{C} / \mathrm{min}$, a scan rate providing adequate time for equilibration. Thermal denaturation was recorded following changes in $[\theta]_{220}$ from $20^{\circ} \mathrm{C}$ to $80^{\circ} \mathrm{C}$ at a rate of $1^{\circ} \mathrm{C} / \mathrm{min}$ in Jasco-750 CD Spectropolarimeter. A fused quartz cell with a pathlength of $1 \mathrm{~cm}$ was used. The protein concentration was $1 \mu \mathrm{M}$. The CD measured mean residual ellipticity at $[\theta]_{220}$ as a function of temperature is normalized at the start of the temperature scan. As shown earlier [22], each thermal denaturation curve was fitted to a two-state unfolding model after assuming a linear dependence of pre- and post-transition baselines on temperature $[23,24]$ :

$$
y(T)=\frac{\left[\left(y_{N}+m_{N} T\right)+\left(y_{D}+m_{D} T\right)\right] \exp \left[-\Delta H_{m} / R\left(1 / T-1 / T_{m}\right)\right]}{1+\exp \left[-\Delta H_{m} / R\left(1 / T-1 / T_{m}\right)\right]}
$$

$y(T)$ is the observed mean residue ellipticity at a given temperature, $m_{N}$ and $m_{D}$ are slopes of the native and denatured baselines, while $y_{N}$ and $y_{D}$ are the intercept of the native and denatured baselines, respectively. $T$ is the temperature in kelvin, $T_{m}$ is the melting temperature in kelvin and $\Delta H_{m}$ is the enthalpy change of denaturation at melting temperature and $R$ is the universal gas constant. Curve fitting of the data points was done in Sigma Plot 13.0 software (Systat Software, Inc., San Jose, CA, USA) using Equation (1) in the dynamic fit.

\subsection{Dynamic Light Scattering Measurements}

The size distribution of the particles present in the protein sample was obtained using a Zetasizer Micro V/ZMV 2000 (Malvern, UK). The reduced and hyperoxidized samples were in the standard buffer, i.e., $50 \mathrm{mM}$ Tris- $\mathrm{HCl}, 100 \mathrm{mM} \mathrm{NaCl} \mathrm{pH} \mathrm{7.4.} \mathrm{The} \mathrm{protein} \mathrm{concentration} \mathrm{was} 2 \mathrm{mg} / \mathrm{mL}$. All measurements were performed at $25^{\circ} \mathrm{C}$. Measurements were made at a fixed angle of $90^{\circ}$ using an incident laser beam of $689 \mathrm{~nm}$. Fifteen measurements were made with an acquisition time of $30 \mathrm{~s}$ for each sample at sensitivity of $10 \%$. The data was analyzed using Zetasizer software provided by the manufacturer to get hydrodynamic diameters of the particles and the volume fraction of particles associated with that particular diameter. The hydrodynamic data obtained from this measurement was used to calculate the apparent molecular weight of reduced and hyperoxidized Prdx6.

\subsection{Native PAGE}

Reduced and hyperoxidized Prdx6 in the standard buffer, i.e., $50 \mathrm{mM}$ Tris- $\mathrm{HCl}, 100 \mathrm{mM} \mathrm{NaCl} \mathrm{pH}$ 7.4 were loaded in a continuous $7.5 \%$ polyacrylamide gel under non-reducing and non-denaturing condition. Proteins were electrophoresed using running buffer of $30 \mathrm{mM}$ beta-alanine and $20 \mathrm{mM}$ 
lactic acid $(85-90 \%), \mathrm{pH} 3.8$ at a constant voltage $(180 \mathrm{~V})$ for $2 \mathrm{~h}$ with reverse polarity. The gel was run in the presence of two markers, bovine albumin (Mr $66.5 \mathrm{kDa}$, pI 4.7-4.9) and high molecular weight horse ferritin (Mr $450 \mathrm{kDa}$, pI 4.4) under non-reducing and non-denaturing conditions. Coomassie brilliant blue G-250 was used for the detection of the proteins on the gel.

\subsection{Homology Modelling}

The complete sequence of rat Prdx6 (consisting of 224 amino acids) was retrieved from UniProtKB database (accession number O35244). The best three templates, based on sequence identity $(91.52 \%$, $91.52 \%, 91.52 \%)$ and coverage $(100 \%, 100 \%$ and $100 \%)$, of models with dimer option were generated from the selected templates (PDB codes: 1PRX, 5B6M and 5B6N), respectively. The reduced Cys47 was converted to hyperoxidized (Cys47-SH to $\mathrm{Cys} 47-\mathrm{SO}_{3} \mathrm{H}$ ) form in Maestro [25]. To remove any steric clashes, energy minimization was performed using the GROMOS96 force field implemented in Swiss-Pdb Viewer [26].

PROCHECK [27] was used to verify the backbone conformation of the modeled structures, and the quality of the models was evaluated by qualitative model energy analysis (QMEAN) [28]. The QMEAN score gives the global score of the model and it ranges from 0 to 1 , the higher the scores, the more reliable are the models. Further, the QMEAN Z-score provides an estimation of the "degrees of nativeness" of the structural features observed in a model and indicates model quality compared to experimental structures. The model having the best validation results was selected for further studies.

\subsection{Molecular Dynamics Simulation}

Desmond [29] was used to perform MD simulations by implementing OPLS-AA 2005 force field $[30,31]$ for reduced and hyperoxidized rat Prdx6 in its dimeric state. Protein Preparation wizard was used to prepare the protein structure in Schrodinger. TIP3P water model was selected to solvate the protein, the orthorhombic periodic boundary box was chosen to construct the required systems for subsequent MD simulations. Appropriate numbers of counter ions were added to the system to maintain charge neutrality. Further, the distance between the box and wall was set to be greater than $10 \AA$ in order to avoid direct interaction with its own periodic image of the protein complex. Steepest descent method was selected to minimize the potential energies of the systems by applying a maximum of 5000 steps with a gradient threshold of $25 \mathrm{kcal} \mathrm{mol}^{-1} \AA^{-1}$, followed by L-BFGS (low-memory Broyden-Fletcher-Goldfarb-Shanno quasi-Newtonian) minimizer until a convergence criterion of $1 \mathrm{kcal} \mathrm{mol}^{-1} \AA^{-1}$ was achieved.

Default parameters were selected to equilibrate the pressure and temperature. Thereafter, the final MD simulation was done on the equilibrated systems for $50 \mathrm{~ns}$ at a constant temperature of $300 \mathrm{~K}$, and constant pressure of $1 \mathrm{~atm}$ with a time step of $2 \mathrm{fs}$. To compute long-range electrostatic interactions, the particle-mesh Ewald method (PME) [32] was applied with a grid spacing of $0.8 \AA$. The van der Waals and short-range electrostatic interactions were smoothly truncated at $9.0 \AA$.

Root mean square deviation (RMSD), root mean square fluctuation (RMSF), radius of gyration, solvent accessible surface area (SASA), internal hydrogen bond contacts of the reduced and hyperoxidized Prdx6 and PCA were calculated using VMD tcl scripts.

\section{Results and Discussion}

It is universally known that the ultimate folded native state conformation, not the primary structure of a protein determines the functional capacity and efficiency of a protein. Therefore, for multifunctional proteins (such as Prdx6, aconitase, activating transcription factor 2, ERK2, MAP kinase, glutamate racemase, etc.) usage of native state conformational change as a mechanism to switch between two different activities seems very common $[22,33]$. To comprehend structural alterations as a possibility for upregulation of aiPLA2 activity due to the hyperoxidation of peroxidatic cysteine residue of Prdx6 [19], we first did the in vitro comparison of the secondary and tertiary structure of hyperoxidized and reduced Prdx6 via various spectroscopic methods (Figure 2). Tryptophan 
fluorescence emission is a very sensitive tool for measuring the polarity of the local environment of tryptophan residues [34], and hence, mostly used as a diagnostic probe for analyzing conformational state of proteins [35]. Prdx6 has three tryptophan (Trp) residues, Trp33, Trp82 and Trp181. The solvent exposure of these Trp residues under different redox conditions is assessed by measuring tryptophan fluorescence of reduced and hyperoxidized Prdx6. As shown in Figure 2A, a decrease in fluorescence intensity and red shift from $328 \mathrm{~nm}$ to $334 \mathrm{~nm}$ of the hyperoxidized Prdx6 in comparison to that of reduced Prdx6 clearly reveals that Trp residues of hyperoxidized Prdx6 (relative to reduced protein) have been shifted to a more polar solvent environment.
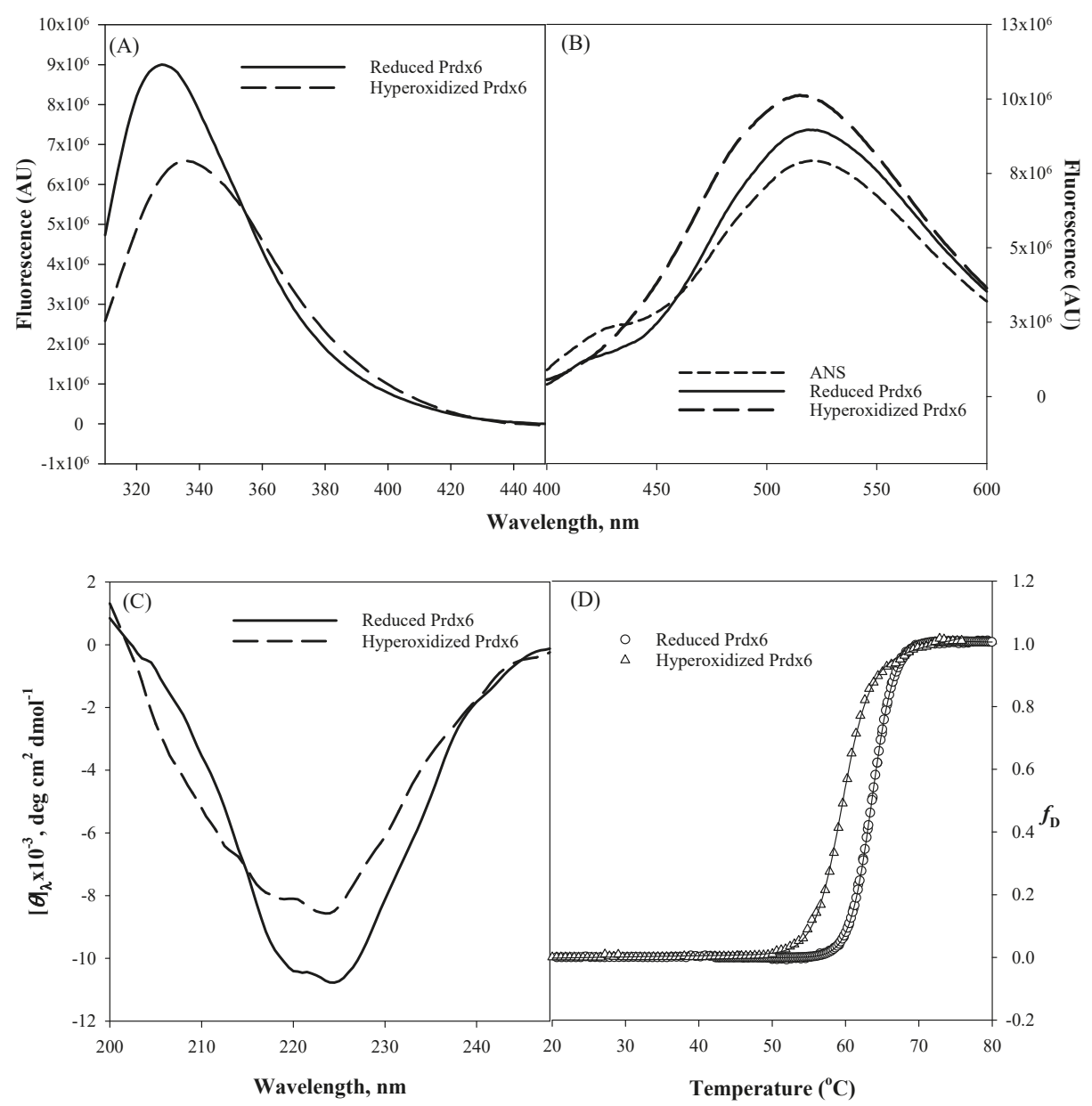

Figure 2. Tryptophan fluorescence (A), 8-Anilinonaphthalene-1-sulfonate (ANS) fluorescence (B), Far-Ultraviolet (UV) Circular Dichroism CD (C) measurements, and normalized thermal-induced denaturation curves (D) of reduced Prdx6 and hyperoxidized Prdx6. All measurements were done at $\mathrm{pH} 7.4(50 \mathrm{mM}$ Tris- $\mathrm{HCl}, 100 \mathrm{mM} \mathrm{NaCl})$ and at $25^{\circ} \mathrm{C}$. Thermal denaturation was recorded following changes in $[\theta]_{220}$ from $20{ }^{\circ} \mathrm{C}$ to $80^{\circ} \mathrm{C}$ at a rate of $1{ }^{\circ} \mathrm{C} / \mathrm{min}$. All spectra are the mean of three independent experiments.

To confirm the likelihood of greater exposition of hydrophobic amino acids in hyperoxidized Prdx6 (as suggested by the Trp fluorescence results), we investigated the ANS binding behaviour of reduced 
and hyperoxidized Prdx6. The fluorescent hydrophobic probe 8-Anilinonaphthalene-1-sulfonate (ANS) is usually used to detect the accessible hydrophobic surfaces on proteins [36,37]. In aqueous solvent, the quantum yield of the ANS probe is very weak, which on binding to a hydrophobic surface increases several fold [38]. As seen in Figure 2B, ANS fluorescence measurement in aqueous solvent shows an emission maximum at $\sim 520 \mathrm{~nm}$, and at $519 \mathrm{~nm}$ and $515 \mathrm{~nm}$ with reduced and hyperoxidized Prdx6, respectively. And there is increase in fluorescence intensity of the hyperoxidized Prdx6 in comparison to that of the aqueous solvent and reduced Prdx6. The blue shift in emission maxima and increase in the fluorescence intensity of ANS fluorescence with hyperoxidized Prdx6 as compared to the aqueous solvent is a clear signature for ANS binding, and indicates the exposure of hydrophobic amino acids to the solvent in the hyperoxidized Prdx6. Such exposure of hydrophobic amino acids in oxidized Prdx6, suggests conformational alterations with opening of the hydrophobic core.

We further analyzed whether the disparity in the hydrophobic core's packing within reduced and hyperoxidized Prdx6 is limited to only tertiary alterations or also has its root in the changes at secondary structure level. The far-UV region of the circular dichroism (CD) spectrum monitors the changes in the secondary structure of protein $[39,40]$. Here we evaluated the effect of redox state on the secondary structure of Prdx6 by performing CD measurements with reduced and hyperoxidized Prdx6 in the far-UV region. The mean residual ellipticity at $\theta_{222}$, the measure of secondary structure content of Prdx6, is shown in Table 1. Figure 2C and Table 1 show the far-UV CD spectra of both proteins, and the decrease in secondary structure content of hyperoxidized Prdx6 (in comparison with reduced Prdx6) indicates the influence of the redox state of Prdx6 for the functional switching of the protein by altering its secondary as well as tertiary structure. Taken together, the results indicate that there is a conformational difference between the reduced and hyperoxidized protein. However, we do not rule out the possibility that oligomer formation may also contribute to the observed spectral properties of the hyperoxidized protein.

We were further interested to see the impact of oxidation mediated conformational change on the thermodynamic stability of Prdx6. To investigate this, we measured the thermodynamic stability of reduced and hyperoxidized Prdx6 via an optical method, i.e., by monitoring the changes in molar ellipticity at $220 \mathrm{~nm}$ over the temperature range of $20-80{ }^{\circ} \mathrm{C}$ (Figure 2D). The transition curve obtained from the thermal-induced denaturation was analyzed using a two-state unfolding model, given above in Equation (1). The analysis gave the change in melting temperature $\left(T_{m}\right)$ and change in enthalpy $\left(\Delta H_{m}\right)$ at the melting temperature of Prdx6, as shown in Table 1 . As seen in Figure $2 \mathrm{D}$ and Table 1, the hyperoxidized Prdx6 shows a decrease of $4{ }^{\circ} \mathrm{C}$ in its $T_{m}$ as compared to that of reduced Prdx6. This decreased stability shows the conformational change of the native state of Prdx6 upon hyperoxidation, which may lead to changes in its activity under physiological condition.

Table 1. Conformational and thermodynamic parameters of reduced and hyperoxidized Prdx6.

\begin{tabular}{|c|c|c|c|c|c|}
\hline Prdx6 Species & $\begin{array}{c}{[\theta]_{222} \times 10^{-3}} \\
\text { Mdeg cm }^{2} \mathrm{dmol}^{-1}\end{array}$ & $\Delta H_{m}, \mathrm{kcal} \mathrm{mol}^{-1}$ & $T_{m},\left({ }^{\circ} \mathrm{C}\right)$ & $\begin{array}{l}\text { Hydrodynamic } \\
\text { Radii, } R_{h}(\mathrm{~nm})\end{array}$ & $\begin{array}{c}\text { Apparent Molecular } \\
\text { Weight (kD) }\end{array}$ \\
\hline Reduced Prdx6 & $10.5 \pm 0.02$ & $634.10 \pm 45.58$ & $63.6 \pm 0.5$ & $5.36 \pm 0.14$ & 50.0 \\
\hline $\begin{array}{c}\text { Hyperoxidized } \\
\text { Prdx } 6\end{array}$ & $8.4 \pm 0.05$ & $499.65 \pm 64.57$ & $59.4 \pm 0.2$ & $36.19 \pm 0.23$ & 337.6 \\
\hline
\end{tabular}

Mean \pm S. D. from three independent experiments.

To investigate the actual molecular level differences in the tertiary interaction, we performed molecular dynamic (MD) simulations for both the proteins (see Figure 3). The initial 3D structure models used while initiating simulation were run at $\operatorname{Prdx} 6$ homology models with their peroxidatic cysteine either reduced (Cys47-SH) or oxidized $\left(\mathrm{Cys} 47-\mathrm{SO}_{3} \mathrm{H}\right)$. The structure validation for the modeled rPrdx6 protein was done via PROCHECK (Ramachandran plot generator, Figure S1) and QMEAN (Figure S2) in-silico tools demonstrated the predicted model had good correlation with the experimental structures and were acceptable for further use. In MD simulation, root mean square deviation (RMSD) changes in $\mathrm{C} \alpha$ atoms of the reduced Prdx6 showed a slow increment during the simulation and 
finally converged at the end of the simulation around $2.5 \AA$. At the same time, hyperoxidized Prdx 6 showed fluctuations at the start, reached $3 \AA$ by $200 \mathrm{~ns}$, and ultimately converging at $2.5 \AA$, indicating more fluctuation in oxidized Prdx6 compared to reduced Prdx6 (Figure 3A). The root mean square fluctuation (RMSF) analysis is an important criterion to measure the stability of the protein under study. As seen in Figure 3B, the hyperoxidized Prdx6 displayed more fluctuations in 4 regions (in comparison to reduced Prdx6) localized in the conserved thioredoxin fold. It must be noted that apart from these 4 peaks, the fluctuations showed by side chains of other amino acids were almost similar, and highly flexible regions seems to mostly lie in the loops. In terms of conformational analysis, the radius of gyration is described as the moment of inertia of the group of atoms from their center of mass. As shown in Figure 3C, we observed, that the hyperoxidized Prdx6 showed a higher gyration radius than that of the reduced Prdx6 throughout the simulation run. Further details on the structural packing of the proteins were assessed by measuring SASA. SASA provides insight about the compactness of the hydrophobic core, which is an important factor for determining protein stability. As illustrated in Figure 3D, the SASA profile of the hyperoxidized Prdx6 simulation run exhibited a higher SASA value than that of reduced Prdx6, which could explain the differences in polarity of the local environment of tryptophan residues in both forms of the protein. However, it seems that the hyperoxidation of Prdx6 did not affect the overall dynamics or stability of the protein, indeed, it somehow disrupted the packing of the hydrophobic core, leading to solvent exposition of hydrophobic amino acids as evidenced by the higher gyration radii, SASA profile, and ANS fluorescence of hyperoxidized Prdx6 as compared to reduced Prdx6.
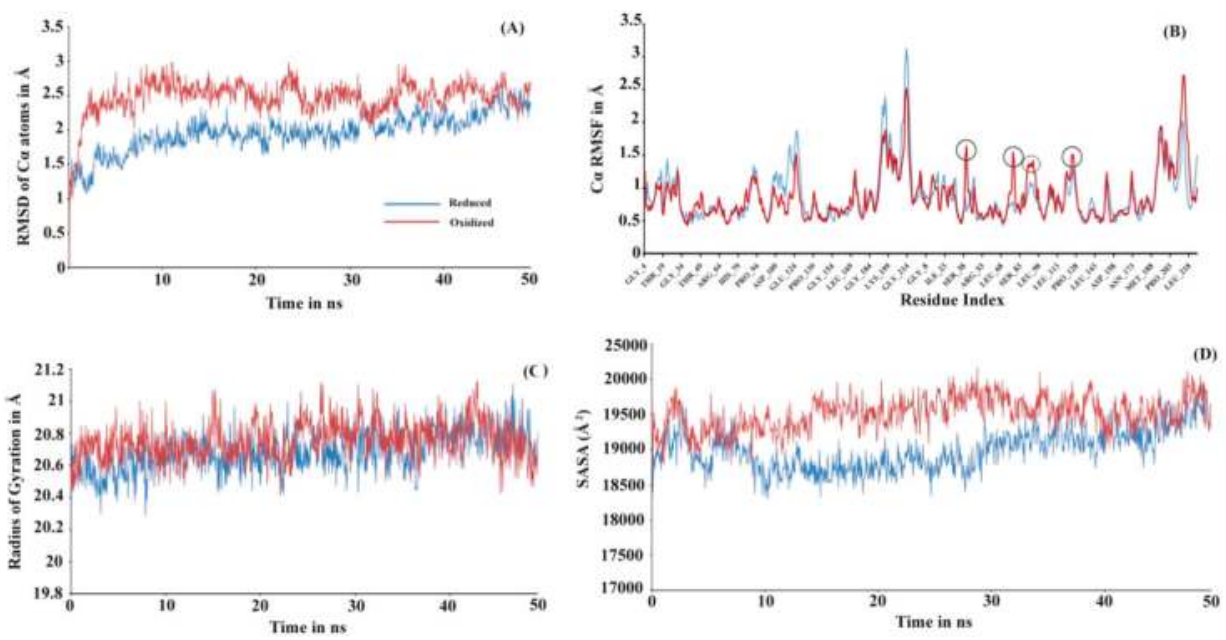

Figure 3. (A) RMSD, (B) RMSF, (C) Radius of gyration and (D) SASA plot of reduced (blue) and hyperoxidized (red) Prdx6 C $\alpha$ atoms along the 50 ns simulation period. RMSD: Root mean square deviation; RMSF: Root mean square fluctuation; SASA: Solvent accessible surface area.

Secondary structure elements, such as alpha-helices and beta-sheets were also monitored throughout the simulation period (see Figure 4). There are $23.11 \%$ helix and $19.17 \%$ beta-sheets in reduced Prdx6, while the hyperoxidized Prdx6 has $21.74 \%$ helix and $18.09 \%$ beta-strands, thereby, the total percentage difference in secondary structure elements in both proteins is only $2 \%$. To assess the contribution of non-covalent interaction on the flexibility of Prdx6, hydrogen bond formation during the simulation period was monitored. For each trajectory frame, total hydrogen bonds present in the protein were calculated. The hydrogen bond analysis revealed a decrease in the total number of hydrogen bonds in hyperoxidized Prdx6 (Figure 5) as compared to reduced Prdx6 during the simulation period. The average hydrogen bonds throughout the simulation for hyperoxidized Prdx6 
was calculated to be 123.515 while for the reduced protein it was 126.823 . However, since this loss does not seem to affect the internal dynamics of the protein (as indicated by RMSD and RMSF plots), the reason for up-regulation of aiPLA $\mathrm{A}_{2}$ activity in hyperoxidized Prdx6 remains ambiguous.

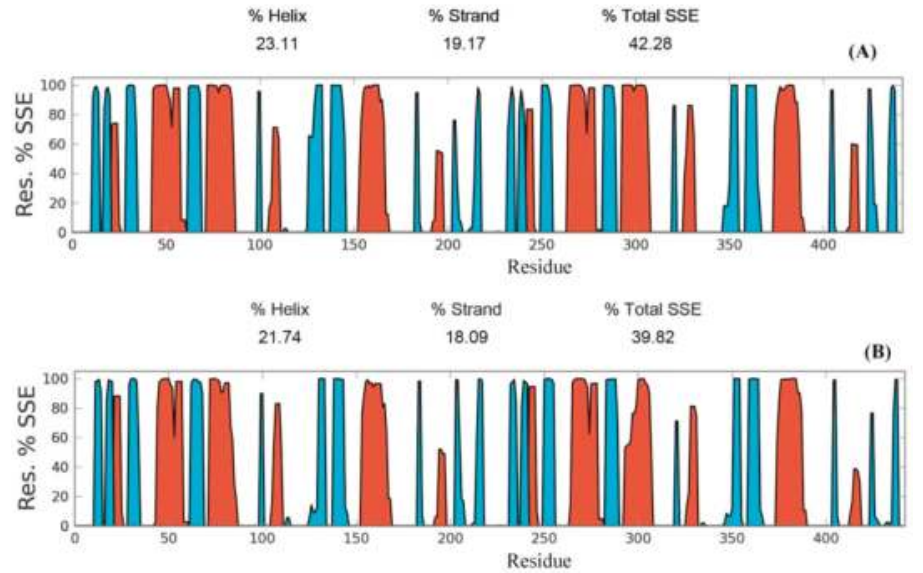

Figure 4. Secondary structure elements evolution of reduced (A) and hyperoxidized (B) Prdx6 during the simulation period. Helices are shown in red and strands are shown in cyan.

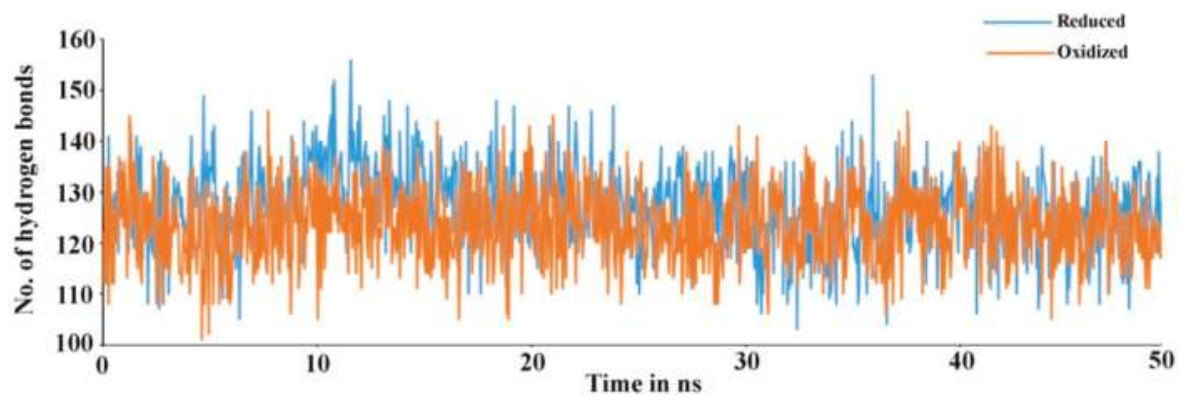

Figure 5. Total number of hydrogen bond found in reduced (blue) and hyperoxidized (orange) Prdx6 during the simulation period.

Prdxs are inherently oligomeric proteins whose multimeric status is known to be influenced by the oxidation states of the peroxidatic cysteine. For instance, hyperoxidation of peroxidatic cysteine to a Cys- $\mathrm{SO}_{2} \mathrm{H}$ and $\mathrm{Cys}-\mathrm{SO}_{3} \mathrm{H}$ under oxidative stress has been reported to alter the quaternary structure of a typical 2-Cys Prdx from a dimer into higher oligomers, thus, forming molecular complexes that led to inactivation of its peroxidase activity [41,42]. In fact, in a homolog of Prdx, this structural change from low molecular weight multimer to a high molecular weight oligomeric complex, has been observed to cause a functional change from peroxidase to molecular chaperone [43]. In addition, subunit associations are often preceded by conformational transitions that cause the exposition of hydrophobic amino acids on the surface for stronger interactions at the oligomeric interface. Taking all this into consideration, it is highly probable that hyperoxidation of Prdx6 causes a similar effect (as that of other Prdxs) on the quaternary structure of the enzyme. To analyze the native state oligomeric composition of Prdx6, the native-PAGE of reduced and hyperoxidized Prdx6 was performed (see Figure 6). It must be noted here that, the crystallographic studies as well as equilibrium sedimentation and DuoLink analyses have shown Prdx6 in reduced (Cys47-SH) and sulfinic forms $\left(\mathrm{Cys} 47-\mathrm{SO}_{2} \mathrm{H}\right)$ to exist as dimers [44-46]. In native PAGE gel we also observed the dimeric nature of reduced Prdx6, as indicated by the protein band (monomer molecular weight, $\mathrm{M}_{\mathrm{r}}: 25 \mathrm{KDa}$ ), which is close to that of serum albumin 
$\left(\mathrm{M}_{\mathrm{r}}\right.$ : 64kDa). However, the hyperoxidized Prdx6 showed a thick band similar to that of horse ferritin, having $\mathrm{M}_{\mathrm{r}}$ of $450 \mathrm{kDa}$.

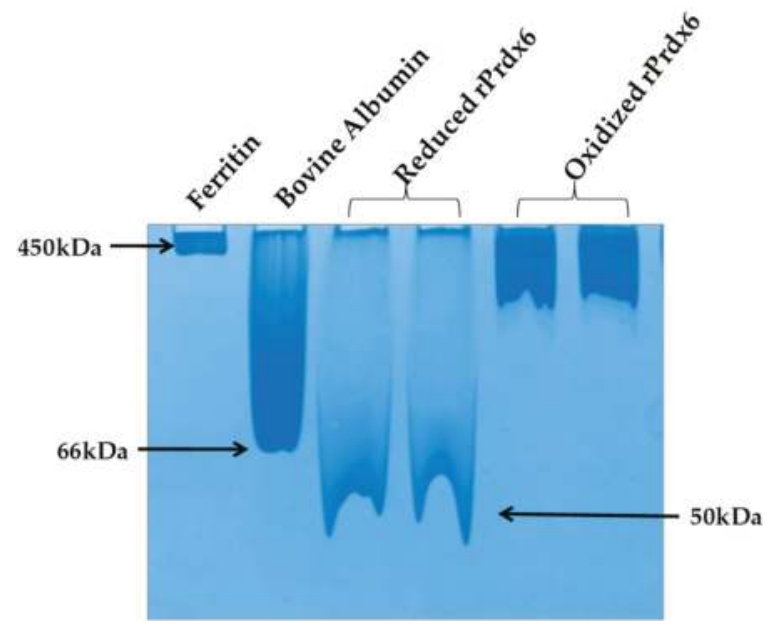

Figure 6. Native-PAGE.Reduced and hyperoxidized Pdrx6s along with bovine serum albumin and horse ferritin as a marker under non-reducing and non-denaturing conditions in the buffer $150 \mathrm{mM}$ beta- alanine and $100 \mathrm{mM}$ lactic acid (85-90\%), pH 3.8.

This varied mobility of both proteins on a native PAGE gel, indicates that hyperoxidized Prdx6 exists in a higher oligomer state. These observations were confirmed by the dynamic light scattering (DLS) measurements at physiological pH 7.4 (See Table 1). The reduced Prdx6 was found to have a hydrodynamic radius of $5.36 \mathrm{~nm}$ (corresponding to that of a protein with $\mathrm{M}_{\mathrm{r}} 50 \mathrm{KDa}$ ) while the hyperoxidized Prdx6 had a hydrodynamic radius of $36.19 \mathrm{~nm}$.; the apparent molecular weight calculated from the hydrodynamic radii of reduced and hyperoxidized Prdx6 are shown in Table 1. Thus, we concluded that the quaternary state of reduced and hyperoxidized Prdx6 is different. This change in the quaternary structure of the proteins is preceded by the conformational change shown by the above biophysical studies (CD and fluorescence) for its subunit association during oligomerization [43,47]. The exposure of hydrophobic residues in hyperoxidized Prdx6 (detected by ANS fluorescence) is necessary for non-covalent interaction among subunits in high oligomers. However, the lesser change in the internal dynamics of the protein (as indicated by RMSD and RMSF plots) might be because MD simulation of hyperoxidized Prdx6 was performed in its dimeric state.

During the redox cycle, the hydrophobic residues (Leu 145, Ile 147, Leu 148 and Tyr 149) between $\beta$-strands ( $\beta b 7$ from each monomer) in Prdx6 play a significant role on the stabilization of Prdx6-Prdx6 homodimerization and Prdx6- $\pi$ GST heterodimerization (an important step on its peroxidase activity) [44]. Our finding that the formation of higher oligomer of Prdx6 on the hyperoxidation may not allow the formation of Prdx6- $\pi$ GST hetero-dimer to recycle the hyperoxidized Prdx6, leading to loss of its peroxidase activity but it might overexpose the catalytic triad for aiPLA2 activity located at the protein surface, inducing the upregulation of its phosphopholipase activity, which has previously been shown in [19]. Therefore, the results lead us to propose that the change in the oligomeric state of Prdx6 due to hyperoxidation might induce the switching of its peroxidase activity to aiPLA2 activity.

\section{Conclusions}

In summary, our study demonstrates that post-translational modifications (like hyperoxidation) cause the alteration of reduced Prdx6 dimer to a multimeric status. The formation of a high order 
oligomer is consequently due to a decrease in protein stability as a result of the opening of some of the hydrophobic groups to the polar solvent. In future, it will be important to further identify the properties of this oligomeric protein and the physiological significance thereof.

Supplementary Materials: The following are available online at http://www.mdpi.com/2076-3921/8/2/33/s1, Figure S1: Ramachandran plot of rat Prdx6 model generated using Procheck. Figure S2: Graphical representation of the absolute quality of rat Prdx6 model evaluated by QMEAN Z-score.

Author Contributions: Conceptualization, S.S., L.R.S., H.R. and A.B.F.; Methodology, S.S., P.K. and H.R.; Software, K.H.S. and P.A.M.; Validation, S.S., R.K.C., L.R.S., H.R.; Formal analysis, S.S., R.K.C., P.N., L.R.S. and H.R.; Investigation, S.S., L.R.S. and H.R.; Resources, H.R.; Data curation, S.S., R.K.C., K.H.S. and P.A.M.; Writing-Original draft, S.S., R.K.C., L.R.S. and H.R.; Writing-Review and Editing, R.K.C., K.H.S., L.R.S., A.B.F., H.R.; Supervision, H.R.; Project administration, H.R.; Funding acquisition, H.R.

Funding: This research was funded by the Department of Biotechnology, Govt. of India; grant number $\mathrm{BT} / 359 / \mathrm{NE} / \mathrm{TBP} / 2012$.

Acknowledgments: We want to thank Faizan Ahmad and Asimul Islam for providing the facility for CD measurements at CIRBSC, Jamia Millia Islamia, New Delhi. We also appreciate Sheldon I. Feinstein for giving us pTYB1 plasmid from UPENN. The workstation used in the simulation studies were funded by DST SYST grant to Potshanbam Angamba Meetei. We gratefully acknowledge the support of NVIDIA Corporation with the donation of the Titan Xp GPU used for this research. Indian Council of Medical Research is also acknowledged for the financial assistance provided in the form of research fellowship to Rimpy Kaur Chowhan.

Conflicts of Interest: The authors declare no conflict of interest.

\section{References}

1. Wood, Z.A.; Schroder, E.; Robin Harris, J.; Poole, L.B. Structure, mechanism and regulation of peroxiredoxins. Trends Biochem. Sci. 2003, 28, 32-40. [CrossRef]

2. Valko, M.; Leibfritz, D.; Moncol, J.; Cronin, M.T.; Mazur, M.; Telser, J. Free radicals and antioxidants in normal physiological functions and human disease. Int. J. Biochem. Cell Biol. 2007, 39, 44-84. [CrossRef] [PubMed]

3. Rhee, S.G.; Kang, S.W.; Chang, T.S.; Jeong, W.; Kim, K. Peroxiredoxin, a novel family of peroxidases. IUBMB Life 2001, 52, 35-41. [CrossRef] [PubMed]

4. Halliwell, B. Antioxidants in human health and disease. Annu Rev. Nutr. 1996, 16, 33-50. [CrossRef] [PubMed]

5. Sies, H. Strategies of antioxidant defense. Eur. J. Biochem. 1993, 215, 213-219. [CrossRef] [PubMed]

6. Mizohata, E.; Sakai, H.; Fusatomi, E.; Terada, T.; Murayama, K.; Shirouzu, M.; Yokoyama, S. Crystal structure of an archaeal peroxiredoxin from the aerobic hyperthermophilic crenarchaeon Aeropyrum pernix K1. J. Mol. Biol. 2005, 354, 317-329. [CrossRef]

7. Rhee, S.G.; Chae, H.Z.; Kim, K. Peroxiredoxins: A historical overview and speculative preview of novel mechanisms and emerging concepts in cell signaling. Free Radic. Biol. Med. 2005, 38, 1543-1552. [CrossRef]

8. Perkins, A.; Nelson, K.J.; Parsonage, D.; Poole, L.B.; Karplus, P.A. Peroxiredoxins: Guardians against oxidative stress and modulators of peroxide signaling. Trends Biochem. Sci. 2015, 40, 435-445. [CrossRef]

9. Fujii, J.; Ikeda, Y. Advances in our understanding of peroxiredoxin, a multifunctional, mammalian redox protein. Redox Rep. 2002, 7, 123-130. [CrossRef]

10. Atkinson, H.J.; Babbitt, P.C. An atlas of the thioredoxin fold class reveals the complexity of function-enabling adaptations. PLoS Comput. Biol. 2009, 5, 1000-1541. [CrossRef]

11. Seo, M.S.; Kang, S.W.; Kim, K.; Baines, I.C.; Lee, T.H.; Rhee, S.G. Identification of a new type of mammalian peroxiredoxin that forms an intramolecular disulfide as a reaction intermediate. J. Biol. Chem. 2000, 275, 20346-20354. [CrossRef] [PubMed]

12. Manevich, Y.; Feinstein, S.I.; Fisher, A.B. Activation of the antioxidant enzyme 1-CYS peroxiredoxin requires glutathionylation mediated by heterodimerization with pi GST. Proc. Natl. Acad. Sci. USA 2004, 101, 3780-3785. [CrossRef]

13. Choi, H.J.; Kang, S.W.; Yang, C.H.; Rhee, S.G.; Ryu, S.E. Crystallization and preliminary X-ray studies of hORF6, a novel human antioxidant enzyme. Acta Crystallogr. D Biol. Crystallogr. 1998, 54, 436-437. [CrossRef] [PubMed] 
14. Fisher, A.B. Peroxiredoxin 6 in the repair of peroxidized cell membranes and cell signaling. Arch. Biochem. Biophys. 2016, 617, 68-83. [CrossRef] [PubMed]

15. Manevich, Y.; Shuvaeva, T.; Dodia, C.; Kazi, A.; Feinstein, S.I.; Fisher, A.B. Binding of peroxiredoxin 6 to substrate determines differential phospholipid hydroperoxide peroxidase and phospholipase A(2) activities. Arch. Biochem. Biophys. 2009, 485, 139-149. [CrossRef] [PubMed]

16. Akiba, S.; Dodia, C.; Chen, X.; Fisher, A.B. Characterization of acidic $\mathrm{Ca}^{2+}$-independent phospholipase A2 of bovine lung. Comp. Biochem. Physiol. B Biochem. Mol. Biol. 1998, 120, 393-404. [CrossRef]

17. Li, H.; Benipal, B.; Zhou, S.; Dodia, C.; Chatterjee, S.; Tao, J.Q.; Sorokina, E.M.; Raabe, T.; Feinstein, S.I.; Fisher, A.B. Critical role of peroxiredoxin 6 in the repair of peroxidized cell membranes following oxidative stress. Free Radic. Biol. Med. 2015, 87, 356-365. [CrossRef]

18. Fisher, A.B. The phospholipase A2 activity of peroxiredoxin 6. J. Lipid Res. 2018, 59, 1132-1147. [CrossRef]

19. Kim, S.Y.; Jo, H.Y.; Kim, M.H.; Cha, Y.Y.; Choi, S.W.; Shim, J.H.; Kim, T.J.; Lee, K.Y. H2O2-dependent hyperoxidation of peroxiredoxin $6(\operatorname{Prd} \times 6)$ plays a role in cellular toxicity via up-regulation of iPLA2 activity. J. Biol. Chem. 2008, 283, 33563-33568. [CrossRef]

20. Chong, S.; Mersha, F.B.; Comb, D.G.; Scott, M.E.; Landry, D.; Vence, L.M.; Perler, F.B.; Benner, J.; Kucera, R.B.; Hirvonen, C.A.; et al. Single-column purification of free recombinant proteins using a self-cleavable affinity tag derived from a protein splicing element. Gene 1997, 192, 271-281. [CrossRef]

21. Moll, J.R.; Ruvinov, S.B.; Pastan, I.; Vinson, C. Designed heterodimerizing leucine zippers with a ranger of pIs and stabilities up to 10(-15) M. Protein Sci. 2001, 10, 649-655. [CrossRef] [PubMed]

22. Rahaman, H.; Zhou, S.; Dodia, C.; Feinstein, S.I.; Huang, S.; Speicher, D.; Fisher, A.B. Increased phospholipase A2 activity with phosphorylation of peroxiredoxin 6 requires a conformational change in the protein. Biochemistry 2012, 51, 5521-5530. [CrossRef] [PubMed]

23. Santoro, M.M.; Bolen, D.W. Unfolding free energy changes determined by the linear extrapolation method. 1. Unfolding of phenylmethanesulfonyl alpha-chymotrypsin using different denaturants. Biochemistry 1988, 27, 8063-8068. [CrossRef] [PubMed]

24. Khan, A.; Das, M.K.; Das, U.; Rahaman, M.H.; Hassan, M.I.; Srinivasan, A.; Singh, T.P.; Ahmad, F. A single mutation induces molten globule formation and a drastic destabilization of wild-type cytochrome $\mathrm{c}$ at $\mathrm{pH}$ 6.0. J. Biol. Inorg. Chem. JBIC 2009, 14, 751-760. [CrossRef] [PubMed]

25. Maestro. Schrödinger Release; Schrödinger, LLC: New York, NY, USA, 2018.

26. Guex, N.; Peitsch, M.C. SWISS-MODEL and the Swiss-PdbViewer: An environment for comparative protein modeling. Electrophoresis 1997, 18, 2714-2723. [CrossRef] [PubMed]

27. Laskowski, R.A.; Moss, D.S.; Thornton, J.M. Main-chain bond lengths and bond angles in protein structures. J. Mol. Biol. 1993, 231, 1049-1067. [CrossRef]

28. Benkert, P.; Tosatto, S.C.; Schomburg, D. QMEAN: A comprehensive scoring function for model quality assessment. Proteins 2008, 71, 261-277. [CrossRef] [PubMed]

29. Bowers, K.J.; Chow, D.E.; Xu, H.; Dror, R.O.; Eastwood, M.P.; Gregerse, B.A.; Klepeis, J.L.; Kolossvary, I.; Moraes, M.A.; Sacerdoti, F.D.; et al. Shaw Scalable algorithms for molecular dynamics simulations on commodity clusters. In Proceedings of the 2006 ACM/IEEE Conference on Supercomputing, Tampa, FL, USA, 11-17 November 2006; p. 43.

30. Kaminski, G.A.; Friesner, R.A.; Tirado-Rives, J.; Jorgensen, W.L. Evaluation and Reparametrization of the OPLS-AA Force Field for Proteins via Comparison with Accurate Quantum Chemical Calculations on Peptides. J. Phys. Chem. B 2001, 105, 6474-6487. [CrossRef]

31. Jorgensen, W.L.; Maxwell, D.S.; Tirado-Rives, J. Development and Testing of the OPLS All-Atom Force Field on Conformational Energetics and Properties of Organic Liquids. J. Am. Chem. Soc. 1996, 118, 11225-11236. [CrossRef]

32. Essmann, U.; Perera, L.; Berkowitz, M.L.; Darden, T.; Lee, H.; Pedersen, L.G. A Smooth Particle Mesh Ewald Method. J. Chem. Phys. 1995, 103, 8577-8593. [CrossRef]

33. Jeffery, C.J. Protein species and moonlighting proteins: Very small changes in a protein's covalent structure can change its biochemical function. J. Proteom. 2016, 134, 19-24. [CrossRef] [PubMed]

34. Lakowicz, J.R. Principles of Fluorescence Spectroscopy; Academic/Plenum: New York, NY, USA, 1999; pp. 611-619.

35. Vivian, J.T.; Callis, P.R. Mechanisms of tryptophan fluorescence shifts in proteins. Biophys. J. 2001, 80, $2093-2109$. [CrossRef] 
36. Semisotnov, G.V.; Rodionova, N.A.; Razgulyaev, O.I.; Uversky, V.N.; Gripas, A.F.; Gilmanshin, R.I. Gilmanshin, Study of the "molten globule" intermediate state in protein folding by a hydrophobic fluorescent probe. Biopolymers 1991, 31, 119-128. [CrossRef] [PubMed]

37. Stryer, L. The interaction of a naphthalene dye with apomyoglobin and apohemoglobin. A fluorescent probe of non-polar binding sites. J. Mol. Biol. 1965, 13, 482-495. [CrossRef]

38. Rosen, C.G.; Weber, G. Dimer formation from 1-amino-8-naphthalenesulfonate catalyzed by bovine serum albumin. A new fluorescent molecule with exceptional binding properties. Biochemistry 1969, 8, 3915-3920. [CrossRef] [PubMed]

39. Yang, J.T.; Wu, C.S.; Martinez, H.M. Calculation of protein conformation from circular dichroism. Methods Enzymol. 1986, 130, 208-269. [PubMed]

40. Kelly, S.M.; Jess, T.J.; Price, N.C. How to study proteins by circular dichroism. Biochim. Biophys. Acta 2005, 1751, 119-139. [CrossRef]

41. Schroder, E.; Littlechild, J.A.; Lebedev, A.A.; Errington, N.; Vagin, A.A.; Isupov, M.N. Crystal structure of decameric 2-Cys peroxiredoxin from human erythrocytes at 1.7 A resolution. Structure 2000, 8, 605-615. [CrossRef]

42. Jang, H.H.; Lee, K.O.; Chi, Y.H.; Jung, B.G.; Park, S.K.; Park, J.H.; Lee, J.R.; Lee, S.S.; Moon, J.C.; Yun, J.W.; et al. Two enzymes in one; two yeast peroxiredoxins display oxidative stress-dependent switching from a peroxidase to a molecular chaperone function. Cell 2004, 117, 625-635. [CrossRef]

43. Wood, Z.A.; Poole, L.B.; Hantgan, R.R.; Karplus, P.A. Dimers to doughnuts: Redox-sensitive oligomerization of 2-cysteine peroxiredoxins. Biochemistry 2002, 41, 5493-5504. [CrossRef]

44. Zhou, S.; Sorokina, E.M.; Harper, S.; Li, H.; Ralat, L.; Dodia, C.; Speicher, D.W.; Feinstein, S.I.; Fisher, A.B. Peroxiredoxin 6 homodimerization and heterodimerization with glutathione S-transferase pi are required for its peroxidase but not phospholipase A2 activity. Free Radic. Biol. Med. 2016, 94, 145-156. [CrossRef] [PubMed]

45. Choi, H.J.; Kang, S.W.; Yang, C.H.; Rhee, S.G.; Ryu, S.E. Crystal structure of a novel human peroxidase enzyme at 2.0 A resolution. Nat. Struct. Biol. 1998, 5, 400-406. [CrossRef] [PubMed]

46. Lee, W.; Kim, K.H.; Kim, E.E. Crystal structures of human peroxiredoxin 6 in different oxidation states. Biochem. Biophys. Res. Commun. 2016, 477, 717-722.

47. Rhee, S.G.; Woo, H.A. Multiple functions of peroxiredoxins: Peroxidases, sensors and regulators of the intracellular messenger $\mathrm{H}_{2} \mathrm{O}_{2}$, and protein chaperones. Antioxid. Redox Signal. 2011, 15, 781-794. [CrossRef] [PubMed]

(C) 2019 by the authors. Licensee MDPI, Basel, Switzerland. This article is an open access article distributed under the terms and conditions of the Creative Commons Attribution (CC BY) license (http:/ / creativecommons.org/licenses/by/4.0/). 


\title{
Oxidation of Peroxiredoxin 6 in the Presence of GSH Increases its Phospholipase $A_{2}$ Activity at Cytoplasmic $\mathrm{pH}$
}

\author{
Suiping Zhou ${ }^{1}$, Chandra Dodia ${ }^{1}$, Sheldon I. Feinstein ${ }^{1}$, Sandra Harper ${ }^{2}$, Henry J. Forman ${ }^{3}$, \\ David W. Speicher ${ }^{2}$ and Aron B. Fisher ${ }^{1, *}$ \\ 1 Institute for Environmental Medicine, University of Pennsylvania Perelman School of Medicine, \\ Philadelphia, PA 19104, USA; Suiping.Zhou@STJUDE.ORG (S.Z.); cdodia@mail.med.upenn.edu (C.D.); \\ sif@pennmedicine.upenn.edu (S.I.F.) \\ 2 Center for Systems and Computational Biology, The Wistar Institute, Philadelphia, PA 19104, USA; \\ sharper@Wistar.org (S.H.); speicher@wistar.org (D.W.S.) \\ 3 Leonard Davis School of Gerontology, The University of Southern California, Los Angeles, CA 19104, USA; \\ peroxideman@gmail.com \\ * Correspondence: abf@upenn.edu; Tel.: +1-215-898-9100; Fax: +1-215-898-0868
}

Received: 14 November 2018; Accepted: 18 December 2018; Published: 24 December 2018

check for updates

\begin{abstract}
The expression of the phospholipase $A_{2}$ activity (aiPLA 2 ) of peroxiredoxin $6(\operatorname{Prdx} 6)$ in the cell cytoplasm is physiologically relevant for the repair of peroxidized cell membranes, but aiPLA 2 assay in vitro indicates that, unlike assay at $\mathrm{pH} 4$, activity at cytosolic $\mathrm{pH}$ is essentially absent with non-oxidized substrate. However, the addition of glutathione (GSH) to the assay medium significantly increased aiPLA 2 activity at cytosolic $\mathrm{pH}$, while oxidized GSH (GSSG) and several other thiols had no effect. By mass spectroscopy (ESI MS), the addition of GSH to Prdx6 paradoxically led to oxidation of its conserved Cys47 residue to a sulfinic acid. The effect of GSH on PLA 2 activity was abolished by incubation under anaerobic conditions, confirming that auto-oxidation of the protein was the mechanism for the GSH effect. Analysis by circular dichroism (CD) and tryptophan fluorescence showed alterations of the protein structure in the presence of GSH. Independently of GSH, the oxidation of Prdx6 by exposure to $\mathrm{H}_{2} \mathrm{O}_{2}$ or the presence of oxidized phospholipid as substrate also significantly increased aiPLA 2 activity at $\mathrm{pH} 7$. We conclude that the oxidation of the peroxidatically active Cys47 of Prdx6 results in an increase of aiPLA 2 activity at pH 7 without effect on the activity of the enzyme at $\mathrm{pH} 4$.
\end{abstract}

Keywords: substrate binding; sulfinic acid; Prdx6 structure; mass spectroscopic analysis

\section{Introduction}

Peroxiredoxins (Prdxs) are a widely distributed family of antioxidant enzymes that use a cysteine thiol group as a catalytic center to catalyze the reduction of hydroperoxides [1]. These enzymes function in anti-oxidant defense and they also have an important role in cell signaling through the regulation or sensing of local peroxide concentration [2]. The mammalian peroxiredoxin (Prdx) family consists of six members with a common mechanism for their peroxidase activity. The three-step peroxidatic cycle for the Prdx proteins involves: (i) reduction of a hydroperoxide substrate through the oxidation of a catalytic Cys to a sulfenic acid, followed by; (ii) formation of a disulfide; and, (iii) reduction of the disulfide to regenerate the active protein. The last mammalian peroxiredoxin to be described was Prdx6, a protein that is expressed in essentially all tissues but at particularly high levels in lung, brain, eye, and testes [3-5]. While Prdx6 is similar to Prdxs 1-5 in its use of a catalytic Cys residue (C47 in 
Prdx6) to reduce $\mathrm{H}_{2} \mathrm{O}_{2}$, short chain hydroperoxides, and peroxynitrite (step i above) [6,7], it expresses several unique features that distinguish it from other Prdx family members.

A major difference between Prdx6 and Prdxs 1-5 relates to both steps (ii) and (iii) (the resolution phases) of the peroxidatic catalytic cycle. These steps in the cycle are accomplished in Prdxs 1-5 by a Cys that is intrinsic to the protein (called the resolving Cys), followed by reduction of the disulfide with thioredoxin [3]. On the other hand, Prdx6 uses glutathione (GSH) catalyzed by GSH S-transferase (GST) to complete the reaction cycle [8-10]. Based on the characteristics of the catalytic mechanism reflecting the number of conserved cysteine residues, Prdxs 1-5 have been called 2-Cys enzymes. While Prdx6 has been called 1-Cys Prdx. Another important difference between Prdx6 and other family members is that $\operatorname{Prdx6} 6$, unlike $\operatorname{Prdx} 1-5$, has the ability to reduce phospholipid hydroperoxides with a rate constant similar to that for the reduction of $\mathrm{H}_{2} \mathrm{O}_{2}\left(\sim 10^{6} \mathrm{M}^{-1} \mathrm{~s}^{-1}\right)[9,11]$.

In addition to differences in the peroxidatic reaction cycle and importantly for this manuscript, Prdx6 expresses several enzymatic functions that are not expressed by Prdxs 1-5. One of these enzymatic functions of Prdx6 is a phospholipase $\mathrm{A}_{2}\left(\mathrm{PLA}_{2}\right)$ activity. This latter activity is not associated with C47 but is based on an enzymatically active site consisting of a Ser-His-Asp catalytic triad [12]. Finally, Prdx6 has a third enzymatic activity that is based on a HxxxxD active site (spanning the amino acids 26-31) that catalyzes lysophosphatidylcholine acyl transferase activity (LPCAT) [13]. Thus, Prdx6 appears to play a unique role in phospholipid metabolism with the ability to catabolize ( $\mathrm{PLA}_{2}$ activity) and/or remodel phospholipids (LPCAT activity) as well as to maintain these phospholipids in their reduced state (peroxidase activity). Regulation of the $\mathrm{PLA}_{2}$ activity of Prdx6 is the major focus of this mms.

Our initial reports describing Prdx6-PLA 2 activity indicated that the enzyme is active at acidic $\mathrm{pH}$ ( $\mathrm{pH} 4)$, but it has relatively little activity at neutral $\mathrm{pH}$ and above [8]. This enzymatic activity at acidic $\mathrm{pH}$ is consistent with the localization of the protein to acidic organelles, such as lung lamellar bodies and lysosomes, where it plays an important role in phospholipid turnover $[6,14]$. Thus, when first described, the enzyme was given the trivial name acidic, $\mathrm{Ca}^{2+}$ independent $\mathrm{PLA}_{2}\left(\mathrm{aiPLA}_{2}\right)$ to reflect its acidic $\mathrm{pH}$ requirement for catalysis and its catalytic activity in the absence of $\mathrm{Ca}^{2+}[15,16]$. However, subsequent studies have indicated that the PLA 2 activity of Prdx6 also plays important roles in the repair of peroxidized cell membranes $[17,18]$, as well as in the activation of NADPH oxidase (type 2) $[19,20]$, functions that presumably require PLA $_{2}$ activity in the cytosol at approximately neutral $\mathrm{pH}$. This requirement can be accomplished by several mechanisms. First, phosphorylation of the protein results in a markedly increased activity at pH 7-8 (as well as at acidic pH) [21]; we have shown that conformational change of Prdx6 upon its phosphorylation is the basis for the enhancement of substrate binding and increased PLA $\mathrm{P}_{2}$ enzymatic activity [22]. Second, the presence of an oxidized substrate, e.g., a phospholipid hydroperoxide, significantly enhanced enzymatic activity at neutral $\mathrm{pH}$ [23]. As a third mechanism, oxidation of the conserved C47 of Prdx6 following the treatment of cells with $\mathrm{H}_{2} \mathrm{O}_{2}$ resulted in increased $\mathrm{PLA}_{2}$ activity at neutral $\mathrm{pH}$ [24].

An additional mechanism that results in increased $\mathrm{Prdx6} 6-\mathrm{PLA}_{2}$ activity at $\mathrm{pH} 7$ was discovered by serendipity. As described above, GSH is required for Prdx6 peroxidase activity; it is commonly used as a reactant in a peroxidase activity assay that is routinely carried out at $\mathrm{pH} 7$ [9]. During our use of this assay, we identified products in the incubation medium that appeared to reflect the presence of $\mathrm{PLA}_{2}$ activity and postulated that this might have been due to the presence of GSH. Further study indicated that GSH did indeed stimulate Prdx6-PLA 2 activity at $\mathrm{pH} 7$, while there was no effect on activity at $\mathrm{pH} 4$ [25]. The present study was undertaken to document this result and to evaluate a possible mechanism for this effect of GSH. This publication is part of a forum on Peroxiredoxin 6 as a Unique Member of the Peroxiredoxin Family. 


\section{Materials and Methods}

\subsection{Reagents}

1,2-Bis palmitoyl-sn-glycero-3-phosphocholine (DPPC), egg yolk phosphatidylcholine (PC), phosphatidylglycerol (PG), 1-palmitoyl-2-linoleoyl-sn-glycero-3-phosphocholine (PLPC), phosphatidylserine (PS), and cholesterol (chol) were purchased from Avanti-Polar Lipids (Birmingham, AL). Extracellular-signal-regulated kinase (Erk2) was purchased from Upstate (Millipore, Billerica, MA, USA). Protein concentration was measured by Coomassie blue binding using bovine $\gamma$-globulin as the standard (Bio-Rad, Hercules, CA, USA). A mouse monoclonal antibody against human Prdx6 was purchased from Chemicon EMD Millipore (Billerica, MA, USA). Bromoenol lactone (BEL) was obtained from Cayman Chemical (Ann Arbor, MI, USA). Reduced glutathione (GSH), oxidized glutathione (GSSG), MJ33 (1-hexadecyl- 3-trifluoroethylglycero -sn-2-phosphomethanol), tris (2-carboxyethyl) phosphine (TCEP), dithiothreitol (DTT), and all other chemicals were purchased from Sigma-Aldrich (St. Louis, MO, USA).

\subsection{Production of Recombinant Prdx6}

The expression of human codon optimized Prdx6 plasmid pJexpress 414:75271—prdx6-optEc in Escherichia coli BL21 (DE3) (Novagen, Madison, WI, USA) has been described previously [25]. The purification and identification of recombinant human Prdx6 protein was carried out by the modification of previously described methods for isolation of the rat and human proteins $[10,22,23,26]$. Purification of recombinant Prdx6 by chromatography utilized an ion exchange diethylaminoethyl (DEAE) column in a fast protein liquid chromatography (FPLC) AKTA purifier system controlled by Unicon 5.1 software (GE Healthcare Biosciences, Uppsala, Sweden). The column was equilibrated with $40 \mathrm{mM}$ Na-acetate buffer ( $\mathrm{pH}$ ) containing $1 \mathrm{mM}$ ethylenediaminetetraacetic acid (EDTA), 3\% glycerol, and $1 \mathrm{mM}$ TCEP. Since the isoelectric point for Prdx6 is $\sim 6.0$, it does not bind to positively charged DEAE resin at $\mathrm{pH} 5$ and the Prdx6 protein was collected from the flow-through. (The column was rejuvenated by eluting bound (non-Prdx6) proteins using a high salt solution (40 mM Na-acetate, $2 \mathrm{M} \mathrm{NaCl}, 1 \mathrm{mM}$ EDTA, 3\% glycerol, $1 \mathrm{mM}$ TCEP, pH 5) (see Supplemental Figure S1). The purified Prdx6 fraction was concentrated using a $10 \mathrm{kDa}$ molecular mass cut-off Amicon Ultra filter (Millipore, Billerica, MA, USA) followed by dialysis against $50 \mathrm{mM}$ Tris- $\mathrm{HCl}$ buffer $(\mathrm{pH} 8)$ containing $1 \mathrm{mM}$ EDTA, $3 \%$ glycerol, and $1 \mathrm{mM}$ TCEP with a $10 \mathrm{kDa}$ molecular mass cut-off Slide-A-Lyzer ${ }^{\circ}$ dialysis cassette (Pierce, Rockford, IL, USA). The preparation was evaluated by polyacrylamide gel electrophoresis (PAGE) stained with Coomassie blue (see Supplemental Figure S1). Immunoblots with monoclonal anti-Prdx6 as the primary and goat anti-mouse IgG as the secondary antibody were used to confirm the presence of Prdx6 in the purified protein preparation; the blots were analyzed and the purity in each band was calculated by the two-color Odyssey technique (LI-COR, Lincoln, NE, USA) [26]. The protein was stored at $-80{ }^{\circ} \mathrm{C}$ before use. For some studies, Prdx6 was phosphorylated by incubation with ERK2 in the presence of ATP and $\mathrm{MgCl}_{2}$, as described previously [22] or oxidized by treating the purified protein with $100 \mu \mathrm{M} \mathrm{H}_{2} \mathrm{O}_{2}$ for $15 \mathrm{~min}$.

\subsection{Measurement of aiPLA $A_{2}$ Activity}

The measurement of Prdx6-PLA 2 (aiPLA 2 ) activity has been described previously $[4,12,15,16]$. A liposomal preparation of lipids reflecting the composition of lung surfactant was used as the substrate for the assay. The lipid mixture contained DPPC, PC, Chol, and PG in the molar ratio 50:25:15:10; liposomes were labeled with tracer $\left[{ }^{3} \mathrm{H}-9,10\right.$-palmitate]-DPPC in the $s n-2$ position. This substrate was used for all assays, unless a different substrate is specifically indicated. Lipids that were dissolved in chloroform were evaporated to dryness under $\mathrm{N}_{2}$ onto the wall of a Corex glass centrifuge tube; the evaporated film was resuspended in $50 \mathrm{mM}$ Tris- $\mathrm{HCl}$ in phosphate-buffered saline (PBS), $\mathrm{pH} 7.4$, vigorously mixed, frozen, and thawed three times by alternating liquid $\mathrm{N}_{2}$ and a $50{ }^{\circ} \mathrm{C}$ water bath, and then extruded under pressure at $50{ }^{\circ} \mathrm{C}$ for 10 cycles through a $0.1 \mu \mathrm{m}$ pore size polycarbonate filter. 
Recovery of ${ }^{3} \mathrm{H}$ in the liposome preparation was $>95 \%$ of the original disintegrations per min (DPMs) that were added to the lipid mixture. Analysis with a dynamic light scattering (DLS) 90 Plus Particle size Analyzer (Brookhaven Instruments, Holtsville, NY, USA) showed a homogeneous population of unilamellar vesicles with a diameter of 100-120 nm. Liposomes were stored overnight at $4{ }^{\circ} \mathrm{C}$ before use.

In experiments, to study the role of an oxidized phospholipid substrate, oxidizable liposomes were generated with PLPC substituting for egg PC in the standard liposomes. These liposomes were exposed to an ${ }^{\bullet} \mathrm{OH}$-generating system $\left(10 \mu \mathrm{M} \mathrm{Cu}^{2+}\right.$ in the presence of $0.2 \mathrm{mM}$ ascorbate) [27] for $45 \mathrm{~min}$ at room temperature. The liposomes were dialyzed for $2 \mathrm{~h}$ against PBS ( $\mathrm{pH} 7.4$ ) using a Slide-A-Lyzer®dialysis cassette as above. These liposomes presumably contained PLPCOOH as an oxidized lipid component.

To measure PLA 2 activity, enzyme (Prdx6) in buffer (Tris-EGTA, pH 7.4) was pre-incubated for $15 \mathrm{~min}$ and the reaction was started by addition of substrate $\left({ }^{3} \mathrm{H}\right.$-labeled liposomes) for a $1 \mathrm{~h}$ incubation. Lipids were then extracted from the liposomal suspension, separated by thin layer chromatography (TLC), and the free fatty acid band was analyzed by scintillation counting. PLA 2 activity was calculated from the liberation of ${ }^{3} \mathrm{H}$-palmitic acid.

To measure PLA 2 activity under anaerobic conditions, the incubation medium first was purged of air in an N-EVAP (Organomation Assoc., Northborough, MA, USA) using a continuous flow of 100\% $\mathrm{N}_{2}$ for $10 \mathrm{~min} ; \mathrm{N}_{2}$ flow then was maintained during the pre-incubation and incubation periods.

\subsection{Mass Spectroscopy (ESI-MS and LC-MS/MS)}

Both hPrdx6 WT and hPrdx6 C91S were gel-filtered using two Superdex 75 (GE Healthcare, Chicago, IL, USA) columns that were connected in series and equilibrated in $10 \mathrm{mM}$ Tris, $100 \mathrm{mM}$ $\mathrm{NaCl}$, pH 7.4 (TBS), and maintained at $4{ }^{\circ} \mathrm{C}$. Each sample was diluted to $0.55 \mathrm{mg} / \mathrm{mL}$ in TBS, with or without addition of $5 \mathrm{mM}$ GSH (final concentration), $\mathrm{pH}$ 7.4. Samples were incubated for $1 \mathrm{~h}$ at $37^{\circ} \mathrm{C}$, and then stored at $0^{\circ} \mathrm{C}$. After $16-20 \mathrm{~h}$ of storage, TCEP (5 mM final concentration) was added to half of each sample. The samples were incubated for $30 \mathrm{~min}$ at $37^{\circ} \mathrm{C}$ and then stored on ice until analysis by electrospray ionization mass spectrometry (ESI MS). Prior to injection onto the liquid chromatography-mass spectroscopy (LC-MS) system, samples were diluted to $0.1 \mathrm{mg} / \mathrm{mL}$. A Dionex C4 Trap column and a self packed Poros C8 analytical column $(20 \mathrm{~cm})$ were interfaced directly with an Orbitrap XL operating at $100 \mathrm{~K}$ resolution. Thermo Xtract software (Thermo Fisher Scientific, Waltham, MA, USA) was used for deconvolution of the monoisotopic masses. A portion of each sample was alkylated with iodoacetamide, followed by denaturation with urea, reduction with DTT, and then alkylation with acrylamide. Samples were digested with trypsin and analyzed using liquid chromatography-tandem mass spectrometry (LC-MS/MS) using an LTQ-Orbitrap XL ${ }^{\mathrm{TM}}$ mass spectrometer (Thermo Fisher Scientific Waltham, MA, USA). Data was searched using MaxQuant software (Max Planck Institute of biochemistry, München, Germay). The following cysteine mass modifications were included in the search: iodoacetamide derivative, 57.0215 Da; acrylamide adduct, $71.0371 \mathrm{Da} ; 2$ oxidations, 31.9898 Da; 3 oxidations, $47.9847 \mathrm{Da}$. The intensity value from the MaxQuant output files for the variable modified cysteine containing peptides DFTPVCTTELGR (C47) and DINAYNCEEPTEK (C91) were plotted with the Excel program to show the relative quantitation for each peptide that was obtained after treatment of the protein with the different buffer conditions.

\subsection{Fluorescence Spectroscopy}

Fluorescence spectroscopy was performed with a spectrofluorometer (PTI, Photon Technology International, Lawrenceville, NJ, USA) equipped with a water bath temperature-controlled sample holder, a single-photon counting system for fluorescence intensity detection, and dual fluorescence and absorbance channels. Measurements were performed with $1 \mu \mathrm{M}$ protein at $22^{\circ} \mathrm{C}$ in microquartz fluorescence cuvettes with a path length of $0.3 \mathrm{~cm}$. Fluorescence was excited at $295 \mathrm{~nm}$ and recorded 
in the range of 310-450 $\mathrm{nm}$ (the emission spectrum of tryptophan) with a $1 \mathrm{~nm}$ slit width for both excitation and emission.

\subsection{Circular Dichroism (CD)}

Prdx6 (6.5 $\mu \mathrm{M}$ in $10 \mathrm{mM}$ Tris buffer, $\mathrm{pH}$ 7) was analyzed for CD in a fused quartz cell with a path length of $0.1 \mathrm{~cm}$ using a Chirascan ${ }^{\mathrm{TM}} \mathrm{CD}$ Spectrometer (Applied Photophysics Ltd. Surrey, UK). Protein with or without GSH or GSSG $(5 \mathrm{mM})$ was incubated for $1 \mathrm{~h}$ at room temperature in $10 \mathrm{mM}$ Tris buffer, pH 7. Spectra were recorded with three repeats in the far-ultraviolet region (190-260 nm) with a bandwidth of $1.0 \mathrm{~nm}$, a step size of $0.5 \mathrm{~nm}$, and an integration time of $30 \mathrm{~s}$.

\subsection{Statistical Analysis}

Data are expressed as means \pm standard error (SE). Differences between mean values were analyzed by two-tailed Student's $t$ test and they were considered statistically significant at $p<0.05$.

\section{Results}

\subsection{Effect of GSH on the PLA 2 Activity of Prdx6}

The $\mathrm{PLA}_{2}$ activity of recombinant human Prdx6 measured at $\mathrm{pH} 4 \mathrm{was} \sim 100 \mathrm{nmol} / \mathrm{min} / \mathrm{mg}$ protein (not shown), but it was $<1 \mathrm{nmol} / \mathrm{min} / \mathrm{mg}$ protein when measured at $\mathrm{pH} 7.4$ using the standard liposomal (non-oxidized) substrate described in Methods (Table 1). The addition of GSH (5 mM) to the incubation medium had no effect on aiPLA 2 activity at $\mathrm{pH} 4$ (not shown) but increased activity at $\mathrm{pH} 7.4$ to $\sim 50 \%$ of the $\mathrm{pH} 4$ value (Table 1). The stimulation of aiPLA 2 activity by GSH was seen at $\mathrm{pH}>5$ (Figure 1). Stimulation of activity was dependent on GSH concentration with maximal effect at $3 \mathrm{mM}$ GSH (Figure 1). GSH-stimulated activity was sensitive to MJ33, a known inhibitor of aiPLA 2 activity, while BEL, an inhibitor of some intracellular, $\mathrm{Ca}^{2+}$ independent PLA 2 enzymes, was ineffective (Table 1). The addition of oxidized GSH (GSSG) or the unrelated thiols, DTT, or TCEP, to the assay resulted in a relatively minor increase in aiPLA $\mathrm{A}_{2}$ activity that was not statistically different from control (Table 1).

Table 1. Effect of protein and substrate modifications on phospholipase $\mathrm{A}_{2}\left(\mathrm{PLA}_{2}\right)$ activity of peroxiredoxin $6(\operatorname{Prdx} 6)$ at $\mathrm{pH} 7.4$.

\begin{tabular}{|c|c|c|}
\hline \multirow[t]{2}{*}{ Condition } & \multicolumn{2}{|c|}{$\begin{array}{c}\mathrm{PLA}_{2} \text { Activity at } \mathrm{pH} 7.4 \\
\mathrm{nmol} / \mathrm{min} / \mathrm{mg}\end{array}$} \\
\hline & $-\mathrm{GSH}$ & $+\mathrm{GSH}$ \\
\hline Control & $0.3 \pm 0.06(6)$ & $51 \pm 1(6)$ \\
\hline +MJ33 & - & $19 \pm 2^{*}(3)$ \\
\hline$+\mathrm{BEL}$ & & $50 \pm 1(4)$ \\
\hline+ GSSG & $3.2 \pm 2.1(3)$ & - \\
\hline+ DTT & $2.0 \pm 1.4(3)$ & - \\
\hline+ TCEP & $0.5 \pm 0.1(3)$ & - \\
\hline Anaerobic & $0.2 \pm 0.1(4)$ & $0.2 \pm \overline{0.1} *(4)$ \\
\hline Liposomes with PLPC ${ }^{\dagger}$ & $0.3 \pm 0.02(6)$ & $48 \pm 1(6)$ \\
\hline Oxidized liposomes with PLPC $^{\dagger}$ & $100 \pm 1^{*}(3)$ & $100 \pm 1^{*}(3)$ \\
\hline Phosphorylated Prdx6 & $1220 \pm 6^{*}(3)$ & $1150 \pm 3^{*}(3)$ \\
\hline Oxidized Prdx6 & $100 \pm 3^{*}(3)$ & $99 \pm 1^{*}(3)$ \\
\hline
\end{tabular}

Human Prdx6 (2 $\mu \mathrm{g})$ was pre-incubated with reagents for $15 \mathrm{~min}$ and then PLA2 activity was measured at pH 7.4 in $\mathrm{Ca}^{2+}$ free buffer. Substrate was 3H-1,2-Bis palmitoyl-sn-glycero-3-phosphocholine (DPPC) in mixed unilamellar liposomes. When added, glutathione (GSH) and other sulfhydryls were at $5 \mathrm{mM}, \mathrm{MJ} 33$ at $3 \mathrm{~mol} \%$ of lipid, and BEL at $0.1 \mathrm{mM}$. Prdx6 was oxidized with $\mathrm{H} 2 \mathrm{O} 2$ or was phosphorylated with Erk2. Values are mean $\pm \mathrm{SE}$ for the number of experiments indicated in parentheses. ${ }^{*}$ Significantly different $(p<0.05)$ from corresponding control (plus or minus GSH). † Liposomes with 1-palmitoyl, 2-linoleoyl, sn-glycero-3-phosphocholine (PLPC) replacing egg phosphatidylcholine (PC). 

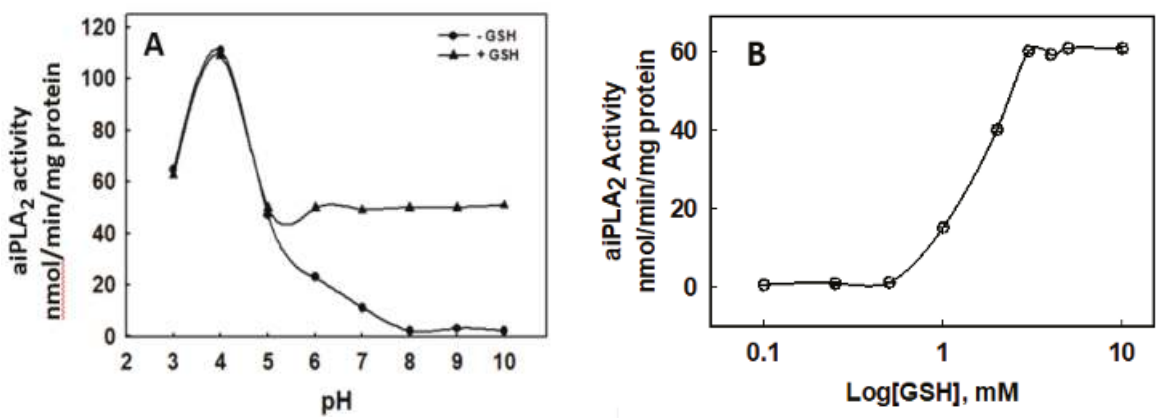

Figure 1. Glutathione (GSH) stimulates the PLA2 activity of Prdx6. (A). pH-dependence for the effect of GSH. GSH concentration was $5 \mathrm{mM}$. (B). Effect of GSH concentration on the stimulation of PLA 2 activity. The effect of GSH is maximal at $3 \mathrm{mM}$.

The basal activity and stimulation of activity by GSH at pH 7.4 was similar for control liposomes (DPPC as substrate) and liposomes containing linoleoyl in the $s n-2$ position of PC (PLPC) as the substrate for the $\mathrm{PLA}_{2}$ reaction (Table 1). As reported previously, aiPLA ${ }_{2}$ activity at $\mathrm{pH} 7.4$ with oxidized PLPC (i.e., PLPCOOH) as the liposomal substrate was significantly increased when compared to control $[17,23]$ and it was increased to a much greater extent with the phosphorylation of $\operatorname{Prdx6}[21,22]$. Oxidation of the Prdx6 protein increased its aiPLA ${ }_{2}$ activity with reduced substrate to the same level as with oxidized liposomes. Activity with PLPCOOH substrate, phosphorylated Prdx6, or with oxidized Prdx6 was not increased further in the presence of GSH (Table 1).

\subsection{Molecular $\mathrm{O}_{2}$ is Required for Generation of the Sulfinic Prdx6}

We postulated that the generation of the sulfinic form of Prdx6 in the presence of GSH represented auto-oxidation of the sulfenic form of the protein. To test this hypothesis, the assay for aiPLA $\mathrm{A}_{2}$ activity was carried out under anaerobic conditions. The aiPLA $\mathrm{A}_{2}$ activity of the protein was markedly inhibited in the absence of $\mathrm{O}_{2}$ (Table 1). The failure of aiPLA ${ }_{2}$ activity to increase in the presence of GSH under anaerobic conditions is compatible with a requirement of molecular oxygen for the oxidation of the sulfenic Prdx6. It is likely that the actual oxidant under aerobic conditions is $\mathrm{H}_{2} \mathrm{O}_{2}$, generated from molecular $\mathrm{O}_{2}$ in the presence of trace metals [28].

\subsection{Prdx6 Modifications in the Presence of GSH Evaluated by ESI-MS and LC-MS/MS}

The effect of GSH on the mass of Prdx6 as well as C91S-Prdx6 was determined using ESI MS (Figure 2). C91 is a non-conserved Cys residue that is present in the human-derived Prdx6 protein used in the present study but in most mammalian species, including rat, mouse and bovine Prdx6; C47 is the lone Cys residue [6]. The conserved peroxidatic Cys (C47) also is the only Cys group that is present in recombinant human C91S-Prdx6 protein. The observed monoisotopic mass for both Prdx6 and C91S-Prdx6 in Tris buffered saline (TBS) deviated by -2 Da from the predicted monoisotopic mass of the sulfhydryl (Figure 2A), as we have published previously [26]. These results are consistent with oxidation of the protein to the sulfenic form, followed by the loss $\mathrm{of}_{2} \mathrm{O}$ and formation of a sulfenylamide between the reactive Cys47 and an adjacent amino acid residue, possibly Thr 48 . In the presence of TCEP, the sulfenylamide bond is reduced, yielding proteins with the expected monoisotopic mass for Prdx6 and for C91S-Prdx6 (sulfhydryl forms). 


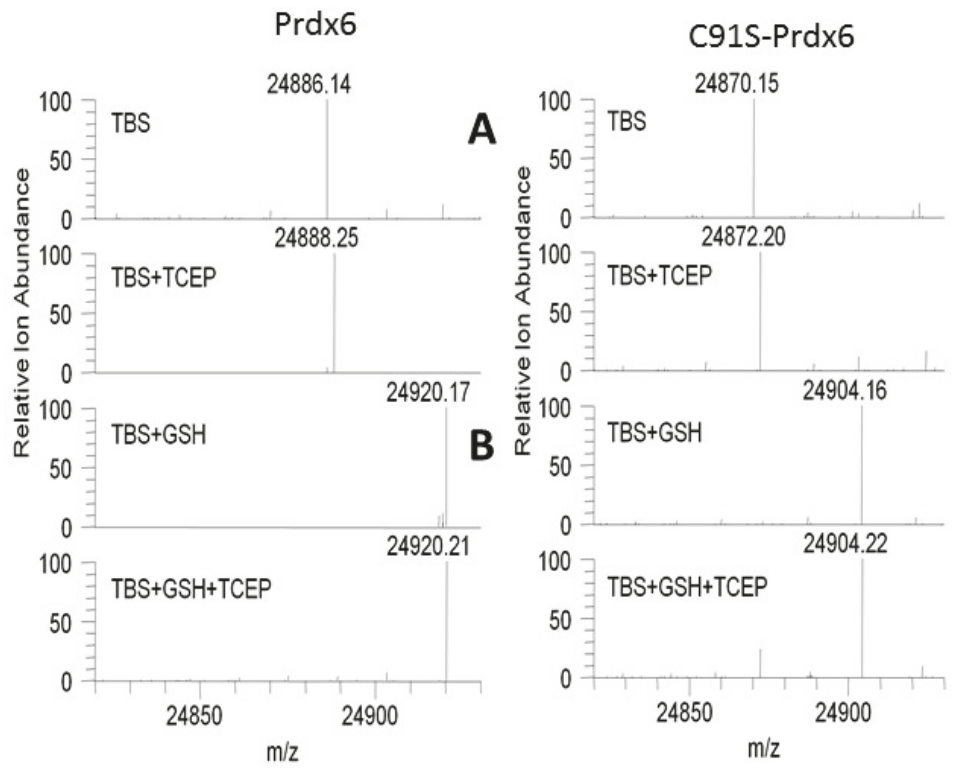

Figure 2. Electrospray ionization mass spectrometry (ESI MS) of wild type and C91S Prdx6. (A) upper 4 panels). Effect of tris (2-carboxyethyl) phosphine (TCEP) on protein mass. The addition of TCEP resulted in an increase of $2 \mathrm{Da}$ in molecular mass of both wild type and C47S-Prdx6. (B) lower 4 panels). Effect of glutathione (GSH) + / TCEP on protein mass. The addition of GSH resulted in a mass increase of $34 \mathrm{Da}$; there was no further effect with addition of TCEP in the presence of GSH. TBS. tris-buffered saline. A and $\mathbf{B}$ were part of the same experiment; A, but not $\mathbf{B}$, was published previously [26] and it is reprinted with permission.

In the presence of GSH added to Prdx6 in TBS solution, the molecular mass of the protein increased to 24,920 , a gain of $34 \mathrm{Da}$ (Figure 2B). Our interpretation of this result is that the addition of GSH leads to reversal of the sulfenylamide to reform the sulfenic (+18 mass increase) and the subsequent oxidation of the sulfenic to sulfinic with the addition of an oxygen atom (+16 Da mass increase) accounts for the total increase in mass. A similar increase in mass of $34 \mathrm{Da}$ in the presence of GSH was seen for C91S-Prdx6, indicating that the non-conserved Cys91 residue does not participate in the reactions, leading to the change in mass. Thus, the $C 47$ residue in the Prdx6 proteins is paradoxically converted to a sulfinic acid (Cys-SOOH) in the presence of $\mathrm{GSH}$; this sulfinic acid is not reduced by the subsequent addition of TCEP (Figure 2B).

The formation of a sulfinic acid at Cys47 of Prdx6 was confirmed by alkylation of the cysteine residues in Prdx6 with iodoacetamide, followed by denaturation, reduction, and alkylation with acrylamide, trypsin digestion, and then analysis by liquid chromatography-tandem mass spectrometry (LC-MS/MS) in order to determine the levels of reduced, accessible cysteine (see Supplemental Figure S2). The presence of a sulfinic acid in the C47-containing digestion product of Prdx6 (i.e., the peptide DFTPVCTTELGR) was observed in the presence of GSH (with or without TCEP), but sulfinic acid was not observed in the peptide containing C91 (i.e., the peptide DINAYNCEEPTEK).

\subsection{GSH Induces Changes in Tryptophan Fluorescence and Circular Dichroism (CD) in hPrdx6}

We examined potential changes in Prdx6 structure following the addition of GSH. Prdx6 has three tryptophan residues, two of which are in close proximity to the enzymatically active sites for peroxidase (C47) and PLA 2 (S32) activities [12]. A change in tryptophan fluorescence is presumed to reflect a change in the local environment of tryptophan residues in the protein [29]. The addition of 
GSH resulted in a decrease of fluorescence intensity (Figure 3), which is compatible with the exposure of a tryptophan residue to a more polar environment [30]. There was no change in Trp fluorescence following the addition of GSSG.

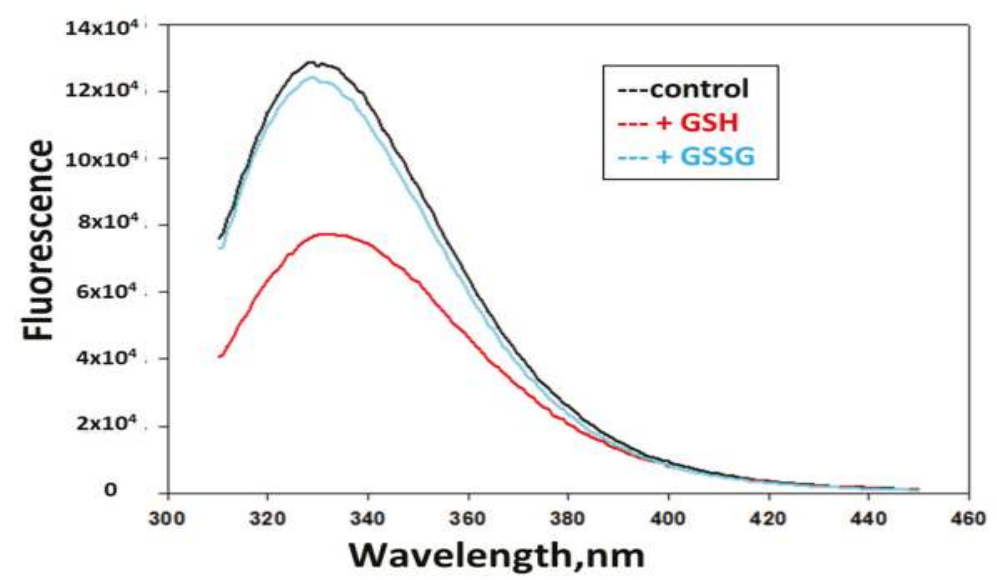

Figure 3. Effect of glutathione (GSH) and oxidized GSH (GSSG) on trptophan fluorescence emission of Prdx6 at $\mathrm{pH} 7$. There is decreased fluorescence of Prdx6 in the presence of GSH while the presence of GSSG had no effect.

The far UV circular dichroism (CD) profile of Prdx6 was also used to evaluate the effect of GSH addition on protein structure. Ignoring the noise below $215 \mathrm{~nm}$, the results show that GSH, but not GSSG, induces a change in signal in the $210-240 \mathrm{~nm}$ region of the CD spectrum (Figure 4). This change reflects a decrease in the $\alpha$-helical content of Prdx6.

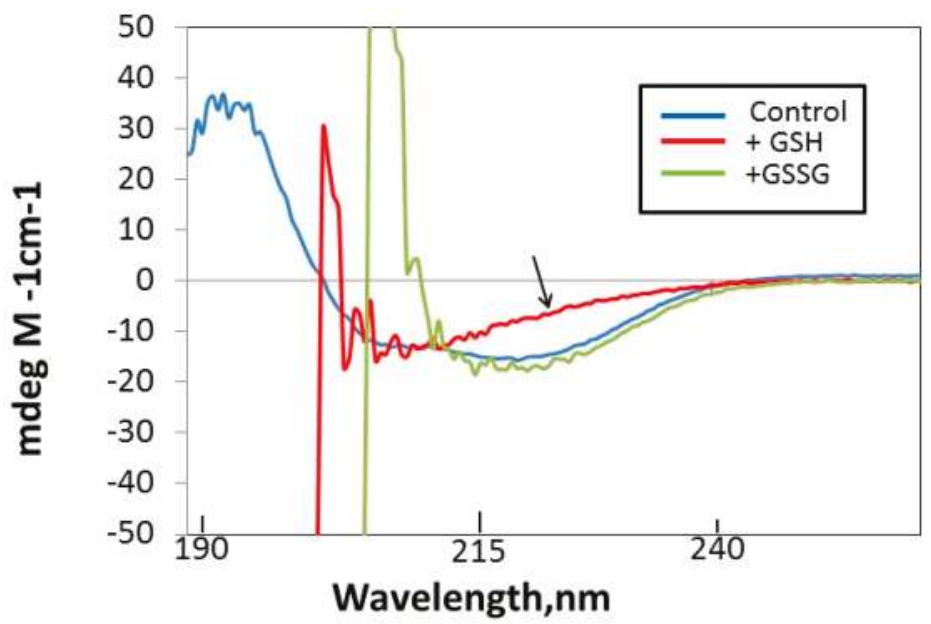

Figure 4. GSH-induced change in the secondary structure of Prdx6 as evaluated by far UV circular dichroism (CD). There is decreased (negative) molar ellipticity at 210-240 $\mathrm{nm}$ in the presence of GSH (arrow); there was no effect of GSSG at this wavelength. 


\subsection{PLA 2 Activity with Protein Modification}

The PLA 2 activity of Prdx6 at pH 7.4 was increased by the oxidation of the protein through its exposure to $\mathrm{H}_{2} \mathrm{O}_{2}$ (Table 1). This increase in activity at $\mathrm{pH} 7.4$ with oxidized Prdx6 was about double the GSH-induced increase that was seen with non-oxidized Prdx6. Activity at $\mathrm{pH} 4$ with oxidized Prdx6 was $102 \pm 2(n=3)$, similar to the value at $\mathrm{pH} 7.4$. There was no effect of GSH on aiPLA 2 activity with either the oxidized protein or the oxidized substrate at either $\mathrm{pH}$.

As we have shown previously, phosphorylation of Prdx6 also results in a marked increase in its aiPLA ${ }_{2}$ activity [22]. The increase in activity at $\mathrm{pH} 4$ was $\sim 20$-fold and, fold-wise, was considerably greater at pH 7.4 (Table 1), so that the resultant activities of phosphorylated Prdx6 were similar at acidic and basic pHs [21,23]. This increased activity with Prdx6 phosphorylation greatly exceeded the increase in activity with Prdx6 oxidation.

\section{Discussion}

The major finding of the present study was that the addition of GSH to the medium that was used for assay of the PLA 2 activity of Prdx6 resulted in: a) a physical change of protein structure, as shown by tryptophan fluorescence and far UV circular dichroism; b) the irreversible oxidation of the protein to the sulfinic acid (as indicated by MS analysis); and, c) an increase of its $\mathrm{PLA}_{2}$ activity at neutral $\mathrm{pH}$. The increased aiPLA 2 activity in the presence of GSH was inhibited by MJ33, a mimic of the enzymatic transition state for some PLA 2 enzymes and a known inhibitor of aiPLA $\mathrm{A}_{2}$ activity [31,32]. These results provide evidence that the catalytic mechanisms for stimulated $\mathrm{PLA}_{2}$ activity at $\mathrm{pH} 7$ and basal activity at $\mathrm{pH} 4$ are similar. Stimulation aiPLA 2 activity at $\mathrm{pH} 7$ appeared to be specific for GSH, since other sulfhydryls (GSSG, DTT, TCEP) were ineffective. Based on these results that confirmed a previous report [24], we conclude that GSH exerts its stimulatory effect on aiPLA 2 activity through oxidation of the protein (Prdx6).

Although this effect of GSH to promote Prdx6 oxidation initially was surprising, since GSH is a mild reductant, further consideration led us to propose the following mechanism. Based on the MS analysis, recombinant Prdx6 after purification and storage was oxidized to the sulfenylamide, a form that has been shown to "protect" some proteins against further auto-oxidation [33]; in the case of Prdx6, the auto-oxidizable site is C47, the active site for peroxidase activity. The Prdx6 sulfenylamide is formed by the oxidation of the thiol to the sulfenyl that rapidly reacts with an adjacent amine in the protein to form the stable sulfenylamide [25]; the specific amino group that was involved in this reaction has not yet been determined. The mechanism for auto-oxidation has been shown to reflect primarily the presence of trace metals $[28,34,35]$. In the presence of TCEP, the sulfenylamide state of the protein can be reversed first to the sulfenic and then reduced to the sulfhydryl; auto-oxidation of the protein under these conditions is prevented by the presence of the strong reductant (TCEP). GSH also is able to reverse sulfenylamide formation, as shown in previous studies with the enzyme protein tyrosine phosphatase B1 (PTPB1) [36]. This reversal reaction likely proceeds through the formation of a disulfide between GSH and the sulfenylamide to form a glutathionylated protein followed by hydrolysis to regenerate the sulfenyl [28]. However, GSH is a relatively weak reductant that cannot, by itself, reduce the sulfenic $[3,10]$, and therefore cannot protect the protein against further oxidation to the sulfinic (and possibly sulfonic) form. Under physiological conditions in vivo, catalysis by glutathione S-transferase (GST) in the presence of GSH regenerates the sulfhydryl, thereby preventing its irreversible oxidation $[10,37,38]$. However, with severe oxidative stress or with GST deficiency, oxidation of Prdx6 could occur in vivo, resulting in a significant increase of intracellular aiPLA $A_{2}$ activity. It is important to note that this increase in aiPLA 2 activity would be accompanied by loss of the GSH peroxidase activity of Prdx6 due to irreversible inactivation of the catalytic Cys 47.

The reactions of Prdx6 that occur in vitro in the absence of GST are shown in Figure 5. To summarize these reactions, exposure of the protein to air during the isolation and storage of recombinant Prdx6 results in the oxidation of the thiol to an unstable sulfenylated protein that rapidly dehydrates to a stable sulfenylamide (reactions 1 and 2). The oxidant (shown as $\mathrm{H}_{2} \mathrm{O}_{2}$ in the figure) is 
generated from atmospheric $\mathrm{O}_{2}$ in the presence of trace metals [27,34,35]. Following the addition of $\mathrm{GSH}$, there is regeneration of the sulfenic protein (reactions 3 and 4). In the presence of GSH, the rate of $\mathrm{H}_{2} \mathrm{O}_{2}$ generation through metal-catalyzed auto-oxidation is greatly increased [34], and the sulfenic can be oxidized to the sulfinic form (reaction 5). The irreversible formation of the sulfinic in the presence of GSH pulls the reaction cycle toward oxidation. Thus, the end result is Prdx6 over-oxidation following the addition of GSH to the protein in vitro, in the absence of GST. Under physiologic conditions in the presence of cellular GST plus GSH, the heterodimerization of Prdx6 with GST leads to a reduction of Prdx6 to the native sulfhydryl (reactions not shown) [26].

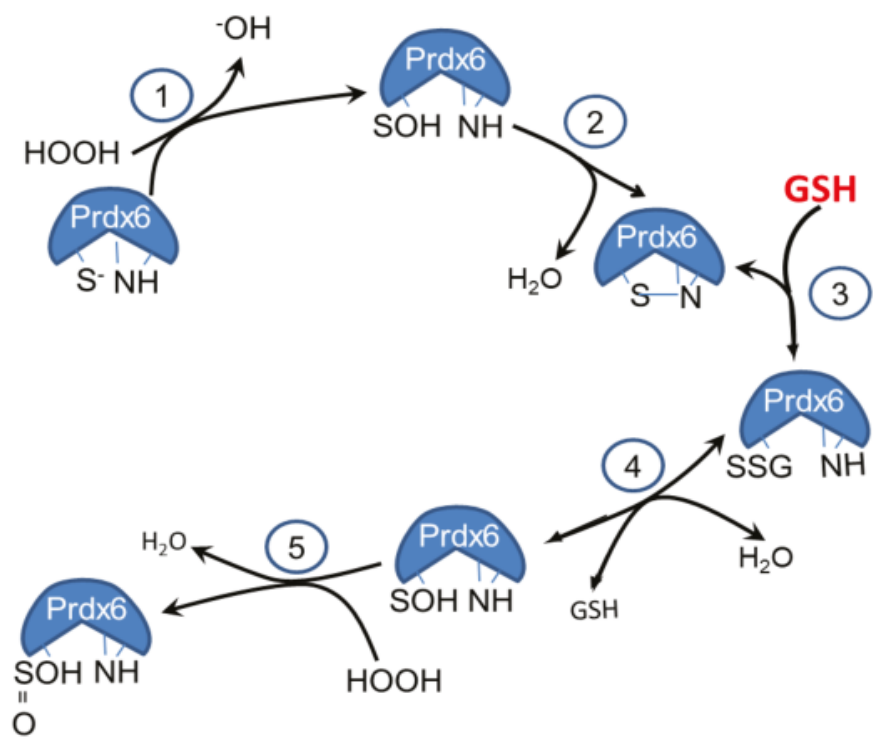

Figure 5. Reactions of Prdx6 with GSH in vitro. Reactions 1 and 2 occur during isolation of Prdx6 in the absence of GSH and GST; auto-oxidation of the protein by oxidant generation (shown here as $\mathrm{HOOH}$ ) in the presence of trace metals leads to the formation of the Prdx6 sulfenic acid (reaction 1) and then dehydration to form the sulfenylamide (reaction 2). Reaction 2 is rapid when compared to the relatively slow rate of $\mathrm{H}_{2} \mathrm{O}_{2}$ formation (reaction 5 in the absence of $\mathrm{GSH}$ ). Reactions 3 and 4 occur in vitro following the addition of GSH in the absence of GST. The sulfenylamide is reversed through glutathionylation of the protein (reaction 3), followed by reformation of the sulfenic acid (reaction 4). The rate of $\mathrm{H}_{2} \mathrm{O}_{2}$ generation is greatly enhanced in the presence of GSH [34], resulting in the oxidation of the sulfenic to the sulfinic (reaction 5 in the presence of GSH).

Similarly to the effect of GSH addition to the assay medium, oxidation of the protein by treatment with $\mathrm{H}_{2} \mathrm{O}_{2}$ prior to the assay also resulted in increased PLA 2 activity (Table 1). A similar result was reported previously that used mutagenesis to show that the increase of activity with $\mathrm{H}_{2} \mathrm{O}_{2}$ treatment required the presence of $\mathrm{C} 47$ in $\operatorname{Prdx6}$ [24]. aiPLA 2 activity in the present study also was increased in the presence of a peroxidized lipid substrate (PLPCOOH), confirming our previous report [23]. Thus, several different reactions demonstrate a similar mechanism to stimulate aiPLA $\mathrm{A}_{2}$ activity in vitro, namely the oxidation of the conserved Cys of Prdx6. These oxidative reactions include: (1) the presence of GSH; (2) pretreatment of the enzyme with $\mathrm{H}_{2} \mathrm{O}_{2}$; or, (3) use of PLPCOOH as the liposomal substrate. Each of these assay conditions in the absence of GST would be expected to result in the oxidation of the C47 of Prdx6.

These findings reflect on the catalytic cycle for peroxidase activity. The reaction of $\mathrm{H}_{2} \mathrm{O}_{2}$ or a hydroperoxide substrate with Prdx6 will result in the formation of a sulfenic acid intermediate as the 
first step in the reduction of the oxidized lipid through peroxidase catalysis. In the absence of GST, the reaction cycle cannot be completed and the sulfenyl protein is susceptible to further oxidation, as shown previously using specific antibodies for the over-oxidized state of Prdx6 [23]. The presence of GST plus GSH prevents over-oxidation and it returns Prdx6 to its native sulhydryl form, thereby completing the peroxidase reaction cycle and preserving its peroxidase function.

Nevertheless, how does Cys oxidation affect aiPLA 2 activity since the C47 residue in Prdx6, while being crucial for its peroxidatic function, has no direct role in the $\mathrm{PLA}_{2}$ reaction? Although our previous studies have shown that reduced (non-oxidized) phospholipid substrate does not bind at $\mathrm{pH} 7$, it does bind to Prdx6 at $\mathrm{pH} 4$; on the other hand, oxidized phospholipids bind to Prdx6 equally at acidic and neutral $\mathrm{pH}$ [23]. $\mathrm{C} 47$ is present as a thiolate at $\mathrm{pH} 7$, but it is protonated to a sulfhydryl at $\mathrm{pH} 4$, possibly resulting in changes in structure that facilitate the binding of substrate [2]. These binding data directly correlate with aiPLA $\mathrm{A}_{2}$ activity. Binding of reduced substrate at $\mathrm{pH} 4$ results in $\mathrm{PLA}_{2}$ activity, while binding of an oxidized phospholipid at $\mathrm{pH} 7$ can result in $\mathrm{PLA}_{2}$ as well as peroxidase activity.

Crystal structure analysis has provided some insights into substrate binding [39]. The crystal structure of the sulfenic protein shows that the active site for Prdx6 binding (and aiPLA 2 -mediated catalysis) is on the protein surface and it is connected to the peroxidatic site by a narrow pocket. We have postulated that the oxidized phospholipid substrate is positioned for activity by binding of the head group to the protein surface and the insertion of the oxidized $s n-2$ fatty acid chain inside of the pocket [12]. On the other hand, crystal structural analysis of oxidized (sulfinic) Prdx6 indicates almost 10 angstroms distance between the H26 and S32 sites that were proposed for phospholipid binding. Because of this relatively long distance, it was suggested that the phospholipid actually may bind to the flat surface across the PLA 2 active site and the peroxidatic active site of the other monomer [40]. However, several factors may modify the protein structure and its interaction with substrate. For example, over-oxidation of $\mathrm{C} 47$ to the sulfinic alters the Prdx6 secondary structure, as shown by $\mathrm{CD}$ analysis in this report. Further, the oxidation of $\mathrm{C} 47$ results in decreased affinity for homodimerization of the protein, resulting in an increased tendency for monomer formation [26]. Finally, phosphorylation (at T177) may lead to structural changes that alter the distance between the crucial amino acids [22]. We have shown, while using a zero-length chemical cross-linking and homology methodology, that several regions of reduced human PRDX6 are in a substantially different conformation from that shown for the crystal structure of the peroxidase catalytic intermediate [41]. Thus, the protein shows considerable plasticity and it can change conformation depending on many variables that could affect Prdx6-substrate interactions. The variable states of Prdx6 require further study before making definitive conclusions concerning the site and mechanism for binding of the phospholipid substrate to the enzyme.

\section{Conclusions}

Isolated recombinant human Prdx6 undergoing auto-oxidation to the sulfenic can form a sulfenylamide, a protected state that prevents auto-oxidation. The addition of GSH results in the regeneration of the sulfenic form that can be irreversibly oxidized to the sulfinic by oxidants that are produced through metal catalyzed auto-oxidation; the generation of oxidants through auto-oxidation occurs at a significantly increased rate in the presence of GSH. Over-oxidation of Prdx6 to the sulfinic results in a marked increase of its aiPLA 2 activity at neutral $\mathrm{pH}$, as shown previously [24] and in this manuscript.

Supplementary Materials: The following are available online at http:/ /www.mdpi.com/2076-3921/8/1/4/s1, Figure S1: Purification of codon optimized recombinant human Prdx6 with an ion-exchange (DEAE cellulose) column, Figure S2: Relative quantitation based on the intensity of modified peptides from LC-MS/MS data analysis after treatment with GSH (+/ -TCEP). 
Author Contributions: Formulated research plan (A.B.F., D.W.S.); generated recombinant Prdx6 (S.I.F., S.Z.); performed experiments (C.D., S.Z., S.H.); interpreted experimental results (A.B.F., S.Z., D.W.S., S.H., H.J.F.); wrote the manuscript (A.B.F., S.Z.).

Funding: This research was supported by grant R01-HL102016 (P.I., A.B.F.) and P30-CA10815 (core Grant to the Wistar Institute), both from the National Institutes of Health of the United States.

Acknowledgments: We thank Yefim Manevich for the original observation suggesting lipase activity during assay of the peroxidase, Shampa Chatterjee and Haitao Li for helpful discussions, Tea Shuvaeva for assistance with the preparation of recombinant Prdx6, and Dawn Williams for assistance with manuscript preparation. The current affiliation of S.Z. is St. Jude Children's Research Hospital, Memphis, TN.

Conflicts of Interest: S.I.F. and A.B.F. have a patent application pending for a peptide inhibitor of peroxiredoxin 6 $\mathrm{PLA}_{2}$ activity and have part ownership of a start-up company to promote clinical use of the peptide inhibitor.

\section{References}

1. Rhee, S.G.; Chae, H.Z.; Kim, K. Peroxiredoxins: A historical overview and speculative preview of novel mechanisms and emerging concepts in cell signaling. Free Radic. Biol. Med. 2005, 38, 1543-1552. [CrossRef] [PubMed]

2. Rhee, S.G.; Woo, H.A.; Kil, I.S.; Bae, S.H. Peroxiredoxin functions as a peroxidase and a regulator and sensor of local peroxides. J. Biol. Chem. 2012, 287, 4403-4410. [CrossRef] [PubMed]

3. Rhee, S.G.; Kang, S.W.; Chang, T.S.; Jeong, W.; Kim, K. Peroxiredoxin, a novel family of peroxidases. IUBMB Life 2001, 52, 35-41. [CrossRef] [PubMed]

4. Kim, T.S.; Dodia, C.; Chen, X.; Hennigan, B.B.; Jain, M.; Feinstein, S.I.; Fisher, A.B. Cloning and expression of rat lung acidic $\mathrm{Ca}^{2+}$-independent PLA2 and its organ distribution. Am. J. Physiol. Lung Cell. Mol. Physiol. 1998, 274, L750-L761. [CrossRef]

5. Singh, A.K.; Shichi, H. A novel glutathione peroxidase in bovine eye. Sequence analysis, mRNA level, and translation. J. Biol. Chem. 1998, 273, 26171-26178. [CrossRef] [PubMed]

6. Fisher, A.B. Peroxiredoxin 6: A bifunctional enzyme with glutathione peroxidase and phospholipase $\mathrm{A}_{2}$ activities. Antioxid. Redox Signal. 2011, 15, 831-844. [CrossRef] [PubMed]

7. Fisher, A.B. Peroxiredoxin 6 in the repair of peroxidized cell membranes and cell signaling. Arch. Biochem. Biophys. 2017, 617, 68-83. [CrossRef]

8. Chen, J.W.; Dodia, C.; Feinstein, S.I.; Jain, M.K.; Fisher, A.B. 1-Cys peroxiredoxin, a bifunctional enzyme with glutathione peroxidase and phospholipase $\mathrm{A}_{2}$ activities. J. Biol. Chem. 2000, 275, 28421-28427. [CrossRef]

9. Fisher, A.B.; Dodia, C.; Manevich, Y.; Chen, J.W.; Feinstein, S.I. Phospholipid hydroperoxides are substrates for non-selenium glutathione peroxidase. J. Biol. Chem. 1999, 274, 21326-21334. [CrossRef]

10. Manevich, Y.; Feinstein, S.I.; Fisher, A.B. Activation of the antioxidant enzyme 1-Cys peroxiredoxin requires glutathionylation mediated by heterodimerization with pi GST. Proc. Natl. Acad. Sci. USA 2004, 101, 3780-3785. [CrossRef]

11. Manevich, Y.; Fisher, A.B. Peroxiredoxin 6, a 1-Cys peroxiredoxin, functions in antioxidant defense and lung phospholipid metabolism. Free Radic. Biol. Med. 2005, 38, 1422-1432. [CrossRef] [PubMed]

12. Manevich, Y.; Reddy, K.S.; Shuvaeva, T.; Feinstein, S.I.; Fisher, A.B. Structure and phospholipase function of peroxiredoxin 6: Identification of the catalytic triad and its role in phospholipid substrate binding. J. Lipid Res. 2007, 48, 2306-2318. [CrossRef] [PubMed]

13. Fisher, A.B.; Dodia, C.; Sorokina, E.M.; Li, H.; Zhou, S.; Raabe, T.; Feinstein, S.I. A novel lysoPhosphatidylcholine acyl transferase activity is expressed by peroxiredoxin 6. J. Lipid Res. 2016, 57, 587-596. [CrossRef] [PubMed]

14. Fisher, A.B.; Dodia, C.; Feinstein, S.I.; Ho, Y.S. Altered lung phospholipid metabolism in mice with targeted deletion of lysosomal-type phospholipase A2. J. Lipid Res. 2005, 46, 1248-1256. [CrossRef] [PubMed]

15. Akiba, S.; Dodia, C.; Chen, X.; Fisher, A.B. Characterization of acidic $\mathrm{Ca}^{2+}$-independent phospholipase $\mathrm{A}_{2}$ of bovine lung. Comp. Biochem. Physiol. B Biochem. Mol. Biol. 1998, 120, 393-404. [CrossRef]

16. Fisher, A.B.; Dodia, C. Role of phospholipase $\mathrm{A}_{2}$ enzymes in degradation of dipalmitoylphosphatidylcholine by granular pneumocytes. J. Lipid Res. 1996, 37, 1057-1064. [PubMed]

17. Li, H.; Benipal, B.; Zhou, S.; Dodia, C.; Chatterjee, S.; Tao, J.Q.; Sorokina, E.M.; Raabe, T.; Feinstein, S.I.; Fisher, A.B. Critical role of peroxiredoxin 6 in the repair of peroxidized cell membranes following oxidative stress. Free Radic. Biol. Med. 2015, 87, 356-365. [CrossRef] 
18. Fisher, A.B.; Vazquez-Medina, J.P.; Dodia, C.; Sorkina, E.M.; Tao, J.Q.; Feinstein, S.I. Peroxiredoxin 6 phospholipid hydroperoxidase acvity in the repair of peroxidized cell membranes. Redox Biol. 2017, 14, 41-46. [CrossRef]

19. Chatterjee, S.; Feinstein, S.I.; Dodia, C.; Sorokina, E.; Lien, Y.C.; Nguyen, S.; Debolt, K.; Speicher, D.; Fisher, A.B. Peroxiredoxin 6 phosphorylation and subsequent phospholipase $A_{2}$ activity are required for agonist-mediated activation of NADPH oxidase in mouse pulmonary microvascular endothelium and alveolar macrophages. J. Biol. Chem. 2011, 286, 11696-11706. [CrossRef]

20. Vazquez-Medina, J.P.; Dodia, C.; Weng, L.; Mesaros, C.; Blair, I.; Feinstein, S.I.; Chatterjee, C.; Fisher, A. The phospholipase $\mathrm{A}_{2}$ activity of peroxiredoxin 6 modulates NADPH oxidase 2 activation via lysophosphatidic acid receptor signaling in the pulmonary endothelium and alveolar macrophages. FASEB J. 2016, 30, 2885-2898. [CrossRef]

21. Wu, Y.; Feinstein, S.I.; Manevich, Y.; Chowdhury, I.; Pak, J.H.; Kazi, A.; Dodia, C.; Speicher, D.W.; Fisher, A.B. Mitogen-activated protein kinase-mediated phosphorylation of peroxiredoxin 6 regulates its phospholipase $\mathrm{A}_{2}$ activity. Biochem. J. 2009, 419, 669-679. [CrossRef] [PubMed]

22. Rahaman, H.; Zhou, S.; Dodia, C.; Feinstein, S.I.; Huang, S.; Speicher, D.; Fisher, A.B. Increased phospholipase $\mathrm{A}_{2}$ activity with phosphorylation of peroxiredoxin 6 requires a conformational change in the protein. Biochemistry 2012, 51, 5521-5530. [CrossRef] [PubMed]

23. Manevich, Y.; Shuvaeva, T.; Dodia, C.; Kazi, A.; Feinstein, S.I.; Fisher, A.B. Binding of peroxiredoxin 6 to substrate determines differential phospholipid hydroperoxide peroxidase and phospholipase $\mathrm{A}_{2}$ activities. Arch. Biochem. Biophys. 2009, 485, 139-149. [CrossRef] [PubMed]

24. Kim, S.Y.; Jo, H.Y.; Kim, M.H.; Cha, Y.Y.; Choi, S.W.; Shim, J.H.; Kim, T.J.; Lee, K.Y. $\mathrm{H}_{2} \mathrm{O}_{2}$-dependent hyperoxidation of peroxiredoxin $6(\operatorname{Prd} \times 6)$ plays a role in cellular toxicity via up-regulation of iPLA2 activity. J. Biol. Chem. 2008, 283, 33563-33568. [CrossRef] [PubMed]

25. Wu, Y.Z.; Manevich, Y.; Baldwin, J.L.; Dodia, C.; Yu, K.; Feinstein, S.I.; Fisher, A.B. Interaction of surfactant protein A with peroxiredoxin 6 regulates phospholipase $A_{2}$ activity. J. Biol. Chem. 2006, 281, 7515-7525. [CrossRef] [PubMed]

26. Zhou, S.; Sorokina, E.; Harper, S.; Ralat, L.; Dodia, C.; Speicher, D.; Feinstein, S.I.; Fisher, A. Peroxiredoxin 6 homodimerization and heterodimerization with glutathione $\mathrm{S}$-transferase pi are required for its peroxidase but not phospholipase $\mathrm{A}_{2}$ activity. Free Radic. Biol. Med. 2016, 94, 145-156. [CrossRef] [PubMed]

27. Manevich, Y.; Sweitzer, T.; Pak, J.H.; Feinstein, S.I.; Muzykantov, V.; Fisher, A.B. 1-Cys peroxiredoxin overexpression protects cells against phospholipid peroxidation-mediated membrane damage. Proc. Natl. Acad. Sci. USA 2002, 99, 11599-11604. [CrossRef]

28. Forman, H.J.; Davies, M.J.; Kramer, A.C.; Miotto, G.; Zaccarin, M.; Zhang, H.; Ursini, F. Protein cysteine oxidation in redox signaling: Caveats on sulfenic acid detection and quantification. Arch. Biochem. Biophys. 2017, 617, 26-37. [CrossRef]

29. Lakowicz, J.R. Principles of Fluorescence Spectroscopy; Academic/Plenum: New York, NY, USA, 1999.

30. Vivian, J.T.; Callis, P.R. Mechanisms of tryptophan fluorescence shifts in proteins. Biophys. J. 2001, 80, 2093-2109. [CrossRef]

31. Fisher, A.B.; Dodia, C.; Chander, A.; Jain, M. A competitive inhibitor of phospholipase $\mathrm{A}_{2}$ decreases surfactant phosphatidylcholine degradation by the rat lung. Biochem. J. 1992, 288 (Pt. 2), 407-411. [CrossRef]

32. Jain, M.K.; Tao, W.J.; Rogers, J.; Arenson, C.; Eibl, H.; Yu, B.Z. Active-site-directed specific competitive inhibitors of phospholipase $\mathrm{A}_{2}$ : Novel transition-state analogues. Biochemistry 1991, 30, 10256-10268. [CrossRef] [PubMed]

33. Sivaramakrishnan, S.; Cummings, A.H.; Gates, K.S. Protection of a single-cysteine redox switch from oxidative destruction: On the functional role of sulfenyl amide formation in the redox-regulated enzyme PTP1B. Bioorg. Med. Chem. Lett. 2010, 20, 444-447. [CrossRef] [PubMed]

34. Albro, P.W.; Corbett, J.T.; Schroeder, J.L. Generation of hydrogen peroxide by incidental metal ion-catalyzed autooxidation of glutathione. J. Inorg. Biochem. 1986, 27, 191-203. [CrossRef]

35. Miller, D.M.; Buettner, G.R.; Aust, S.D. Transition metals as catalysts of "autoxidation" reactions. Free Radic. Biol. Med. 1990, 8, 95-108. [CrossRef]

36. Nagy, P.; Winterbourn, C. Advances in Molecular Toxicology. Redox Chem. Biol. Thiols 2010, 4, 183-222. 
37. Zhou, S.; Lien, Y.C.; Shuvaeva, T.; DeBolt, K.; Feinstein, S.I.; Fisher, A.B. Functional interaction of glutathione S-transferase pi and peroxiredoxin 6 in intact cells. Intern. J. Biochem. Cell. Biol. 2013, 45, 401-407. [CrossRef] [PubMed]

38. Ralat, L.A.; Manevich, Y.; Fisher, A.B.; Colman, R.F. Direct evidence for the formation of a complex between 1-cysteine peroxiredoxin and glutathione S-transferase pi with activity changes in both enzymes. Biochemistry 2006, 45, 360-372. [CrossRef]

39. Choi, H.J.; Kang, S.W.; Yang, C.H.; Rhee, S.G.; Ryu, S.E. Crystal structure of a novel human peroxidase enzyme at 2.0 A resolution. Nat. Struct. Biol. 1998, 5, 400-406. [CrossRef]

40. Kim, K.H.; Lee, W.; Kim, E.E. Crystal structures of human peroxiredoxin 6 in different oxidation states. Biochem. Biophys. Res. Commun. 2016, 477, 717-722. [CrossRef]

41. Rivera-Santiago, R.F.; Harper, S.L.; Zhou, S.; Sriswasdi, S.; Feinstein, S.I.; Fisher, A.B.; Speicher, D.W. Solution structure of the reduced form of human peroxiredoxin- 6 elucidated using zero-length chemical cross-linking and homology modelling. Biochem. J. 2015, 468, 87-98. [CrossRef]

(c) 2018 by the authors. Licensee MDPI, Basel, Switzerland. This article is an open access article distributed under the terms and conditions of the Creative Commons Attribution (CC BY) license (http:/ / creativecommons.org/licenses/by/4.0/). 
Review

\title{
The Role of Peroxiredoxin 6 in Cell Signaling
}

\author{
José A. Arevalo and José Pablo Vázquez-Medina *
}

Department of Integrative Biology, University of California, Berkeley, CA, 94705, USA; josearevalo@berkeley.edu

* Correspondence: jpv-m@berkeley.edu; Tel.: +1-510-664-5063

Received: 7 November 2018; Accepted: 20 November 2018; Published: 24 November 2018

check for updates

\begin{abstract}
Peroxiredoxin 6 ( $\operatorname{Prdx} 6,1$-cys peroxiredoxin) is a unique member of the peroxiredoxin family that, in contrast to other mammalian peroxiredoxins, lacks a resolving cysteine and uses glutathione and $\pi$ glutathione S-transferase to complete its catalytic cycle. Prdx6 is also the only peroxiredoxin capable of reducing phospholipid hydroperoxides through its glutathione peroxidase (Gpx) activity. In addition to its peroxidase activity, Prdx6 expresses acidic calcium-independent phospholipase $\mathrm{A}_{2}\left(\mathrm{aiPLA}_{2}\right)$ and lysophosphatidylcholine acyl transferase (LPCAT) activities in separate catalytic sites. Prdx6 plays crucial roles in lung phospholipid metabolism, lipid peroxidation repair, and inflammatory signaling. Here, we review how the distinct activities of Prdx6 are regulated during physiological and pathological conditions, in addition to the role of Prdx6 in cellular signaling and disease.
\end{abstract}

Keywords: glutathione peroxidase; phospholipase $\mathrm{A}_{2}$; inflammation; lipid peroxidation; NADPH (nicotinamide adenine dinucleotide phosphate) oxidase; phospholipid hydroperoxide

\section{Introduction}

Peroxiredoxins are a ubiquitous family of highly conserved enzymes that share a catalytic mechanism in which a redox-active (peroxidatic) cysteine residue in the active site is oxidized by a peroxide [1]. In peroxiredoxins 1-5 (2-cys peroxiredoxins), the resulting sulfenic acid then reacts with another (resolving) cysteine residue, forming a disulfide that is subsequently reduced by an appropriate electron donor to complete a catalytic cycle [2,3]. In contrast to peroxiredoxins 1-5, peroxiredoxin 6 (Prdx6, 1-cys peroxiredoxin) lacks a resolving cysteine and uses glutathione (GSH) to complete its catalytic peroxidatic reaction $[4,5]$. Aside from the mammalian $\operatorname{Prdx6}, 1$-cys peroxiredoxins that use GSH as the resolving thiol have been described in yeast [6].

Prdx6 is the only mammalian peroxiredoxin capable of reducing phospholipid hydroperoxides through its glutathione peroxidase (Gpx) activity, in addition to reducing short chain hydroperoxides [7]. Moreover, Prdx6 also expresses acidic calcium-independent phospholipase $\mathrm{A}_{2}\left(\mathrm{aiPLA}_{2}\right)$ and lysophosphatidylcholine acyl transferase (LPCAT) activities in separate catalytic sites $[8,9]$. Therefore, Prdx6 is a multi-tasking enzyme that participates in cellular signaling by modulating several pathways through its peroxidase, aiPLA , $_{2}$ and LPCAT activities. The three activities of Prdx6 are differentially regulated by the subcellular localization of the protein, substrate binding, and post-translational modifications [10]. Differential expression of the enzymatic activities of Prdx6 appears to have contrasting roles in several pathologies. Here, we review the current knowledge of the role of Prdx6 in cellular signaling. This publication is part of a forum on Prdx6 as a unique member of the peroxiredoxin family. 


\section{Regulation of the Enzymatic Activities of Prdx6}

The subcellular localization of Prdx6 is crucial for the regulation of its enzymatic activities. Prdx6 exhibits maximal aiPLA $\mathrm{A}_{2}$ activity at an acidic $\mathrm{pH}$ and maximal peroxidase activity at a neutral $\mathrm{pH}$ [10]. Hence, when Prdx6 is localized in lysosomal-type organelles such as lamellar bodies in type II pneumocytes, it functions as an aiPLA ${ }_{2}$, contributing to lung phospholipid metabolism [11]. In contrast, cytosolic Prdx6 functions mainly as a peroxidase under basal conditions [4]. Aside from the cytosol and lysosomal-type organelles, Prdx6 can move to the mitochondria, the plasma membrane, and possibly other organelles, after cellular stimulation with different agonists [12,13]. Prdx6 translocation to the mitochondria controls oxidative stress in the initial step of PINK1/Parkin-mediated mitophagy [14]. $\operatorname{Prdx6}$ translocation to the plasma membrane has several biological effects involving its peroxidase and aiPLA $A_{2}$ activities, which will be described in detail in this manuscript. Prdx6 has also been detected in extracellular fluids, including plasma, bronchoalveolar lavage, and cerebrospinal fluid, but it is unknown whether extracellular Prdx6 functions as a peroxidase or as an aiPLA $2[11,15,16]$.

Several post-translational modifications regulate the enzymatic activities of $\operatorname{Prdx} 6$ by promoting changes in the intracellular localization of the protein or inactivating one or both catalytic sites. The phosphorylation of Prdx6 at threonine 177 by p38 mitogen-activated protein kinase (MAPK), after stimulation with phorbol ester, angiotensin II, or shear stress, induces a conformational change in the protein, promotes its translocation to the plasma membrane, and increases its aiPLA 2 activity $[12,17]$. Prdx6 is also phosphorylated in a circadian manner, suggesting that a switch between peroxidase and aiPLA ${ }_{2}$ activities may occur naturally [18]. Similarly, MAPK activity is required for the targeting of Prdx6 to lysosomal-type organelles, which occurs through the binding of Prdx6 to the chaperone protein 14-3-3ع [19-21]. The hyperoxidation of Prdx6 at cysteine 47 inactivates the Gpx activity while increasing aiPLA 2 . In contrast to the hyperoxidation of 2-cys peroxiredoxins, the hyperoxidation of $\operatorname{Prdx} 6$ is irreversible [22]. The glutathionylation of $\operatorname{Prdx} 6$ by $\pi$ GSH S-transferase $(\pi \mathrm{GST})$ is required for the reduction of the oxidized cysteine and the completion of the peroxidatic catalytic cycle [23]. Prdx6 can also be aberrantly Sumoylated by Sumo1 at lysines 122 and 142 during oxidative stress. Aberrant sumoylation of Prdx6 reduces its gene expression and protein abundance [24-26].

The binding of Prdx6 to different substrates differentially regulates its GPx and aiPLA 2 activities. At an acidic $\mathrm{pH}$, when aiPLA $\mathrm{L}_{2}$ is maximal, Prdx6 binds to reduced phospholipids. In contrast, Prdx6 binds only to oxidized phospholipids at cytosolic $\mathrm{pH}$. The binding of Prdx6 to oxidized phospholipids requires the translocation of Prdx6 from the cytosol to the cell membrane, and has been observed after treating live cells with peroxides [11,27-30]. Cytosolic Prdx6 could also potentially translocate to oxidized intracellular organelle membranes, but this idea remains unexplored.

Aside from posttranslational modifications and subcellular localization, the enzymatic activities of Prdx6 can be regulated by interactions with other proteins. The direct interaction of Prdx6 with the surfactant protein A (SP-A) suppresses aiPLA 2 in a process that is important for the regulation of lung phospholipid metabolism in lamellar bodies of type II pneumocytes [31-33]. Similarly, the interaction of Prdx6 with LIMP2 likely facilitates the binding of Prdx6 to phospholipids in acidic environments [34]. As described above, the binding of Prdx6 to $\pi$ GST is necessary for the reduction of the oxidized cysteine and thus for the completion of the peroxidatic catalytic cycle, but not for aiPLA 2 activity $[23,35,36]$. Prdx6 can also interact with the NADPH oxidase (Nox) subunits p67phox and Noxa1 [37,38]. These interactions seem to be necessary for optimal Nox activity. Interaction of phosphorylated Prdx6 with p6 $7^{\text {phox }}$ inhibits aiPLA 2 and appears to be the mechanism that terminates Nox activation [39].

\section{Signaling by Prdx6 Peroxidase}

Peroxiredoxins are well known for their role in cellular signaling as hydrogen peroxide $\left(\mathrm{H}_{2} \mathrm{O}_{2}\right)$ sensors. As mentioned above, Prdx6 is the only peroxiredoxin capable of reducing phospholipid hydroperoxides in addition to reducing $\mathrm{H}_{2} \mathrm{O}_{2}$ and short-chain peroxides. Hydroperoxide reduction occurs in three steps: peroxidation (the reduction of the hydroperoxide, which oxidizes the cysteine 
to sulfenic acid), resolution (the reduction of sulfenic acid), and recycling (the regeneration of the cysteine active site) [40,41]. This process occurs at the conserved cysteine 47 catalytic site and requires glutathione and $\pi \mathrm{GST}[5,36]$.

Lipid peroxidation products such as malondialdehyde (MDA) and 4-hydroxynonenal (4HNE) have traditionally been viewed as toxic byproducts implicated in the etiology of several diseases [42-45]. However, increasing evidence shows that MDA and 4HNE also elicit biological activities that result in anti-inflammatory and pro-survival effects such as Nrf2 activation and UCP3 upregulation [46,47]. Therefore, lipid hydroperoxide reduction by $\operatorname{Prdx} 6$ is crucial to limit peroxidation-derived pathological effects and to regulate adaptive responses mediated by electrophilic lipid peroxidation products. The only other enzyme known to be able to reduce phospholipid hydroperoxides in mammalian cells is glutathione peroxidase 4 (Gpx4) [48,49]. The expression of Prdx6 and Gpx4 likely varies among tissues, cell types, and possibly developmental stages and disease progression, but it is currently unknown if these two proteins exhibit complementary functions or if one replaces the other in particular pathophysiological conditions.

As described above, Prdx6 is recruited to peroxidized cell membranes following oxidative stress, where it reduces and hydrolyzes the oxidized sn-2 fatty acyl or the sn-2 ester (alkyl) bond of oxidized phospholipids through its GPx and aiPLA 2 activities [30,50]. Thus, Prdx6 actively participates in the prevention and repair of lipid peroxidation. The critical role of both the GPx and aiPLA ${ }_{2}$ activities of Prdx6 in the repair of lipid peroxidation has been extensively demonstrated in cells, lungs, and knock-in mouse models that express either Prdx6 GPx or aiPLA 2 activity after treatment with peroxides and exposure to paraquat or hyperoxia $[28,29,51]$.

A novel lysophosphatidylcholine acyl transferase (LPCAT) activity of Prdx6 coupled to aiPLA 2 was recently described [9]. Prdx6 LPCAT acylates lysophosphatidylcholine (LPC) generated by aiPLA 2 in a continuous process, without the release of the LPC intermediate generated by aiPLA 2 . Thus, LPCAT and aiPLA $A_{2}$ combine to replace an oxidized acyl chain with palmitoyl $\mathrm{CoA}$, effectively repairing oxidized cell membranes. Hence, Prdx6 possesses the ability to reduce peroxidized cell membrane phospholipids through its GPx activity and to replace the oxidized sn-2 fatty acyl group through hydrolysis/reacylation by aiPLA 2 and LPCAT, providing a complete system for the repair of peroxidized cell membranes [30].

The recent discovery of ferroptosis, a distinct cell death pathway characterized by the intracellular accumulation of lipid hydroperoxides [52-55], is generating increasing interest in the role of lipid peroxidation in the progression of several diseases. The role of GPx4, the only other enzyme capable of reducing lipid hydroperoxides, is evident in ferroptosis [54,55]. In contrast, the role of Prdx6 as a regulator of ferroptosis has not been studied, but undoubtedly warrants further investigation.

\section{Signaling by aiPLA}

Studies using Prdx6 knock-in and knock-out mice, intact lung preparations and primary cells, and an aiPLA $A_{2}$ inhibitor (MJ33) show that, aside from its role in lung phospholipid metabolism, aiPLA 2 is necessary for the activation of NADPH oxidase 2 (Nox2) during stimulation with phorbol ester, shear stress, angiotensin II, N-formylmethionine-leucyl-phenylalanine, or endotoxin [12,37,56-60]. The mechanism by which Prdx6 regulates Nox2 starts with the p38 MAPK-mediated phosphorylation of Prdx6, its translocation to the plasma membrane, and the generation of LPC by aiPLA 2 . LPC is then converted to lysophosphatidic acid (LPA) by lysophospholipase D. LPA signals through LPA receptors, activating the small GTPase Rac which moves from the cytosol to the membrane to activate Nox2 [12,60,61].

Initial studies discovered a direct interaction of Prdx6 with p67phox, a cytosolic component of Nox2, and suggested that aiPLA 2 plays a critical role in Nox2 activation [56]. Later studies showed that binding occurs only between phosphorylated Prdx6 and non-phosphorylated p67 ${ }^{\text {phox }}$ and that such an interaction suppresses aiPLA 2 , likely terminating Nox2 activity [39]. Contrasting evidence exists about the role of Prdx6 in the regulation of other members of the NADPH oxidase family. On the one hand, 
MJ33 did not inhibit angiotensin II-stimulated oxidant generation in human pulmonary smooth muscle cells, which express high levels of NADPH oxidase 1 (Nox1) [58]. On the other hand, recent evidence showed that Prdx6 binds to Noxa1, a regulator of Nox1, and that knockdown of Prdx6 or inhibition of aiPLA 2 with MJ33 blunts Nox1-derived oxidant generation and suppresses cell migration [38].

NADPH oxidases are important activators of redox-dependent inflammatory pathways [62]. Thus, aiPLA 2 signaling plays a role in inflammation by regulating Nox-derived oxidant generation. The inhibition of aiPLA 2 with MJ33 protects the lungs from hyperoxia, endotoxin, and ischemia/reperfusion injury by blunting oxidant generation and preventing inflammation $[58,59,63]$. Our unpublished observations suggest that knock-in mice deficient in aiPLA $\mathrm{A}_{2}$ are resistant to sepsis-induced acute lung injury. Signaling effects of aiPLA ${ }_{2}$, independent from the regulation of NADPH oxidases such as the generation of inflammatory mediators derived from arachidonic acid, have been proposed [64,65]. aiPLA 2 , however, does not show a preference for arachidonic acid-containing phospholipids [66,67]. Therefore, it is unclear how aiPLA 2 could regulate inflammatory pathways derived from arachidonic acid release.

\section{Prdx6 Signaling in Disease}

\subsection{Cancer}

Peroxiredoxins have a dual role in carcinogenesis, acting as both tumor suppressors and promoters [68-70]. Such a dual role appears to be consistent with the established role of oxidants in both cell proliferation and death $[68,71,72]$. Increased Prdx6 levels have been detected in various cancers, and the role of Prdx6 in lung cancer invasion is well known [73]. aiPLA 2 promotes cell invasion and metastasis in various models, likely through the regulation of NADPH oxidase, which is needed for cell proliferation [74]. Mice that over-express Prdx6 show a greater increase in the growth of lung tumors compared to wild-type animals. Both aiPLA 2 and Prdx6 peroxidase activities are implicated in lung tumor development through the regulation of redox-sensitive pathways such as MAPK, JNK, JAK/STAT, and AP-1 [75-77].

\subsection{Inflammation}

Prdx6 appears to have a dual role in inflammatory disease. One the one hand, as described above, aiPLA ${ }_{2}$ is necessary for the activation of the pro-inflammatory NADPH oxidase. On the other hand, Prdx6 is crucial to counteract increased reactive oxygen species (ROS) generation and to repair oxidized cell membranes following oxidative stress. Hyperoxidized Prdx6 levels are high in the peripheral blood mononuclear cells of moderate-to-severe asthma patients, where ROS generation is also elevated [78]. Moreover, LPS-treated Prdx6-over-expressing mice show less renal apoptosis and leukocyte infiltration than wild-type controls [79]. Similarly, Prdx6 null mice show increased lung inflammation after intratracheal instillation of lipopolysaccharide (LPS) [80]. Lung inflammation and mortality induced by paraquat or hyperoxia are also increased in Prdx6 null mice [81,82]. In contrast, Prdx6 null mice show reduced inflammation, but increased hepatic oxidative damage and mitochondrial dysfunction after experimental ischemia/reperfusion [83]. Moreover, the inhibition of aiPLA 2 with MJ33 reduces inflammation after hyperoxia or intratracheal LPS exposure $[59,63]$. Therefore, it is likely that Prdx6 plays a dual role in inflammatory conditions, both as an activator of inflammatory pathways related to NADPH oxidase through aiPLA 2 and as a protective/regulatory mechanism through Prdx6 peroxidase activity.

The link between Prdx6 and NfkB, which is one of the most prominent redox-regulated pro-inflammatory regulators, has been known for some time [84]. Prdx6 protects against ischemia/reperfusion injury during liver transplantation by downregulating NfkB [85]. Similarly, Prdx6 expression is inversely correlated with $\mathrm{NfkB}$ during Clonorchis sinensis infection [86]. In contrast, extracellular Prdx6 signals through a toll-like receptor (TLR) after focal cerebral ischemia/reperfusion [87]. Other extracellular oxidized peroxiredoxins released via the exosomal 
pathway can bind to TLR, contributing to sustained inflammatory responses that involve $\mathrm{Nf} k \mathrm{~B}$ signaling. The specific role of Prdx6 in this process, however, remains unknown [88]. Our unpublished observations show that the genetic inactivation (knock-in) of aiPLA $\mathrm{A}_{2}$ prevents the nuclear translocation of $\mathrm{Nf} \kappa \mathrm{B}$ in lung endothelial cells stimulated with LPS. Thus, it appears that Prdx6 peroxidase and aiPLA $A_{2}$ may play contrasting roles in $\mathrm{Nf \kappa B}$ signaling.

\subsection{Metabolic Disease}

Prdx6 is linked to the development of type 2 diabetes. Prdx6 null mice show low insulin and elevated blood glucose levels, compared to wild-type mice, after a glucose tolerance test. Similarly, insulin signaling and pancreatic $\beta$ cell morphology are impaired in Prdx6 knockout mice. Moreover, Prdx6 null mice develop dyslipidemia [89]. Prdx6 appears to also be linked to the generation of hydroxy fatty acids, which are antidiabetic/anti-inflammatory lipid mediators synthesized in white adipose tissue via de novo lipogenesis [90]. The specific role of Prdx6 peroxidase and aiPLA activities $^{2}$ in the development and progression of metabolic disease remains unexplored.

\subsection{Ocular Damage}

The role of Prdx6 in ocular oxidative damage has been extensively investigated [91,92]. Prdx6 expression in the eye declines with age, increasing the risk of cataract formation $[26,93,94]$. Moreover, Prdx6 prevents oxidative stress in human retinal pigment epithelial cells by activating the Phosphoinositide 3-kinase/Protein kinase B (PI3K/AKT) pathway [95] and blunting transforming growth factor beta (TGF- $\beta$ ) signaling [96]. Prdx6 is therefore necessary to prevent cataract formation and to limit aging-induced oxidative stress in the eye. The exposure of human lens epithelial cells to ultraviolet-B light results in Prdx6 hyperoxidation, increased ROS generation, and cellular toxicity $[92,97]$. The function of Prdx6 in the eye is the topic of a separate review article, which is part of this forum.

\subsection{Brain Injury and Neurodegeneration}

The role of Prdx6 in neurodegenerative diseases is controversial [98]. Following a traumatic brain injury, oxidized Prdx6 is detected in the cerebrospinal fluid $[16,99]$. Moreover, Prdx6 signaling through TLR4 increases after an ischemic stroke, leading to NfkB-mediated inflammation and cell death $[87,100,101]$. Similarly, the pharmacological inhibition of aiPLA 2 with MJ33 reduces inflammation in an experimental stroke model, supporting the idea that aiPLA ${ }_{2}$ has a pro-inflammatory role in the brain under such conditions [102].

The impairment of brain neurogenesis is linked to Alzheimer's (AD) and Parkinson's disease (PD) [103,104]. Recent work shows that Prdx6 has an inhibitory effect on neurogenesis [105]. In contrast, Prdx6 reduces oxidative stress and counteracts ROS generation, suggesting that Prdx6 plays a neuroprotective role in AD models [103]. Similarly, Prdx6 reduces inflammation and protects against disruption to the blood-brain barrier in a model of multiple sclerosis [106]. Prdx6 hyperoxidation is observed in a PD mouse model [104]. As discussed above, the hyperoxidation of Prdx6 is irreversible, and inactivates the Gpx function. Therefore, the dual role of Prdx6 in neurodegeneration seems to be linked to the differential expression of Prdx6 peroxidase and aiPLA $A_{2}$ activities.

\subsection{Male Infertility}

Prdx6 plays a crucial role in spermatozoon fertilizing ability [107,108]. Lower levels of Prdx6 are associated with impaired sperm function and poor DNA integrity in infertile men [109]. Sperm motility, viability, fertilization, and blastocyst rates are lower in Prdx6 null mice than they are in wild-type controls [110]. The role of Prdx6 in male fertility is extensively discussed in a separate review article, which is part of this forum. 


\section{Conclusions and Future Directions}

Prdx6 is an intriguing enzyme that contributes to the regulation of a plethora of signaling pathways related to its diverse catalytic activities. The contrasting biological roles of Prdx6 are likely explained by the delicate differential expression of its peroxidase and aiPLA $\mathrm{A}_{2}$ activities. Further investigations on the role of Prdx6 in cell signaling should focus on understanding the mechanisms that control the shift between Prdx6 peroxidase and aiPLA $\mathrm{A}_{2}$ activities under physiological and pathological conditions. Similarly, the role of extracellular Prdx6 in inflammatory signaling remains underexplored. Moreover, the role of $\operatorname{Prdx} 6$ as a complete lipid peroxidation repair enzyme warrants further studies to elucidate how Prdx6 regulates cellular signaling by lipid peroxidation products, as well as the possible role of Prdx6 in novel pathways of cell death.

Author Contributions: J.A.A. and J.P.V.-M. contributed equally to all aspects of this manuscript.

Funding: J.P.V.-M. is supported by University of California startup funds.

Acknowledgments: We thank Aron Fisher, Sheldon Feinstein, and Shampa Chatterjee (University of Pennsylvania) for discussions and input about Prdx6 biology.

Conflicts of Interest: The authors declare no conflict of interest.

\section{References}

1. Perkins, A.; Nelson, K.J.; Parsonage, D.; Poole, L.B.; Karplus, P.A. Peroxiredoxins: Guardians against oxidative stress and modulators of peroxide signaling. Trends Biochem. Sci. 2015, 40, 435-445. [CrossRef] [PubMed]

2. Rhee, S.G.; Kil, I.S. Multiple functions and regulation of mammalian peroxiredoxins. Annu. Rev. Biochem. 2017, 86, 749-775. [CrossRef] [PubMed]

3. Rhee, S.G.; Kang, S.W.; Chang, T.S.; Jeong, W.; Kim, K. Peroxiredoxin, a novel family of peroxidases. IUBMB Life 2001, 52, 35-41. [CrossRef] [PubMed]

4. Kang, S.W.; Baines, I.C.; Rhee, S.G. Characterization of a mammalian peroxiredoxin that contains one conserved cysteine. J. Biol. Chem. 1998, 273, 6303-6311. [CrossRef] [PubMed]

5. Manevich, Y.; Feinstein, S.I.; Fisher, A.B. Activation of the antioxidant enzyme 1-CYS peroxiredoxin requires glutathionylation mediated by heterodimerization with pi GST. Proc. Natl. Acad. Sci. USA 2004, 101, 3780-3785. [CrossRef] [PubMed]

6. Pedrajas, J.R.; McDonagh, B.; Hernandez-Torres, F.; Miranda-Vizuete, A.; Gonzalez-Ojeda, R.; Martinez-Galisteo, E.; Padilla, C.A.; Barcena, J.A. Glutathione is the resolving thiol for thioredoxin peroxidase activity of 1-Cys peroxiredoxin without being consumed during the catalytic cycle. Antioxid. Redox Signal. 2016, 24, 115-128. [CrossRef] [PubMed]

7. Fisher, A.B.; Dodia, C.; Manevich, Y.; Chen, J.W.; Feinstein, S.I. Phospholipid hydroperoxides are substrates for non-selenium glutathione peroxidase. J. Biol. Chem. 1999, 274, 21326-21334. [CrossRef] [PubMed]

8. Huang, C.F.; Sun, Z.J.; Zhao, Y.F.; Chen, X.M.; Jia, J.; Zhang, W.F. Increased expression of peroxiredoxin 6 and cyclophilin A in squamous cell carcinoma of the tongue. Oral Dis. 2011, 17, 328-334. [CrossRef] [PubMed]

9. Fisher, A.B.; Dodia, C.; Sorokina, E.M.; Li, H.; Zhou, S.; Raabe, T.; Feinstein, S.I. A novel lysophosphatidylcholine acyl transferase activity is expressed by peroxiredoxin 6. J. Lipid Res. 2016, 57, 587-596. [CrossRef] [PubMed]

10. Fisher, A.B. Peroxiredoxin 6: A bifunctional enzyme with glutathione peroxidase and phospholipase A(2) activities. Antioxid. Redox Signal. 2011, 15, 831-844. [CrossRef] [PubMed]

11. Fisher, A.B.; Dodia, C.; Chander, A.; Jain, M. A competitive inhibitor of phospholipase A2 decreases surfactant phosphatidylcholine degradation by the rat lung. Biochem. J. 1992, 288 Pt 2, 407-411. [CrossRef]

12. Chatterjee, S.; Feinstein, S.I.; Dodia, C.; Sorokina, E.; Lien, Y.C.; Nguyen, S.; Debolt, K.; Speicher, D.; Fisher, A.B. Peroxiredoxin 6 phosphorylation and subsequent phospholipase $A_{2}$ activity are required for agonist-mediated activation of NADPH oxidase in mouse pulmonary microvascular endothelium and alveolar macrophages. J. Biol. Chem. 2011, 286, 11696-11706. [CrossRef] [PubMed] 
13. Min, Y.; Wi, S.M.; Shin, D.; Chun, E.; Lee, K.Y. Peroxiredoxin-6 negatively regulates bactericidal activity and NF-kappaB activity by interrupting TRAF6-ECSIT complex. Front. Cell. Infect. Microbiol. 2017, 7, 94. [CrossRef] [PubMed]

14. Ma, S.; Zhang, X.; Zheng, L.; Li, Z.; Zhao, X.; Lai, W.; Shen, H.; Lv, J.; Yang, G.; Wang, Q.; et al. Peroxiredoxin 6 is a crucial factor in the initial step of mitochondrial clearance and is upstream of the PINK1-Parkin pathway. Antioxid. Redox Signal. 2016, 24, 486-501. [CrossRef] [PubMed]

15. Wattiez, R.; Noel-Georis, I.; Cruyt, C.; Broeckaert, F.; Bernard, A.; Falmagne, P. Susceptibility to oxidative stress: Proteomic analysis of bronchoalveolar lavage from ozone-sensitive and ozone-resistant strains of mice. Proteomics 2003, 3, 658-665. [CrossRef] [PubMed]

16. Buonora, J.E.; Mousseau, M.; Jacobowitz, D.M.; Lazarus, R.C.; Yarnell, A.M.; Olsen, C.H.; Pollard, H.B.; Diaz-Arrastia, R.; Latour, L.; Mueller, G.P. Autoimmune Profiling Reveals Peroxiredoxin 6 as a Candidate Traumatic Brain Injury Biomarker. J. Neurotrauma 2015, 32, 1805-1814. [CrossRef] [PubMed]

17. Wu, Y.; Feinstein, S.I.; Manevich, Y.; Chowdhury, I.; Pak, J.H.; Kazi, A.; Dodia, C.; Speicher, D.W.; Fisher, A.B. Mitogen-activated protein kinase-mediated phosphorylation of peroxiredoxin 6 regulates its phospholipase A(2) activity. Biochem. J. 2009, 419, 669-679. [CrossRef] [PubMed]

18. Reddy, A.B.; Karp, N.A.; Maywood, E.S.; Sage, E.A.; Deery, M.; O’Neill, J.S.; Wong, G.K.; Chesham, J.; Odell, M.; Lilley, K.S.; et al. Circadian orchestration of the hepatic proteome. Curr. Biol. 2006, 16, 1107-1115. [CrossRef] [PubMed]

19. Sorokina, E.M.; Feinstein, S.I.; Milovanova, T.N.; Fisher, A.B. Identification of the amino acid sequence that targets peroxiredoxin 6 to lysosome-like structures of lung epithelial cells. Am. J. Physiol. Lung Cell. Mol. Physiol. 2009, 297, 871-880. [CrossRef] [PubMed]

20. Sorokina, E.M.; Dodia, C.; Zhou, S.; Tao, J.Q.; Gao, L.; Raabe, T.; Feinstein, S.I.; Fisher, A.B. Mutation of Serine 32 to Threonine in Peroxiredoxin 6 Preserves Its Structure and Enzymatic Function but Abolishes Its Trafficking to Lamellar Bodies. J. Biol. Chem. 2016, 291, 9268-9280. [CrossRef] [PubMed]

21. Sorokina, E.M.; Feinstein, S.I.; Zhou, S.; Fisher, A.B. Intracellular targeting of peroxiredoxin 6 to lysosomal organelles requires MAPK activity and binding to 14-3-3epsilon. Am. J. Physiol. Cell Physiol. 2011, 300, C1430-C1441. [CrossRef] [PubMed]

22. Kim, S.Y.; Jo, H.Y.; Kim, M.H.; Cha, Y.Y.; Choi, S.W.; Shim, J.H.; Kim, T.J.; Lee, K.Y. H2O2-dependent hyperoxidation of peroxiredoxin 6 (Prdx6) plays a role in cellular toxicity via up-regulation of iPLA2 activity. J. Biol. Chem. 2008, 283, 33563-33568. [CrossRef] [PubMed]

23. Zhou, S.; Lien, Y.C.; Shuvaeva, T.; DeBolt, K.; Feinstein, S.I.; Fisher, A.B. Functional interaction of glutathione S-transferase pi and peroxiredoxin 6 in intact cells. Int. J. Biochem. Cell Biol. 2013, 45, 401-407. [CrossRef] [PubMed]

24. Chhunchha, B.; Kubo, E.; Fatma, N.; Singh, D.P. Sumoylation-deficient Prdx6 gains protective function by amplifying enzymatic activity and stability and escapes oxidative stress-induced aberrant Sumoylation. Cell Death Dis. 2017, 8, e2525. [CrossRef] [PubMed]

25. Chhunchha, B.; Fatma, N.; Kubo, E.; Singh, D.P. Aberrant sumoylation signaling evoked by reactive oxygen species impairs protective function of Prdx6 by destabilization and repression of its transcription. FEBS J. 2014, 281, 3357-3381. [CrossRef] [PubMed]

26. Chhunchha, B.; Kubo, E.; Singh, P.; Singh, D.P. Sumoylation-deficient Prdx6 repairs aberrant Sumoylation-mediated Sp1 dysregulation-dependent Prdx6 repression and cell injury in aging and oxidative stress. Aging (Albany NY) 2018, 10, 2284-2315. [CrossRef] [PubMed]

27. Manevich, Y.; Shuvaeva, T.; Dodia, C.; Kazi, A.; Feinstein, S.I.; Fisher, A.B. Binding of peroxiredoxin 6 to substrate determines differential phospholipid hydroperoxide peroxidase and phospholipase A(2) activities. Arch. Biochem. Biophys. 2009, 485, 139-149. [CrossRef] [PubMed]

28. Lien, Y.C.; Feinstein, S.I.; Dodia, C.; Fisher, A.B. The roles of peroxidase and phospholipase A2 activities of peroxiredoxin 6 in protecting pulmonary microvascular endothelial cells against peroxidative stress. Antioxid. Redox Signal. 2012, 16, 440-451. [CrossRef] [PubMed]

29. Li, H.; Benipal, B.; Zhou, S.; Dodia, C.; Chatterjee, S.; Tao, J.Q.; Sorokina, E.M.; Raabe, T.; Feinstein, S.I.; Fisher, A.B. Critical role of peroxiredoxin 6 in the repair of peroxidized cell membranes following oxidative stress. Free Radic. Biol. Med. 2015, 87, 356-365. [CrossRef] [PubMed] 
30. Fisher, A.B. Peroxiredoxin 6 in the repair of peroxidized cell membranes and cell signaling. Arch. Biochem. Biophys. 2017, 617, 68-83. [CrossRef] [PubMed]

31. Fisher, A.B.; Dodia, C.; Chander, A. Inhibition of lung calcium-independent phospholipase A2 by surfactant protein A. Am. J. Physiol. 1994, 267, 335. [CrossRef] [PubMed]

32. Wu, Y.Z.; Manevich, Y.; Baldwin, J.L.; Dodia, C.; Yu, K.; Feinstein, S.I.; Fisher, A.B. Interaction of surfactant protein A with peroxiredoxin 6 regulates phospholipase A2 activity. J. Biol. Chem. 2006, 281, 7515-7525. [CrossRef] [PubMed]

33. Krishnaiah, S.Y.; Dodia, C.; Sorokina, E.M.; Li, H.; Feinstein, S.I.; Fisher, A.B. Binding sites for interaction of peroxiredoxin 6 with surfactant protein A. Biochim. Biophys. Acta 2016, 1864, 419-425. [CrossRef] [PubMed]

34. Kook, S.; Wang, P.; Young, L.R.; Schwake, M.; Saftig, P.; Weng, X.; Meng, Y.; Neculai, D.; Marks, M.S.; Gonzales, L.; et al. Impaired lysosomal integral membrane protein 2-dependent Peroxiredoxin 6 delivery to lamellar bodies accounts for altered alveolar phospholipid content in adaptor protein-3-deficient pearl mice. J. Biol. Chem. 2016, 291, 8414-8427. [CrossRef] [PubMed]

35. Zhou, S.; Sorokina, E.M.; Harper, S.; Li, H.; Ralat, L.; Dodia, C.; Speicher, D.W.; Feinstein, S.I.; Fisher, A.B. Peroxiredoxin 6 homodimerization and heterodimerization with glutathione S-transferase pi are required for its peroxidase but not phospholipase A2 activity. Free Radic. Biol. Med. 2016, 94, 145-156. [CrossRef] [PubMed]

36. Ralat, L.A.; Misquitta, S.A.; Manevich, Y.; Fisher, A.B.; Colman, R.F. Characterization of the complex of glutathione S-transferase pi and 1-cysteine peroxiredoxin. Arch. Biochem. Biophys. 2008, 474, 109-118. [CrossRef] [PubMed]

37. Ambruso, D.R.; Ellison, M.A.; Thurman, G.W.; Leto, T.L. Peroxiredoxin 6 translocates to the plasma membrane during neutrophil activation and is required for optimal NADPH oxidase activity. Biochim. Biophys. Acta 2012, 1823, 306-315. [CrossRef] [PubMed]

38. Kwon, J.; Wang, A.; Burke, D.J.; Boudreau, H.E.; Lekstrom, K.J.; Korzeniowska, A.; Sugamata, R.; Kim, Y.S.; Yi, L.; Ersoy, I.; et al. Peroxiredoxin 6 (Prdx6) supports NADPH oxidase1 (Nox1)-based superoxide generation and cell migration. Free Radic. Biol. Med. 2016, 96, 99-115. [CrossRef] [PubMed]

39. Krishnaiah, S.Y.; Dodia, C.; Feinstein, S.I.; Fisher, A.B. p67(phox) terminates the phospholipase A(2)-derived signal for activation of NADPH oxidase (NOX2). FASEB J. 2013, 27, 2066-2073. [CrossRef] [PubMed]

40. Wood, Z.A.; Schroder, E.; Robin Harris, J.; Poole, L.B. Structure, mechanism and regulation of peroxiredoxins. Trends Biochem. Sci. 2003, 28, 32-40. [CrossRef]

41. Ralat, L.A.; Manevich, Y.; Fisher, A.B.; Colman, R.F. Direct evidence for the formation of a complex between 1 -cysteine peroxiredoxin and glutathione S-transferase pi with activity changes in both enzymes. Biochemistry 2006, 45, 360-372. [CrossRef] [PubMed]

42. Yagi, K. Lipid peroxides and human diseases. Chem. Phys. Lipids 1987, 45, 337-351. [CrossRef]

43. Dexter, D.T.; Carter, C.J.; Wells, F.R.; Javoy-Agid, F.; Agid, Y.; Lees, A.; Jenner, P.; Marsden, C.D. Basal lipid peroxidation in substantia nigra is increased in Parkinson's disease. J. Neurochem. 1989, 52, 381-389. [CrossRef] [PubMed]

44. Halliwell, B.; Chirico, S. Lipid peroxidation: Its mechanism, measurement, and significance. Am. J. Clin. Nutr. 1993, 57, 725S. [CrossRef] [PubMed]

45. Gallelli, C.A.; Calcagnini, S.; Romano, A.; Koczwara, J.B.; de Ceglia, M.; Dante, D.; Villani, R.; Giudetti, A.M.; Cassano, T.; Gaetani, S. Modulation of the Oxidative Stress and Lipid Peroxidation by Endocannabinoids and Their Lipid Analogues. Antioxidants 2018, 7, 93. [CrossRef] [PubMed]

46. Zhang, Y.; Sano, M.; Shinmura, K.; Tamaki, K.; Katsumata, Y.; Matsuhashi, T.; Morizane, S.; Ito, H.; Hishiki, T.; Endo, J.; et al. 4-hydroxy-2-nonenal protects against cardiac ischemia-reperfusion injury via the Nrf2-dependent pathway. J. Mol. Cell. Cardiol. 2010, 49, 576-586. [CrossRef] [PubMed]

47. Wang, Y.N.; Gao, L.; Wu, S.Y.; Qin, S. Low-dose 4-Hydroxy-2-Nonenal (HNE) reperfusion therapy displays cardioprotective effects in mice after myocardial infarction that are abrogated by Genipin. Med. Sci. Monit. 2018, 24, 3702-3709. [CrossRef] [PubMed]

48. Imai, H.; Nakagawa, Y. Biological significance of phospholipid hydroperoxide glutathione peroxidase (PHGPx, GPx4) in mammalian cells. Free Radic. Biol. Med. 2003, 34, 145-169. [CrossRef] 
49. Scheerer, P.; Borchert, A.; Krauss, N.; Wessner, H.; Gerth, C.; Hohne, W.; Kuhn, H. Structural basis for catalytic activity and enzyme polymerization of phospholipid hydroperoxide glutathione peroxidase- 4 (GPx4). Biochemistry 2007, 46, 9041-9049. [CrossRef] [PubMed]

50. Ayala, A.; Munoz, M.F.; Arguelles, S. Lipid peroxidation: Production, metabolism, and signaling mechanisms of malondialdehyde and 4-hydroxy-2-nonenal. Oxid. Med. Cell. Longev. 2014, 2014, 360438. [CrossRef] [PubMed]

51. Fisher, A.B.; Vasquez-Medina, J.P.; Dodia, C.; Sorokina, E.M.; Tao, J.Q.; Feinstein, S.I. Peroxiredoxin 6 phospholipid hydroperoxidase activity in the repair of peroxidized cell membranes. Redox Biol. 2018, 14, 41-46. [CrossRef] [PubMed]

52. Dixon, S.J.; Lemberg, K.M.; Lamprecht, M.R.; Skouta, R.; Zaitsev, E.M.; Gleason, C.E.; Patel, D.N.; Bauer, A.J.; Cantley, A.M.; Yang, W.S.; et al. Ferroptosis: An iron-dependent form of nonapoptotic cell death. Cell 2012, 149, 1060-1072. [CrossRef] [PubMed]

53. Yu, Y.; Xie, Y.; Cao, L.; Yang, L.; Yang, M.; Lotze, M.T.; Zeh, H.J.; Kang, R.; Tang, D. The ferroptosis inducer erastin enhances sensitivity of acute myeloid leukemia cells to chemotherapeutic agents. Mol. Cell. Oncol. 2015, 2, e1054549. [CrossRef] [PubMed]

54. Yang, W.S.; Stockwell, B.R. Ferroptosis: Death by lipid peroxidation. Trends Cell Biol. 2016, 26, 165-176. [CrossRef] [PubMed]

55. Tang, Q.; Bai, L.; Zou, Z.; Meng, P.; Xia, Y.; Cheng, S.; Mu, S.; Zhou, J.; Wang, X.; Qin, X.; et al. Ferroptosis is newly characterized form of neuronal cell death in response to arsenite exposure. Neurotoxicology 2018, 67, 27-36. [CrossRef] [PubMed]

56. Leavey, P.J.; Gonzalez-Aller, C.; Thurman, G.; Kleinberg, M.; Rinckel, L.; Ambruso, D.W.; Freeman, S.; Kuypers, F.A.; Ambruso, D.R. A 29-kDa protein associated with p67phox expresses both peroxiredoxin and phospholipase A2 activity and enhances superoxide anion production by a cell-free system of NADPH oxidase activity. J. Biol. Chem. 2002, 277, 45181-45187. [CrossRef] [PubMed]

57. Ellison, M.A.; Thurman, G.W.; Ambruso, D.R. Phox activity of differentiated PLB-985 cells is enhanced, in an agonist specific manner, by the PLA2 activity of Prdx6-PLA2. Eur. J. Immunol. 2012, 42, 1609-1617. [CrossRef] [PubMed]

58. Lee, I.; Dodia, C.; Chatterjee, S.; Zagorski, J.; Mesaros, C.; Blair, I.A.; Feinstein, S.I.; Jain, M.; Fisher, A.B. A novel nontoxic inhibitor of the activation of NADPH oxidase reduces reactive oxygen species production in mouse lung. J. Pharmacol. Exp. Ther. 2013, 345, 284-296. [CrossRef] [PubMed]

59. Lee, I.; Dodia, C.; Chatterjee, S.; Feinstein, S.I.; Fisher, A.B. Protection against LPS-induced acute lung injury by a mechanism-based inhibitor of NADPH oxidase (type 2). Am. J. Physiol. Lung Cell. Mol. Physiol. 2014, 306, 635-644. [CrossRef] [PubMed]

60. Vazquez-Medina, J.P.; Dodia, C.; Weng, L.; Mesaros, C.; Blair, I.A.; Feinstein, S.I.; Chatterjee, S.; Fisher, A.B. The phospholipase A2 activity of peroxiredoxin 6 modulates NADPH oxidase 2 activation via lysophosphatidic acid receptor signaling in the pulmonary endothelium and alveolar macrophages. FASEB J. 2016, 30, 2885-2898. [CrossRef] [PubMed]

61. Chatterjee, S.; Browning, E.A.; Hong, N.; DeBolt, K.; Sorokina, E.M.; Liu, W.; Birnbaum, M.J.; Fisher, A.B. Membrane depolarization is the trigger for PI3K/Akt activation and leads to the generation of ROS. Am. J. Physiol. Heart Circ. Physiol. 2012, 302, 105-114. [CrossRef] [PubMed]

62. Lee, I.T.; Yang, C.M. Role of NADPH oxidase/ROS in pro-inflammatory mediators-induced airway and pulmonary diseases. Biochem. Pharmacol. 2012, 84, 581-590. [CrossRef] [PubMed]

63. Benipal, B.; Feinstein, S.I.; Chatterjee, S.; Dodia, C.; Fisher, A.B. Inhibition of the phospholipase A2 activity of peroxiredoxin 6 prevents lung damage with exposure to hyperoxia. Redox Biol. 2015, 4, 321-327. [CrossRef] [PubMed]

64. Kim, S.Y.; Chun, E.; Lee, K.Y. Phospholipase A(2) of peroxiredoxin 6 has a critical role in tumor necrosis factor-induced apoptosis. Cell Death Differ. 2011, 18, 1573-1583. [CrossRef] [PubMed]

65. Schmitt, A.; Schmitz, W.; Hufnagel, A.; Schartl, M.; Meierjohann, S. Peroxiredoxin 6 triggers melanoma cell growth by increasing arachidonic acid-dependent lipid signalling. Biochem. J. 2015, 471, 267-279. [CrossRef] [PubMed]

66. Kim, T.S.; Sundaresh, C.S.; Feinstein, S.I.; Dodia, C.; Skach, W.R.; Jain, M.K.; Nagase, T.; Seki, N.; Ishikawa, K.; Nomura, N.; et al. Identification of a human cDNA clone for lysosomal type Ca2+-independent 
phospholipase A2 and properties of the expressed protein. J. Biol. Chem. 1997, 272, 2542-2550. [CrossRef] [PubMed]

67. Akiba, S.; Dodia, C.; Chen, X.; Fisher, A.B. Characterization of acidic Ca(2+)-independent phospholipase A2 of bovine lung. Comp. Biochem. Physiol. B Biochem. Mol. Biol. 1998, 120, 393-404. [CrossRef]

68. Waris, G.; Ahsan, H. Reactive oxygen species: Role in the development of cancer and various chronic conditions. J. Carcinog. 2006, 5, 14. [CrossRef] [PubMed]

69. Rolfs, F.; Huber, M.; Gruber, F.; Bohm, F.; Pfister, H.J.; Bochkov, V.N.; Tschachler, E.; Dummer, R.; Hohl, D.; Schafer, M.; et al. Dual role of the antioxidant enzyme peroxiredoxin 6 in skin carcinogenesis. Cancer Res. 2013, 73, 3460-3469. [CrossRef] [PubMed]

70. Park, M.H.; Jo, M.; Kim, Y.R.; Lee, C.K.; Hong, J.T. Roles of peroxiredoxins in cancer, neurodegenerative diseases and inflammatory diseases. Pharmacol. Ther. 2016, 163, 1-23. [CrossRef] [PubMed]

71. Fleury, C.; Mignotte, B.; Vayssiere, J.L. Mitochondrial reactive oxygen species in cell death signaling. Biochimie 2002, 84, 131-141. [CrossRef]

72. Vander Heiden, M.G.; Cantley, L.C.; Thompson, C.B. Understanding the Warburg effect: The metabolic requirements of cell proliferation. Science 2009, 324, 1029-1033. [CrossRef] [PubMed]

73. Walsh, B.; Pearl, A.; Suchy, S.; Tartaglio, J.; Visco, K.; Phelan, S.A. Overexpression of Prdx6 and resistance to peroxide-induced death in Hepa1-6 cells: Prdx suppression increases apoptosis. Redox Rep. 2009, 14, 275-284. [CrossRef] [PubMed]

74. Ho, J.N.; Lee, S.B.; Lee, S.S.; Yoon, S.H.; Kang, G.Y.; Hwang, S.G.; Um, H.D. Phospholipase A2 activity of peroxiredoxin 6 promotes invasion and metastasis of lung cancer cells. Mol. Cancer Ther. 2010, 9, 825-832. [CrossRef] [PubMed]

75. Benhar, M.; Engelberg, D.; Levitzki, A. ROS, stress-activated kinases and stress signaling in cancer. EMBO Rep. 2002, 3, 420-425. [CrossRef] [PubMed]

76. Yun, H.M.; Park, K.R.; Lee, H.P.; Lee, D.H.; Jo, M.; Shin, D.H.; Yoon, D.Y.; Han, S.B.; Hong, J.T. PRDX6 promotes lung tumor progression via its GPx and iPLA2 activities. Free Radic. Biol. Med. 2014, 69, 367-376. [CrossRef] [PubMed]

77. Yun, H.M.; Park, K.R.; Park, M.H.; Kim, D.H.; Jo, M.R.; Kim, J.Y.; Kim, E.C.; Yoon, D.Y.; Han, S.B.; Hong, J.T. PRDX6 promotes tumor development via the JAK2/STAT3 pathway in a urethane-induced lung tumor model. Free Radic. Biol. Med. 2015, 80, 136-144. [CrossRef] [PubMed]

78. Kwon, H.S.; Bae, Y.J.; Moon, K.A.; Lee, Y.S.; Lee, T.; Lee, K.Y.; Kim, T.B.; Park, C.S.; Moon, H.B.; Cho, Y.S. Hyperoxidized peroxiredoxins in peripheral blood mononuclear cells of asthma patients is associated with asthma severity. Life Sci. 2012, 90, 502-508. [CrossRef] [PubMed]

79. Lee, D.H.; Park, J.H.; Han, S.B.; Yoon, D.Y.; Jung, Y.Y.; Hong, J.T. Peroxiredoxin 6 overexpression attenuates lipopolysaccharide-induced acute kidney injury. Oncotarget 2017, 8, 51096-51107. [CrossRef] [PubMed]

80. Yang, D.; Song, Y.; Wang, X.; Sun, J.; Ben, Y.; An, X.; Tong, L.; Bi, J.; Wang, X.; Bai, C. Deletion of peroxiredoxin 6 potentiates lipopolysaccharide-induced acute lung injury in mice. Crit. Care Med. 2011, 39, 756-764. [CrossRef] [PubMed]

81. Wang, Y.; Feinstein, S.I.; Manevich, Y.; Ho, Y.S.; Fisher, A.B. Lung injury and mortality with hyperoxia are increased in peroxiredoxin 6 gene-targeted mice. Free Radic. Biol. Med. 2004, 37, 1736-1743. [CrossRef] [PubMed]

82. Wang, Y.; Feinstein, S.I.; Manevich, Y.; Ho, Y.S.; Fisher, A.B. Peroxiredoxin 6 gene-targeted mice show increased lung injury with paraquat-induced oxidative stress. Antioxid. Redox. Signal. 2006, 8, 229-237. [CrossRef] [PubMed]

83. Eismann, T.; Huber, N.; Shin, T.; Kuboki, S.; Galloway, E.; Wyder, M.; Edwards, M.J.; Greis, K.D.; Shertzer, H.G.; Fisher, A.B.; et al. Peroxiredoxin-6 protects against mitochondrial dysfunction and liver injury during ischemia-reperfusion in mice. Am. J. Physiol. Gastrointest. Liver Physiol. 2009, 296, 266-274. [CrossRef] [PubMed]

84. Chhunchha, B.; Fatma, N.; Kubo, E.; Rai, P.; Singh, S.P.; Singh, D.P. Curcumin abates hypoxia-induced oxidative stress based-ER stress-mediated cell death in mouse hippocampal cells (HT22) by controlling Prdx6 and NF-kappaB regulation. Am. J. Physiol. Cell Physiol. 2013, 304, 636-655. [CrossRef] [PubMed] 
85. Tu, Q.; Xiong, Y.; Fan, L.; Qiao, B.; Xia, Z.; Hu, L.; Wang, Y.; Peng, G.; Ye, Q. Peroxiredoxin 6 attenuates ischemia and hypoxia induced liver damage of braindead donors. Mol. Med. Rep. 2016, 13, 753-761. [CrossRef] [PubMed]

86. Pak, J.H.; Son, W.C.; Seo, S.B.; Hong, S.J.; Sohn, W.M.; Na, B.K.; Kim, T.S. Peroxiredoxin 6 expression is inversely correlated with nuclear factor-kappaB activation during Clonorchis sinensis infestation. Free Radic. Biol. Med. 2016, 99, 273-285. [CrossRef] [PubMed]

87. Kuang, X.; Wang, L.F.; Yu, L.; Li, Y.J.; Wang, Y.N.; He, Q.; Chen, C.; Du, J.R. Ligustilide ameliorates neuroinflammation and brain injury in focal cerebral ischemia/reperfusion rats: Involvement of inhibition of TLR4/peroxiredoxin 6 signaling. Free Radic. Biol. Med. 2014, 71, 165-175. [CrossRef] [PubMed]

88. Vazquez-Medina, J.P. Chapter 3-Redox Signaling and the Onset of the Inflammatory Cascade. Immun. Inflamm. Health Dis. 2018, 37-42. [CrossRef]

89. Pacifici, F.; Arriga, R.; Sorice, G.P.; Capuani, B.; Scioli, M.G.; Pastore, D.; Donadel, G.; Bellia, A.; Caratelli, S.; Coppola, A.; et al. Peroxiredoxin 6, a novel player in the pathogenesis of diabetes. Diabetes 2014, 63, 3210-3220. [CrossRef] [PubMed]

90. Kuda, O.; Brezinova, M.; Silhavy, J.; Landa, V.; Zidek, V.; Dodia, C.; Kreuchwig, F.; Vrbacky, M.; Balas, L.; Durand, T.; et al. Nrf2-Mediated Antioxidant Defense and Peroxiredoxin 6 Are Linked to Biosynthesis of Palmitic Acid Ester of 9-Hydroxystearic Acid. Diabetes 2018, 67, 1190-1199. [CrossRef] [PubMed]

91. Wahlig, S.; Lovatt, M.; Mehta, J.S. Functional role of peroxiredoxin 6 in the eye. Free Radic. Biol. Med. 2018, 126, 210-220. [CrossRef] [PubMed]

92. Shibata, S.; Shibata, N.; Shibata, T.; Sasaki, H.; Singh, D.P.; Kubo, E. The role of Prdx6 in the protection of cells of the crystalline lens from oxidative stress induced by UV exposure. Jpn. J. Ophthalmol. 2016, 60, 408-418. [CrossRef] [PubMed]

93. Kubo, E.; Miyazawa, T.; Fatma, N.; Akagi, Y.; Singh, D.P. Development- and age-associated expression pattern of peroxiredoxin 6, and its regulation in murine ocular lens. Mech. Ageing Dev. 2006, 127, 249-256. [CrossRef] [PubMed]

94. Hasanova, N.; Kubo, E.; Kumamoto, Y.; Takamura, Y.; Akagi, Y. Age-related cataracts and Prdx6: Correlation between severity of lens opacity, age and the level of Prdx 6 expression. Br. J. Ophthalmol. 2009, 93, 1081-1084. [CrossRef] [PubMed]

95. Zha, X.; Wu, G.; Zhao, X.; Zhou, L.; Zhang, H.; Li, J.; Ma, L.; Zhang, Y. PRDX6 Protects ARPE-19 Cells from oxidative damage via PI3K/AKT signaling. Cell. Physiol. Biochem. 2015, 36, 2217-2228. [CrossRef] [PubMed]

96. Lovicu, F.J.; Schulz, M.W.; Hales, A.M.; Vincent, L.N.; Overbeek, P.A.; Chamberlain, C.G.; McAvoy, J.W. TGF $\beta$ induces morphological and molecular changes similar to human anterior subcapsular cataract. Br. J. Ophthalmol. 2002, 86, 220-226. [CrossRef] [PubMed]

97. Manevich, Y.; Sweitzer, T.; Pak, J.H.; Feinstein, S.I.; Muzykantov, V.; Fisher, A.B. 1-Cys peroxiredoxin overexpression protects cells against phospholipid peroxidation-mediated membrane damage. Proc. Natl. Acad. Sci. USA 2002, 99, 11599-11604. [CrossRef] [PubMed]

98. Hattori, F.; Oikawa, S. Peroxiredoxins in the central nervous system. Subcell. Biochem. 2007, 44, 357-374. [PubMed]

99. Manevich, Y.; Hutchens, S.; Halushka, P.V.; Tew, K.D.; Townsend, D.M.; Jauch, E.C.; Borg, K. Peroxiredoxin VI oxidation in cerebrospinal fluid correlates with traumatic brain injury outcome. Free Radic. Biol. Med. 2014, 72, 210-221. [CrossRef] [PubMed]

100. Shichita, T.; Hasegawa, E.; Kimura, A.; Morita, R.; Sakaguchi, R.; Takada, I.; Sekiya, T.; Ooboshi, H.; Kitazono, T.; Yanagawa, T.; et al. Peroxiredoxin family proteins are key initiators of post-ischemic inflammation in the brain. Nat. Med. 2012, 18, 911-917. [CrossRef] [PubMed]

101. Shichita, T.; Sakaguchi, R.; Suzuki, M.; Yoshimura, A. Post-ischemic inflammation in the brain. Front. Immunol. 2012, 3, 132. [CrossRef] [PubMed]

102. Shanshan, Y.; Beibei, J.; Li, T.; Minna, G.; Shipeng, L.; Li, P.; Yong, Z. Phospholipase A2 of Peroxiredoxin 6 Plays a Critical Role in Cerebral Ischemia/Reperfusion Inflammatory Injury. Front. Cell. Neurosci. 2017, 11, 99. [CrossRef] [PubMed]

103. Power, J.H.; Asad, S.; Chataway, T.K.; Chegini, F.; Manavis, J.; Temlett, J.A.; Jensen, P.H.; Blumbergs, P.C.; Gai, W.P. Peroxiredoxin 6 in human brain: Molecular forms, cellular distribution and association with Alzheimer's disease pathology. Acta Neuropathol. 2008, 115, 611-622. [CrossRef] [PubMed] 
104. Yun, H.M.; Choi, D.Y.; Oh, K.W.; Hong, J.T. PRDX6 Exacerbates Dopaminergic Neurodegeneration in a MPTP Mouse Model of Parkinson's Disease. Mol. Neurobiol. 2015, 52, 422-431. [CrossRef] [PubMed]

105. Yeo, I.J.; Park, M.H.; Son, D.J.; Kim, J.Y.; Nam, K.T.; Hyun, B.K.; Kim, S.Y.; Jung, M.H.; Song, M.J.; Chun, H.O.; et al. PRDX6 Inhibits Neurogenesis through Downregulation of WDFY1-Mediated TLR4 Signal. Mol. Neurobiol. 2018. [CrossRef] [PubMed]

106. Yun, H.M.; Park, K.R.; Kim, E.C.; Hong, J.T. PRDX6 controls multiple sclerosis by suppressing inflammation and blood brain barrier disruption. Oncotarget 2015, 6, 20875-20884. [CrossRef] [PubMed]

107. Lee, D.; Moawad, A.R.; Morielli, T.; Fernandez, M.C.; O’Flaherty, C. Peroxiredoxins prevent oxidative stress during human sperm capacitation. Mol. Hum. Reprod. 2017, 23, 106-115. [CrossRef] [PubMed]

108. Fernandez, M.C.; O'Flaherty, C. Peroxiredoxin 6 is the primary antioxidant enzyme for the maintenance of viability and DNA integrity in human spermatozoa. Hum. Reprod. 2018. [CrossRef] [PubMed]

109. Gong, S.; San Gabriel, M.C.; Zini, A.; Chan, P.; O'Flaherty, C. Low amounts and high thiol oxidation of peroxiredoxins in spermatozoa from infertile men. J. Androl. 2012, 33, 1342-1351. [CrossRef] [PubMed]

110. Moawad, A.R.; Fernandez, M.C.; Scarlata, E.; Dodia, C.; Feinstein, S.I.; Fisher, A.B.; O'Flaherty, C. Deficiency of peroxiredoxin 6 or inhibition of its phospholipase A2 activity impair the in vitro sperm fertilizing competence in mice. Sci. Rep. 2017, 7, 12994. [CrossRef] [PubMed]

(C) 2018 by the authors. Licensee MDPI, Basel, Switzerland. This article is an open access article distributed under the terms and conditions of the Creative Commons Attribution (CC BY) license (http:/ / creativecommons.org/licenses/by/4.0/). 


\title{
Article \\ Identification of Small Peptides that Inhibit NADPH Oxidase (Nox2) Activation
}

\author{
Aron B. Fisher *, Chandra Dodia and Sheldon I. Feinstein \\ Institute for Environmental Medicine, University of Pennsylvania Perelman School of Medicine, \\ Philadelphia, PA 19104, USA; cdodia@pennmedicine.upenn.edu (C.D.); sif@pennmedicine.upenn.edu (S.I.F.) \\ * Correspondence: abf@upenn.edu; Tel.: +1-215-898-9100; Fax: 215-898-0868
}

Received: 26 October 2018; Accepted: 20 November 2018; Published: 5 December 2018

\begin{abstract}
Nicotinamide adenine phosphate (NADPH) oxidase type 2 (Nox2), a major source of reactive oxygen species in lungs, plays an important role in tissue damage associated with acute inflammatory diseases. The phospholipase $\mathrm{A}_{2}\left(\mathrm{PLA}_{2}\right)$ activity of peroxiredoxin $6(\operatorname{Prd} 66)$, called aiPLA $A_{2}$, is required for Nox2 activation through its role in the cellular generation of Rac, a key cytosolic component of the activation cascade. Lung surfactant protein A (SP-A) binds to Prdx6, inhibits its aiPLA $A_{2}$ activity, and prevents activation of Nox2. Based on protein docking software, we previously identified a 16 amino acid (aa) peptide derived from rat SP-A as the Prdx6 binding motif. We now identify the minimal effective sequences of rat/mouse and human SP-A as 9-aa sequences that we have called PLA $\mathrm{A}_{2}$-inhibitory peptide (PIP).These sequences are PIP-1, rat/mouse; PIP-2, human; and PIP-3, a hybrid of PIPs $1 \& 2$. aiPLA 2 activity in vitro was inhibited by $50 \%$ with 7-10 $\mu \mathrm{g}$ PIP/ $\mu \mathrm{g}$ Prdx6. Inhibition of the aiPLA ${ }_{2}$ activity and Nox2 activation of lungs in vivo was similar for intratracheal (IT) and intravenous (IV) administration of PIP-2, but required its incorporation into liposomes as a delivery vehicle; tissue $\frac{1}{2}$ time for decrease of the in vivo inhibition of aiPLA $A_{2}$ activity after PIP-2 administration was $\sim 50 \mathrm{~h}$. These properties suggest that PIP- 2 could be an effective therapeutic agent to prevent tissue injury associated with lung inflammation.
\end{abstract}

Keywords: peroxiredoxin 6; surfactant protein A; phospholipase $\mathrm{A}_{2}$; drug delivery; liposomes

\section{Introduction}

The term 'reactive oxygen species', abbreviated as ROS, comprises superoxide anion $\left(\mathrm{O}_{2}{ }^{-\bullet}\right)$, a free radical, and the non-radical $\mathrm{H}_{2} \mathrm{O}_{2}$, along with other chemically reactive compounds derived from the metabolism of molecular $\mathrm{O}_{2}$. ROS are generated normally during cellular metabolism by a variety of enzymatic as well as non-enzymatic pathways. However, the seven-member family of NADPH oxidases (Nox) and related dual oxidases (Duox) are the only enzymes that are known to generate ROS as their primary product [1]. Nox2, the first of the NOX/Duox family of enzymes to be described, is expressed widely in tissues with especially high levels in polymorphonuclear leukocytes (PMN) and macrophages, where it is localized primarily to intracellular phagolysosomes, and in pulmonary and cardiovascular endothelium where it is localized to the plasma membrane [2]. Intracellular Nox2 is inactive in the resting state but can be activated by a complex and tightly controlled pathway [3]. Control of activation is critical since the uncontrolled production of ROS can lead to oxidative damage to tissues.

The activation of the enzymatic activity of Nox 2 to produce ROS requires the phosphorylation of several cytosolic proteins (p67phox, p47phox , and p40 phox $)$ and the activation of Rac ( 1 or 2, depending on the cell type) [4-6]. Activation of Rac occurs through its dissociation from a complex with Rho protein GDP dissociation inhibitor (Rho-GDI) and formation of Rac-GTP. Activated Rac binds to phosphorylated $6^{67^{p h o x}}$, facilitating its translocation (along with other cytosolic Nox2 co-factors) to 
the plasma membrane where the cytosolic proteins interact with the cell membrane-localized Nox2 complex (consisting of the proteins Nox2 plus p22 ${ }^{\text {phox }}$ ) [4,6,7]; upon activation, the Nox2 protein can transfer an electron from NADPH to molecular $\mathrm{O}_{2}$ to generate $\mathrm{O}_{2}{ }^{-\bullet}$. Dismutation of $\mathrm{O}_{2}{ }^{-\bullet}$, either spontaneously or through the activity of superoxide dismutase, produces $\mathrm{H}_{2} \mathrm{O}_{2}$. For some time, these ROS have been known to play an important role in bodily defenses against infection through their bactericidal activity $[2,8]$. Recent studies have demonstrated that ROS also play an essential role in normal cell biology, providing the molecular signals that regulate cell motility, cell division, programmed cell death, and various other basal biological functions $[9,10]$.

An outstanding question regarding the regulation of Nox2 relates to the upstream signals that initiate the Nox2 activation cascade. Previous studies have indicated that a phospholipase $\mathrm{A}_{2}\left(\mathrm{PLA}_{2}\right)$ enzyme plays an important role [11-13]. PLA 2 represents a large family of lipid hydrolases that includes both secreted proteins that function extracellularly and intracellular proteins with specific subcellular localizations [14]. Furthermore, although all $\mathrm{PLA}_{2}$ s hydrolyze phospholipids at their $s n-2$ position, many show some phospholipid substrate specificity. Earlier, the enzyme known as cytosolic $\mathrm{PLA}_{2}\left(\mathrm{cPLA}_{2}\right)$ was suggested as responsible for Nox2 activation [15], but that was not confirmed by a comprehensive study with cPLA 2 null mice [16].

We recently have described the $\mathrm{PLA}_{2}$ activity of peroxiredoxin $6(\operatorname{Prdx} 6)$ and shown that it is specifically involved in activation of Nox2 [7,17]. This PLA 2 , that we have called aiPLA 2 based on its activity at acidic $\mathrm{pH}$, is expressed widely in tissues. [18,19]. Prdx6 is present mainly in cytosol where it has minimal PLA 2 activity but phosphorylation (via MAP kinases) results in its translocation to the plasma membrane where it binds to cell membrane phospholipids resulting in a marked increase in $\mathrm{PLA}_{2}$ activity [18]. The enzyme also is present in some organelles with acidic internal content such as lysosomes and lysosomal-related organelles; these organelles express aiPLA $A_{2}$ activity in the non-phosphorylated state, albeit at a considerably lower level than for the phosphorylated protein [18]. Nox2 activation by Prdx6 is prevented by the presence of MJ33, a mimic of the substrate transition state, that inhibits aiPLA 2 activity $[17,18,20]$.Activation of Nox2 also is prevented by mutating Prdx6 to a form (D140A-Prdx6) that specifically lacks a crucial member of the catalytic triad necessary for aiPLA $A_{2}$ activity.

Our recent studies have clarified the role of aiPLA 2 in the activation of Nox2 [7,17]. Lipid binding of phosphorylated Prdx6 at the cell membrane is primarily to phosphatidylcholine and the PLA 2 activity of Prdx6 with this substrate generates lysophosphatidylcholine (LPC) that, in turn, can be converted via lysophospholipase D activity to lysophosphatidic acid (LPA). LPA binds to its cell membrane receptor resulting in the generation of active Rac. The pathway for the role of aiPLA 2 in Nox2 activation is shown in Figure 1.

The impetus for our initial investigation of the interaction of Prdx6 with lung surfactant protein A (SP-A) was a publication showing that a serum protein from the Habu snake with homology to lung surfactant protein A (SP-A) inhibited the $\mathrm{PLA}_{2}$ component of its venom, presumably as a way to prevent accidental poisoning [21]. We confirmed that SP-A itself inhibits Habu snake PLA 2 activity and showed further that SP-A can bind to Prdx6 and inhibit its aiPLA ${ }_{2}$ activity [22-24]. Prdx6 is present in lung lysosomal-related organelles, i.e., epithelial cell lamellar bodies (LB), the site of lung surfactant storage [25]. Since SP-A also is present in LB, we postulated that the interaction of Prdx6 with SP-A may be an important physiological mechanism to control the remodeling pathway for the synthesis of lung surfactant phospholipids [23]. Following these initial observations, we identified a 16 amino acid (aa) peptide sequence in SP-A that binds to Prdx6 and inhibits its aiPLA $\mathrm{A}_{2}$ activity [26]. This peptide was identified with the ZDOCK program [27] by using molecular sequences in the Protein Data Base (PDB) in order to predict the molecular sites for interaction of the two proteins (Prdx6 and SP-A). Molecular modeling of SP-A used the sequence between the hydrophobic neck region and the collagen-like carbohydrate recognition domain (CRD) of rat/mouse SP-A [28]. Binding by the predicted SP-A-derived peptide to the Prdx6 protein was confirmed by isothermal titration calorimetry, circular dichroism measurement, and inhibition of its aiPLA $A_{2}$ activity [26]. The purpose of the present 
investigation was to determine the minimal amino acid sequence for an SP-A-derived inhibitory peptide and to evaluate the properties of inhibitory peptides as potential therapeutic agents to prevent Nox2 activation in conditions where excess ROS generation can lead to organ injury. This publication is part of a Forum on Peroxiredoxin 6 as a Unique Member of the Peroxiredoxin Family.

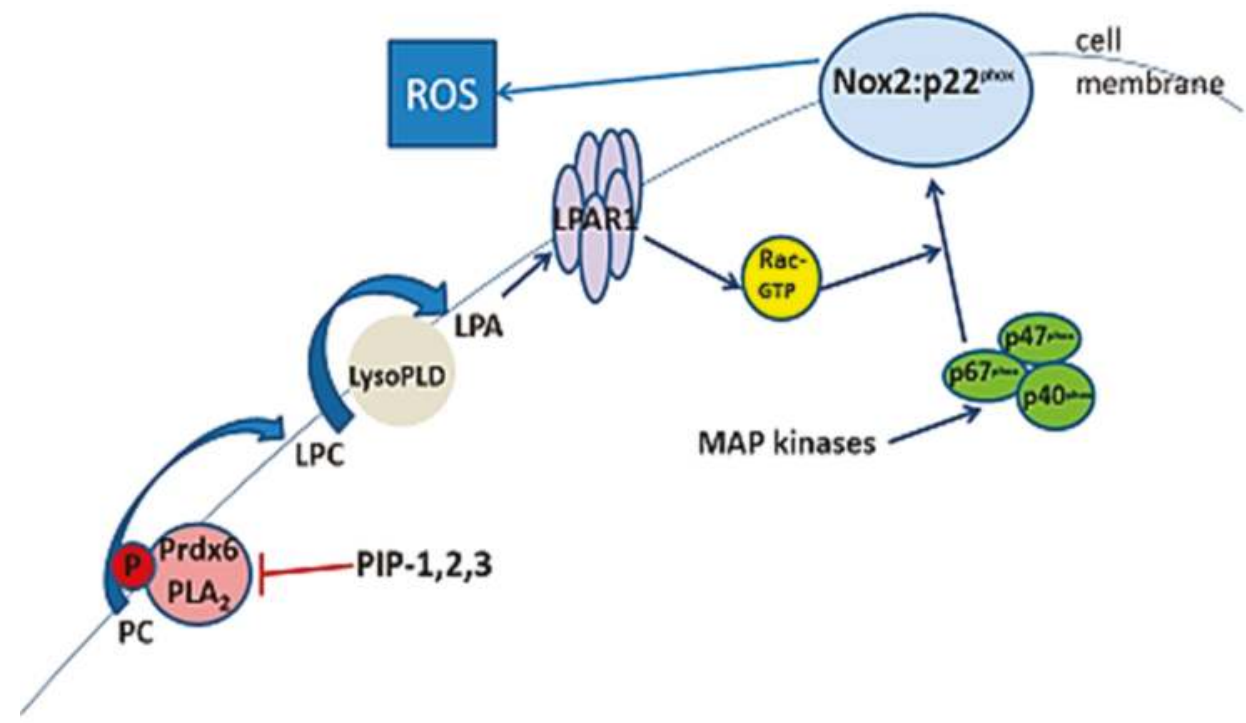

Figure 1. The pathway for activation of NADPH oxidase type 2 (Nox2). This pathway requires generation of lysophosphatidylcholine (LPC) through the PLA 2 activity of phosphorylated Prdx6; LPC is converted to lysophosphatidic acid (LPA) that binds to its cell membrane-localized receptor (LPAR1) leading to the activation of Rac (1 or 2). Activated Rac (Rac-GTP) binds to p67phox and it along with other phosphorylated cytoplasmic factors (shown in green) bind to the membrane-localized Nox2 complex resulting in its activation to generate reactive oxygen species (ROS). The presence of one of the PLA2-inhibitory proteins (PIP-1, -2, or -3) inhibits PLA 2 activity and prevents Nox2 activation. PC, phosphatidylcholine; LysoPLD, lysophospholipase D; MAP kinase, mitogen activated protein kinase. Modified from [7] and reprinted with permission.

\section{Methods}

Mice (C57Bl/6) were purchased from The Jackson Laboratory and maintained in the University of Pennsylvania Animal Care Facilities. We have described previously the generation of D140A-Prdx6 expressing mice using 'knock-in' technology; the lungs of these mice do not express aiPLA $A_{2}$ activity [29]. Subsequently, the neomycin resistance cassette (NRC) and the flippase gene that was introduced to remove the NRC have been removed from the genome of this mouse [19]. All studies using mice were approved by the University of Pennsylvania Institutional Animal Care and Use Committee (IACUC).

Peptides were synthesized by APeptide Co., Ltd. (Shanghai, China) and were supplied with a mass spectroscopic analysis to verify composition; purity as determined by mass spectroscopy was 94\% for PIP-1, $89 \%$ for PIP-2, and 91\% for PIP-3.

For administration to mice, peptides were incorporated into liposomes that were prepared as previously described [30]. Liposome composition was dipalmitoylphosphatidylcholine (DPPC): egg phosphatidylcholine: phosphatidylglycerol: cholesterol in the molar ratio 50:25:10:15. To measure the in vivo effect of the peptides, mice were injected with PIP-2 by either the intratracheal (IT) or the intravenous (IV) route and were sacrificed at intervals; lungs were removed from mice and homogenized for measurement of aiPLA ${ }_{2}$ activity. 
The PLA 2 activity of Prdx6 was measured as described previously [30]. The substrate was dipalmitoylphosphatidylcholine (DPPC) with ${ }^{3} \mathrm{H}-9,10$-palmitate in the $s n-2$ position of DPPC incorporated into lung surfactant-like liposomes as described above; substrate was incubated with enzyme for $60 \mathrm{~min}$ and activity was calculated from the liberation of ${ }^{3} \mathrm{H}$-palmitate as measured by scintillation counting.

The generation of ROS by the intact isolated perfused lung was determined from the increased fluorescence associated with the oxidation of Amplex red in the presence of horseradish peroxidase as described previously [17]. Aliquots of perfusate taken at intervals with increasing time of perfusion were analyzed with a spectrofluorometer. Angiotensin II (AngII) was added to lung perfusate to stimulate ROS production through its activation of $\mathrm{N}_{\mathrm{Ox}} 2$, primarily in the lung endothelial cells since these cells express the relevant receptor.

\section{Results}

\subsection{Minimal Effective Peptide Sequence}

As indicated above, we previously identified a 16 amino acid peptide corresponding to the amino acids at positions 83 to 99 of the carbohydrate-recognition domain (CRD) of rat SP-A; these aa are located at positions 102-118 in the SP-A monomer. The corresponding sequence in the mouse SP-A CRD is identical in aa composition to the rat sequence. This 16-aa peptide inhibits the aiPLA $A_{2}$ activity of human recombinant Prdx6 by $\sim 66 \%$ (Table 1), presumably by binding to Prdx6 as demonstrated previously [26]. We then synthesized peptides in which amino acids were deleted from either the $\mathrm{N}$-terminus or the C-terminus of the 16-aa peptide in order to determine a minimum aa sequence that maintained the ability to inhibit aiPLA 2 activity. Deletion of the C-terminal amino acid (Leu) abolished the ability of the peptide to inhibit aiPLA 2 activity indicating that this aa is required for effectiveness (Table 1). Deletion from the N-terminus to generate 14-, 12-, 10-, or 9-aa peptides had no effect on the inhibitory activity of the peptide but activity was lost with the eight-aa peptide (Table 1). Thus, the minimal effective sequence for inhibition of aiPLA $\mathrm{A}_{2}$ activity is a nine amino acid peptide comprising positions 8 through 16 of the original 16-aa peptide; this nine-aa peptide was called PIP-1.

Table 1. Deletion of N- or C-terminal amino acids from 16-aa rat-derived SP-A peptide: effect on the inhibition of the aiPLA 2 activity of recombinant hPrdx6.

\begin{tabular}{ccccc}
\hline Peptide Length & $\begin{array}{c}\text { Sequence } \\
\text { Delete from } \\
\text { N-term }\end{array}$ & $\begin{array}{c}\text { Activity, } \\
\text { nmol/min/mg Prot. }\end{array}$ & $\begin{array}{c}\text { Sequence } \\
\text { Delete from } \\
\text { C-term }\end{array}$ & $\begin{array}{c}\text { Activity, } \\
\text { nmol/min/mg Prot. }\end{array}$ \\
\hline control & No peptide & 94.8 & Scrambled peptide: & 93.5 \\
16 aa & DEELQTELYEIKHQIL & 32.0 & LELDEEITEYQKQLHI & 32.0 \\
14 aa & ELQTELYEIKHQIL & 33.2 & DEELQTELYEIKHQIL & 102 \\
12 aa & QTELYEIKHQIL & 31.5 & NELQTELYEIKHQ & \\
10 aa & ELYEIKHQIL & 28.6 & No entry & 89.6 \\
9 aa & LYEIKHQIL & 32.3 & ELYEIKHQI & 93.6 \\
8 aa & (PIP-1) & 94.4 & DEELQTEL & 9 \\
\hline
\end{tabular}

Sequential deletions from the $\mathrm{N}$-terminus or $\mathrm{C}$-terminus of the rat/mouse 16-aa inhibitory peptide were used to determine the minimal effective sequence to inhibit the aiPLA 2 activity of peroxiredoxin 6 (Prdx6). The results represent one assay done in duplicate.

We next identified the 16-aa peptide in human SPA that was analogous to the rat/mouse sequence and showed that it also inhibited the aiPLA 2 activity of recombinant human Prdx6 (Table 2). Similarly to the rat/mouse peptide, deletion of seven aa from the N-terminus maintained its ability to inhibit aiPLA $_{2}$ activity while deletion of the C-terminal aa abolished its inhibitory activity (Table 2). The active nine-aa peptide derived from the human SP-A sequence was called PIP-2. 
Table 2. Deletion of amino acids from the N- or C-terminus of the 16-aa human-derived SP-A peptide: effect on the inhibition of aiPLA 2 activity of recombinant $h P r d x 6$.

\begin{tabular}{cccc}
\hline $\begin{array}{c}\text { Peptide, Number of } \\
\text { Amino Acids }\end{array}$ & Sequence & $\begin{array}{c}\text { Activity, } \\
\text { nmol/min/mg Prot. }\end{array}$ & Comment \\
\hline No peptide & Control & 92.0 & $\begin{array}{c}\text { No added peptide } \\
16 \text { aa }\end{array}$ \\
10 aa & DEELQATLHDFRHQIL & 45.0 & aa human peptide \\
9 aa & TLHDFRHQIL & 31.5 & Delete from N-term \\
9 aa & LHDFRHQIL & 29.9 & Delete from N-term \\
\hline
\end{tabular}

Same experiment as in Table 1 but deletions were from the human-derived 16-aa inhibitory peptide. The results represent one assay done in duplicate.

On comparing the PIP-1 (rat/mouse) and PIP-2 (human) peptides, the first aa and the terminal 4 aa were identical. Thus, only aa 2 to 5 differed between the two peptides. To evaluate the aa requirements at positions $2-5$ for activity, we randomly substituted these with the aa that occurred in the effective sequences (PIPs-1 and -2). The nine-aa peptide LYDIRHQIL, representing a hybrid between the human and rat/mouse sequences, was an effective inhibitor of aiPLA $A_{2}$ activity $(\sim 70 \%$ inhibition, similar to PIP-2); this peptide, was called PIP-3. Of note, PIP-3, unlike PIPs-1 and -2, is not part of a known naturally occurring protein. Substitution of an I for the $\mathrm{F}$ at position 4 in the human peptide decreased the ability to inhibit aiPLA 2 by about one-half. An additional 4 peptides synthesized with various combinations of the rat and mouse aa located at positions $2-5$ of PIP- 1 and PIP-2 were ineffective as aiPLA2 inhibitors (not shown). Finally, we synthesized six different peptides based on the PIP-2 sequence with substitutions at position 6 ( $\mathrm{Q}$ for $\mathrm{H}), 7$ (K,H,or $\mathrm{R}$ for $\mathrm{Q})$, and 8 (V or A for I); none of these substituted peptides were effective inhibitors of aiPLA ${ }_{2}$ activity.

\subsection{Species Variability}

The differences between the human and rat/mouse sequences led us to examine the protein database and to extract the amino acid sequences of SP-A for various mammalian species, including five non-human primates, and one avian species (chicken) (Table 3). Only the $\mathrm{L}$ at position 9 in the peptide was invariant for these 19 species that were found in the database. An L occurred at position 1 in all but one species (guinea pig) and only one specie (chicken) did not have an $\mathrm{H}$ at position 6. The aa at positions $2-5$ for the various species generally correspond to either the human or rat peptide sequence or to a combination of those amino acids. Species that show similar sequences to the rat/mouse model for aa in positions 2-5 include the cotton rat, cow, sheep, yak, and pig (Table 3). All sequences of non-human primate SP-A were identical to the human sequence as was the sequence for African elephant SP-A, although the latter was located at position 142-150 in the full length protein instead of position 111-119. The sequences from horse and wolf have a single difference (compared to human) for the aa at position 4 . The consensus amino acids for each of the 9 positions were: (1) $\mathrm{L}, F$; (2) H,Y,L; (3) D,E,L,N; (4) F,I,L,N; (5) R,K; (6) H,Q; (7) Q,K,H,R; (8) I,V,A; (9) L, where the amino acids in italics indicate an amino acid present in only a single species. The greatest differences from the human and rat/mouse sequences were seen for the guinea pig, rabbit, and chicken peptides.

Of note, the nine-aa peptide sequence of the wolf protein did not inhibit aiPLA $\mathrm{A}_{2}$ activity while the sequence from the horse protein was only $~ 50 \%$ effective. These findings indicate that not all naturally occurring sequences are effective inhibitors (at least, of the human protein) and, if so, suggest that the inhibition of aiPLA $\mathrm{A}_{2}$ by SP-A may not represent an important physiologic mechanism for regulating activity of this enzyme. 
Table 3. Amino acids at the 9 amino acid positions in SP-A between 111-119 for various mammalian and 1 avian species.

\begin{tabular}{cccccccccc}
\hline Species & $\mathbf{1}$ & $\mathbf{2}$ & $\mathbf{3}$ & $\mathbf{4}$ & $\mathbf{5}$ & $\mathbf{6}$ & $\mathbf{7}$ & $\mathbf{8}$ & $\mathbf{9}$ \\
\hline Human & $\mathrm{L}$ & $\mathrm{H}$ & $\mathrm{D}$ & $\mathrm{F}$ & $\mathrm{R}$ & $\mathrm{H}$ & $\mathrm{Q}$ & $\mathrm{I}$ & $\mathrm{L}$ \\
Primates + & $\mathrm{L}$ & $\mathrm{H}$ & $\mathrm{D}$ & $\mathrm{F}$ & $\mathrm{R}$ & $\mathrm{H}$ & $\mathrm{Q}$ & $\mathrm{I}$ & $\mathrm{L}$ \\
Elephant (African) \# & $\mathrm{L}$ & $\mathrm{H}$ & $\mathrm{D}$ & $\mathrm{F}$ & $\mathrm{R}$ & $\mathrm{H}$ & $\mathrm{Q}$ & $\mathrm{I}$ & $\mathrm{L}$ \\
Horse & $\mathrm{L}$ & $\mathrm{H}$ & $\mathrm{D}$ & $\mathrm{I}$ & $\mathrm{R}$ & $\mathrm{H}$ & $\mathrm{Q}$ & $\mathrm{I}$ & $\mathrm{L}$ \\
Wolf & $\mathrm{L}$ & $\mathrm{H}$ & $\mathrm{D}$ & $\mathrm{L}$ & $\mathrm{R}$ & $\mathrm{H}$ & $\mathrm{Q}$ & $\mathrm{I}$ & $\mathrm{L}$ \\
Rabbit & $\mathrm{L}$ & $\mathrm{H}$ & $\mathrm{E}$ & $\mathrm{L}$ & $\mathrm{R}$ & $\mathrm{H}$ & $\mathrm{H}$ & $\mathrm{A}$ & $\mathrm{L}$ \\
Chicken & $\mathrm{L}$ & $\mathrm{L}$ & $\mathrm{N}$ & $\mathrm{L}$ & $\mathrm{R}$ & $\mathrm{Q}$ & $\mathrm{R}$ & $\mathrm{I}$ & $\mathrm{L}$ \\
Rat & $\mathrm{L}$ & $\mathrm{Y}$ & $\mathrm{E}$ & $\mathrm{I}$ & $\mathrm{K}$ & $\mathrm{H}$ & $\mathrm{Q}$ & $\mathrm{I}$ & $\mathrm{L}$ \\
Mouse & $\mathrm{L}$ & $\mathrm{Y}$ & $\mathrm{E}$ & $\mathrm{I}$ & $\mathrm{K}$ & $\mathrm{H}$ & $\mathrm{Q}$ & $\mathrm{I}$ & $\mathrm{L}$ \\
Cotton rat & $\mathrm{L}$ & $\mathrm{H}$ & $\mathrm{E}$ & $\mathrm{I}$ & $\mathrm{K}$ & $\mathrm{H}$ & $\mathrm{K}$ & $\mathrm{I}$ & $\mathrm{L}$ \\
Cow & $\mathrm{L}$ & $\mathrm{H}$ & $\mathrm{E}$ & $\mathrm{I}$ & $\mathrm{R}$ & $\mathrm{H}$ & $\mathrm{Q}$ & $\mathrm{V}$ & $\mathrm{L}$ \\
Yak & $\mathrm{L}$ & $\mathrm{H}$ & $\mathrm{E}$ & $\mathrm{I}$ & $\mathrm{R}$ & $\mathrm{H}$ & $\mathrm{Q}$ & $\mathrm{V}$ & $\mathrm{L}$ \\
Sheep & $\mathrm{L}$ & $\mathrm{H}$ & $\mathrm{E}$ & $\mathrm{I}$ & $\mathrm{R}$ & $\mathrm{H}$ & $\mathrm{Q}$ & $\mathrm{V}$ & $\mathrm{L}$ \\
Pig & $\mathrm{L}$ & $\mathrm{H}$ & $\mathrm{E}$ & $\mathrm{I}$ & $\mathrm{R}$ & $\mathrm{H}$ & $\mathrm{Q}$ & $\mathrm{I}$ & $\mathrm{L}$ \\
Guinea pig & $\mathrm{F}$ & $\mathrm{H}$ & $\mathrm{L}$ & $\mathrm{N}$ & $\mathrm{K}$ & $\mathrm{H}$ & $\mathrm{K}$ & $\mathrm{I}$ & $\mathrm{L}$
\end{tabular}

* Human surfactant protein A1. + gorilla, orangutan, baboon, chimpanzee, rhesus monkey; \# peptide is found at aa142-150. Red letters indicate those aa that are not present in the respective positions in either the human or the rat sequence.

\subsection{Physical Properties of Inhibitory Peptides}

The aa sequences and some characteristics of the three inhibitory peptides, PIP-1, PIP-2, and PIP3 , are shown in Table 4 . These peptides have a molecular mass of 1156-1178 with a predicted isoelectric point in the slightly basic range. Each of the three peptides contains four hydrophobic amino acid residues, with two of those on the same surface, and one negatively charged hydrophilic aa. The PIP-2 sequence has three while PIPs- 1 and -3 have only two positively charged aa. PIP- 1 is slightly more hydrophobic than the other two peptides but, in our experience, all three peptides readily dissolve in aqueous solution. The protein binding potential (Boman index) was slightly greater for the more hydrophilic PIP-2 indicating that it may bind slightly better to proteins as compared to PIPs-1 and -3. The UV extinction coefficient of PIPs 1 and 3 reflects the presence of a Tyr residue while PIP-2 does not contain an aa that absorbs UV light. No antigenic determinants were identified in these peptides as determined by the free on-line program provided by the Immunomedicine Group of the Universidad Complutense (Madrid, Spain). The chemical stability of PIP-2 was tested by placing the dry powder on the laboratory shelf at room temperature; its inhibition of the aiPLA $A_{2}$ activity of recombinant human Prdx6 was unchanged when measured after nine months of shelf storage indicating good stability of the peptide as a dry powder (data not shown); stability of the other peptides was not tested.

Table 4. Properties of inhibitory peptides.

\begin{tabular}{cccc}
\hline Properties & Rat/Mouse (PIP-1) & Human (PIP-2) & Hybrid (PIP-3) \\
\hline Number of residues & 9 & 9 & 9 \\
Sequence & LYEIKHQIL & LHDFRHQIL & LYDIRHQIL \\
Molecular weight, g/mol & 1156 & 1178 & 1170 \\
Hydrophobic residues & L,I,I,L & L,F,I,L & L,I,I,L \\
On same surface & I,I & F,I & I,I \\
Grand average hydropathy & 0.1333 & -0.3333 & 0.0666 \\
Charged amino acids: neg pos & $\mathrm{E}$ & $\mathrm{D}$ & $\mathrm{D}, \mathrm{H}, \mathrm{H}$ \\
Iso-electric point, $\mathrm{pH}$ & $\mathrm{K}, \mathrm{H}$ & 8.0 & $\mathrm{R}, \mathrm{H}$ \\
Protein-binding potential, $\mathrm{kcal} / \mathrm{mol}^{-1}$ & 7.7 & 2.3 & 7.8 \\
Extinction coeff. at $280 \mathrm{~nm}, \mathrm{M}^{-1} \mathrm{~cm}^{-1}$ & 0.33 & 0 & 1.58 \\
Antigenic propensity, average & 1490 & 1.057 & 1490 \\
Antigenic determinants & 1.077 & none & 1.072 \\
\hline
\end{tabular}

Calculations and estimations were made by Innovagen's peptide calculator [27] and the Antimicrobial Peptide Database (APD) predictor [31]; antigenic determinants were evaluated by a program from the immunomedicine group of the Universidad Complutense Madrid, Spain [32]. 


\subsection{Inhibition of aiPLA $A_{2}$ Activity In Vitro}

The effect of the PIP peptides on the aiPLA 2 activity of human recombinant Prdx6 was determined by in vitro assay; the effective concentration of inhibitor was corrected for purity of the PIP preparation. Saturating concentrations of all three peptides (PIP-1, PIP-2, PIP-3) inhibited aiPLA 2 activity by $\sim 70 \%$ (Figure 2). The basis for the remaining 30\% of activity that was not inhibited is unclear. The concentration of peptide ( $\mu \mathrm{g} / \mathrm{mg}$ Prdx6) for inhibition of aiPLA 2 activity by $50 \%$ was $\sim 8.3$ for PIP-1, 6.6 for PIP-2, and 10 for PIP-3 indicating slightly greater effectiveness of PIP-2 as an inhibitor. The ratio of the molecular mass of the nine-aa peptides to Prdx6 (monomeric MW 25 kDa) is $\sim 0.047$ while maximal inhibition of activity was seen at a ratio of PIP to Prdx6 concentration of $\sim 0.030$ (Figure 2); this indicates a stoichiometry of approximately 1.5 to 1 for molar binding of the peptide to the Prdx6 monomer at maximal inhibition of activity.

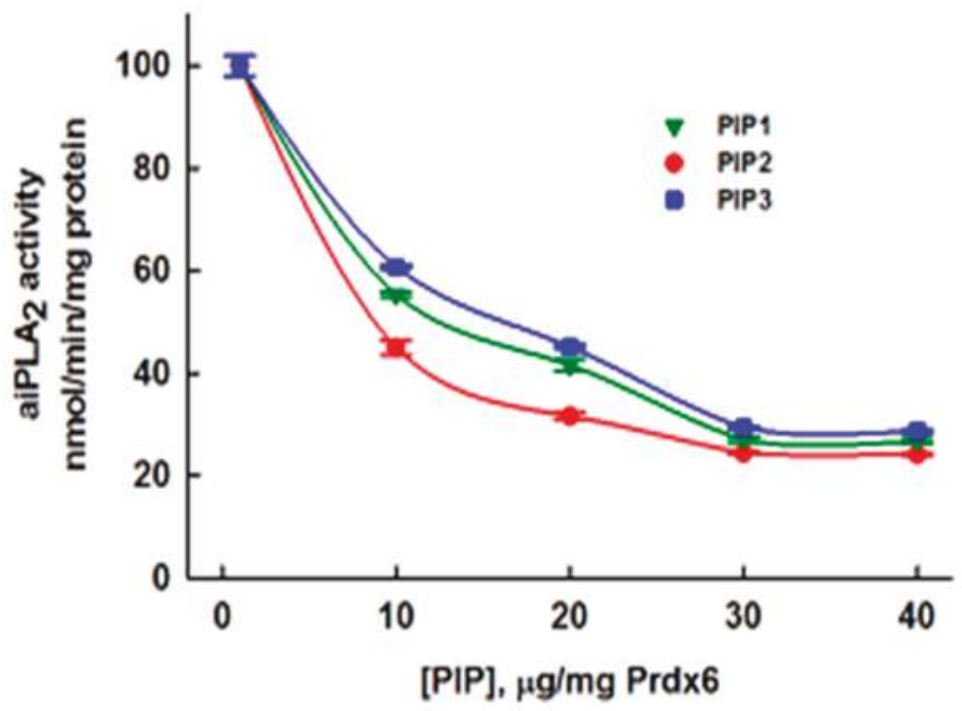

Figure 2. Effect of the concentration of PIP peptides on the aiPLA 2 activity of recombinant human Prdx6. Results are mean + SEM for $n=3$.

As determined by protein truncation and ITC, the site on Prdx6 for binding of the 16-aa peptide derived from rat/mouse protein was in the Prdx6 C-terminus (aa 210-225). This sequence does not include the aiPLA 2 active site (S32-D140-H26) [33]. Thus, unlike MJ33 that competitively inhibits aiPLA 2 activity as an analogue of the substrate transition state [34], inhibition of aiPLA $A_{2}$ activity by the SP-A derived peptide is non-competitive. The mechanism for inhibition of aiPLA $A_{2}$ activity through binding of the peptide to the enzyme is an alteration of the secondary structure of the protein, as shown by far UV circular dichroism [21].

\subsection{Intracellular Delivery of PIP-2}

Most small peptides are unable to cross cell membranes and thus their activity toward intracellular targets requires either aa modification or the use of a 'delivery vehicle'. In order to evaluate the permeability of lung cells to PIP-2, we perfused isolated lungs for 15 min with the peptide alone or with the peptide encapsulated in liposomes; the perfusing medium was then switched to PIP-2 free (to remove any PIP-2 containing extracellular medium), and then Ang II was added to activate endothelial Nox2. Finally, Amplex red (plus horseradish peroxidase) was added to the recirculating perfusate in order to measure ROS production. Lung perfusion and ROS production were determined 
similarly at 15 min after intratracheal instillation of PIP-2, with or without liposomes. Our previous studies in rats and mice have shown that intratracheal instillation of these liposomes results in their rapid distribution throughout the lung and their rapid uptake by lung cells [35]. The linear rate of increase of oxidized Amplex red in the perfusate of control lungs (no PIP) indicates a continuous rate of Ang II-stimulated $\mathrm{H}_{2} \mathrm{O}_{2}$ production during the $1 \mathrm{~h}$ perfusion period (Figure 3). Perfusion with PIP-2 dispersed in saline (no liposomes) essentially had minimal effect on lung ROS production. Treatment of lungs with PIP-2 in liposomes, administered either by the IV or the IT route, led to a marked decrease in the rate of ROS production, compatible with the inhibition of lung aiPLA 2 activity so that lung NOX2 was not activated by Ang II. PIP-2 incorporated into surfactant-like liposomes prior to lung perfusion resulted in $\sim 75 \%$ inhibition of ROS production and results were similar for administration by either the IV or IT route (Figure 3). A similar experiment (not shown) with Nox2 null lungs showed a rate of Amplex red oxidation similar to the PIP-2 inhibited rate, indicating a low level of Amplex red oxidation by non-Nox2 dependent sources of ROS.
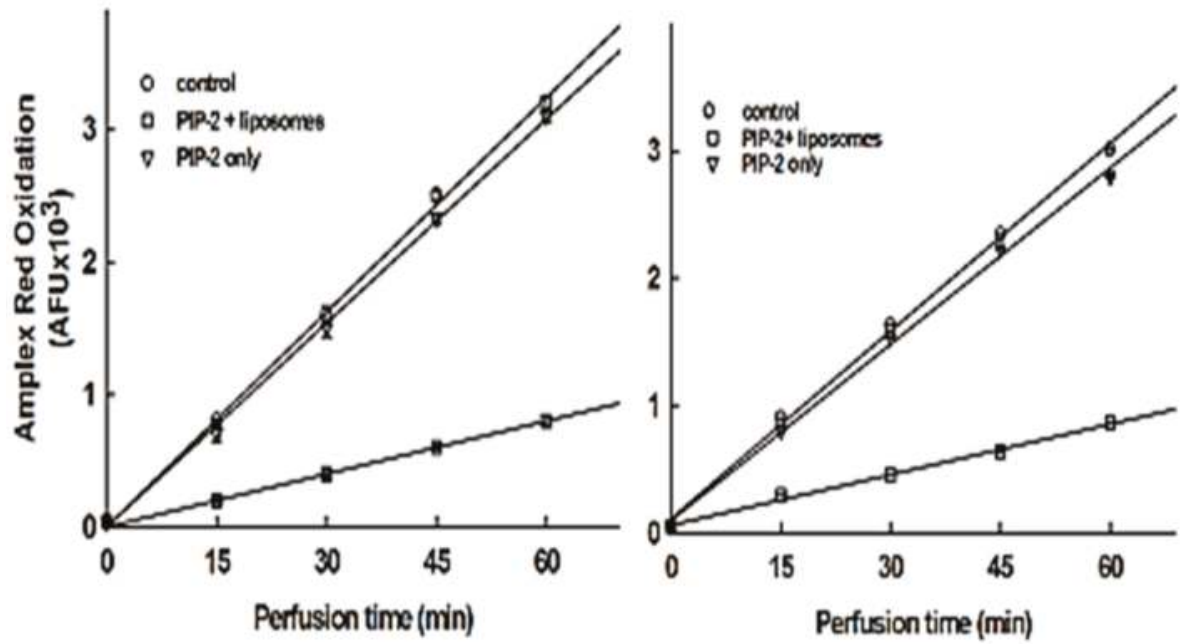

Figure 3. PIP-2 if encapsulated in liposomes inhibits lung ROS production when administered to. mice by either intratracheal (IT) or intravenous (IV) injection. PIP-2, with or without liposomes, and angiotensin II (to stimulate ROS production via NOX2) were administered to intact mice. Lungs were isolated $30 \mathrm{~min}$ later and ROS production was measured in the perfused lung by the oxidation of Amplex red plus horseradish peroxidase that were added to the lung perfusate.

To confirm the requirement for liposomes as a delivery vehicle, lungs were perfused for $15 \mathrm{~min}$ with PIP-2 incorporated or not into liposomes, then perfused with fresh medium to clear extracellular PIP-2, and then homogenized and assayed for aiPLA 2 activity. PIP-2 administered without liposomes had no effect on aiPLA 2 activity of the lung homogenate while PIP-2 in liposomes inhibited activity by $\sim 80 \%$ (Table 5).

Table 5. Liposomes are required for inhibition of aiPLA $\mathrm{A}_{2}$ activity by PIP-2 in isolated mouse lungs.

\begin{tabular}{cc}
\hline Conditions & aiPLA $_{\mathbf{2}}$ activity $\mathbf{n m o l} / \mathbf{m i n} / \mathbf{m g}$ Prot. \\
\hline No PIP & $8.72 \pm 0.16$ \\
PIP-2 in saline & $8.50 \pm 0.26$ \\
PIP-2 in liposomes & $1.55 \pm 0.11$ \\
\hline
\end{tabular}

Lungs were perfused with PIP-2 added directly to the perfusate or encapsulated in liposomes prior to addition. After $15 \mathrm{~min}$, lungs were cleared of perfusate, homogenized and aiPLA ${ }_{2}$ activity was measured. Results are mean \pm range for $n=2$. 


\subsection{Effect of PIP-2 on aiPLA $A_{2}$ Activity In Vivo and its Biological Stability}

To determine the effect and duration of a single dose of PIP-2 on aiPLA $\mathrm{A}_{2}$ activity of mouse lungs in vivo, mice were injected with PIP-2 in liposomes by either the intratracheal (IT) or the intravenous (IV) route; individual lungs were removed at intervals, homogenized, and assayed for aiPLA $\mathrm{A}_{2}$ activity. Lung aiPLA $A_{2}$ activity was inhibited by slightly greater than $80 \%$ after PIP-2 injection by either the IV or IT route (Figure 4). PLA 2 activity in lungs remained depressed for $24 \mathrm{~h}$, had begun recovery by $36 \mathrm{~h}$, and was recovered fully by $72 \mathrm{~h}$. The half-time for recovery was estimated at $\sim 50 \mathrm{~h}$.

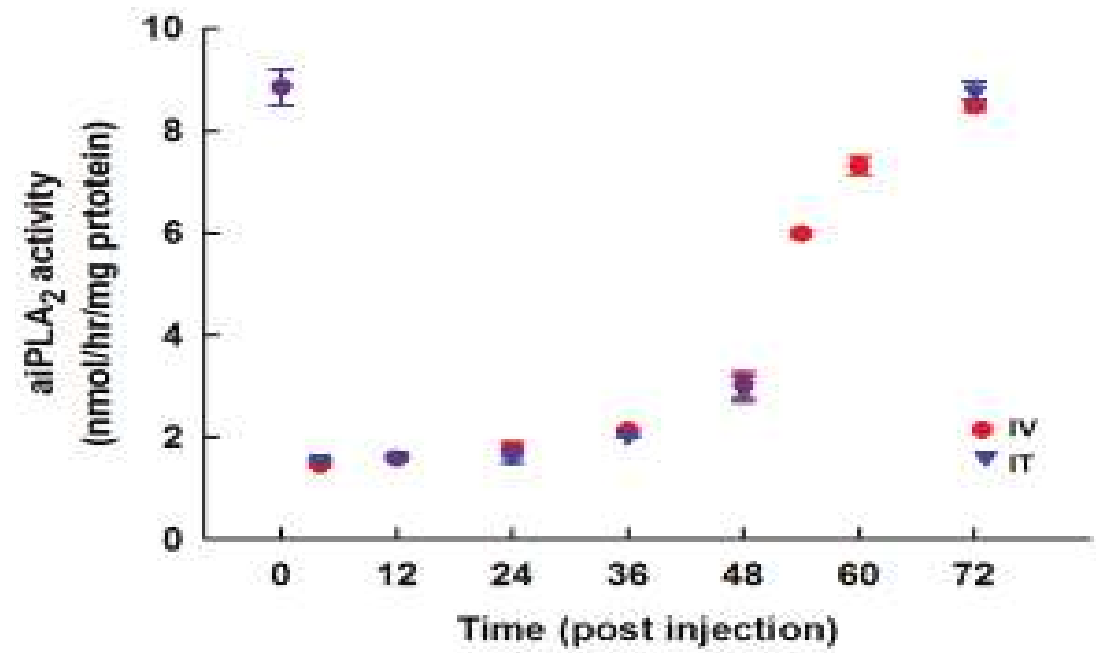

Figure 4. Persistence and stability of PIP-2 in vivo. PIP-2 was administered to mice either intratracheally (IT) or intravenously (IV) at 0 time. Lungs were harvested at intervals between 4 and $72 \mathrm{~h}$ after the PIP-2 administration, homogenized, and analyzed for aiPLA 2 activity. Results are mean + SEM for $n=3-4$.

\subsection{Specificity of $P L A_{2}$ Inhibition}

Lung cells, like those of other organs, have multiple PLA $\mathrm{P}_{2}$ enzymes [14]. We evaluated the specificity of PIP-2 for inhibition of Prdx6 by measuring aiPLA ${ }_{2}$ activity in the lung homogenate of wild type and D140A-Prdx6 mutant mice. Lungs from the mutant mice do not express aiPLA ${ }_{2}$ activity since D140 is a key component of the aiPLA 2 catalytic triad $[29,33]$. Measurement of PLA 2 activity at $\mathrm{pH} 4$ in the absence of $\mathrm{Ca}^{2+}$ is relatively specific for the $\mathrm{PLA}_{2}$ activity of Prdx6 (aiPLA 2 ) [18]. This activity was inhibited by $91 \%$ following addition of PIP- 2 to the assay of the lung homogenate (Table 6). Although Prdx6 has relatively little $\mathrm{PLA}_{2}$ activity when measured at $\mathrm{pH} 7$, other lung $\mathrm{PLA}_{2}$ enzymes, some of which are $\mathrm{Ca}^{2+}$-dependent for activity, show activity at neutral $\mathrm{pH}$; this activity was not affected by mutation of D140 in Prdx6 (Table 6). Unlike the effect of PIP-2 on aiPLA 2 activity at $\mathrm{pH} 4$, the addition of PIP-2 had no effect on activity of the lung PLA $\mathrm{P}_{2}$ enzymes that are active at $\mathrm{pH}$ 7. Thus, aiPLA 2 appears to be the only $\mathrm{PLA}_{2}$ enzyme, at least in the lung, that is inhibited by PIP-2. That result is not surprising since the specificity of binding of PIP-2 to the Prdx6 protein is the basis for its inhibition of aiPLA 2 activity and other $\mathrm{PLA}_{2}$ enzymes do not share aa sequence homology with Prdx6. 
Table 6. PIP-2 specificity as an inhibitor of aiPLA 2 as shown by the lack of effect on other PLA 2 enzymes.

\begin{tabular}{ccccc}
\hline \multirow{2}{*}{ Conditions } & \multicolumn{4}{c}{ PLA $_{2}$ activity, nmol/min/mg Prot. } \\
\cline { 2 - 5 } & \multicolumn{2}{c}{$\mathrm{pH} \mathrm{4}$} & \multicolumn{2}{c}{ pH 7 + Ca $^{2+}$} \\
\cline { 2 - 5 } & WT & D140A-Prdx6 & WT & D140A-Prdx6 \\
\hline No inhibitor & $8.7 \pm 0.16$ & $0.2 \pm 0.03$ & $8.5 \pm 0.26$ & $8.3 \pm 0.26$ \\
+PIP-2 & $1.6 \pm 0.10$ & $0.2 \pm 0.06$ & $8.5+0.30$ & $8.5 \pm 0.10$ \\
\hline
\end{tabular}

Lungs from wild type (WT) and D140A-Prdx6 'knock-in' mice were cleared of blood and homogenized; PLA 2 activity of the lung homogenate was measured at $\mathrm{pH} 4$ in the absence of $\mathrm{Ca}^{2+}$ and at $\mathrm{pH} 7$ in the presence of $\mathrm{Ca}^{2+}$. D140A-Prdx6 does not express aiPLA ${ }_{2}$ activity. Results are mean \pm range for $n=2$.

\section{Discussion}

The goal of the present investigation was to follow up on our published observation that a 16-aa peptide derived from the rat SP-A sequence could bind to Prdx6 and inhibit its aiPLA ${ }_{2}$ activity [26]. We first verified, through search of the Protein Data Base (PDB), that the rat and mouse sequences in the relevant part of the SP-A carbohydrate recognition domain (CRD), were identical. We next verified the corresponding region in the human SP-A CRD and confirmed that this peptide also inhibited aiPLA $_{2}$ activity, similar to the rat/mouse peptide. We found that progressive deletion of seven aa from the $\mathrm{N}$-terminus of either the rat/mouse or the human 16aa sequences had no effect on the inhibitory activity of the peptides, while activity was lost with deletion of eight aa from the N-terminus or deletion of the C-terminal aa. Thus, a nine-aa peptide represents the minimal sequence that was effective as an aiPLA $A_{2}$ inhibitory peptide.

Examination of the sequences of the two peptides (human and rat/mouse) showed identical aa in position 1 and positions 6-9 (LxxxxQHIL), while peptides 2-5 varied. We have named these PLA $_{2}$-inhibitory peptides as PIP-1 (rat/mouse) and PIP-2 (human). Substitution of aa 2 and 4 from the rat/mouse sequence into the corresponding positions of the human sequence resulted in a hybrid peptide (called PIP-3) that also had aiPLA 2 inhibitory activity. However, a hybrid peptide with the aa from positions 3 and 5 of the rat/mouse sequence inserted into the human sequence was not active while insertion of an I for $\mathrm{F}$ at position 4 of the human sequence decreased activity by $\sim 50 \%$. Thus, only some aa in positions $2-5$ supported activity of the peptide. Furthermore, a review of the natural sequences from a variety of species in the PDB indicated that, while the human sequence was well represented and found intact in non-human primates and the African elephant, other species showed variable aa in eight of the nine positions and only the terminal leucine was present in all. Thus, it is not possible to accurately predict the peptide sequences that will be effective as inhibitors of aiPLA 2 activity and further testing of individual constructs will be necessary in order to fully grasp the role of individual aa and their combination for aiPLA ${ }_{2}$ inhibition. Since there is only modest conservation of the inhibitory sequence in various species while at least one corresponding naturally occurring sequence (in wolf SP-A) does not inhibit aiPLA $A_{2}$ activity, we conclude that SP-A modulation of aiPLA 2 activity is unlikely to represent an important physiological function.

PIP-2 was selected as the prototype peptide for further testing. This peptide effectively inhibited the aiPLA 2 activity of recombinant Prdx6 in vitro. Calculation of the concentration of peptide required for maximal inhibition of activity indicated binding that was approximately to 1.5:1 of inhibitor to enzyme on a molar basis. PIP-2, administered to mice by either the IT or IV route, also inhibited the endogenous aiPLA ${ }_{2}$ activity in the homogenized lung; the inhibition by either route of administration was similar. Like many peptides [36], PIP-2 was not able to cross the cell membrane and its effectiveness as an inhibitor required its administration with a liposomal carrier. Surprisingly, the peptide within the lung cells appeared to be relatively stable, and inhibition of aiPLA $A_{2}$ activity was demonstrated with a half-time of $\sim 50 \mathrm{~h}$ after peptide administration. Testing of lungs with genetic absence of aiPLA 2 (D140A-Prdx6 mutation) or under assay conditions that do not support aiPLA $\mathrm{A}_{2}$ activity ( $\mathrm{pH}$ 7) provide evidence that aiPLA $\mathrm{A}_{2}$ is the only lung $\mathrm{PLA}_{2}$ enzyme that is inhibited by the PIP-2 peptide. 
The ability of PIP-2 to inhibit the activation of Nox2 in response to angiotensin II was demonstrated with the isolated perfused lung preparation using Amplex red in the perfusate as a trap for the generated ROS. This result was expected based on our previous studies demonstrating that aiPLA 2 activity in lungs is required for activation of Nox2 [7,17], although Prdx6 also may be involved in the activation of Nox1 [37]. At any rate, our previous studies have shown that nearly all ROS production in response to angiotensin II is abolished with 'knock-out' of Nox2 and that the addition of an aiPLA 2 inhibitor to Nox2 null lungs has little additional effect $[7,17,20]$. Thus, the effect of PIP-2 in angiotensin II-treated lungs appears to be predominantly due to the inhibition of Nox2 activation with essentially no contribution due to inhibition of Nox1.

\section{Conclusions}

The present studies indicate that the PIP peptides can effectively prevent ROS generation by the intact mouse lung. Based on results with mouse lungs, both the inhibitory dose of PIP-2 as well as its persistence within lung cells are in a reasonable range for potential therapeutic application to treat conditions with excess ROS generation subsequent to Nox2 activation. One potential therapeutic use of the PIP peptides might be to prevent inflammation-mediated tissue injury such as occurs with the Acute Lung Injury syndrome [21]. As PIP-2 is derived from a normal lung protein, it is expected to be relatively non-toxic by itself, although its possible antigenicity as well as the long term effects of the inhibition of aiPLA 2 activity will require further evaluation.

Author Contributions: Formulated research plan (A.B.F., S.I.F.); generated recombinant Prdx6 (S.I.F.); performed experiments (C.D.); interpreted experimental results (A.B.F., S.I.F.); wrote the manuscript (A.B.F.).

Funding: This research was supported in part by grant R01-HL102016 (P.I, A.B.F.) from the National Institutes of Health of the United States.

Acknowledgments: We thank Shampa Chatterjee for helpful discussion and Dawn Williams for assistance with manuscript preparation.

Conflicts of Interest: S.I.F. and A.B.F. have a patent application pending for peptide inhibitors of peroxiredoxin 6 $\mathrm{PLA}_{2}$ activity and have part ownership of a start-up company to promote their clinical use.

\section{References}

1. Bedard, K.; Krause, K.H. The NOX family of ROS-generating NADPH oxidases: Physiology and pathophysiology. Physiol. Rev. 2007, 87, 245-313. [CrossRef] [PubMed]

2. Babior, B.M. NADPH oxidase: An update. Blood 1999, 93, 1464-1476. [PubMed]

3. Diebold, B.A.; Smith, S.M.; Li, Y.; Lambeth, J.D. NOX2 As a Target for Drug Development: Indications, Possible Complications, and Progress. Antioxid. Redox Signal. 2015, 23, 375-405. [CrossRef] [PubMed]

4. Pick, E.; Gorzalczany, Y.; Engel, S. Role of the rac1 p21-GDP-dissociation inhibitor for rho heterodimer in the activation of the superoxide-forming NADPH oxidase of macrophages. Eur. J. Biochem. 1993, 217, 441-455. [CrossRef] [PubMed]

5. Pick, E. Cell-free NADPH oxidase activation assays: "In vitro veritas". Methods Mol. Biol. 2014, 1124, $339-403$. [CrossRef] [PubMed]

6. Brandes, R.P.; Weissmann, N.; Schroder, K. Nox family NADPH oxidases: Molecular mechanisms of activation. Free Radic. Biol. Med. 2014, 76, 208-226. [CrossRef] [PubMed]

7. Vazquez-Medina, J.P.; Dodia, C.; Weng, L.; Mesaros, C.; Blair, I.; Feinstein, S.I.; Chatterjee, C.; Fisher, A. The phospholipase $\mathrm{A}_{2}$ activity of peroxiredoxin 6 modulates NADPH oxidase 2 activation via lysophosphatidic acid receptor signaling in the pulmonary endothelium and alveolar macrophages. FASEB J. 2016, 30, 2885-2898. [CrossRef]

8. Nauseef, W.M. Biological roles for the NOX family NADPH oxidases. J. Biol. Chem. 2008, 283, 16961-16965. [CrossRef]

9. Bernard, K.; Hecker, L.; Luckhardt, T.R.; Cheng, G.; Thannickal, V.J. NADPH oxidases in lung health and disease. Antioxid. Redox Signal. 2014, 20, 2838-2853. [CrossRef] 
10. Moloney, J.N.; Cotter, T.G. ROS signalling in the biology of cancer. Semin. Cell Dev. Biol. 2018, 80, 50-64. [CrossRef]

11. Bromberg, Y.; Pick, E. Unsaturated fatty acids as second messengers of superoxide generation by macrophages. Cell Immunol. 1983, 79, 240-252. [CrossRef]

12. Henderson, L.M.; Chappell, J.B.; Jones, O.T. Superoxide generation is inhibited by phospholipase A2 inhibitors. Role for phospholipase A2 in the activation of the NADPH oxidase. Biochem. J. 1989, 264, 249-255. [CrossRef] [PubMed]

13. Dana, R.; Malech, H.L.; Levy, R. The requirement for phospholipase A2 for activation of the assembled NADPH oxidase in human neutrophils. Biochem. J. 1994, 297, 217-223. [CrossRef] [PubMed]

14. Burke, J.E.; Dennis, E.A. Phospholipase A2 structure/function, mechanism, and signaling. J. Lipid Res. 2009, 50, S237-S242. [CrossRef] [PubMed]

15. Dana, R.; Leto, T.L.; Malech, H.L.; Levy, R. Essential requirement of cytosolic phospholipase A2 for activation of the phagocyte NADPH oxidase. J. Biol. Chem. 1998, 273, 441-445. [CrossRef]

16. Rubin, B.B.; Downey, G.P.; Koh, A.; Degousee, N.; Ghomashchi, F.; Nallan, L.; Stefanski, E.; Harkin, D.W.; Sun, C.; Smart, B.P.; et al. Cytosolic phospholipase A2-alpha is necessary for platelet-activating factor biosynthesis, efficient neutrophil-mediated bacterial killing, and the innate immune response to pulmonary infection: cPLA2-alpha does not regulate neutrophil NADPH oxidase activity. J. Biol. Chem. 2005, 280, 7519-7529. [CrossRef]

17. Chatterjee, S.; Feinstein, S.I.; Dodia, C.; Sorokina, E.; Lien, Y.C.; Nguyen, S.; Debolt, K.; Speicher, D.; Fisher, A.B. Peroxiredoxin 6 phosphorylation and subsequent phospholipase A2 activity are required for agonist-mediated activation of NADPH oxidase in mouse pulmonary microvascular endothelium and alveolar macrophages. J. Biol. Chem. 2011, 286, 11696-11706. [CrossRef]

18. Fisher, A.B. The Phospholipase A2 Activity of Peroxiredoxin 6. J. Lipid Res. 2018, 59, 1132-1147. [CrossRef]

19. Vazquez-Medina, J.P.; Tao, J.Q.; Patel, P.; Bannitz-Fernandes, R.; Dodia, C.; Sorokina, E.M.; Feinstein, S.I.; Chatterjee, S.; Fisher, A.B. Genetic inactivation of the phospholipase $A_{2}$ activity of peroxiredoxin 6 in mice protects against LPS-induced acute lung injury. Am. J. Physiol. Lung 2018. under review.

20. Lee, I.; Dodia, C.; Chatterjee, S.; Zagorski, J.; Mesaros, C.; Blair, I.A.; Feinstein, S.I.; Jain, M.; Fisher, A.B. A novel nontoxic inhibitor of the activation of NADPH oxidase reduces reactive oxygen species production in mouse lung. J. Pharmacol. Exp. Ther. 2013, 345, 284-296. [CrossRef]

21. Lee, I.; Dodia, C.; Chatterjee, S.; Feinstein, S.I.; Fisher, A.B. Protection against LPS-induced acute lung injury by a mechanism based inhibitor of NADPH-oxidase (Type 2). Am. J. Physiol. Lung Cell Mol. Physiol. 2014, 306, 635-644. [CrossRef] [PubMed]

22. Fisher, A.B.; Dodia, C.; Chander, A.; Beers, M.F.; Bates, S.R. Inhibition of Trimeresurus flavoviridis phospholipase A2 by lung surfactant protein A (SP-A). Biochim. Biophys. Acta 1994, 1211, 256-262. [CrossRef]

23. Wu, Y.Z.; Manevich, Y.; Baldwin, J.L.; Dodia, C.; Yu, K.; Feinstein, S.I.; Fisher, A.B. Interaction of surfactant protein A with peroxiredoxin 6 regulates phospholipase A2 activity. J. Biol. Chem. 2006, 281, 7515-7525. [CrossRef] [PubMed]

24. Fisher, A.B.; Dodia, C.; Chander, A. Inhibition of lung calcium-independent phospholipase A2 by surfactant protein A. Am. J. Physiol. Lung Cell Mol. Physiol. 1994, 267, L335-L341. [CrossRef] [PubMed]

25. Sorokina, E.M.; Feinstein, S.I.; Zhou, S.; Fisher, A.B. Intracellular targeting of peroxiredoxin 6 to lysosomal organelles requires MAPK activity and binding to 14-3-3epsilon. Am. J. Physiol. Lung Cell Mol. Physiol. 2011, 300, C1430-C1441. [CrossRef] [PubMed]

26. Krishnaiah, S.; Dodia, C.; Sorokina, E.; Feinstein, S.I.; Fisher, A. Binding sites for interaction of peroxiredoxin 6 with surfactatn protein A. BBA Proteins Proteom. 2015, 1864, 419-425. [CrossRef] [PubMed]

27. Protein Docking and Design program. Available online: https://zlab.bu.edu/zlab/index.shtml (accessed on 26 October 2018).

28. Head, J.F.; Mealy, T.R.; McCormack, F.X.; Seaton, B.A. Crystal structure of trimeric carbohydrate recognition and neck domains of surfactant protein A. J. Biol. Chem. 2003, 278, 43254-43260. [CrossRef]

29. Li, H.; Benipal, B.; Zhou, S.; Dodia, C.; Chatterjee, S.; Tao, J.Q.; Sorokina, E.M.; Raabe, T.; Feinstein, S.I.; Fisher, A.B. Critical role of peroxiredoxin 6 in the repair of peroxidized cell membranes following oxidative stress. Free Radic. Biol. Med. 2015, 87, 356-365. [CrossRef]

30. Fisher, A.B.; Dodia, C.; Feinstein, S.I.; Ho, Y.S. Altered lung phospholipid metabolism in mice with targeted deletion of lysosomal-type phospholipase A2. J. Lipid Res. 2005, 46, 1248-1256. [CrossRef] 
31. Tools for Antimicrobial Peptides. Available online: aps.unmc.edu/AP/tools.php (accessed on 26 October 2018).

32. Predicted Antigenic Peptides. Available online: http://imed.med.ucm.es/Tools/antigenic.pl (accessed on 26 October 2018).

33. Manevich, Y.; Reddy, K.S.; Shuvaeva, T.; Feinstein, S.I.; Fisher, A.B. Structure and phospholipase function of peroxiredoxin 6: Identification of the catalytic triad and its role in phospholipid substrate binding. J. Lipid Res. 2007, 48, 2306-2318. [CrossRef]

34. Jain, M.K.; Tao, W.J.; Rogers, J.; Arenson, C.; Eibl, H.; Yu, B.Z. Active-site-directed specific competitive inhibitors of phospholipase A2: Novel transition-state analogues. Biochemistry 1991, 30, 10256-10268. [CrossRef] [PubMed]

35. Fisher, A.B.; Dodia, C.; Chander, A. Beta-adrenergic mediators increase pulmonary retention of instilled phospholipids. J. Appll. Physiol. 1985, 59, 743-748. [CrossRef] [PubMed]

36. Yang, N.J.; Hinner, M.J. Getting across the cell membrane: An overview for small molecules, peptides, and proteins. Methods Mol. Biol. 2015, 1266, 29-53. [CrossRef] [PubMed]

37. Kwon, J.; Wang, A.; Burke, D.J.; Boudreau, H.E.; Lekstrom, K.J.; Korzeniowska, A.; Sugamata, R.; Kim, Y.S.; Yi, L.; Ersoy, I.; et al. Peroxiredoxin 6 (Prdx6) supports NADPH oxidase1 (Nox1)-based superoxide generation and cell migration. Free Radic. Biol. Med. 2016, 96, 99-115. [CrossRef] [PubMed]

(c) 2018 by the authors. Licensee MDPI, Basel, Switzerland. This article is an open access article distributed under the terms and conditions of the Creative Commons Attribution (CC BY) license (http:/ / creativecommons.org/licenses/by/4.0/). 


\title{
Peroxiredoxin6 in Endothelial Signaling
}

\author{
Priyal Patel and Shampa Chatterjee * \\ Institute for Environmental Medicine and Department of Physiology, University of Pennsylvania Perelman \\ School of Medicine, Philadelphia, PA 19104, USA; patpri@pennmedicine.upenn.edu \\ * Correspondence: shampac@pennmedicine.upenn.edu
}

Received: 25 January 2019; Accepted: 5 March 2019; Published: 13 March 2019

\begin{abstract}
Peroxiredoxins ( $\operatorname{Prdx}$ ) are a ubiquitous family of highly conserved antioxidant enzymes with a cysteine residue that participate in the reduction of peroxides. This family comprises members $\operatorname{Prdx1} 1-6$, of which Peroxiredoxin $6(\operatorname{Prd} x 6)$ is unique in that it is multifunctional with the ability to neutralize peroxides (peroxidase activity) and to produce reactive oxygen species (ROS) via its phospholipase $\left(\mathrm{PLA}_{2}\right)$ activity that drives assembly of NADPH oxidase (NOX2). From the crystal structure, a C47 residue is responsible for peroxidase activity while a catalytic triad (S32, $\mathrm{H} 26$, and D140) has been identified as the active site for its $\mathrm{PLA}_{2}$ activity. This paradox of being an antioxidant as well as an oxidant generator implies that Prdx6 is a regulator of cellular redox equilibrium (graphical abstract). It also indicates that a fine-tuned regulation of Prdx6 expression and activity is crucial to cellular homeostasis. This is specifically important in the endothelium, where ROS production and signaling are critical players in inflammation, injury, and repair, that collectively signal the onset of vascular diseases. Here we review the role of Prdx6 as a regulator of redox signaling, specifically in the endothelium and in mediating various pathologies.
\end{abstract}

Keywords: phospholipase A2; glutathione peroxidase; reactive oxygen species; redox balance; endothelium; inflammation; diabetes

\section{Introduction}

Peroxiredoxins (Prdx) are a family of enzymes that primarily function as antioxidants to scavenge peroxide in biological systems. The six isoforms of mammalian Prdxs (Prdx1 to 6) are distributed across various cellular sites of reactive oxygen species (ROS) production, such as the cytosol, mitochondria, and peroxisomes [1,2]. Prdxs are divided into two subgroups: Those that have one (Prdx6) cysteine (Cys) residue to participate in the redox cycle and those that have two (Prdx1-5). The enzymes Prdx1-5 use thioredoxin as an electron donor in their redox cycle. However, Prdx6 does not use thioredoxin and uses glutathione (GSH) as the reductant instead [3]. Prdxs are small proteins with sizes varying between 22 and $27 \mathrm{KDa}$; of these, Prdx6 in its native form is a $26 \mathrm{KDa}$ protein and consists of 224 amino acids. The human Prdx6 gene comprises 11,542 base pairs and is located on Chromosome 1. The protein encoded by this gene is a member of the thiol-specific antioxidant protein family. Prdx6 is reported to be expressed in almost all cell types with high expression levels noted in lung endothelial and epithelial cells, lens epithelial cells, hepatocytes, leukocytes, neutrophils, etc. [4,5].

Prdx6 has long been established as a bifunctional enzyme. The antioxidant property, i.e., the peroxidase activity, is dependent on the catalytic Cys at position 47 [6], which is reduced by GSH S-transferase-bound GSH to complete the catalytic cycle [7], while the other enzymatic function of Prdx6 (a calcium-independent phospholipase ( $\left.\mathrm{PLA}_{2}\right)$ activity) is dependent on a catalytic triad: Ser32, His26, and Asp140 [8], which catalyze the hydrolysis of the acyl group of phospholipids. The PLA 2 activity of Prdx6 has been reported to play a major role in the metabolism of the phospholipids of lung surfactant [9] and to activate NADPH oxidase [10,11]. Prdx6 is a cytosolic enzyme, but upon 
stimulation of cells (with inflammatory stimuli), it is phosphorylated and the phosphorylated form translocates to the plasma membrane, where it supports NADPH oxidase activity [5].

Thus Prdx6 is unique in that it possesses both glutathione peroxidase (GPx) and calcium independent phospholipase $\mathrm{A}_{2}\left(\mathrm{PLA}_{2}\right)$ activities [9]. Prdx6 is able to act as an antioxidant by limiting oxidative stress by reducing short-chain hydroperoxides through its peroxidase activity. However, the PLA $\mathrm{P}_{2}$ activity specific to Prdx6 leads to the generation of oxidants [11]. Thus, while the peroxidase activity is crucial in protecting against oxidative stress, the $\mathrm{PLA}_{2}$ activity plays an important role in the production of reactive oxygen species (ROS). These two paradoxical abilities of Prdx6 seem to point to a regulatory role of this enzyme in oxidative stress. It is conceivable that Prdx6 acts as a regulator or rheostat to fine tune ROS levels via the two activities, so as to enable optimal ROS levels for maintaining vascular homeostasis.

The lungs are one of the major organs exposed to the environment. The airways are in direct contact with a wide range of chemical and biological components in the atmosphere. Environmental agents also affect the lung vasculature via the alveolar-capillary structure, where pulmonary gas exchange occurs. The lung is also highly vascularized, with the endothelium that lines the lung vessels comprising $>30 \%$ of the lungs [12]. Moreover, the endothelium, specifically the pulmonary endothelium, is the converging site of inflammation, whereby polymorphonuclear neutrophils (PMN) adhere to the vessel wall, followed by their transmigration into tissue. Reports have established that endothelial redox signaling facilitates lung inflammation via upregulation of adherence and transmigration of PMN, macrophages, and other immune cells [12-14].

Endothelial oxidative stress arises as a consequence of an imbalance between the production of ROS and the antioxidant defenses. The increase in ROS (either external or generated by the cell) leads to alteration of cellular proteins and organelles and is a major cause of cell death. Among the antioxidant defenses is Prdx6, which is highly expressed in the lung; indeed both endothelial and non-endothelial cells of the lung express high amounts of Prdx6 [11,15]. In addition to acting as an antioxidant, we reported that Prdx6 also participates in the generation of ROS, specifically in endothelial cells [11]. This review will focus on how these contradictory roles of Prdx6 facilitate the regulation vascular homeostasis and disease.

\section{Peroxiredoxin 6 in the Endothelium}

The endothelium is a critical component of vascular function by virtue of the signaling pathways that are activated in response to both physical forces, associated with blood flow (endothelial mechanotransduction) $[16,17]$ and chemical stimuli (endothelial chemotransduction) $[12,18]$ from chemical toxins, bacterial endotoxins, etc. Prdx6 expression in the endothelium has been reported, and it has been observed showing a steep increase with oxidative pathologies [19]. Examination of the aortic wall of subjects with aortic aneurysm showed a high expression of Prdx6 in the atherosclerotic plaques [20]. Lack of Prdx6 in the endothelium has been noted to increase sensitivity to oxidative stress. Conversely, it also leads to decreased ROS production in response to various stimuli [21]. Studies evaluating the relative roles of the peroxidase (GPx) and $\mathrm{PLA}_{2}$ activities of Prdx6 in pulmonary microvascular cells exposed directly to the oxidant (tert-butyl hydroperoxide) revealed that both activities participated in protecting cells from oxidative stress [22].

\section{Peroxiredoxin 6 in Endothelial Mechanotransduction}

The endothelium by virtue of its location "senses" the alteration of blood flow, as would occur with ischemia-reperfusion (I/R). Our work in the past decade has shown that the stop and restart of blood flow to the lung activates "flow-sensitive" machinery on lung endothelium comprising a $\mathrm{K}_{\text {ATP }}$ channel and NADPH oxidase 2 (NOX2) that leads to the production of ROS $[23,24]$. Our work has shown that the deletion of NOX2 (null mice) leads to a complete abrogation of ROS production with lung ischemia and reperfusion $[25,26]$. The deletion of Prdx6 (Prdx6-null mice) also led to diminution of ROS with lung ischemia [27]. This seemed paradoxical, as a lack of the antioxidant would be 
expected to increase ROS production. Our investigations revealed that Prdx6 was required for NOX2 activation. Indeed, we showed that in pulmonary microvascular endothelial cells, the phospholipase activity $\left(\mathrm{PLA}_{2}\right)$ of Prdx6 was a key event in NOX2 activation $[11,28]$.

However, Prdx6 does act as an antioxidant in other models of I/R that involve systemic organs [29], for instance, in liver I/R, where ROS production is believed to be predominantly via mitochondrial ROS, deletion of Prdx6, and increased injury. Isolation of mitochondria after ischemia or I/R demonstrated that a lack of mitochondrial Prdx6 led to mitochondrial dysfunction via disruption of mitochondrial respiration [29]. In a model of intestinal I/R (achieved by occlusion of the superior mesenteric artery), Prdx6 was found to play a protective role as delivery of exogenous Prdx6 significantly reduced I/R injury. However the administration of mutant forms of Prx6 (Prx6C47S) that do not possess the peroxidase activity had no protective effect [30]. Elsewhere, a hind limb model of I/R was found to show reduced injury upon exogenous administration of Prdx6 [31]. In a cerebral ischemia-reperfusion model, where non-endothelial cells were also evaluated, blocking Prdx6-PLA 2 (either by siRNA or by a PLA2 inhibitor MJ33) reduced pro-inflammatory cytokines, and increased neuronal survival was compared to the wild type. In this study, both in vitro (oxygen-glucose deprivation/recovery) and in vivo (middle cerebral artery occlusion) models were used and I/R represented hypoxia-reoxygenation [32]. Thus, in several systemic models of I/R, Prdx6, either in endogenous form or administered exogenously, neutralizes oxidative stress, thus reducing the extent of tissue injury destruction with I/R. Overall, in the models of systemic I/R, the antioxidant effect of Prdx6 was significant, while lung I/R showed Prdx6-PLA 2 activity. This discrepancy arises because systemic $\mathrm{I} / \mathrm{R}$ models differ greatly from lung I/R-in the lung, the stop of blood flow does not compromise oxygen supply as the lung parenchyma obtains oxygen from the alveolus, but the systemic organs are dependent on blood flow for oxygen supply [33]. Lung I/R is thus a mechanotransduction event, where endothelial signaling with alteration of flow occurs due to loss of the mechanical component of flow and is independent of the partial oxygen pressures. In contrast, systemic I/R represents both altered flow stimulus and the effects of anoxia or hypoxia, followed by reoxygenation. The ROS generated by lung I/ R has been reported to be via NADPH oxidase 2, whose assembly is dependent on the PLA 2 activity of Prx6 [11,27]. Thus, loss of Prdx6 compromises ROS production with mechanotransduction. In systemic I/R, ROS is produced via either xanthine oxidase or the disrupted mitochondrial electron system (complex I-complex III) [34,35]. These pathways do not seem to involve Prdx6. Thus, in metabolically active organs, lack of Prdx6 leads to enhanced I/R injury, while in lungs where normoxia is maintained throughout I/R, and where the ROS production occurs via Prdx6-PLA 2 activity, lack of Prdx6 leads to compromised ROS production [27].

\section{Peroxiredoxin 6 in Endothelial Chemotransduction}

Pulmonary endothelial cells are exposed to inhaled agonists via the alveolar capillary interface or agonists in the systemic circulation. Exposure to paraquat (PQ), a toxic herbicide, results in cell death of lung endothelial cells [36-38]. PQ, a prototypical redox cycling agent, is rapidly taken up and accumulates in endothelial cells. It produces ROS, leading to oxidative stress and apoptosis by a mitochondrial dependent pathway [39]. Pulmonary endothelial cells, when exposed to PQ, show a significant increase in oxidative damage and cell death [40]. In Prdx6-null mice, PQ administration led to increased lung injury. Although the effect on the pulmonary endothelium was not evaluated per se, vascular leakiness, an index of endothelial injury, showed a significant increase in Prdx6-null mice treated with PQ [36]. This indicates that Prdx6 is pivotal in protection, presumably via its peroxidase activity, against PQ.

Chemotransduction, associated with the endotoxin LPS, involves a role for Prdx6-PLA 2 activity [41]. LPS is a component of the outer membrane in Gram-negative bacteria and is involved in the pathogenesis of sepsis [42,43]. We reported that LPS exposure on endothelial cells leads to ROS production via the NOX2 pathway [41]. This requires $\mathrm{PLA}_{2}$ activation of Prdx6. Indeed, we previously demonstrated that Prdx6-PLA 2 generates lysophosphatidylcholine (LPC), which is 
converted to lysophosphatidic acid (LPA) by the lysophospholipase D activity of autotaxin. The binding of LPA to its receptor (LPAR) leads to an assembly of NOX2 components on the cell membrane [28]. Thus Prdx6-PLA 2 activity facilitates (via LPA production) ROS generation by endothelial cells in response to agonists such as LPS (Figure 1). However, it is not clear if the PLA 2 signaling pathway is effective in NOX2 activation only within the same cell. Studies elsewhere have shown that PLA 2 products, such as eicosanoids and platelet-activating factor engage receptors in a paracrine fashion [44]. Other cells, such as PMN, also show Prdx6-PLA2 activity and, therefore, it is possible that PLA 2 products secreted from non-endothelial and endothelial cells can activate NOX2 in a paracrine manner. Investigations into intercellular cross talk via $\mathrm{PLA}_{2}$ products have not been reported as yet. Our studies monitored $\mathrm{PLA}_{2}$ and NOX2 activation in entire endothelial monolayers; such methods are insufficient to detect the local and paracrine effects of PLA 2 products, therefore, the NOX2 activation within each cell type of our ROS measurements, and thus, to an extent, the PLA 2 cleavage. The methods we used showed a conclusive link between Prdx6-PLA 2 activity; indeed we demonstrated that a lack of Prdx6-PLA 2 activity, as achieved by mutations in Asp140, led to reduction in ROS [28].

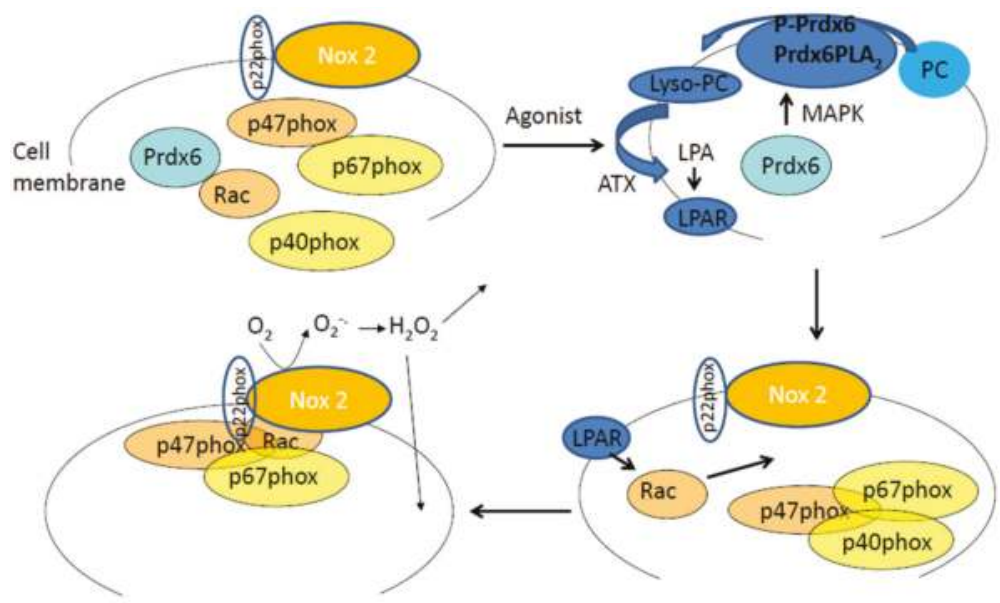

Figure 1. The Prdx6-PLA 2 activity and the production of reactive oxygen species (ROS) by endothelial cells in response to an agonist. In the cytosol are Prdx6 and cytosolic subunits of NADPH 2 oxidase (p40phox, p67phox, p47phox, and Rac). Upon phosphorylation (in response to an agonist, Angiotensin II, or LPS) Prdx6 translocates to the plasma membrane. P-Prdx6 has phosphospholipase $\mathrm{A}_{2}$ activity via which it hydrolyses membrane phosphatidylcholine (PC) to lysophosphatidylcholine (lyso-PC). Lyso-PC is catalyzed to lysophosphatidic acid (LPA) by the enzyme autotaxin (ATX). LPA binds to its receptor on the cell membrane, and the resulting signaling cascade leads to Rac phosphorylation that in turn enables assembly of the cytosolic components of NADPH oxidase 2 with the membrane bound components (gp91phox or Nox2 and p22phox). The assembled enzyme reduces molecular oxygen to superoxide which then dismutates to hydrogen peroxide. $\mathrm{H}_{2} \mathrm{O}_{2}$ can participate in extracellular and intracellular signaling cascades.

In vivo exposures to LPS either via the systemic circulation or intratracheal instillation also resulted in ROS generation by the lung endothelium via the NOX2 pathway. Deleting Prdx6 by the use of Prdx6-null mice or by the inhibitor MJ33 resulted in a decrease in endothelial ROS production $[41,45]$. However, in other models of LPS-induced systemic injury, such as kidney damage, that involve an inflammatory response, Prdx6 seemed to be participating in a protective role. Prdx6-overexpressing mice showed decreased mortality and renal injury following the LPS challenge, compared to wild type (WT) mice. The inflammatory response of the kidney to LPS in the form of infiltration of macrophages, T-cells, and neutrophils, were also lower in Prdx6-overexpressing mice, as compared to 
wild-type mice [46]. This indicated that LPS-induced chemotransduction involved ROS generation (Prdx6-PLA 2 activity) in certain models of injury, while in others, it was the antioxidant activity of $\operatorname{Prdx6}$ (peroxidase activity) that was observed in response to ROS generation that presumably occurred via non NOX2 pathways.

Angiotensin II (Ang II) is an endogenous agonist that raises blood pressure primarily through vasoconstriction by acting on the endothelium and producing ROS [47]. We and others showed that Ang II activates the NOX2 pathway on endothelial cells in vitro and on the lung endothelium in vivo, via Prdx6-PLA 2 activation [11,28]. Blocking PLA2 activation can potentially provide a pharmacological approach to Ang II-induced vasocontriction.

A unique feature of $\operatorname{Prdx} 6$ is the regulation of its antioxidant action by partner protein glutathione S-transferase Pi (GST $\pi$ ). GST $\pi$ is a member of the phase II detoxification enzyme family that catalyzes the formation of thioether bonds between GSH and electrophilic centers on small proteins. One such protein is Prdx6 and GST- $\pi$ is well established to catalyze the conjugation of the antioxidant GSH to Prdx6 [7,48]. GSH is not able to access the catalytic cysteine residue on Prdx6. Upon conversion to its anionic form, GS- (by GST $\pi$ ), it can bind to Prdx6 (Figure 2). The glutathionylation of the oxidized cysteine in Prdx6 is followed by a spontaneous reduction of the mixed disulfide and restoration of enzymatic activity of $\operatorname{Prdx6}$ (Figure 2B) [7]. GST $\pi$ has been reported to be highly expressed in endothelial cells, specifically with pathologies such as neurological disorders [49], and protects against endothelial permeability and damage in response to inflammatory stimuli [50]. Studies using several oxidant and inflammation stimuli have demonstrated that GST $\pi$ acts as a negative regulator of endothelial dysfunction [51]. These studies did not investigate the role of Prdx6 per se; however, based on the fact that GST- $\pi$ can exert its protective function via activation of the oxidized Prdx6 [48], it is presumable that Prdx6 plays a role in protection against endothelial dysfunction in oxidant-induced pathologies.

A.

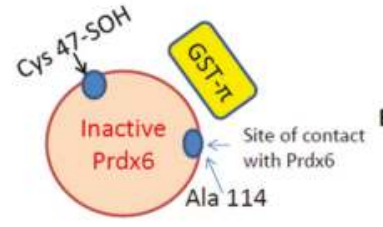

B.
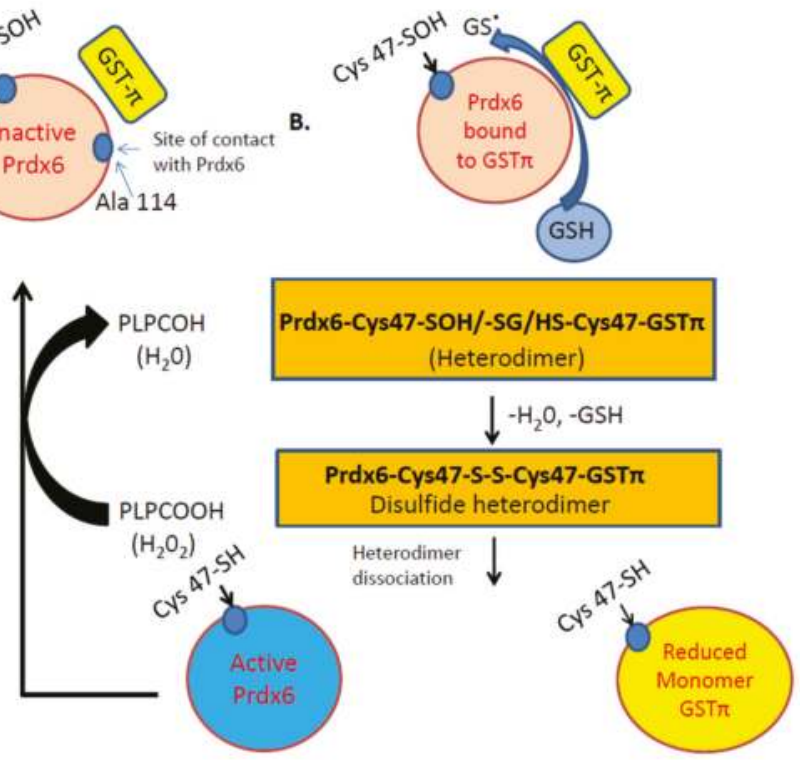

Figure 2. Illustration of the Peroxidase activity of Prdx6. A. Inactive Prdx6: its active site (Cys 47) needs to be oxidized to Cys-sulfenic acid (Cys47-SOH). B. After oxidation of Cys47 to sulfenic acid (-SOH), the Prdx6 forms a heterodimer with thiolate anion (via GST $\pi$ ). S-glutathionylation of the heterodimer, followed by its alignment with the catalytic Cys47 of GST $\pi$, results in the formation of a disulfide-based heterodimer. Reduction of this disulfide bond by GSH causes heterodimer dissociation to active Prdx6 monomer. The active monomer reduces phospholipid hydroperoxide (PLPCOOH) to PLPCOH. 


\section{Peroxiredoxin 6 in Inflammatory Response}

ROS-induced signaling has been well established as playing a role in the onset and amplification of inflammation. The endothelium is a converging site of inflammation, where PMN, macrophages, and other immune cells adhere to and extravasate from blood to tissue. An enhanced ROS generation on the endothelium is thus a first step in inflammation [52]. We showed that ROS production by the endothelium in response to either chemotransduction or mechanotransduction is an inflammatory stimulus [53]. Endothelial ROS leads to an increase in cellular adhesion molecules and pro-inflammatory cytokines that recruit PMN and other immune cells to the vascular wall. ROS produced by PMN in addition to the endothelial ROS, leads to oxidative stress in the vasculature and leads to opening of inter-endothelial cell-cell junctions that in turn promotes the migration of PMN, etc., across the vascular wall [52]. Thus, enzymes with roles in redox balance, i.e., with both antioxidants as well as ROS-generating capacity, play a critical role in inflammatory and immune responses. Prdx6 possesses both of these activities and, therefore, it is reasonable to assume that this enzyme would regulate inflammation in vivo.

Upregulation of Prdx6 has been observed under conditions of increased ROS generation in various models of injury, implying that oxidative stress leads to increased Prdx6 transcription. This also implies that Prdx6 expression can be indicative of oxidative stress pathologies. Studies in patients with peripheral arterial disease show that circulating levels of PRDX1, 2, 4, and 6 are markedly raised [54]. In patients with abdominal aortic aneurysms, there are increased levels of Prdx6, both in the plasma and in the tissue from the aneurysm [20]. Lack of Prdx6 (PRDX6-null mice) showed significantly higher aortic lesions in response to oxidative stress [55]. Prdx6 is also high in serum of patients with osteoarthritis and those with femoral neck fracture and there are strong correlations between the levels of these molecules in the serum and severity of these conditions [56]. It is not clear in all of these models of inflammation whether Prdx6 participates in redox imbalance through protective antioxidant functions or by redox signaling via activation of NOX2. In an oxidative stress environment, hyperoxidation of Prdx6 is reported to upregulate its PLA2 activity [57]. Conversely, environments with a high inflammation and oxidative stress load, such as aortic lesions or aneurysms, can cause post-translation modification of Prdx6, such that it loses its antioxidant activity [58]. The major pro-inflammatory transcription factor NFKB has been observed to be regulated by Prdx6 [19]. The Prdx6 promoter ( $-1139 \mathrm{bp}$ ) containing $\mathrm{kB}$ binding sites, showed reduced promoter activity in Prdx6 null cells [59]. Besides the peroxidase activity that facilitates protection from oxidative stress, Prdx6 also protects by downregulating NFKB [60].

\section{Prdx6 in Wound Repair}

Wound repair is based on the balance between oxidative stress and regeneration. Thus, most of the injury- and repair-regulated genes encode for antioxidant enzymes, which scavenge on ROS [61,62]. Among the wound-regulated genes that have been identified, one is Prdx6 [61]. In mice, skin wounds were found to have an overexpression of Prdx6 in the epidermis [63]. The epidermis of psoriatic patients and cells of the wound granulation tissue also showed high expression of Prdx6 [61,63].

Prdx6 seems to be protective against dermal injury and to facilitate wound repair. Indeed, mice overexpressing Prdx6 in the epidermis were protected from UVA- and UVB-induced skin damage [61,63]. These mice also showed accelerated wound closure [64]. Similarly, lack of Prdx6, i.e., Prdx6-null mice, increased keratinocyte apoptosis and endothelial damage. In another study using an excision model of injury, the role of the Prdx6 in the endothelium was found to be crucial in the repair of endothelial cells damaged by oxidative stress [21]. Prdx6-null mice showed the appearance of granulated tissue associated with hemorrhage due to endothelial damage. Using chimeric mice (wild-type and Prdx6-null mice with WT- and Prdx6-null bone marrow cells) and ultrastructural analysis of tissue, it was observed that Prdx6 expression on the endothelium correlated with the formation of new blood vessels, suggesting that Prdx6 is required for endothelial cell integrity and viability in the wound tissue [21]. The onset of hemorrhage correlating with the formation 
of novel blood vessels suggests the importance of Prdx6 for endothelial cell maintenance, structure, and viability in wounded tissue. However, lack of Prdx6 affected the endothelial cell integrity, structure, and function, only during oxidative stress and not under normal conditions, implying that the protective role was crucial only post-injury and did not affect the endothelium under basal conditions. Overall, these studies seem to reveal the role for the peroxidase activity of Prdx6 in protecting the epidermis from oxidative damage. However, it is not clear if peroxidase and/or $\mathrm{PLA}_{2}$ activities might participate in wound repair. This is because transcription factors, such as NFKB, that are crucial for skin wound repair processes are regulated both by ROS and Prdx6 [65] and there is some evidence for the role of Prdx6-PLA 2 activity in NFKB regulation [59].

\section{Prdx6 in the Pathogenesis of Diabetes}

Increased oxidative stress appears to be a major factor leading to insulin resistance and pathogenesis of diabetes [66]. Pancreatic $\beta$-cells that produce insulin express very low levels of antioxidant enzymes and are thus susceptible to oxidative stress [67]. Although $\beta$-cells express Prdx6 [68], studies using insulin-producing RINm5F cells have shown that Prdx6 expression (both mRNA and protein) is downregulated in response to proinflammatory cytokines [69]. This reduces the antioxidant capacity of Prdx6. Furthermore, lack of Prdx6 (in mice) causes the development of a phenotype similar to early-stage Type II diabetes in terms of both reduced glucose-dependent insulin secretion and increased insulin resistance [70].

Dysfunction of the endothelium is similarly observed in diabetes [71]. Under conditions of oxidative stress, the endothelial repair mechanisms are hindered. This is because endothelial repair occurs via endothelial progenitor cells (EPC) [72]. Under basal conditions, EPCs are immature cells and differentiate into mature endothelial cells. With vascular injury, EPC mobilization from the peripheral circulation (aided via growth factors and cytokines) to sites of damage is a crucial component of repair and angiogenesis. Both type 1 and type 2 diabetics have less circulating EPCs than matched healthy subjects. Diabetic EPCs also show reduced proliferation, adhesion, migration, and impaired development of tubules for the formation of a vascular network [71,73].

As oxidative stress and insulin resistance are associated with a proinflammatory state, inflammation often accompanies diabetes [71]. The link between diabetes, inflammation, and Prdx6 is not clear. On one hand, inflammation can often lower expression of Prdx6, while on the other, it is overexpressed in some inflammatory pathologies, such as inflammatory bowel disease (IBD) [74]. Indeed, human colonic biopsies of IBD patients showed high expression of Prdx6. Mice that lack Prdx6 show a marked increase in proinflammatory cytokines (IL-1 $\beta$ and TNF- $\alpha$ ) and in matrix metalloproteases (MMP-2 and -9) in response to an inflammatory stimulus [75]. Elsewhere, these mice showed an insulin resistance phenotype [70]. Insulin resistance-associated inflammation could be partly regulated by the Prdx6, although the role of its $\mathrm{PLA}_{2}$ versus peroxidase activities in this regulation has not been clearly defined.

A recent report seems to point to a role for Prdx6 in glucose homeostasis, primarily via its antioxidant role [69]. Reports elsewhere indicate that the pathophysiological impairments associated with diabetes, such as sarcopenia (loss of muscle mass), muscle atrophy, and diabetic myopathy can potentially be rescued by Prdx6 [76]. Gene expression of MyoD and myogenin, that participate in the differentiation of muscle cells, was observed to be significantly lower in Prdx6-null mice as compared to wild type controls [76]. This points to a role for Prdx6 in the maintenance of muscle mass and points to a possible use of this enzyme for therapy in diabetic myopathy and sarcopenia. Thus, Prdx6 could potentially represent diabetes susceptibility in humans. Moreover, associations between Prdx6 expression and inflammatory endothelial phenotype are possible factors in endothelial dysfunction with diabetes.

\section{Conclusions}

The family of peroxiredoxins has been recognized as major scavenging enzymes in mammalian systems. Of these, Prdx6 is unique in that its peroxidase activity facilities oxidant scavenging, while Prdx6-PLA2 activity is crucial in oxidant generation (Figure 3). The dual function of this 
enzyme presumably enables it to act as a "regulatory body", whereby its protective role and its oxidant-generating action is not exceeded, so as to perturb vascular homeostasis. This optimal regulation of Prdx6 expression and activity is crucial in fine tuning cellular ROS levels and seems to occur via complex signaling cascades that involve NFKB and oxidants. While upregulation of Prdx6 is protective, it is also associated with several pathologies ranging from aortic lesions to diabetes susceptibility. Low levels or lack of Prdx6 are also associated with inflammatory diseases. These observations and reports indicate that regulation of the peroxidase and PLA $\mathrm{P}_{2}$ activities is complex and intersects with several other transcriptional pathways. Further studies using Prdx6 mutants and null systems on diverse models of inflammation and injury are needed to strengthen our knowledge regarding the relationship between Prdx6 regulation and oxidant and antioxidant signaling and the final physiological and pathophysiological effects.

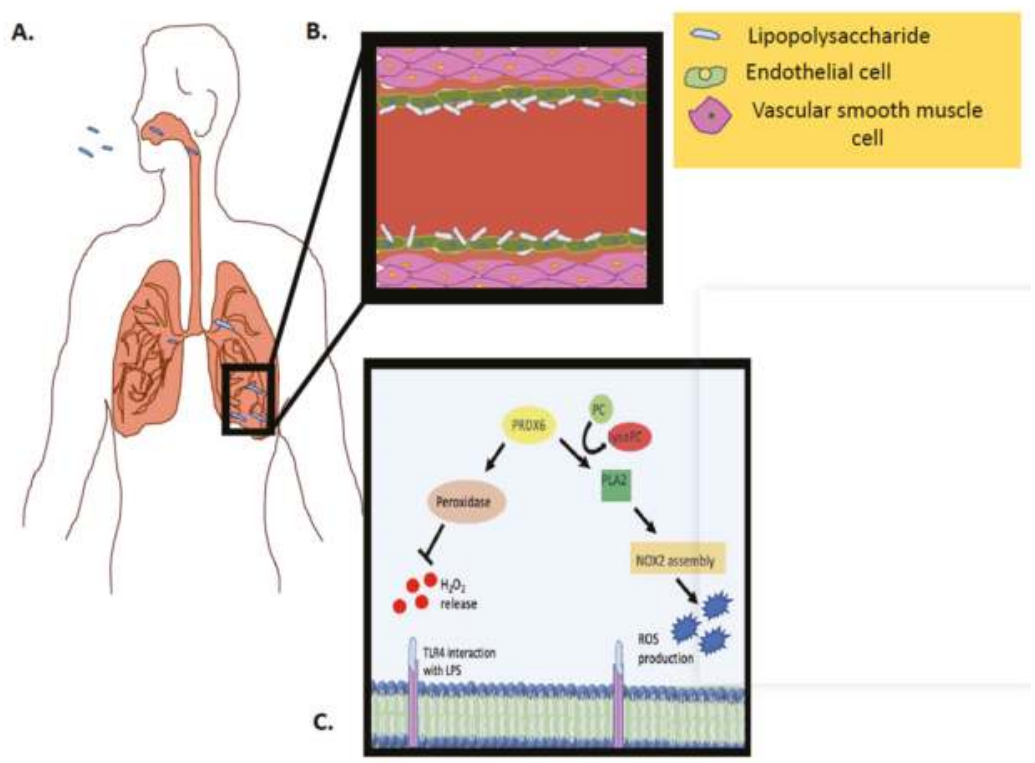

Figure 3. Schematic representation of Prdx6 activity ( $\mathrm{PLA}_{2}$ and peroxidase) in vivo, in response to an inflammatory stimulus. (A) LPS inhalation and interaction with pulmonary capillary. (B) LPS inhalation and interaction with endothelial cells in pulmonary capillary. (C) LPS interaction with the endothelial cell membrane and the Prdx6-PLA2 activity as well as the Prdx6-peroxidase activity.

Funding: This research received no external funding.

Conflicts of Interest: The authors declare no conflict of interest.

\section{References}

1. Rhee, S.G.; Chae, H.Z.; Kim, K. Peroxiredoxins: A historical overview and speculative preview of novel mechanisms and emerging concepts in cell signaling. Free Radic. Biol. Med. 2005, 38, 1543-1552. [CrossRef] [PubMed]

2. Rhee, S.G.; Kang, S.W.; Chang, T.S.; Jeong, W.; Kim, K. Peroxiredoxin, a novel family of peroxidases. IUBMB Life 2001, 52, 35-41. [CrossRef] [PubMed]

3. Zhou, S.; Sorokina, E.M.; Harper, S.; Li, H.; Ralat, L.; Dodia, C.; Speicher, D.W.; Feinstein, S.I.; Fisher, A.B. Peroxiredoxin 6 homodimerization and heterodimerization with glutathione S-transferase pi are required for its peroxidase but not phospholipase A2 activity. Free Radic. Biol. Med. 2016, 94, 145-156. [CrossRef] [PubMed] 
4. Nicolussi, A.; D’Inzeo, S.; Capalbo, C.; Giannini, G.; Coppa, A. The role of peroxiredoxins in cancer. Mol. Clin. Oncol. 2017, 6, 139-153. [CrossRef] [PubMed]

5. Ambruso, D.R.; Ellison, M.A.; Thurman, G.W.; Leto, T.L. Peroxiredoxin 6 translocates to the plasma membrane during neutrophil activation and is required for optimal NADPH oxidase activity. Biochim. Biophys. Acta. 2012, 1823, 306-315. [CrossRef] [PubMed]

6. Chen, J.W.; Dodia, C.; Feinstein, S.I.; Jain, M.K.; Fisher, A.B. 1-Cys peroxiredoxin, a bifunctional enzyme with glutathione peroxidase and phospholipase A2 activities. J. Biol. Chem. 2000, 275, 28421-28427. [CrossRef] [PubMed]

7. Manevich, Y.; Feinstein, S.I.; Fisher, A.B. Activation of the antioxidant enzyme 1-CYS peroxiredoxin requires glutathionylation mediated by heterodimerization with pi GST. Proc. Natl. Acad. Sci. USA 2004, 101, 3780-3785. [CrossRef]

8. Manevich, Y.; Reddy, K.S.; Shuvaeva, T.; Feinstein, S.I.; Fisher, A.B. Structure and phospholipase function of peroxiredoxin 6: Identification of the catalytic triad and its role in phospholipid substrate binding. J. Lipid Res. 2007, 48, 2306-2318. [CrossRef]

9. Manevich, Y.; Fisher, A.B. Peroxiredoxin 6, a 1-Cys peroxiredoxin, functions in antioxidant defense and lung phospholipid metabolism. Free Radic. Biol. Med. 2005, 38, 1422-1432. [CrossRef]

10. Fisher, A.B. The phospholipase A2 activity of peroxiredoxin 6. J. Lipid Res. 2018, 59, 1132-1147. [CrossRef]

11. Chatterjee, S.; Feinstein, S.I.; Dodia, C.; Sorokina, E.; Lien, Y.C.; Nguyen, S.; Debolt, K.; Speicher, D.; Fisher, A.B. Peroxiredoxin 6 phosphorylation and subsequent phospholipase A2 activity are required for agonist-mediated activation of NADPH oxidase in mouse pulmonary microvascular endothelium and alveolar macrophages. J. Biol. Chem. 2011, 286, 11696-11706. [CrossRef] [PubMed]

12. Chatterjee, S. Endothelial Mechanotransduction, Redox Signaling and the Regulation of Vascular Inflammatory Pathways. Front. Physiol. 2018, 9, 524. [CrossRef] [PubMed]

13. Chatterjee, S.; Fisher, A.B. Endothelium: A Comprehensive Reference; Cambridge University Press: Cambridge, MA, USA, 2007.

14. Sarantos, M.R.; Zhang, H.; Schaff, U.Y.; Dixit, N.; Hayenga, H.N.; Lowell, C.A.; Simon, S.I. Transmigration of neutrophils across inflamed endothelium is signaled through LFA-1 and Src family kinase. J. Immunol. 2008, 181, 8660-8669. [CrossRef] [PubMed]

15. Kim, H.S.; Pak, J.H.; Gonzales, L.W.; Feinstein, S.I.; Fisher, A.B. Regulation of 1-cys peroxiredoxin expression in lung epithelial cells. Am. J. Respir. Cell Mol. Biol. 2002, 27, 227-233. [CrossRef] [PubMed]

16. Browning, E.A.; Chatterjee, S.; Fisher, A.B. Stop the flow: A paradigm for cell signaling mediated by reactive oxygen species in the pulmonary endothelium. Annu. Rev. Physiol. 2012, 74, 403-424. [CrossRef] [PubMed]

17. Chatterjee, S.; Fisher, A.B. Mechanotransduction: Forces, sensors, and redox signaling. Antioxid. Redox Signal. 2014, 20, 868-871. [CrossRef] [PubMed]

18. Chatterjee, S.; Fisher, A.B. Mechanotransduction in the endothelium: role of membrane proteins and reactive oxygen species in sensing, transduction, and transmission of the signal with altered blood flow. Antioxid. Redox Signal. 2014, 20, 899-913. [CrossRef] [PubMed]

19. Chhunchha, B.; Fatma, N.; Bhargavan, B.; Kubo, E.; Kumar, A.; Singh, D.P. Specificity protein, Sp1-mediated increased expression of Prdx6 as a curcumin-induced antioxidant defense in lens epithelial cells against oxidative stress. Cell Death Dis. 2011, 2, e234. [CrossRef] [PubMed]

20. Burillo, E.; Jorge, I.; Martinez-Lopez, D.; Camafeita, E.; Blanco-Colio, L.M.; Trevisan-Herraz, M.; Ezkurdia, I.; Egido, J.; Michel, J.B.; Meilhac, O.; et al. Quantitative HDL Proteomics Identifies Peroxiredoxin-6 as a Biomarker of Human Abdominal Aortic Aneurysm. Sci. Rep. 2016, 6, 38477. [CrossRef] [PubMed]

21. Kumin, A.; Schafer, M.; Epp, N.; Bugnon, P.; Born-Berclaz, C.; Oxenius, A.; Klippel, A.; Bloch, W.; Werner, S. Peroxiredoxin 6 is required for blood vessel integrity in wounded skin. J. Cell Biol. 2007, 179, 747-760. [CrossRef] [PubMed]

22. Lien, Y.C.; Feinstein, S.I.; Dodia, C.; Fisher, A.B. The roles of peroxidase and phospholipase A2 activities of peroxiredoxin 6 in protecting pulmonary microvascular endothelial cells against peroxidative stress. Antioxid. Redox Signal. 2012, 16, 440-451. [CrossRef] [PubMed]

23. Chatterjee, S.; Levitan, I.; Wei, Z.; Fisher, A.B. KATP channels are an important component of the shear-sensing mechanism in the pulmonary microvasculature. Microcirculation 2006, 13, 633-644. [CrossRef] [PubMed] 
24. Chatterjee, S.; Browning, E.A.; Hong, N.; DeBolt, K.; Sorokina, E.M.; Liu, W.; Birnbaum, M.J.; Fisher, A.B. Membrane depolarization is the trigger for PI3K/Akt activation and leads to the generation of ROS. Am. J. Physiol. Heart Circ. Physiol. 2012, 302, H105-H114. [CrossRef] [PubMed]

25. Zhang, Q.; Matsuzaki, I.; Chatterjee, S.; Fisher, A.B. Activation of endothelial NADPH oxidase during normoxic lung ischemia is KATP channel dependent. Am. J. Physiol. Lung Cell Mol. Physiol. 2005, 289, L954-L961. [CrossRef] [PubMed]

26. Zhang, Q.; Chatterjee, S.; Wei, Z.; Liu, W.D.; Fisher, A.B. Rac and PI3 kinase mediate endothelial cell-reactive oxygen species generation during normoxic lung ischemia. Antioxid. Redox Signal. 2008, 10, 679-689. [CrossRef] [PubMed]

27. Chatterjee, S.; Feinstein, S.; Hong, N.K.; Debolt, K. Paradoxical response of ROS production in peroxiredoxin 6 null mice to ischemia. FASEB J. 2007, 21, A1201.

28. Vazquez-Medina, J.P.; Dodia, C.; Weng, L.; Mesaros, C.; Blair, I.A.; Feinstein, S.I.; Chatterjee, S.; Fisher, A.B. The phospholipase A2 activity of peroxiredoxin 6 modulates NADPH oxidase 2 activation via lysophosphatidic acid receptor signaling in the pulmonary endothelium and alveolar macrophages. FASEB J. 2016, 30, 2885-2898. [CrossRef] [PubMed]

29. Eismann, T.; Huber, N.; Shin, T.; Kuboki, S.; Galloway, E.; Wyder, M.; Edwards, M.J.; Greis, K.D.; Shertzer, H.G.; Fisher, A.B.; et al. Peroxiredoxin-6 protects against mitochondrial dysfunction and liver injury during ischemia-reperfusion in mice. Am. J. Physiol. Gastrointest. Liver Physiol. 2009, 296, G266-G274. [CrossRef] [PubMed]

30. Gordeeva, A.E.; Temnov, A.A.; Charnagalov, A.A.; Sharapov, M.G.; Fesenko, E.E.; Novoselov, V.I. Protective Effect of Peroxiredoxin 6 in Ischemia/Reperfusion-Induced Damage of Small Intestine. Dig. Dis. Sci. 2015, 60, 3610-3619. [CrossRef] [PubMed]

31. Kubyshkin, A.V.; Novosyolov, S.V.; Fomochkina, I.I.; Kharchenko, V.Z.; Pisarev, A.A.; Gordeeva, A.E.; Beketov, A.A.; Kochkina, A.V.; Fedosov, M.I.; Anisimova, L.V.; et al. Expression of caspase-3 and the cytokine level in experimental reperfusion syndrome upon treatment with peroxiredoxin 6. Biophysics 2017, 62, 848. [CrossRef]

32. Shanshan, Y.; Beibei, J.; Li, T.; Minna, G.; Shipeng, L.; Li, P.; Yong, Z. Phospholipase A2 of Peroxiredoxin 6 Plays a Critical Role in Cerebral Ischemia/Reperfusion Inflammatory Injury. Front. Cell. Neurosci. 2017, 11, 99. [CrossRef] [PubMed]

33. Chatterjee, S.; Chapman, K.E.; Fisher, A.B. Lung ischemia: A model for endothelial mechanotransduction. Cell Biochem. Biophys. 2008, 52, 125-138. [CrossRef] [PubMed]

34. Granger, D.N.; Kvietys, P.R. Reperfusion injury and reactive oxygen species: The evolution of a concept. Redox Biol. 2015, 6, 524-551. [CrossRef]

35. Wu, M.Y.; Yiang, G.T.; Liao, W.T.; Tsai, A.P.; Cheng, Y.L.; Cheng, P.W.; Li, C.Y.; Li, C.J. Current Mechanistic Concepts in Ischemia and Reperfusion Injury. Cell Physiol. Biochem. 2018, 46, 1650-1667. [CrossRef]

36. Wang, Y.; Feinstein, S.I.; Manevich, Y.; Ho, Y.S.; Fisher, A.B. Peroxiredoxin 6 gene-targeted mice show increased lung injury with paraquat-induced oxidative stress. Antioxid. Redox Signal. 2006, 8, 229-237. [CrossRef] [PubMed]

37. Liu, G.; Feinstein, S.I.; Wang, Y.; Dodia, C.; Fisher, D.; Yu, K.; Ho, Y.S.; Fisher, A.B. Comparison of glutathione peroxidase 1 and peroxiredoxin 6 in protection against oxidative stress in the mouse lung. Free Radic. Biol. Med. 2010, 49, 1172-1181. [CrossRef]

38. Smith, P.; Heath, D. The pathology of the lung in paraquat poisoning. J. Clin. Pathol. Suppl. (R. Coll. Pathol.) 1975, 9, 81-93. [CrossRef]

39. Day, B.J.; Patel, M.; Calavetta, L.; Chang, L.Y.; Stamler, J.S. A mechanism of paraquat toxicity involving nitric oxide synthase. Proc. Natl. Acad. Sci. USA 1999, 96, 12760-12765. [CrossRef]

40. Tsukamoto, M.; Tampo, Y.; Sawada, M.; Yonaha, M. Paraquat-induced oxidative stress and dysfunction of the glutathione redox cycle in pulmonary microvascular endothelial cells. Toxicol. Appl. Pharmacol. 2002, 178, 82-92. [CrossRef] [PubMed]

41. Lee, I.; Dodia, C.; Chatterjee, S.; Feinstein, S.I.; Fisher, A.B. Protection against LPS-induced acute lung injury by a mechanism based inhibitor of NADPH-oxidase (Type 2). Am. J. Physiol. Lung Cell Mol. Physiol. 2014. [CrossRef] 
42. Parrillo, J.E.; Parker, M.M.; Natanson, C.; Suffredini, A.F.; Danner, R.L.; Cunnion, R.E.; Ognibene, F.P. Septic shock in humans. Advances in the understanding of pathogenesis, cardiovascular dysfunction, and therapy. Ann. Intern. Med. 1990, 113, 227-242. [CrossRef] [PubMed]

43. Beutler, B.; Rietschel, E.T. Innate immune sensing and its roots: The story of endotoxin. Nat. Rev. Immunol. 2003, 3, 169-176. [CrossRef]

44. Lagarde, M.; Gualde, N.; Rigaud, M. Metabolic interactions between eicosanoids in blood and vascular cells. Biochem. J. 1989, 257, 313-320. [CrossRef] [PubMed]

45. Hood, E.D.; Greineder, C.F.; Dodia, C.; Han, J.; Mesaros, C.; Shuvaev, V.V.; Blair, I.A.; Fisher, A.B.; Muzykantov, V.R. Antioxidant protection by PECAM-targeted delivery of a novel NADPH-oxidase inhibitor to the endothelium in vitro and in vivo. J. Controll. Release off. J. Controll. Release Soc. 2012, 163, 161-169. [CrossRef]

46. Lee, D.H.; Park, J.H.; Han, S.B.; Yoon, D.Y.; Jung, Y.Y.; Hong, J.T. Peroxiredoxin 6 overexpression attenuates lipopolysaccharide-induced acute kidney injury. Oncotarget 2017, 8, 51096-51107. [CrossRef] [PubMed]

47. Itoh, T.; Kajikuri, J.; Tada, T.; Suzuki, Y.; Mabuchi, Y. Angiotensin II-induced modulation of endothelium-dependent relaxation in rabbit mesenteric resistance arteries. J. Physiol. 2003, 548, 893-906. [CrossRef]

48. Ralat, L.A.; Manevich, Y.; Fisher, A.B.; Colman, R.F. Direct evidence for the formation of a complex between 1 -cysteine peroxiredoxin and glutathione $S$-transferase $\pi$ with activity changes in both enzymes. Biochemistry 2006, 45, 360-372. [CrossRef]

49. Shang, W.; Liu, W.H.; Zhao, X.H.; Sun, Q.J.; Bi, J.Z.; Chi, Z.F. Expressions of glutathione S-transferase alpha, $\mathrm{mu}$, and pi in brains of medically intractable epileptic patients. BMC Neurosci. 2008, 9, 67. [CrossRef]

50. Yang, Y.; Yin, F.; Hang, Q.; Dong, X.; Chen, J.; Li, L.; Cao, P.; Yin, Z.; Luo, L. Regulation of Endothelial Permeability by Glutathione S-Transferase Pi Against Actin Polymerization. Cell. Physiol. Biochem. 2018, 45, 406-418. [CrossRef]

51. Conklin, D.J.; Haberzettl, P.; Prough, R.A.; Bhatnagar, A. Glutathione-S-transferase P protects against endothelial dysfunction induced by exposure to tobacco smoke. Am. J. Physiol. Heart Circ. Physiol. 2009, 296, H1586-H1597. [CrossRef]

52. Walzog, B.; Gaehtgens, P. Adhesion Molecules: The Path to a New Understanding of Acute Inflammation. News Physiol. Sci. 2000, 15, 107-113. [CrossRef]

53. Browning, E.; Wang, H.; Hong, N.; Yu, K.; Buerk, D.G.; DeBolt, K.; Gonder, D.; Sorokina, E.M.; Patel, P.; De Leon, D.D.; et al. Mechanotransduction drives post ischemic revascularization through K(ATP) channel closure and production of reactive oxygen species. Antioxid. Redox Signal. 2014, 20, 872-886. [CrossRef]

54. El Eter, E.; Al Masri, A.; Habib, S.; Al Zamil, H.; Al Hersi, A.; Al Hussein, F.; Al Omran, M. Novel links among peroxiredoxins, endothelial dysfunction, and severity of atherosclerosis in type 2 diabetic patients with peripheral atherosclerotic disease. Cell Stress Chaperones 2014, 19, 173-181. [CrossRef]

55. Wang, X.; Phelan, S.A.; Forsman-Semb, K.; Taylor, E.F.; Petros, C.; Brown, A.; Lerner, C.P.; Paigen, B. Mice with targeted mutation of peroxiredoxin 6 develop normally but are susceptible to oxidative stress. J. Biol. Chem. 2003, 278, 25179-25190. [CrossRef] [PubMed]

56. Kuroiwa, T. New biomarkers of osteoarthritis. Osteoarthr. Cartil. 2016, 24, S89. [CrossRef]

57. Kim, S.Y.; Jo, H.Y.; Kim, M.H.; Cha, Y.Y.; Choi, S.W.; Shim, J.H.; Kim, T.J.; Lee, K.Y. $\mathrm{H}_{2} \mathrm{O}_{2}$-dependent hyperoxidation of peroxiredoxin $6(\operatorname{Prd} \times 6)$ plays a role in cellular toxicity via up-regulation of iPLA2 activity. J. Biol. Chem. 2008, 283, 33563-33568. [CrossRef] [PubMed]

58. Chhunchha, B.; Fatma, N.; Kubo, E.; Singh, D.P. Aberrant sumoylation signaling evoked by reactive oxygen species impairs protective function of Prdx6 by destabilization and repression of its transcription. FEBS J. 2014, 281, 3357-3381. [CrossRef] [PubMed]

59. Fatma, N.; Kubo, E.; Takamura, Y.; Ishihara, K.; Garcia, C.; Beebe, D.C.; Singh, D.P. Loss of NF-kappaB control and repression of Prdx6 gene transcription by reactive oxygen species-driven SMAD3-mediated transforming growth factor beta signaling. J. Biol. Chem. 2009, 284, 22758-22772. [CrossRef] [PubMed]

60. Tu, Q.; Xiong, Y.; Fan, L.; Qiao, B.; Xia, Z.; Hu, L.; Wang, Y.; Peng, G.; Ye, Q. Peroxiredoxin 6 attenuates ischemia and hypoxiainduced liver damage of braindead donors. Mol. Med. Rep. 2016, 13, 753-761. [CrossRef] [PubMed]

61. Munz, B.; Frank, S.; Hubner, G.; Olsen, E.; Werner, S. A novel type of glutathione peroxidase: Expression and regulation during wound repair. Biochem. J. 1997, 326 Pt 2, 579-585. [CrossRef] 
62. auf dem Keller, U.; Kumin, A.; Braun, S.; Werner, S. Reactive oxygen species and their detoxification in healing skin wounds. J. Investig. Dermatol. Symp. Proc. 2006, 11, 106-111. [CrossRef] [PubMed]

63. Frank, S.; Munz, B.; Werner, S. The human homologue of a bovine non-selenium glutathione peroxidase is a novel keratinocyte growth factor-regulated gene. Oncogene 1997, 14, 915-921. [CrossRef] [PubMed]

64. Kumin, A.; Huber, C.; Rulicke, T.; Wolf, E.; Werner, S. Peroxiredoxin 6 is a potent cytoprotective enzyme in the epidermis. Am. J. Pathol. 2006, 169, 1194-1205. [CrossRef] [PubMed]

65. Ambrozova, N.; Ulrichova, J.; Galandakova, A. Models for the Study of Skin Wound Healing. The Role of Nrf2 and NF-kappaB; Biomedical Papers of the Medical Faculty of Palacky University in Olomouc; Palacky University in Olomouc: Olomouc, Czech Republic, 2017; Volume 161, pp. 1-13.

66. Hurrle, S.; Hsu, W.H. The etiology of oxidative stress in insulin resistance. Biomed. J. 2017, 40, $257-262$. [CrossRef] [PubMed]

67. Kajimoto, Y.; Kaneto, H. Role of oxidative stress in pancreatic beta-cell dysfunction. Ann. N. Y. Acad. Sci. 2004, 1011, 168-176. [CrossRef] [PubMed]

68. Wood, Z.A.; Schroder, E.; Robin Harris, J.; Poole, L.B. Structure, mechanism and regulation of peroxiredoxins. Trends Biochem. Sci. 2003, 28, 32-40. [CrossRef]

69. Paula, F.M.; Ferreira, S.M.; Boschero, A.C.; Souza, K.L. Modulation of the peroxiredoxin system by cytokines in insulin-producing RINm5F cells: down-regulation of PRDX6 increases susceptibility of beta cells to oxidative stress. Mol. Cell. Endocrinol. 2013, 374, 56-64. [CrossRef]

70. Pacifici, F.; Arriga, R.; Sorice, G.P.; Capuani, B.; Scioli, M.G.; Pastore, D.; Donadel, G.; Bellia, A.; Caratelli, S.; Coppola, A.; et al. Peroxiredoxin 6, a novel player in the pathogenesis of diabetes. Diabetes 2014, 63, 3210-3220. [CrossRef]

71. Avogaro, A.; Albiero, M.; Menegazzo, L.; de Kreutzenberg, S.; Fadini, G.P. Endothelial dysfunction in diabetes: The role of reparatory mechanisms. Diabetes Care 2011, 34 (Suppl. 2), S285-S290. [CrossRef]

72. Altabas, V. Diabetes, Endothelial Dysfunction, and Vascular Repair: What Should a Diabetologist Keep His Eye on? Int. J. Endocrinol. 2015, 2015, 848272. [CrossRef]

73. Fadini, G.P.; Sartore, S.; Albiero, M.; Baesso, I.; Murphy, E.; Menegolo, M.; Grego, F.; Vigili de Kreutzenberg, S.; Tiengo, A.; Agostini, C.; et al. Number and function of endothelial progenitor cells as a marker of severity for diabetic vasculopathy. Arterioscler. Thromb. Vasc. Biol. 2006, 26, 2140-2146. [CrossRef] [PubMed]

74. Melhem, H.; Spalinger, M.R.; Cosin-Roger, J.; Atrott, K.; Lang, S.; Wojtal, K.A.; Vavricka, S.R.; Rogler, G.; Frey-Wagner, I. Prdx6 Deficiency Ameliorates DSS Colitis: Relevance of Compensatory Antioxidant Mechanisms. J. Crohns Colitis 2017, 11, 871-884. [CrossRef] [PubMed]

75. Yang, D.; Song, Y.; Wang, X.; Sun, J.; Ben, Y.; An, X.; Tong, L.; Bi, J.; Bai, C. Deletion of peroxiredoxin 6 potentiates lipopolysaccharide-induced acute lung injury in mice. Crit. Care Med. 2011, 39, 756-764. [CrossRef] [PubMed]

76. Pacifici, F.; Capuani, B.; Piermarini, F.; Pastore, D.; Arriga, R.; Coppola, A.; Rea, S.; Donadel, G.; Bellia, A.; Della-morte, D.; et al. Prdx6 Prevents Diabetic Myopathy by Improving Skeletal Muscle Cell Differentiation; American Diabetes Association: Arlington, VA, USA, 2018; Volume 67.

(C) 2019 by the authors. Licensee MDPI, Basel, Switzerland. This article is an open access article distributed under the terms and conditions of the Creative Commons Attribution (CC BY) license (http:/ / creativecommons.org/licenses/by/4.0/). 


\title{
Regulation of Oxidative Stress in Corneal Endothelial Cells by Prdx6
}

\author{
Matthew Lovatt ${ }^{1,2, *}$, Khadijah Adnan ${ }^{1}$, Gary S. L. Peh ${ }^{1,2}$ and Jodhbir S. Mehta ${ }^{1,2,3,4, *}$ \\ 1 Tissue Engineering and Stem Cell group, Singapore Eye Research Institute (SERI), Singapore 169856, \\ Singapore; khadijah.adnan@seri.com.sg (K.A.); garypeh@gmail.com (G.S.L.P.) \\ 2 Eye-ACP, Duke-NUS Graduate Medical School, Singapore 169857, Singapore \\ 3 Singapore National Eye Centre (SNEC), Singapore168751, Singapore \\ 4 School of Material Science and Engineering, Nanyang Technological University, Singapore 639977, Singapore \\ * Correspondence: lovatt.matthew.jason@seri.com.sg (M.L.); jodmehta@gmail.com (J.S.M.); \\ Tel.: +65-622-772-55 (J.S.M.); Fax: +65-622-772-90 (J.S.M.)
}

Received: 30 October 2018; Accepted: 1 December 2018; Published: 4 December 2018

check for updates

\begin{abstract}
The inner layer of the cornea, the corneal endothelium, is post-mitotic and unable to regenerate if damaged. The corneal endothelium is one of the most transplanted tissues in the body. Fuchs' endothelial corneal dystrophy (FECD) is the leading indication for corneal endothelial transplantation. FECD is thought to be an age-dependent disorder, with a major component related to oxidative stress. Prdx6 is an antioxidant with particular affinity for repairing peroxidised cell membranes. To address the role of Prdx6 in corneal endothelial cells, we used a combination of biochemical and functional studies. Our data reveal that Prdx6 is expressed at unusually high levels at the plasma membrane of corneal endothelial cells. RNAi-mediated knockdown of Prdx6 revealed a role for Prdx6 in lipid peroxidation. Furthermore, following induction of oxidative stress with menadione, Prdx6-deficient cells had defective mitochondrial membrane potential and were more sensitive to cell death. These data reveal that Prdx6 is compartmentalised in corneal endothelial cells and has multiple functions to preserve cellular integrity.
\end{abstract}

Keywords: Prdx6; cornea; Fuchs' endothelial corneal dystrophy; lipid peroxidation; mitochondrial membrane potential

\section{Introduction}

The cornea is a transparent refractive structure at the front of the eye. The cornea is approximately $500 \mu \mathrm{m}$ thick and composed of several layers, including a protective outer epithelial cell layer; an acellular Bowman's layer; a stromal layer; an acellular Descemet's membrane; and a single uniform layer of cells on the posterior surface, termed the corneal endothelium (CE) [1-3]. Corneal endothelial cells (CEnCs) are neural crest derived and have striking hexagonal morphology. The CE is essential for maintaining corneal hydration and therefore optimal corneal transparency. This is achieved through a pump-leak mechanism: nutrients from the aqueous humor are allowed to passively diffuse through the 'leaky' endothelium into the stroma and, concurrently, an ionic pump drives fluid from the stroma into the aqueous humor. This dynamic 'barrier and pump' function serves to maintain corneal hydration and transparency vital for visual acuity.

Corneal endothelial cells are growth-arrested and cannot regenerate [1-3]. Age-dependent degeneration and decline in number of CEnCs is known to occur [4,5]. Furthermore, CEnCs are metabolically active and subjected to persistent UV exposure. Indeed, UV exposure is known to induce DNA damage and apoptosis of CEnCs [6]. Therefore, to maintain functional integrity and corneal transparency, CEnCs must possess intrinsic mechanisms to control their level of oxidative 
stress. Damage to the CE due to age-related degeneration or genetic corneal dystrophies is one of the leading causes of corneal blindness. Currently, CEnC dysfunction can only be remedied by a corneal transplant, which replaces the dysfunctional cell layer and restores vision. Corneal tissue is the most transplanted tissue in the body.

The most common corneal endothelial dystrophy is Fuchs' endothelial corneal dystrophy (FECD) [7]. A number of factors, including age, sex, and several genetic loci, are implicated in FECD. However, oxidative stress is also thought to contribute to the pathogenesis of FECD: cornea tissues from Fuchs' patients display an overall increase in reactive oxygen species (ROS), and human CEnC cell lines derived from FECD patients are more vulnerable to oxidative insults [8]. Interestingly, proteomic analysis of pooled CE from FECD patients has revealed a specific downregulation of the peroxiredoxin (Prdx) family of antioxidants [9].

The Prdx protein family contains six isoforms that are capable of reducing hydrogen peroxide and alkyl hydroperoxides. The Prdx family is characterised by a conserved catalytic cysteine (Cys) in the N-terminus. All Prdx proteins, with the exception of Prdx6, additionally contain an additional conserved resolving cysteine in the C-terminus. However, Prdx6 possesses only a single $N$-terminus catalytic cysteine. Furthermore, Prdx6 is the only member of the family to possess both phospholipase A2 (PLA $)$ activity and lysophosphatidylcholine acyl transferase (LPCAT) activity $[2,10,11]$. Peroxides such as hydrogen peroxide oxidize the $\mathrm{N}$-terminal Cys to form sulfenic acid. Normally, an intermolecular disulfide bond is formed with a second adjacent C-terminal Cys residue, which is then reduced by thioredoxin to complete the catalytic cycle. However, for 1-Cys Prdx6, glutathione is used as the reductant [12].

Although Prdx6 is primarily a cytosolic protein, its recruitment to the plasma membrane is thought to be essential for its role in repairing peroxidised membranes [13]. We recently identified an antibody, TAG-2A12, as a unique marker for CEnCs [14]. Interestingly, immunohistochemistry and flow cytometry revealed that TAG-2A12 labelled the cell surface of CEnC. The target antigen bound by TAG-2A12 was identified to be Prdx6 by mass spectrometry [14]. However, by flow cytometry, commercially available antibodies to Prdx6 do not label the cell surface of CEnCs, suggesting that TAG-2A12 recognises an epitope associated with membrane-bound Prdx6. This was the first report of the expression of this protein on the corneal endothelial surface. However, membrane Prdx6 has also been reported in activated neutrophils [15] as well as in the human lung carcinoma cell line, A549, treated with peroxide [16]. It has been postulated that cytosolic Prdx6 can translocate to the plasma membrane, bind oxidised phospholipids, and perform a fundamental role in repair of peroxidised cell membranes [13].

In this study, we aimed to confirm the cell surface expression of Prdx6 and to characterise the function of Prdx6 in human CEnCs. We report that high levels of Prdx6 can be isolated from the plasma membrane of CEnCs. The level of Prdx6 diminishes during oxidative stress. Using siRNA to target Prdx6 in a CE cell line, we demonstrate that Prdx6 is required to maintain both lipid peroxidation as well as cell viability through the regulation of mitochondrial function.

\section{Material and Methods}

\subsection{Chemicals and Reagents}

All reagents were purchased from Sigma (now under Merck, Darmstadt, Germany) unless otherwise stated.

\subsection{Induction of Oxidative Stress}

Specific reagents were selected to induce oxidative stress in different cellular compartments. Cumene hydroperoxide $(\mathrm{CH})$, which is lipophilic, was selected because it has been previously demonstrated to induce lipid peroxidation at the plasma membrane [17]. Tert-butyl hydroperoxide $(\mathrm{tBHP})$ was selected as a stable alternative to hydrogen peroxide that initiates reactive oxygen 
species (ROS) and induces lipid peroxidation and apoptosis. Menadione (MN) was used to increase intracellular ROS. Furthermore, MN treatment of normal CEnCs has been demonstrated to mimic pathological changes seen in ex vivo FECD specimens [18]. Suitable doses of each compound were chosen based on either manufacturers' instructions or published data, or were empirically determined.

\subsection{Human Corneal Tissue and Cell Culture}

Primary human corneal endothelial cells (pCEnCs) obtained from cadaveric corneal tissue unsuitable for transplantation were procured through Lions Eye Institute for Transplant and Research (Tampa, FL, USA). Isolated pCEnCs were expanded using a dual-media approach until passage 2 or passage 3, in $6 \mathrm{~cm}$ plates, as previously described [19]. Thereafter, cultures were maintained in M5 media consisting of Human endothelial-SFM (Life Technologies, Thermo Fisher Scientific, Waltham, MA, USA) supplemented with 5\% serum (EquaFetal ${ }^{\circledR}$ Atlas Biologicals, Fort Collins, CO, USA). To isolate corneal stromal fibroblasts, stromal tissue fragments were digested with collagenase I $\left(1 \mathrm{mg} / \mathrm{mL}\right.$, Worthington, Lakewood, NJ, USA) for $24 \mathrm{~h}$ at $37^{\circ} \mathrm{C}$. Single cells were suspended in Dulbecco's Modified Eagle Medium (DMEM) 10\% bovine serum and cultured until confluent. Human retinal microvascular endothelial cells (RMECs, Angio Proteomie, cAP-0010) were maintained in M5 $10 \%$ serum and used at passage 5 .

The SV40-transformed human corneal endothelial cell line (B4G12, [20]), the human lung adenocarcinoma A549 cell line (ATCC; CCL-185), HEK293T, and the spontaneous arising retinal pigmented epithelial cell line ARPE19 were maintained at $37^{\circ} \mathrm{C}, 5 \% \mathrm{CO}_{2}$ in DMEM (high glucose) supplemented with 10\% bovine serum (Gibco; Thermo Fisher Scientific, Waltham, MA, USA) together with antibiotics.

Where indicated, cells were treated with tert-butyl hydroperoxide (tBHP) $500 \mu \mathrm{m}$ for $3 \mathrm{~h}$ at $37^{\circ} \mathrm{C}$.

\subsection{Cell Fractionation and Western Blotting}

Cell surface proteins were isolated using the Pierce Cell Surface Isolation Kit (Thermo Fisher Scientific). Briefly, confluent cultures of cells were incubated with the cell membrane impermeable, cleavable biotinylation reagent EZ-Link ${ }^{\mathrm{TM}}$ Sulfo-NHS-SS-Biotin at $4{ }^{\circ} \mathrm{C}$ for $30 \mathrm{~min}$. Following cell lysis, labelled proteins were isolated by incubation with NeutrAvidin agarose for $1 \mathrm{~h}$. Following extensive washing, proteins were eluted in sodium dodecyl sulfate-polyacrylamide gel electrophoresis (SDS-PAGE) sample buffer containing $50 \mathrm{mM}$ dithiothreitol (DTT).

Plasma Membrane Isolation

Plasma membrane fractions were isolated using the Plasma Membrane Protein Extraction Kit (Abcam, ab65400, Cambridge, UK). Briefly, cells were chilled on ice, washed in ice-cold phosphate buffered saline (PBS), and scraped into ice-cold PBS. Cell pellets were lysed in homogenization buffer containing protease inhibitors. Homogenization was completed with low power sonication at $4{ }^{\circ} \mathrm{C}$. Total membrane proteins were pelleted by centrifugation at $10,000 \times \mathrm{g}$ for $30 \mathrm{~min}$ at $4{ }^{\circ} \mathrm{C}$. The supernatant (cytoplasmic fraction) was removed. Plasma membrane proteins were purified by resuspending the total membrane pellet in a combination of lower phase/upper phase solutions, and centrifugation. The exact constituents of these solutions is proprietary, but most likely based on an aqueous polymer two-phase separation system which separates plasma membranes based on their affinity for two immiscible polymers, such as, polyethylene glycol and dextran [21]. Membrane pellets were dissolved in $0.5 \%$ Triton X-100 in PBS. Proteins were quantitated by BCA assay (Pierce, Thermo Fisher Scientific) and equivalent amounts loaded on 4-20\% mini-PROTEAN ${ }^{\circledR}$ TGX $^{\mathrm{TM}}$ Gels (Bio-Rad, Hercules, CA, USA). Gels were transferred to PVDF membranes and blocked in $5 \%$ non-fat milk. The following antibodies were used for immunoblotting: PRDX6 (4A3, ab16947, Abcam), CD325 (N-Cadherin, clone 8C11,), and $\beta$-Catenin (clone 14) (both from BD Biosciences, San Jose, CA, USA). $\mathrm{Na}^{+} / \mathrm{K}^{+}$-ATPase (sc71638, Santa Cruz Biotechnology, Dallas, TX, USA) and GAPDH (clone FF26A/F9 and $\beta$-Actin clone 2F1-1, both BioLegend) served as loading controls. 
Blots were washed in PBST (PBS + 0.1\% tween-20), probed with HRP-conjugated secondary antibodies (Cell signalling Technology, Danvers, MA, USA), and visualised by chemiluminescence. Bands were quantified using ChemiDoc ${ }^{\mathrm{TM}} \mathrm{MP}$ imaging system and image lab software (Bio-Rad, Hercules, CA, USA).

\subsection{RNAi Knockdown of Prdx6}

Confluent cultures of B4G12 cells were harvested and seeded in 12-well plates at $40 \mathrm{k} / \mathrm{cm}^{2}$. Cells were transfected with $10 \mu \mathrm{m}$ Silencer ${ }^{\circledR}$ select validated siRNA (Ambion ${ }^{\circledR}$ by Life Technologies, Thermo Fisher Scientific, Waltham, MA, USA) together with Lipofectamine ${ }^{\mathrm{TM}}$ RNAiMAX transfection reagent (Thermo Fisher Scientific) at the time of seeding, according to the manufacturers' instructions. The following siRNA reagents were used: Silencer ${ }^{\circledR}$ select Prdx6 (ID\# s18430) and, as control, Silencer ${ }^{\circledR}$ select negative control \#1. After $24 \mathrm{~h}$ of culture, media was changed and cells were re-transfected. Cells were analysed the following day. Knockdown of Prdx6 was confirmed by $48 \mathrm{~h}$ post-transfection by directly lysing cells in SDS-PAGE sample buffer and probing western blots with anti-Prdx6 antibodies. Bands were quantified using ChemiDoc ${ }^{\mathrm{TM}} \mathrm{MP}$ imaging system and image lab software (Bio-Rad, Hercules, CA, USA). Alternatively, knockdown of Prdx6 was analysed by real-time PCR analysis. Briefly, total RNA was extracted using RNeasy kit (Qiagen, Venlo, Netherlands) and 500 ng was reversed transcribed with iSCRIPT (Bio-Rad). Real-time PCR was performed using TaqMan ${ }^{\circledR}$ gene expression assays (Thermo Fisher Scientific). Relative quantification was normalised using GAPDH and calculated by $2^{-\Delta \Delta C t}$.

\subsection{Lipid Peroxidation Assay}

Lipid peroxidation was measured using the Click-iT ${ }^{\mathrm{TM}}$ Lipid Peroxidation Imaging Kit (Thermo Fisher Scientific) according to the manufacturer's instructions, with modifications for adaptation for flow cytometry. Briefly, B4G12 cells were treated with $100 \mu \mathrm{m} \mathrm{CH}$ in media containing $50 \mu \mathrm{m}$ linoleamide alkyne (LAA) for $2 \mathrm{~h}$ at $37^{\circ} \mathrm{C}$. Cells were harvested by cell dissociation in TrypLE Express (Thermo Fisher Scientific) and washed in PBS/0.1\% bovine serum albumin (BSA). Cells were pelleted by centrifugation and resuspended in $100 \mu \mathrm{L}$ of $3.7 \%$ paraformaldehyde (PFA) for $15 \mathrm{~min}$ at room temperature. Cells were washed in PBS/0.1\% BSA and resuspended in PBS/0.05\% Triton X-100 for $10 \mathrm{~min}$ at room temperature. Next, $1 \mathrm{~mL}$ PBS/1\% BSA was directly added to cells and incubated for $20 \mathrm{~min}$ at room temperature. Cells were pelleted and gently washed in PBS without BSA. Cell pellets were incubated in Click-iT reaction cocktail containing Alexa Fluor 488 azide in the presence of $\mathrm{CuSO}_{4}$, for $30 \mathrm{~min}$ at room temperature protected from light. Cells were immediately analysed on a BD FACSVerse ${ }^{\mathrm{TM}}$ flow cytometer (BD Biosciences).

\subsection{Cell Viability Assay: Flow Cytometry}

Transfected B4G12 cells were treated with $\mathrm{CH}(100 \mu \mathrm{m})$ for $4 \mathrm{~h}$ at $37{ }^{\circ} \mathrm{C}$ in a tissue culture incubator. Cells were washed in PBS and harvested by trypsinisation. Aliquots (100 $\mu \mathrm{L})$ of cells were transferred to Eppendorf tubes and incubated with $5 \mu \mathrm{L}$ of FITC-Annexin V and $10 \mu \mathrm{L}$ of PI (BioLegend) for $15 \mathrm{~min}$ at room temperature in Annexin V binding buffer. Cells were re-suspended in $400 \mu \mathrm{L}$ Annexin $\mathrm{V}$ buffer and immediately analysed on a BD FACSVerse ${ }^{\mathrm{TM}}$ flow cytometer.

\subsubsection{Cell Viability Assay: xCELLigence}

Cell viability was assessed using the xCELLigence real-time cell analyser (ACEA Bioscience, Agilent, San Diego, CA, USA). siRNA-transfected B4G12 cells were seeded at $4 \times 10^{4}$ in triplicate in an E-Plate 96 (ACEA Biosciences) and left to attach for $18 \mathrm{hrs.} \mathrm{Cells} \mathrm{were} \mathrm{left} \mathrm{untreated} \mathrm{or}$ treated with indicated compounds. The electrical impedance readings of overall cell viability were recorded, using the xCELLigence real-time cell analyser, throughout the experiment for at least $8 \mathrm{~h}$. The percentage of viable cells was calculated for each time point relative to time zero, which was set as the last impedance reading prior to addition of compounds. Data shown are representative of 
three independent experiments. Statistical analysis was performed using GraphPad software (Prism, version 7, GraphPad, San Diego, CA, USA). Groups were compared with two-way ANOVA, followed by post-hoc Bonferroni test, for multiple comparisons, with $p$-value $<0.05$ considered significant.

\subsubsection{Cell Viability Assay: Mitochondrial Membrane Potential ( $\Delta \Psi \mathrm{m})$}

Mitochondrial membrane potential was measured using the TMRE assay (Cell Signalling Technology). Briefly, siRNA-transfected cells were treated with $50 \mu \mathrm{m} \mathrm{MN}$ for 90 min or the potent $\triangle \Psi \mathrm{m}$ disruptor CCCP $(50 \mu \mathrm{m})$ for $15 \mathrm{~min}$. The mitochondrial membrane dye, TMRE, was added at a final concentration of $200 \mathrm{nM}$ for $20 \mathrm{~min}$. Cells were trypsinised and immediately analysed by flow cytometry.

\section{Results}

\subsection{Membrane Expression of Prdx6 in Corneal Endothelial Cells}

We compared the membrane localisation of Prdx6 in primary and transformed cell lines derived from the eye. We incorporated in our analysis the human CEnC line B4G12 [20], as well as the spontaneous arising retinal epithelial cell line ARPE19. As a non-eye control, we used human embryonic kidney cells (HEK293T). Cell surface proteins were isolated by biotinylation of cells and subsequent immunoprecipitation with neutravidin agarose, as detailed in Section 2.4. Western blotting of eluted surface proteins with Prdx6 antibodies revealed that Prdx6 was primarily detected in pCEnCs (Figure 1A). Prdx6 was similarly detected in B4G12 cells, albeit at low levels. No detectable surface Prdx6 was detected in HEK293T or corneal stromal fibroblasts, despite the abundance of cytosolic Prdx6 (Figure 1A). To verify that Prdx6 can be detected at the cell surface in B4G12 cells, we repeated our experiments using a greater number of B4G12 cells, as well as pCEnCs isolated from fresh donors (Figure 1B). Corroborating our previous result, high surface Prdx6 levels were detected in pCEnCs (Figure 1B). Low levels of Prdx6 were also detected in B4G12 cells. The surface level of Prdx6 was not unique to pCEnCs because the cell line ARPE19 similarly had detectable expression of Prdx6 in cell surface extracts. However, the greatest surface levels of Prdx6 were detected in pCEnCs.

A

\section{Total cell lysate}

B

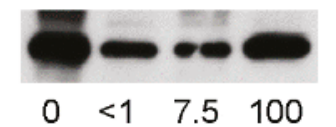

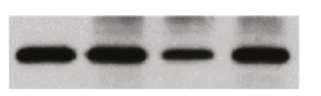

$\begin{array}{lllll}100 & 3 & 43 & 38 & \text { relative cell surface }\end{array}$

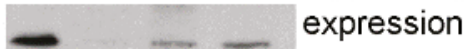

Cell surface

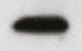

Blot: Prdx6
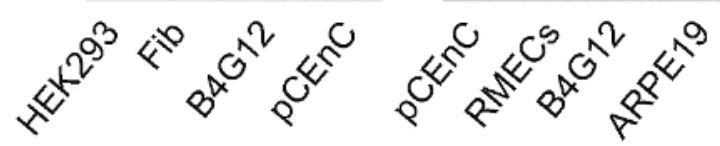

Figure 1. (A,B) Prdx6 is predominantly expressed at the cell surface in human corneal endothelial cells (CEnCs). The indicated cells had their cell surface biotinylated using Sulfo-NHS-SS-Biotin. Cell lysates were subjected to immunoprecipitation with NeutrAvidin ${ }^{\mathrm{TM}}$ agarose. Eluted proteins were probed with Prdx6 antibodies. For comparative purposes, an aliquot of cell lysate prior to immunoprecipitation was used for analysis of total cellular Prdx6 levels. Bands were quantitated, and relative surface Prdx6 levels were normalised against total Prdx6 levels. Primary human corneal endothelial cell (pCEnC) levels were arbitrarily set to 100. Fib: corneal fibroblasts. RMECs: retinal microvascular endothelial cells. 


\subsection{Prdx6 Levels are Sensitive to Oxidative Stress}

Western blot analysis of the cell surface fraction, from pCEnCs treated with tert-butyl hydroperoxide (tBHP), revealed that Prdx6 levels were diminished in pCEnCs under oxidative stress. The affect was apparent for both cell surface-bound Prdx6 as well the unbound fraction. Importantly, membrane-levels of $\mathrm{N}$-Cadherin, $\beta$-Catenin, and $\mathrm{Na}^{+} \mathrm{K}^{+}$-ATPase were not affected by tBHP treatment (Figure 2A). Membrane proteins, such as $\mathrm{N}$-Cadherin and $\mathrm{Na}^{+} \mathrm{K}^{+}$-ATPase, were not detected in the unbound flow-through fraction, which validated our cell surface isolation protocol. To confirm these data, we employed an alternative protocol for the isolation of plasma membrane (PM) proteins (Section 2.4). Purified PM proteins were extracted from untreated or tBHP treated pCEnCs. Similar to our previous observation, Prdx6 levels were downregulated during oxidative stress (Figure 2B). As controls for these experiments, we used the lung carcinoma A549 cells. In contrast to pCEnCs, A549 demonstrated an overall increase in PM bound Prdx6 (Figure 2B and Figure S1), although statistical analysis revealed the differences to be insignificant. However, our data is consistent with previous reports demonstrating translocation of Prdx6 to the PM following tBHP treatment [16]. In B4G12 cells, plasma membrane Prdx6 was not altered by tBHP, despite a decrease in levels of cytoplasmic Prdx6 following tBHP treatment (Figure S1). These results suggest subtle differences between primary and transformed CEnCs.

Taken together, our data suggest that CEnCs have Prdx6 constitutively associated with the plasma membrane.

A

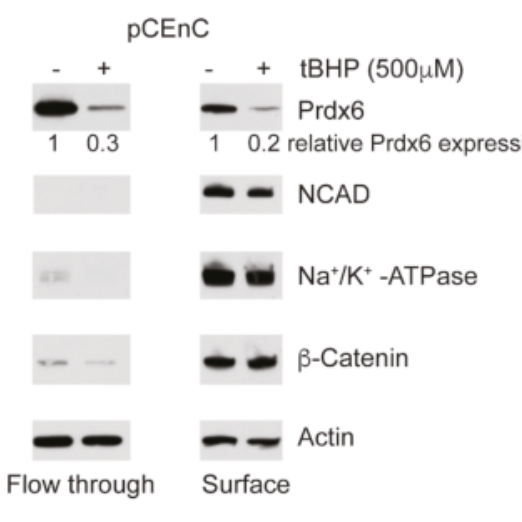

B

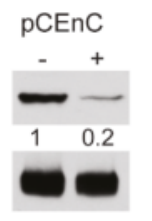

C

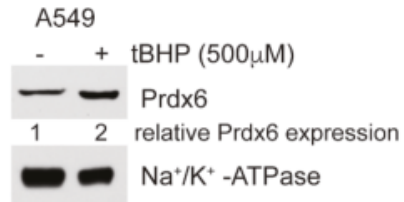

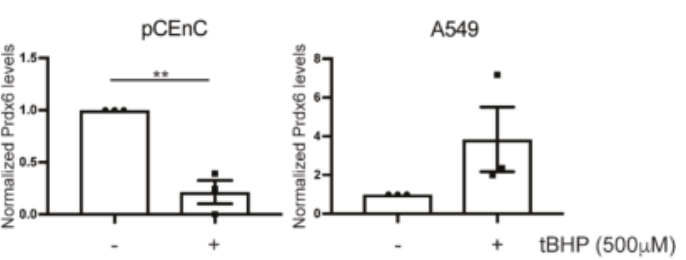

Figure 2. Prdx6 levels are sensitive to oxidative stress. (A) Primary cultures of human CEnCs) were treated with tert-butyl hydroperoxide (tBHP) for $3 \mathrm{~h}$. pCEnCs were biotinylated and cell surface proteins purified by immunoprecipitation. The flow-through, unbound fraction served as a control for membrane fractionation. (B) pCEnCs and (C) A549 cells were treated with tBHP for $3 \mathrm{~h}$ and plasma membrane was isolated by density dependent centrifugation. Data from three independent experiments \pm SEM is shown. Prdx6 levels were normalized to $\mathrm{Na}^{+} / \mathrm{K}^{+}$-ATPase and expressed relative to untreated $(-)$ controls. Student $t$-test was performed to evaluate statistical significance $(* * p$-value $<0.005)$.

\subsection{Prdx6 is Required for a Normal Lipid Peroxidation Response}

To elucidate the function of Prdx6 in CEnCs, we employed RNAi-mediated knockdown of Prdx6 in CEnCs. Our initial attempts to knockdown Prdx6 in pCEnCs did not reveal significant loss of gene and/or protein expression. Therefore, we utilised the CE cell line B4G12. B4G12 cells were amenable to transient transfection of siRNA, resulting in downregulation of Prdx6 mRNA at 24 and $48 \mathrm{~h}$ post-transfection (Figure $3 \mathrm{~A}$ ). This resulted in a $\sim 80 \%$ knockdown efficiency of protein 
$48 \mathrm{~h}$ post-transfection compared to B4G12 cells transfected with negative control siRNA reagents (Figure 3B).

A

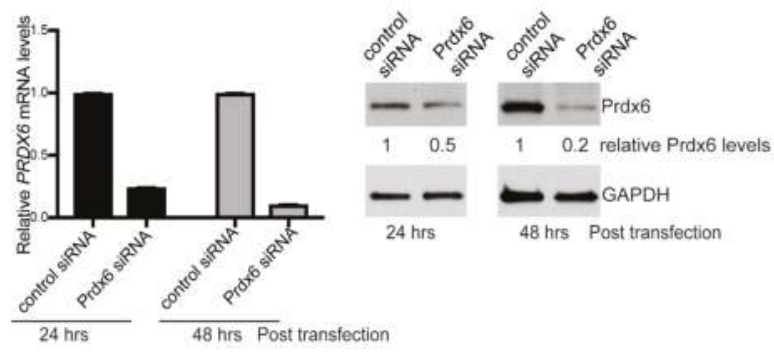

C

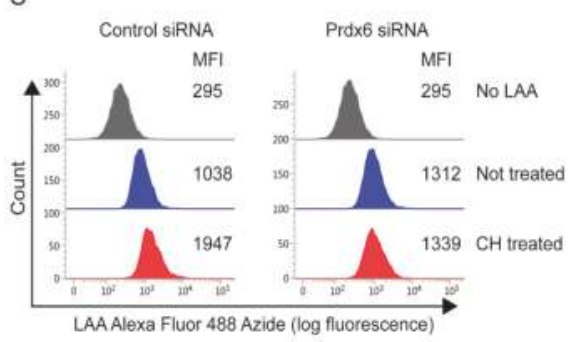

D

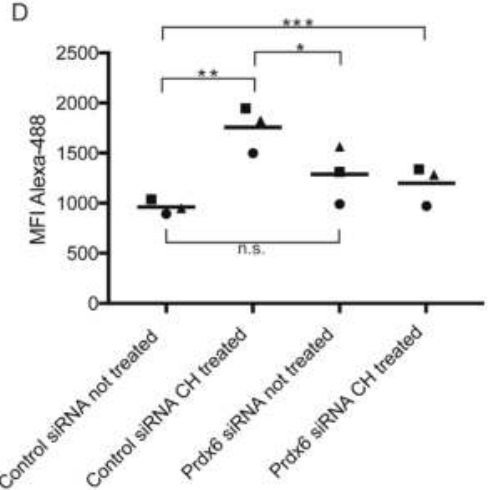

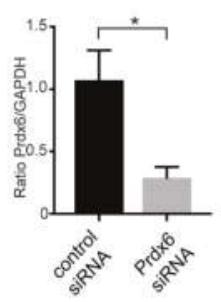

Figure 3. Targeted knockdown of Prdx6 in CEnCs reveals a role for Prdx6 in regulating lipid peroxidation. (A) Prdx6 mRNA levels were determined by qPCR analysis. Expression levels are shown relative to control siRNA treated B4G12 CEnCs and normalized to GAPDH. (B) Representative western blot analysis of aliquots of siRNA-transfected B4G12 CEnCs probed with anti-Prdx6 antibodies. Protein levels were quantitated relative to GAPDH and normalised to control siRNA. Data also expressed as mean $\pm \operatorname{SEM}(n=6)$. ${ }^{*} p$-value $(<0.05)$ was determined by student $t$-test. (C) Lipid peroxidation was measured in B4G12 CEnCs incubated with linoleamide alkyne (LAA) in the presence (cumene hydroperoxide ( $\mathrm{CH}$ ) treated) or absence of $\mathrm{CH}$ (not treated). B4G12 CEnCs incubated in the absence of LAA served as negative controls. (D) Data are expressed as mean fluorescence intensity (MFI) from three independent experiments. Two-way ANOVA with multiple comparisons was used to test statistical significance. Asterix $\left(^{*}\right)$ indicates statistical significance; ${ }^{*} p<0.05,{ }^{* *} p<0.005,{ }^{* * *} p<0.01$, n.s.: no significant difference. 
To explore the influence of Prdx6 on cellular membranes, we treated B4G12 cells with cumene hydroperoxide $(\mathrm{CH})$ and measured lipid peroxidation by flow cytometry. In cells transfected with control siRNA, $\mathrm{CH}$ induced lipid peroxidation, as judged by a $\sim 2$-fold increase in mean fluorescent (MFI) intensity of the Alexa Fluor 488 fluorophore (Figure 3C,D). Interestingly, the level of lipid peroxidation in untreated Prdx6 knockdown B4G12 cells was slightly higher compared to controls. However, this was not statistically significant (Figure 3D). Surprisingly, in response to CH, B4G12 cells lacking Prdx6 were unable to respond to $\mathrm{CH}$ and the fluorescence intensity of LAA-AF remained comparable to untreated cells (Figure 3C,D).

\subsection{Loss of Prdx6 Does Not Affect Cell Viability in Response to Cumene Hydroperoxide}

To explore whether loss of Prdx6 will affect apoptosis, we labelled B4G12 cells with Annexin V and propidium iodide (PI) following exposure to $\mathrm{CH}$ for $4 \mathrm{~h}$. In response to $\mathrm{CH}$, a large proportion ( $40 \%$ ) of cells were judged to be apoptotic $\left(\mathrm{AnV}^{+} / \mathrm{PI}^{+}\right)$in both control and Prdx6 siRNA-transfected B4G12 cells. However, the response between control and Prdx6-deficient cells to $\mathrm{CH}$ was not statistically significant (Figure 4A). To verify these data, we employed xCELLigence for real-time monitoring of cell viability. The addition of $\mathrm{CH}$ to both control and Prdx6-deficient cells resulted in a time-dependent decrease in cell viability with overlapping kinetics (Figure 4B), suggesting Prdx6 expression is not required to inhibit apoptosis in CEnCs.

A

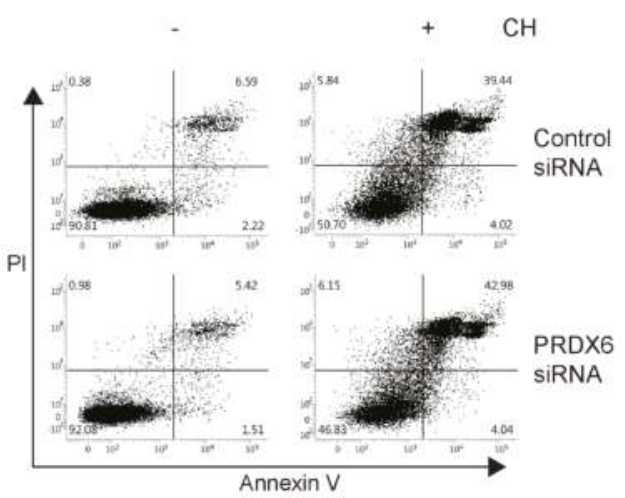

B

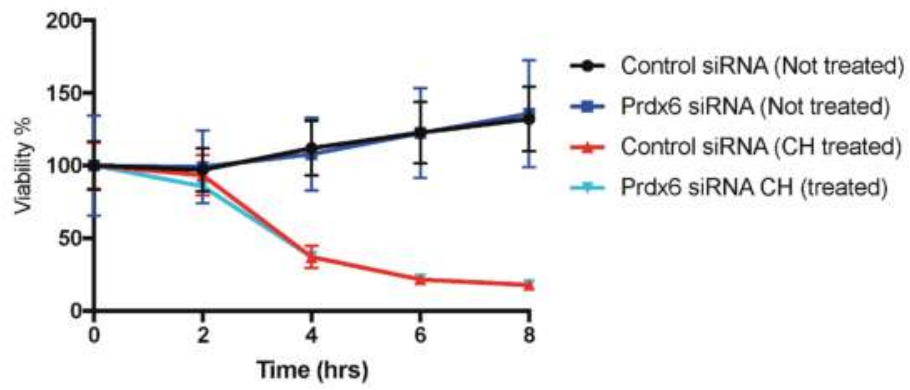

Figure 4. Normal apoptosis in the absence of Prdx6. (A) B4G12 CEnCs were treated with $\mathrm{CH}(100 \mu \mathrm{m})$ for $4 \mathrm{~h}$ and stained with Annexin $\mathrm{V}$ and propidium iodide (PI). Representative FACS plots are shown and the percentages of viable $\left(\mathrm{AnV}^{-} \mathrm{PI}^{-}\right)$, early, $\left(\mathrm{AnV}^{+} \mathrm{PI}^{-}\right)$, late apoptotic $\left(\mathrm{AnV}^{+} \mathrm{PI}^{+}\right)$, and necrotic $\left(\mathrm{AnV}^{-} \mathrm{PI}^{+}\right)$are shown. (B) B4G12 CEnC cells were seeded on xCELLigence plates and continuously monitored for $8 \mathrm{~h}$ after the addition of $\mathrm{CH}(50 \mu \mathrm{m})$. 


\subsection{Regulation of Mitochondrial Membrane Potential by Prdx6}

Treatment of CEnCs with menadione (MN) has been demonstrated to reduce mitochondrial membrane potential $(\Delta \Psi \mathrm{m})$, induce mitochondrial dysfunction, and to partially mimic phenotypes associated with FECD [18]. Preliminary data demonstrated that the potent $\triangle \Psi \mathrm{m}$ disruptor CCCP caused a significant loss in TMRE fluorescence, indicating loss of $\Delta \Psi \mathrm{m}$ in both control and Prdx6 siRNA-transfected B4G12 cells. However, MN did not cause $\Delta \Psi \mathrm{m}$ in this time frame (Figure $5 \mathrm{~A}$ and Figure S2). Therefore, we performed time courses to establish whether MN induces $\Delta \Psi \mathrm{m}$ with prolonged incubation (Figure S2). Compared to tBHP, MN induced a more robust $\Delta \Psi \mathrm{m}$ in a time-dependent fashion (Figure S2). Following a 90-min exposure to MN, differences between control and Prdx6 knockdown cells could be detected, with Prdx6 knockdown cells displaying greater loss of $\Delta \Psi \mathrm{m}$ compared to controls (Figure 5A). Therefore, in response to MN, loss of Prdx6 influences mitochondrial function.

We treated control and Prdx6 knockdown B4G12 cells with MN or tBHP and measured cellular viability with $x$ CELLigence (Figure $5 \mathrm{~B}$ ). Compared to $\mathrm{tBHP}, \mathrm{MN}$ rapidly decreased cell viability in control and Prdx6 knockdown B4G12. However, for Prdx6-deficient cells, loss of viability was consistently accelerated compared to controls. The augmented cell death in Prdx6 knockdown cells was not seen with $\mathrm{tBHP}$, suggesting the effects are specific to MN (Figure 5B). Taken together, it appears that loss of Prdx6 renders B4G12 cells more susceptible to oxidative stress and accelerates cell death in response to $\mathrm{MN}$.

A

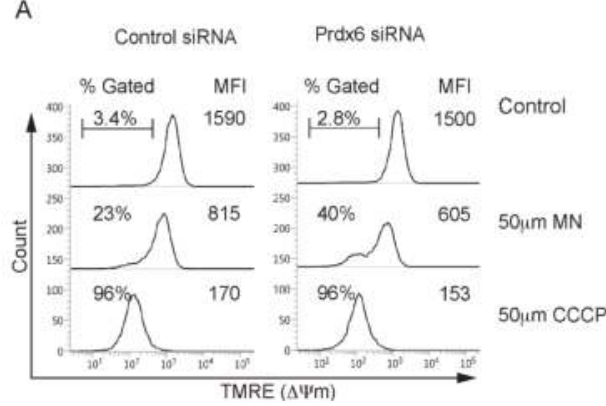

C

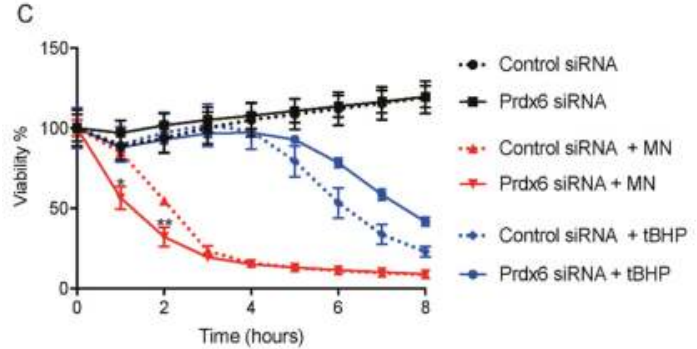

B

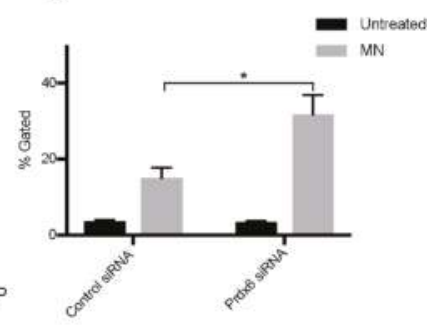

Figure 5. Prdx6-deficient cells are susceptible to cell death induced by menadione MN. (A) Representative FACS plots of TMRE mitochondrial membrane potential $(\triangle \Psi \mathrm{m})$ in siRNA-transfected B4G12 cells following treatment with $50 \mu \mathrm{m} \mathrm{MN} \mathrm{(90} \mathrm{min)} \mathrm{or} 50 \mu \mathrm{m} \mathrm{CCCP}$ (15 min). Percentage of cells with loss of $\triangle \Psi \mathrm{m}$ is shown as well as overall TMRE mean fluorescence intensity (MFI). (B) Data are presented as mean values \pm SEM $(n=4)$ of percentage TMRE negative. Two-way ANOVA reveals statistical significance $\left({ }^{*} p<0.005\right)$ between MN treated control and Prdx6 siRNA-transfected cells. (C) Viability in response to MN and tBHP was assessed as in Figure 4B. Data is presented as mean values $\pm \operatorname{SEM}(n=3)$. Statistical analysis for each time point was carried out using two-way ANOVA with Bonferroni post-hoc multiple comparisons test $\left.{ }^{*} p<0.0001,{ }^{* *} p<0.001\right)$. 


\section{Discussion}

Corneal endothelial cells are susceptible to oxidative stress. In part, FECD is thought to be an oxidative stress disease [22]. The late onset of FECD suggests that the continual exposure to UV-induced oxidative stress gradually renders endothelial cells in FECD more susceptible to oxidative damage. Consistent with this, a decrease in Prdx (including Prdx6) levels has been demonstrated [9]. Furthermore, an increase in oxidative damage in ex vivo FECD tissue has been reported [8]. Menadione induces intracellular ROS in cultures of normal human CEnCs and produces effects similar to that seen in cells derived from FECD tissue [18].

We report that Prdx6 levels are compartmentalised to the plasma membrane in both primary cultures of CEnCs as well as the CE cell line B4G12. In A549 cells Prdx6 translocates to the plasma membrane in response to oxidative stress in order to protect the cell membrane. We reasoned that Prdx6 might play a similar function in CEnC. However, in primary CEnCs oxidative stress resulted in a decrease in both cytosolic as well as PM Prdx6 levels. Likewise, cytoplasmic Prdx6 in B4G12 was reduced following oxidative stress. However, the PM levels did not change within the 3-h timeframe. In an attempt to elucidate the function of plasma membrane associated Prdx6, we performed knockdown of Prdx6 followed by treatment with $\mathrm{CH}$. Cumene hydroperoxide induces lipid peroxidation at the plasma membrane with no effect on mitochondria [17]. We predicted that Prdx6-deficient cells would have increased sensitivity to lipid peroxidation. However, in response to $\mathrm{CH}$, the level of lipid peroxidation did not increase, suggesting Prdx6 is required for cells to respond to $\mathrm{CH}$. Our data on Prdx6 knockdown of B4G12 endothelial cells contradicts that described for pulmonary microvascular endothelial cells (PMVECs) isolated from the lungs of Prdx6-deficient mice. In response to tBHP, Prdx6-deficient PMVECs are more sensitive to lipid peroxidation [13]. Interestingly, both peroxidase as well as PLA $_{2}$ activity was required for Prdx6 to mediate membrane repair following lipid peroxidation [13]. The discrepancy between these results is unclear. Both $\mathrm{CH}$ and tBHP induce lipid peroxidation and apoptosis to the same extent. We can only speculate that in the absence of Prdx6, compensatory mechanisms might be induced to maintain cell membrane integrity in CEnC.

Alternatively, Prdx6 might actively contribute to lipid peroxidation. Indeed, following oxidative stress, Prdx6 PM levels were rapidly diminished, an effect not seen with other PM proteins. In this scenario, loss of Prdx6 may be protective. Indeed, viability in the absence of Prdx6 was greater compared to controls in response to tBHP. However, in response to $\mathrm{CH}$, apoptosis was comparable between control and Prdx6 siRNA-transfected B4G12 cells (Figure 4A). This suggests that the level of Prdx6 may impact how cells respond to different types of ROS. These data do not rule out that non-apoptotic cell death pathways such as ferroptosis [23] might be affected by Prdx6. Indeed, similar to Prdx6, GPx4 also uses GSH as its physiological reductant, (which is required for repair of peroxidised membranes), and loss of its expression drives ferroptosis [24].

Prdx6 is known to translocate to the PM in activated neutrophils and associate with components of the NADPH oxidase complex, and is required to enhance the generation of superoxide [15]. Whether or not PM Prdx6 in pCEnCs is associated with components of the NADPH oxidase is not currently known. A role for Prdx6 in generating superoxide may appear contradictory to the antioxidant role of Prdx6. However, localised peroxide is emerging as a niche for signal transduction. For example, localised inactivation of Prdx1 in lipid rafts is required for the generation of highly localised $\mathrm{H}_{2} \mathrm{O}_{2}$ within a signalling microdomain [25]. Currently it remains unclear as to why CEnCs have high Prdx6 levels at the PM.

Prdx6 has been demonstrated to be rapidly recruited to mitochondrial in CCCP-treated HeLa cells and is required to block the induction of mitophagy [26]. Prdx6 has also been revealed to translocate to mitochondria in hepatocytes in response to an ischemia-reperfusion injury model [27]. Furthermore, Prdx6-deficient mice have increased generation of mitochondrial-produced $\mathrm{H}_{2} \mathrm{O}_{2}$ and increased hepatocyte injury in response to ischemia-reperfusion injury [27]. Interestingly, loss of mitochondrial membrane potential and induction of mitophagy is strongly implicated in $\operatorname{FECD}[18,28]$. 


\section{Conclusions}

Consistent with these findings, we report that loss of Prdx6 results in heightened loss of mitochondrial membrane potential, together with accelerated cell death in B4G12 in response to MN. Taken together, our data suggest that oxidative stress results in a decrease in Prdx6. In turn, mitochondria become more sensitive to oxidative damage, which we suggest is responsible for the increased mitochondrial dysfunction apparent in FECD.

Supplementary Materials: The following are available online at http:/ /www.mdpi.com/2076-3921/7/12/180/s1, Figure S1. Cytoplasmic and plasma membrane (PM) proteins were purified from A549 and B4G12 cell lines left untreated $(-)$ or treated $(+)$ for $3 \mathrm{~h}$ with tBHP. Figure S2. Menadione disrupts mitochondrial membrane potential. B4G12 cells were treated with the indicated compounds for the desired times.

Author Contributions: M.L.: conceptualisation, study design, acquisition of data, data analysis and interpretation, writing of manuscript. K.A. and G.S.L.P.: procurement, isolation, and culture of primary human corneal endothelial cells. J.S.M.: acquisition of funding, data interpretation, and writing of manuscript.

Funding: This research was funded by the Singapore National Medical Research Council (NMRC), Clinician Scientist Award (NMRC/CSA-INV/0004/2015).

Conflicts of Interest: The authors declare that they have no competing interests. The funders had no role in study design, data collection and analysis, decision to publish, or preparation of the manuscript.

\section{References}

1. Peh, G.S.L.; Beuerman, R.W.; Colman, A.; Tan, D.T.; Mehta, J.S. Human corneal endothelial cell expansion for corneal endothelium transplantation: An overview. Transplantation 2011, 91, 811-819. [CrossRef] [PubMed]

2. Wahlig, S.; Lovatt, M.; Mehta, J.S. Functional role of peroxiredoxin 6 in the eye. Free Radic. Biol. Med. 2018, 126, 210-220. [CrossRef] [PubMed]

3. Bourne, W.M. Biology of the corneal endothelium in health and disease. Eye 2003, 17, 912-918. [CrossRef] [PubMed]

4. Laing, R.A.; Sanstrom, M.M.; Berrospi, A.R.; Leibowitz, H.M. Changes in the corneal endothelium as a function of age. Exp. Eye Res. 1976, 22, 587-594. [CrossRef]

5. Galgauskas, S.; Norvydaitè, D.; Krasauskaitè, D.; Stech, S.; Ašoklis, R.S. Age-related changes in corneal thickness and endothelial characteristics. Clin. Interv. Aging 2013, 8, 1445-1450. [CrossRef] [PubMed]

6. Liu, C.; Vojnovic, D.; Kochevar, I.E.; Jurkunas, U.V. UV-A Irradiation Activates Nrf2-Regulated Antioxidant Defense and Induces p53/Caspase3-Dependent Apoptosis in Corneal Endothelial Cells. Investig. Ophthalmol. Vis. Sci. 2016, 57, 2319-2327. [CrossRef] [PubMed]

7. Vedana, G.; Villarreal, G.; Jun, A.S. Fuchs endothelial corneal dystrophy: Current perspectives. Clin. Ophthalmol. 2016, 10, 321-330.

8. Jurkunas, U.V.; Bitar, M.S.; Funaki, T.; Azizi, B. Evidence of oxidative stress in the pathogenesis of fuchs endothelial corneal dystrophy. Am. J. Pathol. 2010, 177, 2278-2289. [CrossRef]

9. Jurkunas, U.V.; Rawe, I.; Bitar, M.S.; Zhu, C.; Harris, D.L.; Colby, K.; Joyce, N.C. Decreased expression of peroxiredoxins in Fuchs' endothelial dystrophy. Investig. Ophthalmol. Vis. Sci. 2008, 49, 2956-2963. [CrossRef]

10. Fisher, A.B.; Dodia, C.; Sorokina, E.M.; Li, H.; Zhou, S.; Raabe, T.; Feinstein, S.I. A novel lysophosphatidylcholine acyl transferase activity is expressed by peroxiredoxin 6. J. Lipid Res. 2016, 57, 587-596. [CrossRef]

11. Fisher, A.B. The phospholipase A2 activity of peroxiredoxin 6. J. Lipid Res. 2018, 59, 1132-1147. [CrossRef] [PubMed]

12. Fisher, A.B. Peroxiredoxin 6: A bifunctional enzyme with glutathione peroxidase and phospholipase A activities. Antioxid. Redox Signal. 2011, 15, 831-844. [CrossRef] [PubMed]

13. Li, H.; Benipal, B.; Zhou, S.; Dodia, C.; Chatterjee, S.; Tao, J.-Q.; Sorokina, E.M.; Raabe, T.; Feinstein, S.I.; Fisher, A.B. Critical role of peroxiredoxin 6 in the repair of peroxidized cell membranes following oxidative stress. Free Radic. Biol. Med. 2015, 87, 356-365. [CrossRef] [PubMed]

14. Ding, V.; Chin, A.; Peh, G.; Mehta, J.S.; Choo, A. Generation of novel monoclonal antibodies for the enrichment and characterization of human corneal endothelial cells (hCENC) necessary for the treatment of corneal endothelial blindness. MAbs 2014, 6, 1439-1452. [CrossRef] [PubMed] 
15. Ambruso, D.R.; Ellison, M.A.; Thurman, G.W.; Leto, T.L. Peroxiredoxin 6 translocates to the plasma membrane during neutrophil activation and is required for optimal NADPH oxidase activity. Biochim. Biophys. Acta 2012, 1823, 306-315. [CrossRef] [PubMed]

16. Manevich, Y.; Shuvaeva, T.; Dodia, C.; Kazi, A.; Feinstein, S.I.; Fisher, A.B. Binding of peroxiredoxin 6 to substrate determines differential phospholipid hydroperoxide peroxidase and phospholipase $\mathrm{A}(2)$ activities. Arch. Biochem. Biophys. 2009, 485, 139-149. [CrossRef] [PubMed]

17. Vroegop, S.M.; Decker, D.E.; Buxser, S.E. Localization of damage induced by reactive oxygen species in cultured cells. Free Radic. Biol. Med. 1995, 18, 141-151. [CrossRef]

18. Halilovic, A.; Schmedt, T.; Benischke, A.-S.; Hamill, C.; Chen, Y.; Santos, J.H.; Jurkunas, U.V. Menadione-Induced DNA Damage Leads to Mitochondrial Dysfunction and Fragmentation During Rosette Formation in Fuchs Endothelial Corneal Dystrophy. Antioxid. Redox Signal. 2016, 24, 1072-1083. [CrossRef]

19. Peh, G.S.L.; Chng, Z.; Ang, H.-P.; Cheng, T.Y.D.; Adnan, K.; Seah, X.-Y.; George, B.L.; Toh, K.-P.; Tan, D.T.; Yam, G.H.F.; et al. Propagation of human corneal endothelial cells: A novel dual media approach. Cell Transplant. 2015, 24, 287-304. [CrossRef]

20. Valtink, M.; Gruschwitz, R.; Funk, R.H.W.; Engelmann, K. Two clonal cell lines of immortalized human corneal endothelial cells show either differentiated or precursor cell characteristics. Cells Tissues Organs (Print) 2008, 187, 286-294. [CrossRef]

21. Schindler, J.; Nothwang, H.G. Aqueous polymer two-phase systems: Effective tools for plasma membrane proteomics. Proteomics 2006, 6, 5409-5417. [CrossRef] [PubMed]

22. Jurkunas, U.V. Fuchs Endothelial Corneal Dystrophy through the Prism of Oxidative Stress. Cornea 2018, 37 (Suppl. 1), S50-S54. [CrossRef]

23. Dixon, S.J.; Lemberg, K.M.; Lamprecht, M.R.; Skouta, R.; Zaitsev, E.M.; Gleason, C.E.; Patel, D.N.; Bauer, A.J.; Cantley, A.M.; Yang, W.S.; et al. Ferroptosis: An iron-dependent form of nonapoptotic cell death. Cell 2012, 149, 1060-1072. [CrossRef] [PubMed]

24. Yang, W.S.; Stockwell, B.R. Ferroptosis: Death by Lipid Peroxidation. Trends Cell Biol. 2016, 26, 165-176. [CrossRef] [PubMed]

25. Woo, H.A.; Yim, S.H.; Shin, D.H.; Kang, D.; Yu, D.-Y.; Rhee, S.G. Inactivation of peroxiredoxin I by phosphorylation allows localized $\mathrm{H}(2) \mathrm{O}(2)$ accumulation for cell signaling. Cell 2010, 140, 517-528. [CrossRef] [PubMed]

26. Ma, S.; Zhang, X.; Zheng, L.; Li, Z.; Zhao, X.; Lai, W.; Shen, H.; Lv, J.; Yang, G.; Wang, Q.; et al. Peroxiredoxin 6 Is a Crucial Factor in the Initial Step of Mitochondrial Clearance and Is Upstream of the PINK1-Parkin Pathway. Antioxid. Redox Signal. 2016, 24, 486-501. [CrossRef] [PubMed]

27. Eismann, T.; Huber, N.; Shin, T.; Kuboki, S.; Galloway, E.; Wyder, M.; Edwards, M.J.; Greis, K.D.; Shertzer, H.G.; Fisher, A.B.; et al. Peroxiredoxin-6 protects against mitochondrial dysfunction and liver injury during ischemia-reperfusion in mice. Am. J. Physiol. Gastrointest. Liver Physiol. 2009, 296, G266-G274. [CrossRef] [PubMed]

28. Benischke, A.-S.; Vasanth, S.; Miyai, T.; Katikireddy, K.R.; White, T.; Chen, Y.; Halilovic, A.; Price, M.; Price, F.; Liton, P.B.; et al. Activation of mitophagy leads to decline in Mfn2 and loss of mitochondrial mass in Fuchs endothelial corneal dystrophy. Sci. Rep. 2017, 7, 6656. [CrossRef]

(C) 2018 by the authors. Licensee MDPI, Basel, Switzerland. This article is an open access article distributed under the terms and conditions of the Creative Commons Attribution (CC BY) license (http:/ / creativecommons.org/licenses/by/4.0/). 


\title{
Review
}

\section{Radioprotective Role of Peroxiredoxin 6}

\author{
Mars G. Sharapov ${ }^{1, *}$, Vladimir I. Novoselov ${ }^{1}$ and Sergey V. Gudkov ${ }^{2,3,4}$ \\ 1 Laboratory of Mechanisms of Reception, Institute of Cell Biophysics of the Russian Academy of Sciences, \\ 142290 Pushchino, Russia; novoselov-vi@rambler.ru \\ 2 Wave Research Center, Prokhorov General Physics Institute of the Russian Academy of Sciences, \\ 119991 Moscow, Russia; s_makariy@rambler.ru \\ 3 Department of Experimental Clinical Studies, Moscow Regional Research and Clinical Institute (MONIKI), \\ 129110 Moscow, Russia \\ 4 The Institute of Biology and Biomedicine, Lobachevsky State University of Nizhni Novgorod, \\ 603950 Nizhni Novgorod, Russia \\ * Correspondence: sharapov.mars@gmail.com
}

Received: 28 November 2018; Accepted: 1 January 2019; Published: 5 January 2019

\begin{abstract}
Peroxiredoxin $6(\operatorname{Prd} x 6)$ is a member of an evolutionary ancient family of peroxidase enzymes with diverse functions in the cell. Prdx6 is an important enzymatic antioxidant. It reduces a wide range of peroxide substrates in the cell, thus playing a leading role in the maintenance of the redox homeostasis in mammalian cells. Beside peroxidase activity, Prdx6 has been shown to possess an activity of phospholipase A2, an enzyme playing an important role in membrane phospholipid metabolism. Moreover, Prdx6 takes part in intercellular and intracellular signal transduction due to its peroxidase and phospholipase activity, thus facilitating the initiation of regenerative processes in the cell, suppression of apoptosis, and activation of cell proliferation. Being an effective and important antioxidant enzyme, Prdx6 plays an essential role in neutralizing oxidative stress caused by various factors, including action of ionizing radiation. Endogenous Prdx6 has been shown to possess a significant radioprotective potential in cellular and animal models. Moreover, intravenous infusion of recombinant Prdx6 to animals before irradiation at lethal or sublethal doses has shown its high radioprotective effect. Exogenous Prdx6 effectively alleviates the severeness of radiation lesions, providing normalization of the functional state of radiosensitive organs and tissues, and leads to a significant elevation of the survival rate of animals. Prdx 6 can be considered as a potent and promising radioprotective agent for reducing the pathological effect of ionizing radiation on mammalian organisms. The radioprotective properties and mechanisms of radioprotective action of Prdx6 are discussed in the current review.
\end{abstract}

Keywords: peroxiredoxin 6; ionizing radiation; radioprotection; antioxidant activity

\section{Introduction}

Ionizing radiation is the flow of photons, elementary particles, and nuclear fission fragments capable of ionizing matter. The ionization process is usually defined as the conversion of neutral atoms or molecules into ions and radicals [1]. Ionizing radiation has a direct and indirect influence on living organisms. The direct effect includes damaging biological molecules via immediate contact with a quantum or particle of ionizing radiation. Indirect influence is related to the formation of water radiolysis products in the cell, namely reactive oxygen species (ROS) (Figure 1). The most widely known members of the ROS group are the superoxide anion radical $\left(\mathrm{O}_{2}{ }^{\bullet-}\right)$, hydroperoxide radical $\left(\mathrm{HO}_{2}{ }^{\bullet}\right)$, hydrogen peroxide $\left(\mathrm{H}_{2} \mathrm{O}_{2}\right)$, hydroxyl radical $\left(\mathrm{HO}^{\bullet}\right)$, singlet oxygen $\left({ }^{1} \mathrm{O}_{2}\right)$, etc. [2]. Every 100 electron-volts of absorbed ionizing radiation energy generates on average $2.4 \mathrm{HO}^{\bullet}$ radicals, 2.8 solvated electrons, 0.4 hydrogen atoms, $0.8 \mathrm{H}_{2} \mathrm{O}_{2}$ molecules, $0.4 \mathrm{H}_{2}$ molecules and much less of other compounds [3]. 


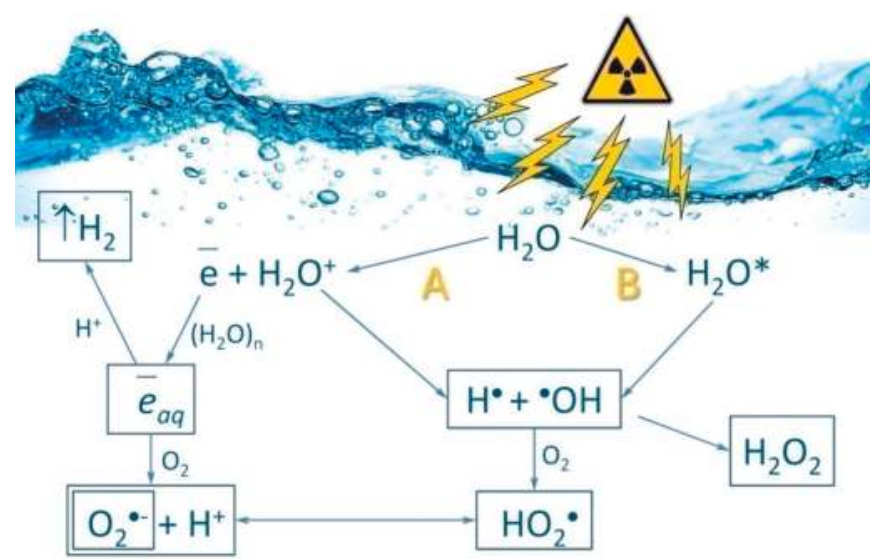

Figure 1. Schematic representation of water radiolysis. The reactions are ionization (A) and excitation (B), which produce reactive oxygen species (ROS). Primary $\left(\mathrm{HO}^{\bullet}, \mathrm{H}^{\bullet}\right)$ and secondary $\left(\mathrm{H}_{2} \mathrm{O}_{2}, \mathrm{O}_{2}{ }^{\bullet-}\right.$,

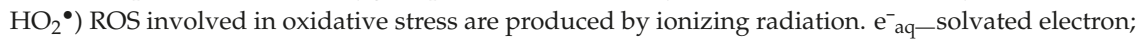
$\mathrm{H}_{2} \mathrm{O}^{*}$ - excited water molecule.

The situation when intracellular ROS concentration exceeds the capacity of antioxidant systems is called oxidative stress. Oxidative stress is accompanied by processes dangerous for cell living and functioning, such as lipid peroxidation [4], protein oxidation [5], and nucleic acid modification [6]. Oxidative DNA damage is closely related to mutagenesis and carcinogenesis processes and development of severe diseases [7-9]. The damage of DNA molecules is also one of the basic reasons for post-exposure death of living systems. A significant portion (around $70-80 \%$ ) of DNA damage caused by radiation is due to ROS formed during water radiolysis, and only $20 \%-30 \%$ is caused by direct absorption of high-energy quanta of ionizing radiation by target molecules [10-12]. (Figure 2).

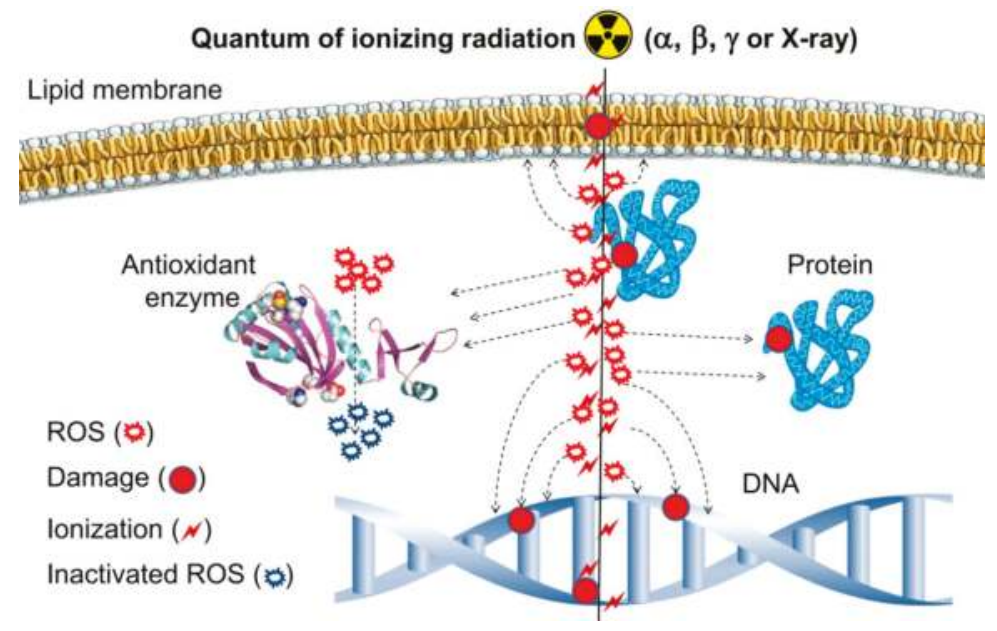

Figure 2. Schematic representation of the effects of ionizing radiation on a living cell.

Living organisms have developed different protective mechanisms in the course of evolution, the leading role among them belonging to antioxidants, because they are the suppressors of free radical oxidation alleviating the consequences of exposure to ionizing radiation [12,13]. Due to antioxidants, living systems are capable of maintaining the physiological ROS level and, as a result, their redox 
homeostasis. The antioxidant protection system includes low molecular weight compounds and antioxidant enzymes [14-16]. Low molecular weight compounds include vitamins, bioflavonoids, antioxidant hormones, low molecular weight thiols, etc. The most important antioxidant enzymes are superoxide dismutases (SODs), catalase, glutathione peroxidases (GPxs), glutathione reductases (GRs), thioredoxins (Trxs), and peroxiredoxins (Prdxs). A significant interest in these enzymes is caused by the fact that peroxiredoxins is an evolutionarily ancient family of peroxidases. Prdxs are detected in all living organisms, both in aerobic and in anaerobic ones. During the increase of organization complexity from bacteria and protists to multicellular organisms, the increase of the number of isoforms of peroxiredoxins took place. Hence, three peroxiredoxin isoforms have been detected in bacteria [17], five in yeast [18], six in mammals [19], and nine in plants [20]. The increase of Prdx isoform number in eukaryotes is caused by specialization of the enzymes in intracellular compartments and by their substrate specificity [21]. The evolutionary success of peroxiredoxins, which allowed them to spread across the whole living world, is due to the following reasons: (1) wide substrate specificity; (2) catalytic efficiency; (3) multifunctionality; (4) their involvement in different cellular processes.

Prdxs perform their catalytic function by a conservative cysteine residue $\left(\mathrm{C}_{\mathrm{P}}\right.$ - peroxidatic cysteine) in the active site, and they do not contain any auxiliary cofactors [16,22]. Prdxs play an important role in the regulation of ROS level in the cell, because they are capable of reducing various inorganic and organic peroxides [23-30]. Among mammalian peroxiredoxins (Prdx1-6), Prdx6 draws particular attention because of its ability to reduce the widest range of substrates, including $\mathrm{H}_{2} \mathrm{O}_{2}$, peroxynitrite, alkyl peroxides, phospholipid peroxides, etc. [31-33]. Due to its antioxidant properties, Prdx6 plays an important role in maintaining the redox balance in mammalian cells $[34,35]$. Animals with PRDX6 gene knockout, despite normal expression of the genes encoding other antioxidant enzymes, display a high sensitivity to oxidative stress (caused by hyperoxygenation, effect of peroxides, paraquat, etc.), which is accompanied by an elevated level of oxidative damage of animal organs and tissues [30]. Beside peroxidase activity, Prdx6 has been shown to possess an activity of $\mathrm{Ca}^{2+}$-independent phospholipase A2 (aiPLA2), which is normally expressed only under acidic conditions (in lysosomes and lamellar bodies, at $\mathrm{pH} 4-5$ ) and plays an important role in the metabolism of phospholipids and intracellular/intercellular signal transduction [36,37]. Thus, Prdx6 is a unique bifunctional enzyme (Figure 3) participating in many cellular processes [38].

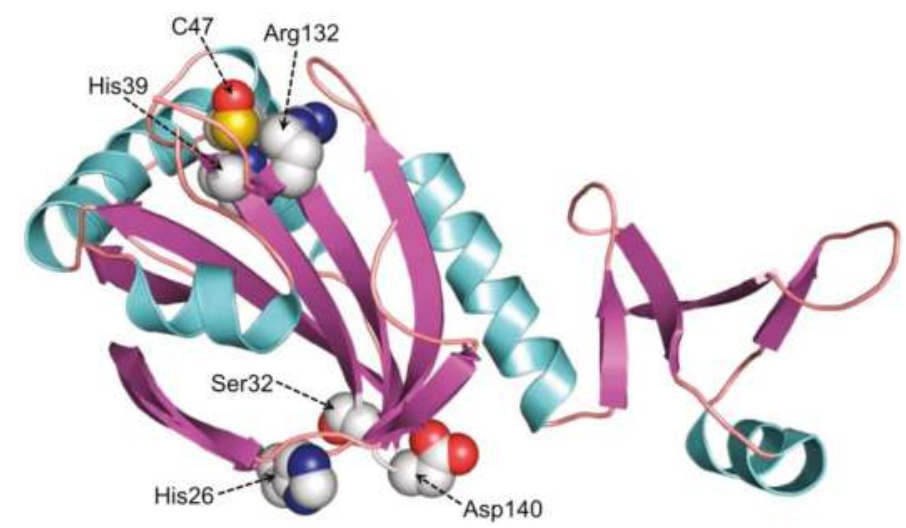

Figure 3. The schematic structure of human Prdx6 (Peroxiredoxin 6). Amino acid residues in the peroxidase catalytic center (His39, Cys47, Arg132) and phospholipase A2 active center (His26, Ser32, Asp140) are shown. The structure was built in Pymol.0.99.

This publication is part of a Forum on "Peroxiredoxin 6 as a Unique Member of the Peroxiredoxin Family". The radioprotective role of Prdx6 in mammalian organism and possible mechanisms of its radioprotective effect are discussed in the present review. 


\section{Regulation of PRDX6 Expression}

The character of expression of different peroxiredoxin isoforms in mammals exhibits cellular, tissue and organ specificity. The major factor affecting the level of PRDX1-6 gene expression is elevation of the ROS level, which can be caused by external and internal factors. It has been demonstrated that the action of hyperoxygenation, pro-oxidants (heme, transition metals, xenobiotics), hydroperoxides (of organic and inorganic nature), UV and ionizing radiation leads to an elevation of PRDX1-6 expression level [39-44]. The major role in the regulation of PRDX1-6 gene expression belongs to transcription factor NRF2 [45-48]. Along with NRF2, other transcription factors also participate in PRDX1-6 gene expression, such as HIF, AP-1, NF-kB, c-Myc, C/EBP, FOXO3, etc. [49-55].

It is worth mentioning that $P R D X 6$ expression is regulated by numerous transcription factors (Figure 4). Factors NRF2, HIF1 $\alpha$ and $C / E B P \beta$ enhance PRDX6 expression, while NF-kB has a suppressive effect on the expression level of PRDX6. Analysis of the PRDX6 gene promoter showed the presence of binding sites for each of the aforementioned transcription factors [56,57].

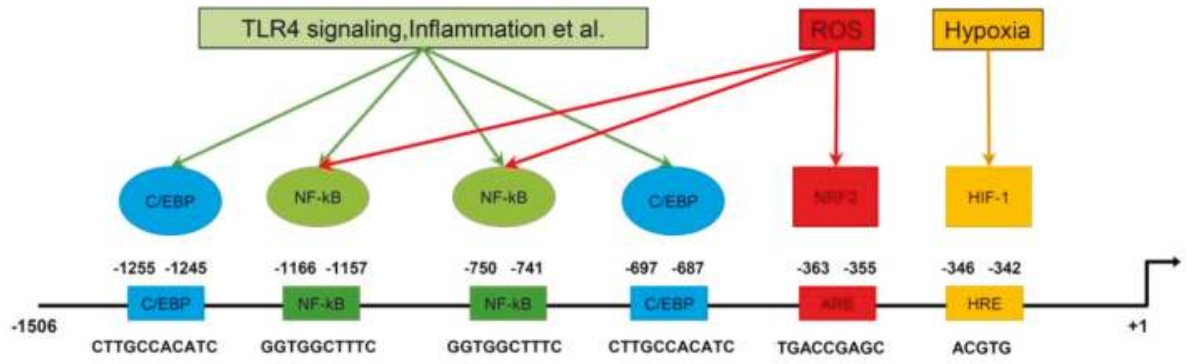

Figure 4. Schematic representation of the regulation of PRDX6 expression. The PRDX6 promoter and binding sites of different transcription factors are shown.

Beside transcription factors, other enzymes, immunomodulators, etc. are also involved in the regulation of PRDX1-6 expression [39,50,58-60]. It has been shown recently, that nucleophosmin (NPM1), a DNA/RNA chaperone, stimulates PRDX6 expression, and NPM1 gene knockdown or addition of a specific inhibitor of nucleophosmin, NSC348884, to cell cultures suppresses PRDX6 expression. On the contrary, an increase of NPM1 level also provides an increase of Prdx6 level [61]. Another important mechanism of peroxiredoxin gene expression regulation is mediated by microRNAs [62-64]. PRDX6 expression is suppressed via miR-24-3p, which specifically binds to the 3'-untranslated region of mRNA, thus suppressing PRDX6 gene expression [65]. The miR-24-3p level in gastric cancer cell line N87 is significantly lowered, which, in turn, stimulates cancer cell growth and metastasis formation [65].

Thus, PRDX6 gene expression level can be regulated by a complex of factors, which allows «flexible» reaction of the transcriptional machinery on the changing of internal and external conditions for the cell, accompanied by alteration of ROS level.

\section{Role of Endogenous Prdxs in Radioresistance of Mammalian Cells}

Adaptive induction of Prdxs synthesis occurs in cells in response to exposure to ionizing radiation and other factors that provoke an elevation of cellular ROS level. High radioprotective potential of peroxiredoxins has been shown in a series of experiments in animal models and cell cultures. UV and X-ray irradiation of rat skin has been shown to increase Prdx1, Prdx2, Prdx3 and Prdx6 expression level $[43,66]$, and X-ray irradiation of murine testes has been testified to lead to a multifold increase of Prdx1 and Prdx2 [44]. Besides that, exposed mice have displayed a significant increase in Prdx1 and Prdx2 expression levels in the brain [67-69], and in Prdx6 expression level in the liver and spleen $[70,71]$. 
Many ionizing radiation-resistant cancer cell lines demonstrate high-level peroxiredoxin expression. For instance, a leading role of Prdx2 has been shown in the radiosensitivity of human colon cancer cells (HCT116, Caco-2, T84 and LoVo) and breast cancer cells (MCF + FIR3) [72-74]. Suppression of PRDX2 expression significantly weakens the resistance of these cancer cells to radiation. Aggressive radioresistant brain tumor species, glioblastoma, shows a high PRDX4 expression level [75]. PRDX4 gene knockdown in glioblastoma cells leads to increased sensitivity of the cells to ionizing radiation, suppression of growth, and metastasis formation [76]. A notable elevation of Prdx6 level has been detected in many cancer species, many of which have high radioresistance (Table 1).

Table 1. Carcinogenic role of Prdx6 in various chemo- and radio-resistant forms of human cancer.

\begin{tabular}{|c|c|c|}
\hline Type of Cancer & Mechanism of Action/Molecular Target & References \\
\hline Brain & resistance to reactive oxygen species (ROS) & [77] \\
\hline Lungs & $\begin{array}{l}\text { resistance to ROS, activation of JAK2/STAT3, stimulation of metastasis, activation of } \\
\text { iPLA2 activity, P38 activation via PI3K/Akt }\end{array}$ & [78-80] \\
\hline Breast & $\begin{array}{l}\text { resistance to ROS, stimulation of metastasis, stimulation of expression uPAR, Est-1, } \\
\text { MMP-9, RhoC, TIMP-2 }\end{array}$ & {$[81,82]$} \\
\hline Esophagus & resistance to ROS & [83] \\
\hline Stomach & resistance to ROS, stimulation of metastasis, suppression of caspase- 8 activation & [84] \\
\hline Cervix & resistance to ROS, suppression of TRAIL activated caspase-10 & [85] \\
\hline Liver & resistance to ROS & {$[86]$} \\
\hline Ovaries & resistance to ROS, stimulation of metastasis & [87] \\
\hline Bladder & resistance to ROS, stimulation of NF-kB & [51] \\
\hline Prostate & resistance to ROS, stimulation of metastasis & [88] \\
\hline Skin & resistance to ROS, stimulation of metastasis via activation of aiPLA2 activity & [89] \\
\hline
\end{tabular}

Table 1 show that antioxidant function of Prx6 plays the most crucial role in radioresistance of cancer cells, but beside that, it's signaling and regulatory function is also important, which will be discussed below. In vitro and in vivo experiments showed that suppression of PRDXs genes expression in cancer cells led to loss of their radioresistance, which allows to consider them as potential targets during cancer radiotherapy [90-94].

\section{Application of Exogenous Prdx6 as a Radioprotector}

The level of ROS formation in many cases of exposure to ionizing radiation exceeds the ability of living cells to eliminate them, and massive damage of nucleic acids, proteins, and lipids is observed in such conditions. Damage of biological macromolecules is one of the main reasons of post-irradiation death of animals [95]. Radioprotective drugs are used in practice to prevent the harmful consequences of the action of ionizing radiation. On the whole, radioprotective agents can be divided into two classes: (1) compounds preventing damage of macromolecules; (2) compounds stimulating post-irradiation recovery. Low-molecular antioxidants, enzymatic antioxidants, antioxidant synthesis inducers, molecule stabilizers, and compounds causing hypoxia can be assigned to the first class. A large number of compounds affecting post-irradiation recovery of macromolecules and anti-apoptotic agents, compounds involved in chemical reparation, etc. can be assigned to the second class [96-98]. Basically, radioprotective compounds differ in the structure and mechanism of action. The main groups of radioprotective compounds are listed in Table 2 by structure and mechanism of action. More detailed data on the main classes of radioprotective compounds can be found in reviews [96,99]. 
Table 2. The main classes of radioprotective compounds (mechanisms of action, time of administration (before or after irradiation), tissue specificity of action, and dose reduction factors).

\begin{tabular}{|c|c|c|c|c|}
\hline $\begin{array}{l}\text { Type of Radioprotective } \\
\text { Compounds }\end{array}$ & Mechanism of Action & $\begin{array}{l}\text { Time of } \\
\text { Medication }\end{array}$ & Tissue Specificity & DRF * \\
\hline Sulfhydryl compounds & $\begin{array}{c}\text { - antiradical; } \\
\text { - donation of } \mathrm{H} \text {-atom; } \\
\text { - formation of mixed disulfides; } \\
\text {-hypoxia }(\downarrow) \text {; } \\
\text {-redox regulation }(\downarrow)\end{array}$ & before irradiation & all tissues & $1.3-2.7$ \\
\hline Antioxidants & $\begin{array}{c}\text { - antiradical; } \\
\text { - redox regulation }(\downarrow) ; \\
\text { - hypoxia }(\downarrow) ; \\
\text {-immunity stimulation }(\downarrow)\end{array}$ & before irradiation & all tissues & $1.1-1.3$ \\
\hline Inhibitors of ACE & $\begin{array}{l}\text {-effects on the renin-angiotensin system; } \\
\text { - inhibition of collagen synthesis? }(\downarrow)\end{array}$ & after irradiation & $\begin{array}{l}\text { does not protect the } \\
\text { gastrointestinal tract }\end{array}$ & $<1.2$ \\
\hline $\begin{array}{l}\text { Immunomodulators and } \\
\text { cytokines }\end{array}$ & $\begin{array}{l}\text { - stimulation of immunity; } \\
\text { - cytokine production; } \\
\text { - signaling cascades }\end{array}$ & $\begin{array}{l}\text { before or after } \\
\text { irradiation }\end{array}$ & $\begin{array}{l}\text { mostly hematopoietic } \\
\text { system }\end{array}$ & $1.1-1.4$ \\
\hline Prostaglandins & $\begin{array}{c}\text { - tissue hormones } \\
-?(\downarrow)\end{array}$ & before irradiation & $\begin{array}{l}\text { hematopoietic system, } \\
\text { gastrointestinal tract, } \\
\text { hair follicles }\end{array}$ & $<1.3$ \\
\hline $\begin{array}{l}\text { Metal salts and } \\
\text { metallothionein }\end{array}$ & $\begin{array}{l}\text { - induction of metallothionein; } \\
\text { - antiradical }\end{array}$ & before irradiation & $\begin{array}{l}\text { mostly hematopoietic } \\
\text { system }\end{array}$ & $<1.2$ \\
\hline DNA_binding agents & $\begin{array}{l}\text { - electron transfer; } \\
\text { - compaction of chromatin }(\downarrow)\end{array}$ & before irradiation & all tissues & $<1.3$ \\
\hline $\begin{array}{l}\text { Hypoxia_inducing } \\
\text { compounds }\end{array}$ & $\begin{array}{c}\text { - hypoxia; } \\
\text { - redox regulation }(\downarrow)\end{array}$ & before irradiation & all tissues & $1.2-1.5$ \\
\hline $\begin{array}{l}\text { Selenium containing } \\
\text { compounds }\end{array}$ & $\begin{array}{c}\text { - stimulation of glutathione peroxidase } \\
\text { activity; } \\
\text { - antiradical; } \\
\text { - redox regulation }(\downarrow)\end{array}$ & $\begin{array}{l}\text { before or after } \\
\text { irradiation }\end{array}$ & $\begin{array}{l}\text { mostly gastrointestinal } \\
\text { tract }\end{array}$ & $<1.3$ \\
\hline $\begin{array}{l}\text { Nucleic acids and their } \\
\text { derivatives }\end{array}$ & $\begin{array}{c}\text { - antiradical; } \\
\text { - effect on repair systems; } \\
\text { - signaling cascades; } \\
-?(\downarrow)\end{array}$ & $\begin{array}{l}\text { before or after } \\
\text { irradiation }\end{array}$ & all tissues & $1.1-1.4$ \\
\hline Fullerenes & $\begin{array}{c}\text { - antiradical; } \\
\text { - membrane protection; } \\
-?(\downarrow)\end{array}$ & before exposure & all tissues & $<1.3$ \\
\hline Adsorbents & $\begin{array}{l}\text { - binding of radionuclides; } \\
\text { - acceleration of radionuclide excretion }\end{array}$ & after irradiation & gastrointestinal tract & $* *$ \\
\hline
\end{tabular}

It should be noted that actively dividing cells (epithelial, embryonic and stem cells) are the most sensitive to the action of ionizing radiation, that is why this type of cells needs particular radioprotection. Development of novel effective radioprotective compounds acting primarily by preserving these tissue types is an important and actual task. In this regard, the promising direction in the creation of effective radioprotective agents is the application of antioxidant enzymes, which are several orders of magnitude more active than the currently used low-molecular compounds. Attempts to use such enzymes as catalase and superoxide dismutase were made earlier, but they have all been unsuccessful [100-102]. This is explained first of all by the fact that organic hydroperoxides (products of oxidation of proteins, lipids, etc.) comprise a large portion of the whole ROS pool produced as a result of irradiation, while catalase and superoxide dismutase are not capable of neutralizing such types of ROS. As mentioned before, the peroxiredoxin family is the group neutralizing the widest range of ROS, which is why the application of Prdxs as radioprotectors seems the most promising approach.

Application of exogenous recombinant Prdx6 in model animal experiments has shown high efficiency in the treatment of disorders attended by oxidative stress, such as severe chemical and thermal burns of the upper respiratory tract, acute inflammation of respiratory organs caused by bacterial endotoxins (LPS), and ischemia-reperfusion injuries [103-107]. Infusion of Prdx6 before the action of the aforementioned factors provides suppression of oxidative stress, thus preventing the damage of actively proliferating tissues. Prdx6 infusion after the damage, for example, after thermal burns of the upper respiratory tract, leads to a faster recovery of tissues, suppression of cell necrosis, 
and apoptosis $[108,109]$. Thus, the obtained experimental data has evidenced that exogenous Prdx6 possesses a high antioxidant potential and could be promising in the treatment of pathologies accompanied by the development of oxidative stress, particularly, those caused by ionizing radiation.

The survival rate of 6-week male mice (line Kv:SHK) was studied after irradiation with sublethal and lethal doses (5-11 Gy) and intravenous infusion of recombinant Prdx6 solution before X-ray action [110,111]. The radioprotective effect of exogenous Prdx6 was maximal upon intravenous injection 15-30 min before irradiation. The optimal concentration was about $20 \mu \mathrm{g} / \mathrm{g}$ of body weight. Injection of a larger amount of the protein did not lead to significant growth of its radioprotective effect. The radioprotective effect of Prdx6 was clearly visible 7 days after irradiation. The control group which had not received Prdx6 injection before irradiation demonstrated typical symptoms of acute radiation syndrome, whereas animals which received an intravenous injection of Prdx6 at that moment did not differ from intact, non-irradiated animals (Figure 5).
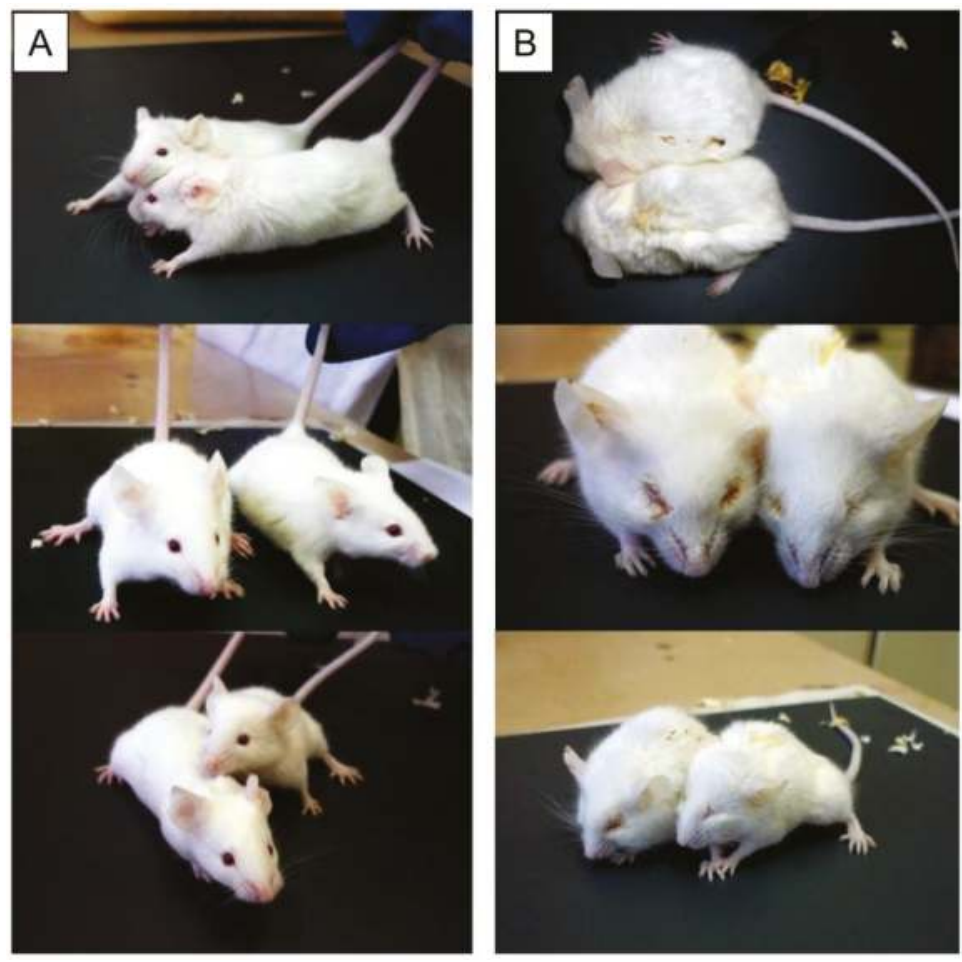

Figure 5. Mice after X-ray irradiation at a dose of 7 Gy (after 7 days). (A) Intravenous administration of Prdx6 before irradiation $(20 \mu \mathrm{g} / \mathrm{g}),(\mathbf{B})$ administration of $0.9 \% \mathrm{NaCl}$ in the same volume. Irradiation of animals was carried out on RUT-15 (Moscow, Russia) at a dose rate of 1 Gy per minute.

Mutant variant Prdx6-C47S, which has no peroxidase activity, was studied in the same manner. It was surprising that even this variant had a slight radioprotective effect. The results on the survival rate of mice receiving Prdx6 and its mutant form Prdx6-C47S are present in Figure 6A. An average lifespan of irradiated mice was 7 days, and the maximal survival time was 13 days. Prdx6 injection 15 min before X-ray irradiation significantly increased the survival of animals $(p<0.001)$. Approximately $95 \%$ of animals were alive over 30 days. The Figure $6 \mathrm{~B}$ shows linear dose dependencies of 30-day survival of mice [12]. Dose reduction factor (DRF) for Prdx6 was around 1.4 [110,111]. 
(A)

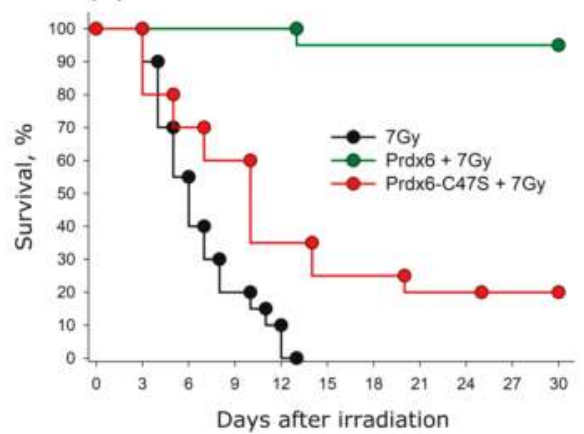

(B)

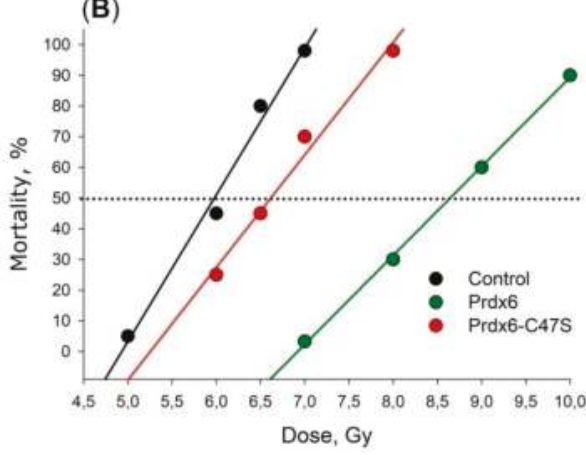

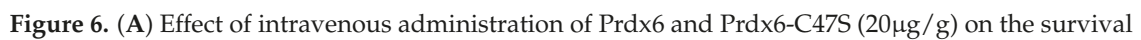
of mice exposed to X-rays at a lethal dose of 7 Gy. (B) Effect of intravenous administration of Prdx6 and Prdx6-C47S $(20 \mu \mathrm{g} / \mathrm{g})$ on the mortality of mice at sublethal and lethal doses of X-rays.

Table 2 lists DRF values for some of the radioprotective compounds. As it can be seen from Table 2, there are compounds with higher DRF values, moreover, there is a large number of compounds with comparable DRF values. However, the noticeable competitive advantage of Prdx6 over other preparations listed in Table 2 is lack of toxicity and adverse effects [112]. For example, for KGF and G-CSF, course application is supposed to be able to stimulate tumor growth [113]. Injection of Interleukin-1 often causes significant temperature elevation, vomiting, headache, and fatigue [114]. Sulfhydryl preparations are effective as radioprotectors in doses close to acute toxic doses [98].

Death after exposure to doses of ionizing radiation close to $10 \mathrm{~Gy}$ is usually caused by injuries of the digestive tract, particularly the small intestine. We found that injection of Prdx6 significantly protects the small intestine from the damaging effects of ionizing radiation (Figure 7). We must note that the protective effect of exogenous Prdx6 has also been shown earlier on an ischemia-reperfusion model of small intestine injury $[106,107]$.

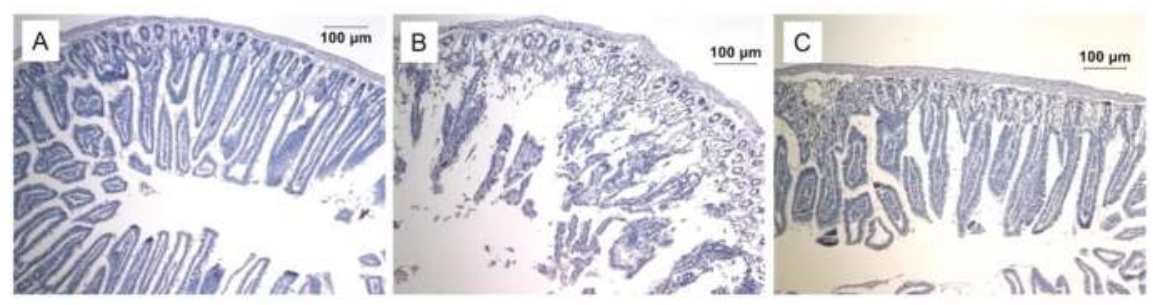

Figure 7. Effect of intravenous administration of $\operatorname{Prdx} 6(20 \mu \mathrm{g} / \mathrm{g}) 15 \mathrm{~min}$ before exposure to X-ray radiation (dose $10 \mathrm{~Gy}$ ) on the small intestine morphology. Micrographs of the small intestine stained with hematoxylin-eosin $(\times 100)$ of $(\mathbf{A})$ intact mice, $(\mathbf{B})$ irradiated mice, $(\mathbf{C})$ irradiated mice that received Prdx6.

It is known that the death of small laboratory animals (mice and rats) after exposure to ionizing radiation at doses of 3-10 Gy is due to the hematopoietic syndrome as a result of mass death of bone marrow cells [115]. This is also accompanied by a depletion of the bone marrow stem cell depot. As a result, the amount of blood cells in peripheral blood changes, causing immune deficiency and development of haemorrhagia. Intravenous injection of Prdx6 before irradiation significantly decreases the severity of radiation-induced leukopenia and thrombocytopenia (Figure 8) [110,111]. 
(A)

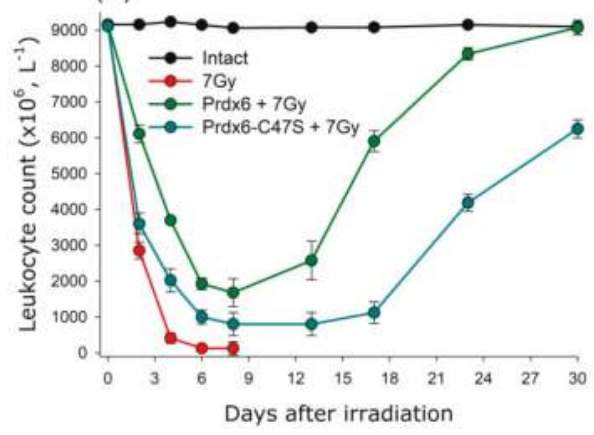

(B)

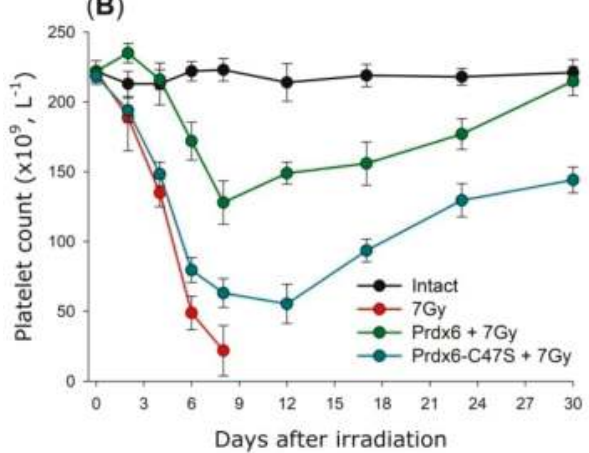

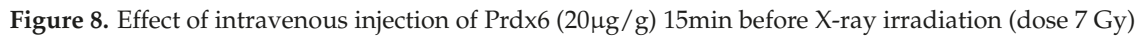
on the leukocyte (A) and platelet (B) count in the peripheral blood of irradiated mice. The data are given as means $\pm \operatorname{SEM}(n=5)$.

Besides that, Prdx6 injection was shown to suppress genomic DNA damage significantly in bone marrow cells under action of X-ray radiation at a dose of $1.5 \mathrm{~Gy}$. Linear dose dependence of micronuclei (MN) formation in polychromatophylic erythrocytes (PCE) after total X-ray irradiation of mice (Figure 9) showed that injection of Prdx6 in $20 \mu \mathrm{g} / \mathrm{g}$ dose 15 min before irradiation by 1.5 Gy dose led to DNA damage compared to that observed in mice irradiated by merely $0.1-0.2 \mathrm{~Gy}$. It is interesting to note that the mutant variant, Prdx6-C47S, did also demonstrate genoprotective properties (Figure 9), which obviously cannot be related to antioxidant properties of this protein.

(A)

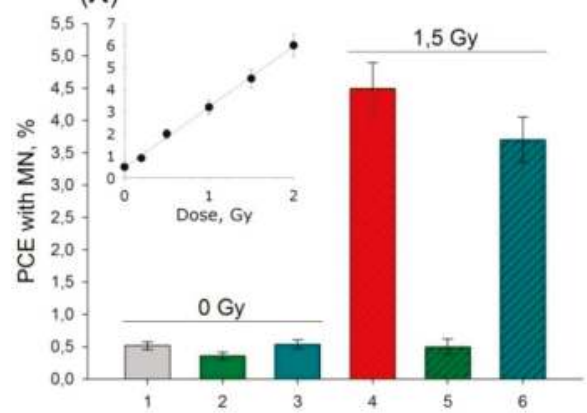

(B)

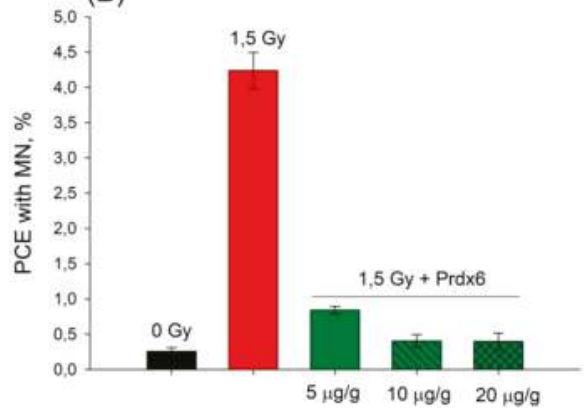

Figure 9. Effect of intravenous injection of Prdx6 and Prdx6-C47S 15 min before irradiation with X-rays (dose $1.5 \mathrm{~Gy}$ ) on the formation of PCE with MN in the bone marrow cells of mice. The data are given as means \pm SEM $(n=5)$. (A) 1 -intact mice; 2 -non-irradiated mice received Prdx6 $(20 \mu \mathrm{g} / \mathrm{g})$; 3-non-irradiated mice received Prdx6-C47S (20 $\mu \mathrm{g} / \mathrm{g})$; 4-irradiated mice; 5-irradiated mice received

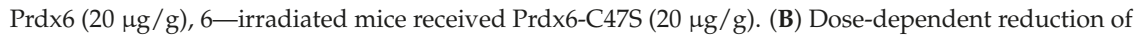
PCE with MN level depending on intravenous Prdx6 (5, 10, $20 \mu \mathrm{g} / \mathrm{g}$ ) injection $15 \mathrm{~min}$ before 1,5 Gy irradiation was shown.

Apparently, the radioprotective effect of Prdx6 is mediated by several components. First of all, by the peroxidase activity of $\operatorname{Prdx} 6$, which provides neutralization of a wide range of peroxide substrates, including long-lived reactive protein species (LRPS), Prdx6 eliminating LRPS more effectively than it was shown earlier for such compounds as inosine, guanosine, vitamin C, and L-methionine [116,117]. Secondly, it is caused also by the signaling and regulatory function of Prdx6, which facilitates triggering of recovery processes in stress conditions and is not related to its peroxidase activity $[110,111]$. 


\section{Molecular Mechanisms of Radioprotective Effect of Endogenous and Exogenous Prdx6}

There is no doubt that the most important component of the radioprotective effect of exogenous $\operatorname{Prdx6}$ is its peroxidase activity, which is proved by a significant decrease of the radioprotective effect after injection of mutant Prdx6-C47S variant lacking peroxidase activity (Figure 6). We noticed earlier that Prdx6 neutralizes the widest range of hydroperoxides compared to other peroxiredoxin family members. It is known that the action of ionizing radiation results in the generation of ROS of various natures, including peroxides of phospholipids and long-lived reactive protein species (LRPS), which are effectively neutralized by Prdx6. Finally, an important role in the radioprotective action of Prdx6 is played by its signaling and regulatory activity. The proposed scheme of possible events after the action of ionizing radiation on the cell and the role of exogenous and endogenous Prdx6 in these processes is shown in Figure 10.

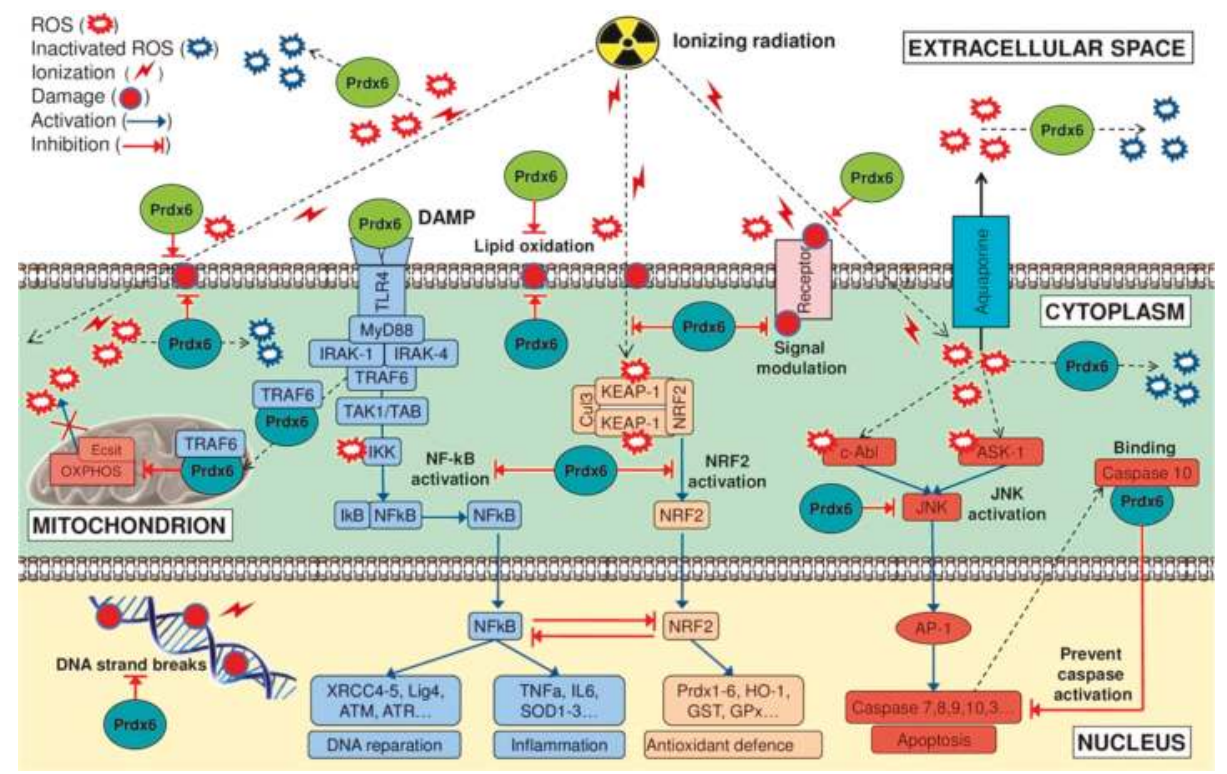

Figure 10. Schematic representation of the molecular mechanism of radioprotection by endogenous (cyan) and exogenous (green) Prdx6 under the action of ionizing radiation.

\subsection{Endogenous Prdx6}

Prdx6 is an important antioxidant enzyme, which is related to its wide substrate specificity and high catalytic efficiency. However, Prdx6 is important not only as an antioxidant, but also as a signaling and regulatory protein. Prdxs are known to be capable of «fine sensitivity» to alterations in the redox status of the cell due to high lability of thiol groups in the active site. Depending on the ROS level in the cell and the redox degree of $C_{P}$ (peroxidatic cysteine), Prdxs direct cell development via interaction with key regulatory proteins, «switching» the cell from one signaling pathway to another [22]. Due to the slower process of sulfenic acid $\left(\mathrm{C}_{\mathrm{P}}-\mathrm{SOH}\right)$ reduction in the active site of Prdxs compared to $\mathrm{C}_{\mathrm{P}}-\mathrm{SH}$ oxidation kinetics, accumulation of oxidized peroxiredoxins takes place in the cell [118]. In this regard, during reduction of oxidized cysteine $\mathrm{C}_{\mathrm{P}}-\mathrm{SOH}$, peroxiredoxins can form intermolecular disulfide bonds with reducing proteins (Trx1, Trx2, PDI, $\pi \mathrm{GST}$ ) and other thiol (-SH) group-containing proteins, such as transcription factors, kinases, phosphatases, receptors, ionic channels, etc., thus modulating their activity and affecting many cellular processes (Figure 10). Particularly, Prdxs localized in the cell 
nucleus interact with the most important transcription factors: NF- $\mathrm{kB}, \mathrm{p} 53, \mathrm{C}-\mathrm{Myc}, \mathrm{PTEN}$, p53, etc., thus indirectly affecting expression of many genes [22,119].

Excessive ROS content in the cell leads to overoxidation of the peroxidase cysteine $\left(\mathrm{C}_{\mathrm{P}}-\mathrm{SO}_{2} \mathrm{H} /\right.$ $\mathrm{C}_{\mathrm{P}}-\mathrm{SO}_{3} \mathrm{H}$ ) of Prdx6, which in turn leads to an increase of $\mathrm{Ca}^{2+}$-independent activity of phospholipase A2 (aiPLA2) [36]. The functional relation of these two Prdx6 activities was demonstrated in in vivo experiments. $\mathrm{H}_{2} \mathrm{O}_{2}$ was added to HeLa cell culture in different (1-1000 $\left.\mu \mathrm{M}\right)$ concentrations, and arrest of cell cycle in $\mathrm{G}_{2}-\mathrm{M}$ phase was observed already at concentrations above $100 \mu \mathrm{M}$, which correlated with overoxidation of peroxidase cysteine of Prdx6 and elevation of aiPLA2 activity proportionally to $\mathrm{H}_{2} \mathrm{O}_{2}$ concentration [36]. Besides that, independently of the oxidation level of the peroxidase centre, Prdx6 phospholipase activity is increased by more than 10 times after specific phosphorylation of Thr177 residue by mitogen-activated protein kinases, MAPKs (ERK2, p38 $\gamma$ and p388) [120]. Activation of phospholipase aiPLA2 activity of Prdx6 has been shown to lead to growth of the level of lysophospholipids and fatty acids, which play a role of secondary messengers in both normal and pathological states [121]. The phospholipase activity of intracellular Prdx6 has been shown to stimulate signaling pathways (p38, PI3K/Akt) and facilitate arachidonic acid formation. Arachidonic acid, in turn, affects Src (SFK) kinases, which stimulate cell growth and division $[89,122]$.

It has been shown that Prdx6 stimulates cell proliferation via JAK2/STAT3 signaling pathway [80]. Meanwhile, Prdx6 interacts directly with JAK2 protein, as immunohistochemical analysis showed colocalization of these proteins in lung cancer cells. Prdx6 affects the expression level of proinflammatory cytokines, especially CCL5 chemokine stimulating cell division, via JAK2/STAT3 signaling pathway [80].

Elevation of Prdx6 content in HeLa cells has been shown to provide resistance to TRAIL(TNF-dependent apoptosis-inducing ligand)-induced apoptosis. Prdx6 binds to DED-domain (Death Effector Domain) of initiatory caspase-10 and thus prevents the formation of DISC (Death-Inducing Signaling Complex) and downstream activation of effectory caspases (caspase-3 and caspase-7) [85]. Besides that, in vitro studies testified that Prdx6 binding to caspase-10 decreases along with the growth of $\mathrm{H}_{2} \mathrm{O}_{2}$ amount added and, on the contrary, increases upon addition of dithiothreitol (DTT) as a reducing agent, speaking for the dependence of interaction of Prdx6 with caspase-10 DED-domain on the degree of reduction of the Prdx6 peroxidase center. Thus, both endogenous and exogenous Prdx6 can play an important anti-apoptotic role, blocking apoptosis progression via binding and inactivating key regulators of programmed cell death [85].

Moreover, endogenous Prdx6 has been shown to play an important role in suppression of mitochondrial ROS (mROS) generation. Upon activation of NF-kB mediated by TLR4 stimulation, TRAF6-ECSIT complex is induced, which facilitates OXPHOS-dependent mROS generation. Endogenous Prdx6 has been shown to bind to C-terminal domain of TRAF6 protein and prevent TRAF6-ECSIT complex formation and mROS generation [123].

Thus, the radioprotective potential of endogenous Prdx6 is related to both its catalytic properties and various signaling and regulatory roles of this protein in the cell.

\subsection{Exogenous Prdx6}

As discussed above, exposure of a living organism to ionizing radiation leads to a burst of ROS level in the cells, which results in the development of oxidative stress. Injection of exogenous antioxidant enzyme Prdx6 before irradiation can affect the level of peroxides in the organism, thus preventing the development of oxidative stress and normalizing the redox status of the cells. A question arises: how can Prdx6 present in bloodstream neutralize ROS in the cells if it does not pass into them? It is known that, beside passive diffusion, hydroperoxides can be actively transported from cells to intercellular space by aquaporins [124-126]. Therefore, exogenous Prdx6 present in extracellular (intercellular) space can participate in elimination of both peroxides formed in intercellular space and peroxides excreted from the cells (Figure 10). As it was noted before, NRF2 is a key transcription factor regulating cell response on oxidative stress, which affects the expression of many 
antioxidant enzymes $[46,47,127]$. It was shown that Prdx6 injection in intact animals decreased NRF2 gene expression in a dose-dependent manner, and Prdx6 injection before 1.5 Gy irradiation of mice normalized NRF2 transcription level virtually to normal values (Figure 11), which is obviously related to a decrease in ROS level in the cells. Conversely, injection of Prdx6-C47S in intact animals and those irradiated at a dose of 1.5 Gy did not significantly affect the NRF2 expression level in animal bone marrow cells (Figure 11).

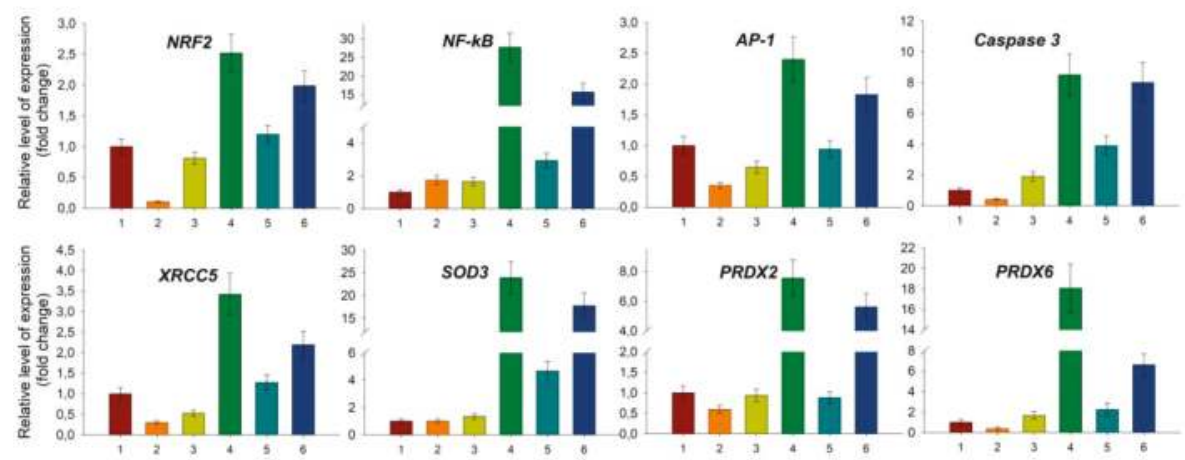

Figure 11. Changes in the expression level of some genes in bone marrow cells 24 hours after whole-body irradiation at a dose of 1.5 Gy and the effect of intravenous administration of Prdx6 and Prdx6-C47S $(20 \mu \mathrm{g} / \mathrm{g}) 15 \mathrm{~min}$ before irradiation. The data presented as mean \pm SEM $(n=5)$. 1-intact mice; 2-non-irradiated mice received $\operatorname{Prdx6}(20 \mu \mathrm{g} / \mathrm{g}) ; 3$-non-irradiated mice received

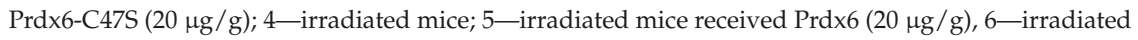
mice received Prdx6-C47S $(20 \mu \mathrm{g} / \mathrm{g})$.

Another crucial transcription factor participating in response to ionizing radiation is NF-kB. NF-kB is known to play an important role in resistance of cells to radiation [128], and elevated ROS level, as in the case of NRF2, which significantly increases NF-kB gene expression [129]. Moreover, NF-kB and NRF2 signaling pathways are closely interconnected. An increase of NF-kB suppresses NRF2 gene expression and vice versa [130]. NRF2 activity suppression can be achieved also via competitive interaction of NF-kB with CBP (CREB binding protein), which is a transcription coactivator of NRF2, and via NF-kB-mediated activation of HDAC3 (histone deacetylase 3), which locally reduces histone acetylation in the ARE locus, thus hampering NRF2 binding to ARE and transcription of antioxidant response genes [131]. During inflammation reactions, a reverse situation can take place, when NRF2 inhibits NF-kB signaling pathway which involves RAC1 protein (small GTPase protein of Rho family) [132]. A relation between NF-kB and NRF2 has also been shown in Nrf2-null mice. The levels of NF-kB and pro-inflammatory cytokines controlled by this factor are significantly higher in these mice than in wild-type animals [133]. Thus, NF-kB and NRF2 pathways are closely related to each other. The common final goal of each of them is avoiding apoptosis and providing cell survival under stress conditions, but the common goal is achieved via different ways. The conditions of «switching» between NF-kB and NRF2 pathways essentially depend on biological species, tissue type, and physiological state of the organism [134,135], and the key role in this process can belong to peroxiredoxins.

Exogenous Prdx6 can affect NF-kB level in various ways: First, as in the case of NRF2, by regulating ROS level in the cell; second, via TLR4/NF-kB signaling pathway. It was shown that after one day following injection of exogenous recombinant Prdx6, the expression level of NF-kB in intact mice is slightly increased (by 2-3 times) (Figure 11). After one day following exposure of mice untreated with Prdx6 to ionizing radiation at $1.5 \mathrm{~Gy}$, a drastic burst (of around 30 times) of the expression of expression level and some genes regulated by NF-kB (SOD3, XRCC4, XRCC5, ATR) took place in the 
animal bone marrow. It must also be noted that this effect on the expression of the studied genes was preserved up to 30 days after the exposure to ionizing radiation. The obtained data on NF-kB activation correlate with the results of work [136], where mice were exposed to a dose of $1 \mathrm{~Gy}$ and NF-kB activation took place in $3 \mathrm{~h}, 24 \mathrm{~h}$, and 1 month after irradiation. Injection of Prdx6 before the exposure decreased the expression of NF-kB and genes regulated by this transcription factor to the values close to those in intact animals, which could possibly be related to ROS suppression (Figure 11).

Peroxiredoxins are localized predominantly inside the cell, except the secreted forms ( $\operatorname{Prdx} 4$ and Prdx6), but after damage of plasma membrane by different factors (viral/bacterial infections, toxins, ionizing radiation, etc.) they appear in intercellular space and play a role of danger signals (DAMP-Damage-Associated Molecular Patterns) [137]. DAMPs can play both positive and negative roles: in some cases they activate the immune system and trigger regenerative processes, in other cases they stimulate angiogenesis and tumor growth [52,137-141]. The signaling function of exogenous Prdx6 is likely to be realized via the TLR4/NF-kB signaling pathway [142]. Quite recently, Prdx6 released during ischemia damage of the brain from broken cells was shown to play a role of an endogenous ligand of the TLR4 receptor [142]. Influence on the TLR4/NF-kB signaling pathway has been also shown for other members of the peroxiredoxin family [143]. Interaction of Prdx6 with TLR4 triggers a cascade of processes, the leading role being played by NF-kB (Figure 11), which allows launching emergency reparation processes and suppressing apoptosis development [144]. Besides that, we assume that intravenous injection of recombinant Prdx6 in animals $15 \mathrm{~min}$ before the exposure to X-rays can lead to a pre-conditioning effect. Up to the moment of action of ionizing radiation, cells have already launched the reparation mechanism and antioxidant response via the stimulation of the TLR4/NF-kB signaling pathway by injected exogenous Prdx6, which is recognized as DAMP. So, the last stimulus, action of ionizing radiation, does not lead to a synergistic increase of NF-kB expression. Meanwhile, intravenous injection of recombinant Prdx6, which turned out to be the most effective, allows exogenous Prdx6 to distribute around the organism in the fastest manner and to reach TLR4 receptors on cell surfaces in comparison to intramuscular and intraperitoneal injections. Thus, the activation of the NF-kB signaling pathway, which happens due to both binding of Prdx6 to TLR4 receptor and regulation of intracellular/extracellular ROS formed under the exposure to ionizing radiation, allows the cells to be protected from apoptosis by triggering inflammatory and reparation processes and activation of anti-apoptotic factors [144].

The anti-apoptotic effect of exogenous Prdx6 can be related to a transcription factor AP-1, which is one of the key regulators of apoptosis. Injection of exogenous Prdx6 suppresses the expression level of AP-1 and caspase-3 (Figure 11). It should be mentioned that the activation of AP-1 transcription factor is also mediated by ROS. Elevation of ROS content provides oxidation and activation of ASK-1 kinase (Apoptosis Signal regulating Kinase 1), which in turn activates protein kinase JNK (c-Jun $\mathrm{N}$-terminal kinase). JNK activates AP-1 [145]. JNK/AP-1 signaling pathway, contrary to NF-kB and NRF2, stimulates apoptosis of the cells [146-148]. Inhibition of JNK/AP-1 pathway activation by antioxidants has been shown to prevent $\mathrm{H}_{2} \mathrm{O}_{2}$-induced apoptosis [149-151]. Being a powerful antioxidant, exogenous Prdx6 lowers ROS concentration in the cells and in this way, probably, prevents activation of ASK-1 and AP-1. Thus, apoptosis suppression in the presence of exogenous Prdx6 can be related to NF-kB activation and suppression of the JNK/AP-1 signaling pathway.

Besides that, recombinant Prdx6 has been recently shown to form ion-selective channels in artificial membranes in in vitro studies. Meanwhile, the oxidized form of Prdx6 is incorporated into the membrane much more effectively, than the reduced one, which may be explained by increased phospholipase A2 activity [152]. It is important to note that earlier phosphorylated Prdx6 (with more active aiPLA2) was shown to move to the plasma membrane in intact cells (mouse pulmonary microvascular endothelium and alveolar macrophages) [153]. Moreover, treatment of A549 cells with peroxides leads to lipid peroxidation and translocation of Prdx6 from the cytosol to the cell membrane [154]. So, Prdx6 could be incorporated into the cell membrane (through aiPLA2), thus performing a function of ion channel and playing an important regulatory role. 
Thus, we suppose that the basics of the radioprotective properties of Prdx6 are, on the one hand, its ability to neutralize a wide range of ROS, and, on the other hand, its signaling and regulatory activity, which facilitates triggering the cellular mechanisms of restoration of distorted redox homeostasis.

\section{Practical Aspects of Prdx6 Radioprotective Action}

\subsection{Prdx6 Suppression in Treatment of Radioresistant Cancer}

Cancer cells have elevated ROS level compared to normal ones, which is related to accumulation of internal metabolism distortions and effect of external factors such as hypoxia, increase of metabolic activity of oxidases, lipoxygenases, impairment of mitochondria functioning, effect of immune cells of the organism, etc. To be protected from oxidative stress, cancer cells developed a powerful system of antioxidant protection, its most important elements being peroxiredoxins. As mentioned before, high Prdxs level is observed in many cases of cancer disease, particularly in types resistant to ionizing radiation [94,155]. Application of small interfering RNAs (siRNAs) for PRDXs gene suppression in combination with chemotherapy could be an effective approach in cancer treatment. Delivery of siRNAs to the cell can be carried out in various ways; more can be found in the following reviews $[156,157]$. Particularly, this strategy was successfully applied in both in vitro and in vivo conditions when suppressing PRDX1 expression in human lung cancer and colon cancer $[90,158]$. Suppression of PRDX2 expression by siRNAs enhances the efficacy of the action of radiation and cisplatin on gastric cancer cells [159]. A combined use of chemotherapeutic agents producing ROS or ionizing radiation [160] with specific inhibitors of Prdxs seems also quite a promising approach. Such inhibitors are auranofin, adenantine, imexon, buthionine, sulfoximine, etc. For instance, SK053 compound has been shown to covalently bind and inhibit thioredoxins, which play a role of reducing agents in the catalytic cycle, and all peroxiredoxins, thus blocking cell division and activating apoptosis, in the Burkitt lymphoma model [161-163]. A specific inhibitor of Prdx6, thiacremonone discovered recently in garlic extract, is a dose-dependent suppressor of lung cancer cell growth (lines A549 and NCI-H460), which acts through triggering apoptosis [164]. SVT toxin from Turan blunt-nosed viper (Vipera lebetinaturanica) indirectly (affecting AP-1) inhibits PRDX6 expression. Studies in animal models of lung cancer (A549 and NCI-H460) demonstrated effective dose-dependent alleviation of Prdx6 level and apoptosis stimulation by SVT [165]. Thus, specific suppression of Prdx6 can be a promising approach in the treatment of some radioresistant types of cancer.

\subsection{Prdx6 Application as a Radioprotective Agent}

Studies showed that Prdx6 injection prior to whole-body irradiation in sublethal and lethal doses significantly decreases the severity of radiation damage and increases the survival rate of animals. Assessment of Prdx6 as a radioprotector opens a new way for creating modern effective and safe radioprotectors. However, it should be noted that extensive clinical trials of Prdx6 as a drug are required. As noted before, there is no ideal radioprotector up to date. The most effective chemical radioprotectors have serious adverse effects, which restrict their application in effective concentrations. On the contrary, Prdx6 is a natural radioprotector and does not exert toxicity, while its efficiency is not lower than that of many known synthetic radioprotectors (Table 2). Prdx6-based preparations could be applied individually (perhaps in a complex of liposomes or perfluorocarbons) [112] or in combination with conventional modern radioprotectors from common practice, which could significantly decrease the probability of adverse effects and severity of the consequences of ionizing radiation exposure [166]. We suggest that the most promising is the application of radioprotective agents with different mechanisms of action, for example, Prdx6 as an antioxidant and indralin $[97,167,168]$, an agent lowering oxygen consumption by the tissues, as a hypoxant, which could provide a synergistic radioprotective effect. 


\section{Conclusions}

There is no doubt that Prdx6, an important antioxidant enzyme, plays a leading role in maintaining redox homeostasis in mammalian cells [19,169,170]. Moreover, being a signaling and regulatory protein, Prdx6 is involved in the regulation of many cellular processes [38]. Impairment of Prdx6 function in the cell, alteration (growth or reduction) of its expression level, and change of its localization lead to development of various pathologies [31,155,171].

Experiments in animal models of diseases accompanied by development of oxidative stress showed that application of exogenous Prdx6 can correct the pathologic process course and facilitate faster recovery of damaged organs and tissues [103,106-108]. Particularly, exogenous Prdx6 application alleviates the severity of ionizing radiation damage, increasing the survival rate of animals exposed to sublethal and lethal doses $[110,111]$. Thus, $\operatorname{Prdx6}$ can be considered as a promising radioprotective agent for alleviating the pathological effect of ionizing radiation on mammalian organism.

Funding: The work was supported by the Grants of the President of the Russian Federation (MK-2261.2017.4, MD-3811.2018.11), Russian Foundation for Basic Research (grants No. 17-44-500476 r_a, 17-04-00356-a, 19-04-00080-a), R\&D program (AAAA-A18-118021390190-1) and the «Molecular and Cell Biology» program of the Presidium of the Russian Academy of Sciences.

Acknowledgments: We are thankful to Eugeniy E. Fesenko and Vadim I. Bruskov for helpful discussions and valuable comments. The authors are grateful to the Center for Collective Use of the ICB RAS and GPI RAS for the equipment provided.

Conflicts of Interest: The authors declare that they have no conflict of interest.

\section{References}

1. Sankaranarayanan, K. Estimation of the hereditary risks of exposure to ionizing radiation: History, current status, and emerging perspectives. Heal. Phys. 2001, 80, 363-369. [CrossRef]

2. Halliwell, B. Reactive oxygen species in living systems: Source, biochemistry, and role in human disease. Am. J. Med. 1991, 91, 14S-22S. [CrossRef]

3. Ward, J.F. DNA Damage Produced by Ionizing Radiation in Mammalian Cells: Identities, Mechanisms of Formation, and Reparability. Prog. Nucleic Acid Res. Mol. Biol. 1988. [CrossRef]

4. Konings, A.W.T.; Drijver, E.B. Radiation effects on membranes. I. Vitamin E deficiency and lipid peroxidation. Peroxidation. Radiat. Res. 1979, 80, 494-501. [CrossRef] [PubMed]

5. Bruskov, V.I.; Karp, O.E.; Garmash, S.A.; Shtarkman, I.N.; Chernikov, A.V.; Gudkov, S.V. Prolongation of oxidative stress by long-lived reactive protein species induced by $\mathrm{X}$-ray radiation and their genotoxic action. Free Radic. Res. 2012, 46, 1280-1290. [CrossRef] [PubMed]

6. Chernikov, A.V.; Gudkov, S.V.; Usacheva, A.M.; Bruskov, V.I. Exogenous 8-Oxo-7,8-dihydro-2'deoxyguanosine: Biomedical Properties, Mechanisms of Action, and Therapeutic Potential. Biochemistry 2017, 82, 1686-1701. [CrossRef] [PubMed]

7. Lankin, V.Z.; Tikhaze, A.K.; Kapel'ko, V.I.; Shepel'kova, G.S.; Shumaev, K.B.; Panasenko, O.M.; Konovalova, G.G.; Belenkov, Y.N. Mechanisms of oxidative modification of low density lipoproteins under conditions of oxidative and carbonyl stress. Biochemistry 2007, 72, 1081-1090. [CrossRef]

8. Lankin, V.Z.; Tikhaze, A.K. Role of Oxidative Stress in the Genesis of Atherosclerosis and Diabetes Mellitus: A Personal Look Back on 50 Years of Research. Curr. Aging Sci. 2017. [CrossRef]

9. Sies, H. Oxidative stress: A concept in redox biology and medicine. Redox Biol. 2015, 4, 180-183. [CrossRef]

10. Riley, P.A. Free radicals in biology: Oxidative stress and the effects of ionizing radiation. Int. J. Radiat. Biol. 1994, 65, 27-33. [CrossRef]

11. Cadet, J.; Douki, T.; Ravanat, J.-L. Oxidatively generated base damage to cellular DNA. Free Radic. Biol. Med. 2010, 49, 9-21. [CrossRef] [PubMed]

12. Gudkov, S.V.; Shilyagina, N.Y.; Vodeneev, V.A.; Zvyagin, A.V. Targeted Radionuclide Therapy of Human Tumors. Int. J. Mol. Sci. 2016, 17, 33. [CrossRef] [PubMed]

13. Weiss, J.F.; Landauer, M.R. Radioprotection by antioxidants. Ann. N. Y. Acad. Sci. 2000, 899, 44-60. [CrossRef] [PubMed] 
14. Maritim, A.C.; Sanders, R.A.; Watkins, J.B. Diabetes, oxidative stress, and antioxidants: A review. J. Biochem. Mol. Toxicol. 2003, 17, 24-38. [CrossRef] [PubMed]

15. Sokolov, A.V.; Kostevich, V.A.; Varfolomeeva, E.Y.; Grigorieva, D.V.; Gorudko, I.V.; Kozlov, S.O.; Kudryavtsev, I.V.; Mikhalchik, E.V.; Filatov, M.V.; Cherenkevich, S.N.; et al. Capacity of ceruloplasmin to scavenge products of the respiratory burst of neutrophils is not altered by the products of reactions catalyzed by myeloperoxidase. Biochem. Cell Biol. 2018. [CrossRef] [PubMed]

16. Sharapov, M.G.; Ravin, V.K.; Novoselov, V.I. Peroxiredoxins as multifunctional enzymes. Mol. Biol. (Mosk) 2014, 48, 600-628. [CrossRef] [PubMed]

17. Dubbs, J.M.; Mongkolsuk, S. Peroxiredoxins in bacterial antioxidant defense. Subcell. Biochem. 2007, 44, 143-193. [CrossRef]

18. Park, S.G.; Cha, M.K.; Jeong, W.; Kim, I.H. Distinct physiological functions of thiol peroxidase isoenzymes in Saccharomyces cerevisiae. J. Biol. Chem. 2000, 275, 5723-5732. [CrossRef]

19. Rhee, S.G. Overview on Peroxiredoxin. Mol. Cells 2016, 39, 1-5. [CrossRef]

20. Dietz, K.-J. Peroxiredoxins in plants and cyanobacteria. Antioxid. Redox Signal. 2011, 15, 1129-1159. [CrossRef]

21. Knoops, B.; Loumaye, E.; Van der Eecken, V. Evolution of the peroxiredoxins. Peroxiredoxin Syst. 2007. [CrossRef]

22. Rhee, S.G.; Kil, I.S. Multiple Functions and Regulation of Mammalian Peroxiredoxins. Annu. Rev. Biochem. 2016, 85, 1-27. [CrossRef] [PubMed]

23. Neumann, C.A.; Krause, D.S.; Carman, C.V.; Das, S.; Dubey, D.P.; Abraham, J.L.; Bronson, R.T.; Fujiwara, Y.; Orkin, S.H.; Van Etten, R.A. Essential role for the peroxiredoxin Prdx1 in erythrocyte antioxidant defence and tumour suppression. Nature 2003, 424, 561-565. [CrossRef] [PubMed]

24. Londoño-Vallejo, J.A. Telomere instability and cancer. Biochimie 2008, 90, 73-82. [CrossRef] [PubMed]

25. Maciejowski, J.; de Lange, T. Telomeres in cancer: Tumour suppression and genome instability. Nat. Rev. Mol. Cell Biol. 2017, 18, 175-186. [CrossRef]

26. Lee, T.H.; Kim, S.U.; Yu, S.L.; Kim, S.H.; Park, D.S.; Moon, H.B.; Dho, S.H.; Kwon, K.S.; Kwon, H.J.; Han, Y.H.; et al. Peroxiredoxin II is essential for sustaining life span of erythrocytes in mice. Blood 2003, 101, 5033-5038. [CrossRef] [PubMed]

27. Wonsey, D.R.; Zeller, K.I.; Dang, C.V. The c-Myc target gene PRDX3 is required for mitochondrial homeostasis and neoplastic transformation. Proc. Natl. Acad. Sci. USA 2002, 99, 6649-6654. [CrossRef]

28. Zhang, Y.-G.; Wang, L.; Kaifu, T.; Li, J.; Li, X.; Li, L. Featured Article: Accelerated decline of physical strength in peroxiredoxin-3 knockout mice. Exp. Biol. Med. 2016, 241, 1395-1400. [CrossRef]

29. Iuchi, Y.; Okada, F.; Tsunoda, S.; Kibe, N.; Shirasawa, N.; Ikawa, M.; Okabe, M.; Ikeda, Y.; Fujii, J. Peroxiredoxin 4 knockout results in elevated spermatogenic cell death via oxidative stress. Biochem. J. 2009, 419, 149-158. [CrossRef]

30. Wang, X.; Phelan, S.A.; Forsman-Semb, K.; Taylor, E.F.; Petros, C.; Brown, A.; Lerner, C.P.; Paigen, B. Mice with targeted mutation of peroxiredoxin 6 develop normally but are susceptible to oxidative stress. J. Biol. Chem. 2003, 278, 25179-25190. [CrossRef]

31. Perkins, A.; Poole, L.B.; Karplus, P.A. Tuning of peroxiredoxin catalysis for various physiological roles. Biochemistry 2014, 53, 7693-7705. [CrossRef] [PubMed]

32. Peshenko, I.V.; Singh, A.K.; Shichi, H. Bovine eye 1-Cys peroxiredoxin: Expression in E. coli and antioxidant properties. J. Ocul. Pharmacol. Ther. 2001, 17, 93-99. [CrossRef] [PubMed]

33. Fisher, A.B.; Vasquez-Medina, J.P.; Dodia, C.; Sorokina, E.M.; Tao, J.-Q.; Feinstein, S.I. Peroxiredoxin 6 phospholipid hydroperoxidase activity in the repair of peroxidized cell membranes. Redox Biol. 2018, 14, 41-46. [CrossRef] [PubMed]

34. Fisher, A.B. Redox signaling across cell membranes. Antioxid. Redox Signal. 2009, 11, 1349-1356. [CrossRef] [PubMed]

35. Fisher, A.B. Peroxiredoxin 6: A bifunctional enzyme with glutathione peroxidase and phospholipase A2 activities. Antioxid. Redox Signal. 2011, 15, 831-844. [CrossRef] [PubMed]

36. Kim, S.Y.; Jo, H.-Y.; Kim, M.H.; Cha, Y.-Y.; Choi, S.W.; Shim, J.-H.; Kim, T.J.; Lee, K.-Y. $\mathrm{H}_{2} \mathrm{O}_{2}$-dependent hyperoxidation of peroxiredoxin $6(\operatorname{Prdx} 6)$ plays a role in cellular toxicity via up-regulation of iPLA2 activity. J. Biol. Chem. 2008, 283, 33563-33568. [CrossRef] [PubMed]

37. Fisher, A.B. The phospholipase $\mathrm{A}_{2}$ activity of peroxiredoxin 6. J. Lipid Res. 2018, 59, 1132-1147. [CrossRef] 
38. Fisher, A.B. Peroxiredoxin 6 in the repair of peroxidized cell membranes and cell signaling. Arch. Biochem. Biophys. 2017, 617, 68-83. [CrossRef]

39. Bast, A.; Erttmann, S.F.; Walther, R.; Steinmetz, I. Influence of iNOS and COX on peroxiredoxin gene expression in primary macrophages. Free Radic. Biol. Med. 2010, 49, 1881-1891. [CrossRef]

40. Kim, H.S.; Kang, S.W.; Rhee, S.G.; Clerch, L.B. Rat lung peroxiredoxins I and II are differentially regulated during development and by hyperoxia. Am. J. Physiol. Lung Cell. Mol. Physiol. 2001, 280, L1212-L1217. [CrossRef]

41. Kim, H.-S.; Manevich, Y.; Feinstein, S.I.; Pak, J.H.; Ho, Y.S.; Fisher, A.B. Induction of 1-cys peroxiredoxin expression by oxidative stress in lung epithelial cells. Am. J. Physiol. Lung Cell. Mol. Physiol. 2003, 285, L363-L369. [CrossRef]

42. Das, K.C.; Pahl, P.M.; Guo, X.L.; White, C.W. Induction of peroxiredoxin gene expression by oxygen in lungs of newborn primates. Am. J. Respir. Cell. Mol. Biol. 2001, 25, 226-232. [CrossRef] [PubMed]

43. Ito, T.; Kimura, S.; Seto, K.; Warabi, E.; Kawachi, Y.; Shoda, J.; Tabuchi, K.; Yamagata, K.; Hasegawa, S.; Bukawa, H.; et al. Peroxiredoxin I plays a protective role against UVA irradiation through reduction of oxidative stress. J. Dermatol. Sci. 2014, 74, 9-17. [CrossRef] [PubMed]

44. Lee, K.; Park, J.S.; Kim, Y.J.; Soo Lee, Y.; Sook Hwang, T.; Kim, D.J.; Park, E.M.; Park, Y.M. Differential expression of Prx I and II in mouse testis and their up-regulation by radiation. Biochem. Biophys. Res. Commun. 2002, 296, 337-342. [CrossRef]

45. Nguyen, T.; Sherratt, P.J.; Pickett, C.B. Regulatory Mechanisms Controlling Gene Expression Mediated By the Antioxidant Response Element. Annu. Rev. Pharmacol. Toxicol. 2003, 43, 233-260. [CrossRef] [PubMed]

46. Ishii, T.; Itoh, K.; Takahashi, S.; Sato, H.; Yanagawa, T.; Katoh, Y.; Bannai, S.; Yamamoto, M. Transcription factor Nrf2 coordinately regulates a group of oxidative stress-inducible genes in macrophages. J. Biol. Chem. 2000, 275, 16023-16209. [CrossRef]

47. Ma, Q. Role of Nrf2 in Oxidative Stress and Toxicity. Annu. Rev. Pharmacol. Toxicol. 2013, 53, 401-426. [CrossRef] [PubMed]

48. Taguchi, K.; Fujikawa, N.; Komatsu, M.; Ishii, T.; Unno, M.; Akaike, T.; Motohashi, H.; Yamamoto, M. Keap1 degradation by autophagy for the maintenance of redox homeostasis. Proc. Natl. Acad. Sci. USA 2012, 109, 13561-13566. [CrossRef] [PubMed]

49. Hess, A.; Wijayanti, N.; Neuschäfer-Rube, A.P.; Katz, N.; Kietzmann, T.; Immenschuh, S. Phorbol esterdependent activation of peroxiredoxin I gene expression via a protein kinase C, Ras, p38 mitogen-activated protein kinase signaling pathway. J. Biol. Chem. 2003, 278, 45419-45434. [CrossRef]

50. Egler, R.A.; Fernandes, E.; Rothermund, K.; Sereika, S.; de Souza-Pinto, N.; Jaruga, P.; Dizdaroglu, M.; Prochownik, E. V Regulation of reactive oxygen species, DNA damage, and c-Myc function by peroxiredoxin 1. Oncogene 2005, 24, 8038-8050. [CrossRef]

51. Quan, C.; Cha, E.-J.; Lee, H.-L.; Han, K.H.; Lee, K.M.; Kim, W.-J. Enhanced expression of peroxiredoxin I and VI correlates with development, recurrence and progression of human bladder cancer. J. Urol. 2006, 175, 1512-1516. [CrossRef]

52. Riddell, J.R.; Maier, P.; Sass, S.N.; Moser, M.T.; Foster, B.A.; Gollnick, S.O. Peroxiredoxin 1 stimulates endothelial cell expression of VEGF via TLR4 dependent activation of HIF-1 $\alpha$. PLoS ONE 2012, 7, e50394. [CrossRef] [PubMed]

53. Luo, W.; Chen, I.; Chen, Y.; Alkam, D.; Wang, Y.; Semenza, G.L. PRDX2 and PRDX4 are negative regulators of hypoxia-inducible factors under conditions of prolonged hypoxia. Oncotarget 2016, 7, 6379-6397. [CrossRef] [PubMed]

54. Xi, H.; Gao, Y.-H.; Han, D.-Y.; Li, Q.-Y.; Feng, L.-J.; Zhang, W.; Ji, G.; Xiao, J.-C.; Zhang, H.-Z.; Wei, Q. Hypoxia inducible factor- $1 \alpha$ suppresses Peroxiredoxin 3 expression to promote proliferation of CCRCC cells. FEBS Lett. 2014, 588, 3390-3394. [CrossRef] [PubMed]

55. Shah, F.; Goossens, E.; Atallah, N.M.; Grimard, M.; Kelley, M.R.; Fishel, M.L. APE1/Ref-1 knockdown in pancreatic ductal adenocarcinoma-Characterizing gene expression changes and identifying novel pathways using single-cell RNA sequencing. Mol. Oncol. 2017, 11, 1711-1732. [CrossRef]

56. Gallagher, B.M.; Phelan, S.A. Investigating transcriptional regulation of Prdx6 in mouse liver cells. Free Radic. Biol. Med. 2007, 42, 1270-1277. [CrossRef] [PubMed] 
57. Pak, J.H.; Son, W.C.; Seo, S.B.; Hong, S.J.; Sohn, W.M.; Na, B.K.; Kim, T.S. Peroxiredoxin 6 expression is inversely correlated with nuclear factor- $\mathrm{kB}$ activation during Clonorchis sinensis infestation. Free Radic. Biol. Med. 2016, 99, 273-285. [CrossRef] [PubMed]

58. Cong, N.; Huang, W.; Yuan, J.-P.; Li, G.-Z.; Zhai, G.-S.; Li, B.-S. Peroxiredoxin1 promotes cell proliferation, migration and invasion of colorectal cancer via p38MAPK signaling. Eur. Rev. Med. Pharmacol. Sci. 2018, 22, 1922-1928.

59. Sun, H.; Feng, L.; Wang, A.; Wang, J.; Liu, L.; Jin, M.; Shen, G.; Jin, C.; Lee, D.; Kwon, T.; et al. Peroxiredoxin I deficiency increases LPS-induced lethal shock in mice. Mol. Med. Rep. 2018, 18, 2427-2432. [CrossRef]

60. Immenschuh, S.; Stritzke, J.; Iwahara, S.; Ramadori, G. Up-regulation of heme-binding protein 23 (HBP23) gene expression by lipopolysaccharide is mediated via a nitric oxide-dependent signaling pathway in rat Kupffer cells. Hepatology 1999, 30, 118-127. [CrossRef]

61. Liu, G.-Y.; Shi, J.-X.; Shi, S.-L.; Liu, F.; Rui, G.; Li, X.; Gao, L.-B.; Deng, X.-L.; Li, Q.-F. Nucleophosmin Regulates Intracellular Oxidative Stress Homeostasis via Antioxidant PRDX6. J. Cell. Biochem. 2017, 118, 4697-4707. [CrossRef] [PubMed]

62. Guo, Q.J.; Mills, J.N.; Bandurraga, S.G.; Nogueira, L.M.; Mason, N.J.; Camp, E.R.; Larue, A.C.; Turner, D.P.; Findlay, V.J. MicroRNA-510 promotes cell and tumor growth by targeting peroxiredoxin1 in breast cancer. Breast Cancer Res. 2013, 15, R70. [CrossRef] [PubMed]

63. Hopkins, B.L.; Nadler, M.; Skoko, J.J.; Bertomeu, T.; Pelosi, A.; Shafaei, P.M.; Levine, K.; Schempf, A.; Pennarun, B.; Yang, B.; et al. A Peroxidase Peroxiredoxin 1-Specific Redox Regulation of the Novel FOXO3 microRNA Target let-7. Antioxid. Redox Signal. 2018, 28, 62-77. [CrossRef] [PubMed]

64. Joris, V.; Gomez, E.L.; Menchi, L.; Lobysheva, I.; Di Mauro, V.; Esfahani, H.; Condorelli, G.; Balligand, J.-L.; Catalucci, D.; Dessy, C. MicroRNA-199a-3p and MicroRNA-199a-5p Take Part to a Redundant Network of Regulation of the NOS (NO Synthase)/NO Pathway in the Endothelium. Arterioscler. Thromb. Vasc. Biol. 2018, 38, 2345-2357. [CrossRef] [PubMed]

65. Li, Q.; Wang, N.; Wei, H.; Li, C.; Wu, J.; Yang, G. miR-24-3p Regulates Progression of Gastric Mucosal Lesions and Suppresses Proliferation and Invasiveness of N87 Via Peroxiredoxin 6. Dig. Dis. Sci. 2016, 61, 3486-3497. [CrossRef] [PubMed]

66. Zhang, S.; Wang, W.; Gu, Q.; Xue, J.; Cao, H.; Tang, Y.; Xu, X.; Cao, J.; Zhou, J.; Wu, J.; et al. Protein and miRNA profiling of radiation-induced skin injury in rats: The protective role of peroxiredoxin- 6 against ionizing radiation. Free Radic. Biol. Med. 2014, 69, 96-107. [CrossRef] [PubMed]

67. Zhang, B.; Su, Y.; Ai, G.; Wang, Y.; Wang, T.; Wang, F.; Ionizing, P.I. Involvement of peroxiredoxin I in protecting cells from radiation-induced death. J. Radiat. Res. 2005, 46, 305-312. [CrossRef]

68. Chen, W.-C.; McBride, W.H.; Iwamoto, K.S.; Barber, C.L.; Wang, C.-C.; Oh, Y.-T.; Liao, Y.-P.; Hong, J.-H.; de Vellis, J.; Shau, H. Induction of radioprotective peroxiredoxin-I by ionizing irradiation. J. Neurosci. Res. 2002, 70, 794-798. [CrossRef]

69. Miura, Y.; Kano, M.; Yamada, M.; Nishine, T.; Urano, S.; Suzuki, S.; Endo, T.; Toda, T. Proteomic study on $\mathrm{X}$-irradiation-responsive proteins and ageing: Search for responsible proteins for radiation adaptive response. J. Biochem. 2007, 142, 145-155. [CrossRef]

70. An, J.H.; KIM, J.; Seong, J. Redox signaling by ionizing radiation in mouse liver. Ann. N. Y. Acad. Sci. 2004, 1030, 86-94. [CrossRef]

71. An, J.H.; Seong, J.S. Proteomics analysis of apoptosis-regulating proteins in tissues with different radiosensitivity. J. Radiat. Res. 2006, 47, 147-155. [CrossRef] [PubMed]

72. Cerda, M.B.; Lloyd, R.; Batalla, M.; Giannoni, F.; Casal, M.; Policastro, L. Silencing peroxiredoxin-2 sensitizes human colorectal cancer cells to ionizing radiation and oxaliplatin. Cancer Lett. 2017, 388, 312-319. [CrossRef] [PubMed]

73. Wang, T.; Diaz, A.J.G.; Yen, Y. The role of peroxiredoxin II in chemoresistance of breast cancer cells. Breast Cancer Targets Ther. 2014, 6, 73-80. [CrossRef] [PubMed]

74. Diaz, A.J.G.; Tamae, D.; Yen, Y.; Li, J.; Wang, T. Enhanced radiation response in radioresistant MCF-7 cells by targeting peroxiredoxin II. Breast Cancer Targets Ther. 2013, 5, 87-101. [CrossRef]

75. Kim, T.H.; Song, J.; Kim, S.H.; Parikh, A.K.; Mo, X.; Palanichamy, K.; Kaur, B.; Yu, J.; Yoon, S.O.; Nakano, I.; et al. Piperlongumine treatment inactivates peroxiredoxin 4, exacerbates endoplasmic reticulum stress, and preferentially kills high-grade glioma cells. Neuro Oncol. 2014, 16, 1354-1364. [CrossRef] [PubMed] 
76. Kim, T.H.; Song, J.; Alcantara Llaguno, S.R.; Murnan, E.; Liyanarachchi, S.; Palanichamy, K.; Yi, J.-Y.; Viapiano, M.S.; Nakano, I.; Yoon, S.O.; et al. Suppression of peroxiredoxin 4 in glioblastoma cells increases apoptosis and reduces tumor growth. PLoS ONE 2012, 7, e42818. [CrossRef]

77. Park, C.-K.; Kim, J.H.; Moon, M.J.; Jung, J.H.; Lim, S.-Y.; Park, S.-H.; Kim, J.-H.; Kim, D.G.; Jung, H.-W.; Cho, B.-K.; et al. Investigation of molecular factors associated with malignant transformation of oligodendroglioma by proteomic study of a single case of rapid tumor progression. J. Cancer Res. Clin. Oncol. 2008, 134, 255-262. [CrossRef]

78. Lehtonen, S.T.; Svensk, A.-M.; Soini, Y.; Pääkkö, P.; Hirvikoski, P.; Kang, S.W.; Säily, M.; Kinnula, V.L. Peroxiredoxins, a novel protein family in lung cancer. Int. J. Cancer 2004, 111, 514-521. [CrossRef]

79. Yun, H.-M.; Park, K.-R.; Lee, H.P.; Lee, D.H.; Jo, M.; Shin, D.H.; Yoon, D.-Y.; Han, S.B.; Hong, J.T. PRDX6 promotes lung tumor progression via its GPx and iPLA2 activities. Free Radic. Biol. Med. 2014, 69, 367-376. [CrossRef]

80. Yun, H.-M.; Park, K.-R.; Park, M.H.; Kim, D.H.; Jo, M.R.; Kim, J.Y.; Kim, E.-C.; Yoon, D.Y.; Han, S.B.; Hong, J.T. PRDX6 promotes tumor development via the JAK2/STAT3 pathway in a urethane-induced lung tumor model. Free Radic. Biol. Med. 2015, 80, 136-144. [CrossRef]

81. Chang, X.-Z.; Li, D.-Q.; Hou, Y.-F.; Wu, J.; Lu, J.-S.; Di, G.-H.; Jin, W.; Ou, Z.-L.; Shen, Z.-Z.; Shao, Z.-M. Identification of the functional role of peroxiredoxin 6 in the progression of breast cancer. Breast Cancer Res. 2007, 9, 1-15. [CrossRef] [PubMed]

82. Karihtala, P.; Mäntyniemi, A.; Kang, S.W.; Kinnula, V.L.; Soini, Y. Peroxiredoxins in breast carcinoma. Clin. Cancer Res. 2003, 9, 3418-3424. [PubMed]

83. Fujita, Y.; Nakanishi, T.; Hiramatsu, M.; Mabuchi, H.; Miyamoto, Y.; Miyamoto, A.; Shimizu, A.; Tanigawa, N. Proteomics-based approach identifying autoantibody against peroxiredoxin VI as a novel serum marker in esophageal squamous cell carcinoma. Clin. Cancer Res. 2006, 12, 6415-6420. [CrossRef] [PubMed]

84. Hoshino, I.; Nagata, M.; Takiguchi, N.; Nabeya, Y.; Ikeda, A.; Yokoi, S.; Kuwajima, A.; Tagawa, M.; Matsushita, K.; Satoshi, Y.; et al. Panel of autoantibodies against multiple tumor-associated antigens for detecting gastric cancer. Cancer Sci. 2017, 108, 308-315. [CrossRef] [PubMed]

85. Choi, H.; Chang, J.-W.; Jung, Y.-K. Peroxiredoxin 6 interferes with TRAIL-induced death-inducing signaling complex formation by binding to death effector domain caspase. Cell. Death Differ. 2011, 18, 405-414. [CrossRef] [PubMed]

86. Walsh, B.; Pearl, A.; Suchy, S.; Tartaglio, J.; Visco, K.; Phelan, S.A. Overexpression of Prdx6 and resistance to peroxide-induced death in Hepa1-6 cells: Prdx suppression increases apoptosis. Redox Rep. 2009, 14, 275-284. [CrossRef]

87. Pak, J.H.; Choi, W.H.; Lee, H.M.; Joo, W.-D.; Kim, J.-H.; Kim, Y.-T.; Kim, Y.-M.; Nam, J.-H. Peroxiredoxin 6 overexpression attenuates cisplatin-induced apoptosis in human ovarian cancer cells. Cancer Investig. 2011, 29, 21-28. [CrossRef]

88. Raatikainen, S.; Aaaltomaa, S.; Kärjä, V.; Soini, Y.; Karja, V.; Soini, Y. Increased Peroxiredoxin 6 Expression Predicts Biochemical Recurrence in Prostate Cancer Patients After Radical Prostatectomy. Anticancer Res. 2015, 35, 6465-6470.

89. Schmitt, A.; Schmitz, W.; Hufnagel, A.; Schartl, M.; Meierjohann, S. Peroxiredoxin 6 triggers melanoma cell growth by increasing arachidonic acid-dependent lipid signalling. Biochem. J. 2015, 471, 267-279. [CrossRef]

90. Chen, M.-F.; Keng, P.C.; Shau, H.; Wu, C.-T.; Hu, Y.-C.; Liao, S.-K.; Chen, W.-C. Inhibition of lung tumor growth and augmentation of radiosensitivity by decreasing peroxiredoxin I expression. Int. J. Radiat. Oncol. Biol. Phys. 2006, 64, 581-591. [CrossRef]

91. Li, G.; Xie, B.; Li, X.; Chen, Y.; Xu, Y.; Xu-Welliver, M.; Zou, L. Downregulation of peroxiredoxin-1 by $\beta$-elemene enhances the radiosensitivity of lung adenocarcinoma xenografts. Oncol. Rep. 2015, 33, 1427-1433. [CrossRef] [PubMed]

92. Kwee, J.K. A paradoxical chemoresistance and tumor suppressive role of antioxidant in solid cancer cells: A strange case of Dr. Jekyll and Mr. Hyde. Biomed. Res. Int. 2014, 2014. [CrossRef] [PubMed]

93. Song, I.-S.; Kim, H.-K.; Jeong, S.-H.; Lee, S.-R.; Kim, N.; Rhee, B.D.; Ko, K.S.; Han, J. Mitochondrial peroxiredoxin III is a potential target for cancer therapy. Int. J. Mol. Sci. 2011, 12, 7163-7185. [CrossRef] [PubMed]

94. Zhang, B.; Wang, Y.; Su, Y. Peroxiredoxins, a novel target in cancer radiotherapy. Cancer Lett. 2009, 286, 154-160. [CrossRef] [PubMed] 
95. Prosser, C.L.; Painter, E.E.; Lisco, H.; Brues, A.M.; Jacobson, L.O.; Swift, M.N. The Clinical Sequence of Physiological Effects of Ionizing Radiation in Animals. Radiology 1947, 49, 299-313. [CrossRef] [PubMed]

96. Gudkov, S.V.; Popova, N.R.; Bruskov, V.I. Radioprotectors: History, Trends and Prospects. Biofizika 2015, 60, 801-811. [PubMed]

97. Vasin, M.V. Comments on the mechanisms of action of radiation protective agents: Basis components and their polyvalence. Springerplus 2014, 3, 414. [CrossRef]

98. Weiss, J.F.; Landauer, M.R. History and development of radiation-protective agents. Int. J. Radiat. Biol. 2009, 85, 539-573. [CrossRef]

99. Gudkov, A.V.; Komarova, E.A. Radioprotection: Smart games with death. J. Clin. Investig. 2010, 120, 2270-2273. [CrossRef]

100. Petkau, A. Role of superoxide dismutase in modification of radiation injury. Br. J. Cancer. Suppl. 1987, 8, 87-95.

101. Petkau, A. Radiation protection by superoxide dismutase. Photochem. Photobiol. 1978, 28, 765-774. [CrossRef] [PubMed]

102. Epperly, M.W.; Melendez, J.A.; Zhang, X.; Nie, S.; Pearce, L.; Peterson, J.; Franicola, D.; Dixon, T.; Greenberger, B.A.; Komanduri, P.; et al. Mitochondrial targeting of a catalase transgene product by plasmid liposomes increases radioresistance in vitro and in vivo. Radiat. Res. 2009, 171, 588-595. [CrossRef] [PubMed]

103. Palutina, O.A.; Sharapov, M.G.; Temnov, A.A.; Novoselov, V.I. Nephroprotective Effect Exogenous Antioxidant Enzymes during Ischemia/Reperfusion-Induced Damage of Renal Tissue. Bull. Exp. Biol. Med. 2016, 160, 322-326. [CrossRef] [PubMed]

104. Novoselov, S.V.; Peshenko, I.V.; Popov, V.I.; Novoselov, V.I.; Bystrova, M.F.; Evdokimov, V.J.; Kamzalov, S.S.; Merkulova, M.I.; Shuvaeva, T.M.; Lipkin, V.M.; et al. Localization of 28-kDa peroxiredoxin in rat epithelial tissues and its antioxidant properties. Cell Tissue Res. 1999, 298, 471-480. [CrossRef]

105. Chuchalin, A.G.; Novoselov, V.I.; Shifrina, O.N.; Soodaeva, S.K.; Yanin, V.A.; Barishnikova, L.M. Peroxiredoxin VI in human respiratory system. Respir. Med. 2003, 97, 147-151. [CrossRef]

106. Gordeeva, A.E.; Temnov, A.A.; Charnagalov, A.A.; Sharapov, M.G.; Fesenko, E.E.; Novoselov, V.I. Protective Effect of Peroxiredoxin 6 in Ischemia/Reperfusion-Induced Damage of Small Intestine. Dig. Dis Sci. 2015, 60, 3610-3619. [CrossRef]

107. Sharapov, M.G.; Gordeeva, A.E.; Goncharov, R.G.; Tikhonova, I.V.; Ravin, V.K.; Temnov, A.A.; Fesenko, E.E.; Novoselov, V.I. The Effect of Exogenous Peroxiredoxin 6 on the State of Mesenteric Vessels and the Small Intestine in Ischemia-Reperfusion Injury. Biophysics 2017, 62, 998-1008. [CrossRef]

108. Volkova, A.G.; Sharapov, M.G.; Ravin, V.K.; Gordeeva, A.E.; Karaduleva, E.V.; Mubarakshina, E.K.; Temnov, A.A.; Fesenko, E.E.; Novoselov, V.I. Effects of Different Antioxidant Enzymes on The Tracheal Epithelium Regeneration After Chemical Burn. Russ. Pulmonol. 2014, 84-90. [CrossRef]

109. Sharapov, M.; Volkova, A.; Mubarakshina, E.; Novoselov, V.; Soodaeva, S.; Klimanov, I. Antioxidant systems in rat trachea upon thermal and chemical burns of upper airway. Eur. Respir. J. 2013, 42, P527.

110. Sharapov, M.G.; Gudkov, S.V.; Gordeeva, A.E.; Karp, O.E.; Ivanov, V.E.; Shelkovskaya, O.V.; Bruskov, V.I.; Novoselov, V.I.; Fesenko, E.E. Peroxiredoxin 6 is a natural radioprotector. Dokl Biochem. Biophys. 2016, 467, 110-112. [CrossRef]

111. Sharapov, M.G.; Novoselov, V.I.; Fesenko, E.E.; Bruskov, V.I.; Gudkov, S.V. The role of peroxiredoxin 6 in neutralization of X-ray mediated oxidative stress: Effects on gene expression, preservation of radiosensitive tissues and postradiation survival of animals. Free Radic. Res. 2017, 51, 148-166. [CrossRef]

112. Novoselov, V.I.; Ravin, V.K.; Sharapov, M.G.; Sofin, A.D.; Kukushkin, N.I.; Fesenko, E.E. Modified peroxiredoxins as prototypes of drugs with powerful antioxidant action. Biophysics 2011, 56. [CrossRef]

113. Metcalf, D. Hematopoietic cytokines. Blood 2008, 111, 485-491. [CrossRef] [PubMed]

114. Veltri, S.; Smith, J.W. Interleukin 1 trials in cancer patients: A review of the toxicity, antitumor and hematopoietic effects. Stem Cells 1996, 14, 164-176. [CrossRef] [PubMed]

115. Stone, H.B.; Moulder, J.E.; Coleman, C.N.; Ang, K.K.; Anscher, M.S.; Barcellos-Hoff, M.H.; Dynan, W.S.; Fike, J.R.; Grdina, D.J.; Greenberger, J.S.; et al. Models for Evaluating Agents Intended for the Prophylaxis, Mitigation and Treatment of Radiation Injuries Report of an NCI Workshop, December 3-4, 2003. Radiat. Res. 2004, 162, 711-728. [CrossRef] 
116. Gudkov, S.V.; Garmash, S.A.; Shtarkman, I.N.; Chernikov, A.V.; Karp, O.E.; Bruskov, V.I. Long-lived protein radicals induced by $\mathrm{X}$-ray irradiation are the source of reactive oxygen species in aqueous medium. Dokl Biochem. Biophys. 2010, 430, 1-4. [CrossRef]

117. Karp, O.E.; Gudkov, S.V.; Garmash, S.A.; Shtarkman, I.N.; Chernikov, A.V.; Bruskov, V.I. Genotoxic effect of long-lived protein radicals in vivo generated by X-ray irradiation. Dokl Biochem. Biophys. 2010, 434, 250-253. [CrossRef]

118. Peskin, A.V.; Dickerhof, N.; Poynton, R.A.; Paton, L.N.; Pace, P.E.; Hampton, M.B.; Winterbourn, C.C. Hyperoxidation of peroxiredoxins 2 and 3: Rate constants for the reactions of the sulfenic acid of the peroxidatic cysteine. J. Biol. Chem. 2013, 288, 14170-14177. [CrossRef]

119. Rhee, S.G.; Woo, H.A. Multiple functions of peroxiredoxins: Peroxidases, sensors and regulators of the intracellular messenger $\mathrm{H}_{2} \mathrm{O}_{2}$, and protein chaperones. Antioxid. Redox Signal. 2011, 15, 781-794. [CrossRef]

120. Wu, Y.; Feinstein, S.I.; Manevich, Y.; Chowdhury, I.; Pak, J.H.; Kazi, A.; Dodia, C.; Speicher, D.W.; Fisher, A.B. Mitogen-activated protein kinase-mediated phosphorylation of peroxiredoxin 6 regulates its phospholipase $\mathrm{A}_{2}$ activity. Biochem. J. 2009, 419, 669-679. [CrossRef]

121. Farooqui, A.A. Lipid Mediators in the Neural Cell Nucleus: Their Metabolism, Signaling, and Association with Neurological Disorders. Neuroscientist 2009, 15, 392-407. [CrossRef] [PubMed]

122. Zha, X.; Wu, G.; Zhao, X.; Zhou, L.; Zhang, H.; Li, J.; Ma, L.; Zhang, Y. PRDX6 Protects ARPE-19 Cells from Oxidative Damage via PI3K/AKT Signaling. Cell. Physiol. Biochem. 2015, 36, 2217-2228. [CrossRef] [PubMed]

123. Min, Y.; Wi, S.M.; Shin, D.; Chun, E.; Lee, K.-Y. Peroxiredoxin-6 Negatively Regulates Bactericidal Activity and NF-kB Activity by Interrupting TRAF6-ECSIT Complex. Front. Cell. Infect. Microbiol. 2017, 7, 1-13. [CrossRef]

124. Bienert, G.P.; Møller, A.L.; Kristiansen, K.A.; Schulz, A.; Møller, I.M.; Schjoerring, J.K.; Jahn, T.P. Specific aquaporins facilitate the diffusion of hydrogen peroxide across membranes. J. Biol. Chem. 2007, 282, 1183-1192. [CrossRef] [PubMed]

125. Bienert, G.P.; Chaumont, F. Aquaporin-facilitated transmembrane diffusion of hydrogen peroxide. Biochim. Biophys. Acta 2014, 1840, 1596-1604. [CrossRef] [PubMed]

126. Tornroth-Horsefield, S.; Hedfalk, K.; Fischer, G.; Lindkvist-Petersson, K.; Neutze, R. Structural insights into eukaryotic aquaporin regulation. FEBS J. 2010, 584, 2580-2588. [CrossRef] [PubMed]

127. Ishii, T. Close teamwork between Nrf2 and peroxiredoxins 1 and 6 for the regulation of prostaglandin D2 and E2 production in macrophages in acute inflammation. Free Radic. Biol. Med. 2015, 88, 189-198. [CrossRef]

128. Baldwin, A.S. Control of oncogenesis and cancer therapy resistance by the transcription factor NF-kappaB. J. Clin. Investig. 2001, 107, 241-246. [CrossRef]

129. Takada, Y.; Mukhopadhyay, A.; Kundu, G.C.; Mahabeleshwar, G.H.; Singh, S.; Aggarwal, B.B. Hydrogen peroxide activates NF-kappa B through tyrosine phosphorylation of I kappa B alpha and serine phosphorylation of p65: Evidence for the involvement of I kappa B alpha kinase and Syk protein-tyrosine kinase. J. Biol. Chem. 2003, 278, 24233-24241. [CrossRef]

130. Li, W.; Khor, T.O.; Xu, C.; Shen, G.; Jeong, W.-S.; Yu, S.; Kong, A.-N. Activation of Nrf2-antioxidant signaling attenuates NFkappaB-inflammatory response and elicits apoptosis. Biochem. Pharmacol. 2008, 76, 1485-1489. [CrossRef]

131. Liu, G.-H.; Qu, J.; Shen, X. NF-kappaB/p65 antagonizes Nrf2-ARE pathway by depriving CBP from Nrf2 and facilitating recruitment of HDAC3 to MafK. Biochim. Biophys. Acta 2008, 1783, 713-727. [CrossRef] [PubMed]

132. Cuadrado, A.; Martín-Moldes, Z.; Ye, J.; Lastres-Becker, I. Transcription factors NRF2 and NF-kB are coordinated effectors of the Rho family, GTP-binding protein RAC1 during inflammation. J. Biol. Chem. 2014, 289, 15244-15258. [CrossRef] [PubMed]

133. Yao, J.; Zhao, L.; Zhao, Q.; Zhao, Y.; Sun, Y.; Zhang, Y.; Miao, H.; You, Q.-D.; Hu, R.; Guo, Q.-L. NF-kB and Nrf2 signaling pathways contribute to wogonin-mediated inhibition of inflammation-associated colorectal carcinogenesis. Cell. Death Dis. 2014, 5, e1283. [CrossRef] [PubMed]

134. Wang, W.; Xia, T.; Yu, X. Wogonin suppresses inflammatory response and maintains intestinal barrier function via TLR4-MyD88-TAK1-mediated NF-kB pathway in vitro. Inflamm. Res. 2015, 64, 423-431. [CrossRef] [PubMed] 
135. Lee, W.; Ku, S.-K.; Bae, J.-S. Anti-inflammatory Effects of Baicalin, Baicalein, and Wogonin In Vitro and In Vivo. Inflammation 2015, 38, 110-125. [CrossRef] [PubMed]

136. Rithidech, K.N.; Reungpatthanaphong, P.; Honikel, L.; Rusek, A.; Simon, S.R. Dose-rate effects of protons on in vivo activation of nuclear factor-kappa B and cytokines in mouse bone marrow cells. Radiat. Environ. Biophys. 2010, 49, 405-419. [CrossRef] [PubMed]

137. Vénéreau, E.; Ceriotti, C.; Bianchi, M.E. DAMPs from Cell Death to New Life. Front. Immunol. 2015, 6, 422. [CrossRef]

138. Riddell, J.R.; Bshara, W.; Moser, M.T.; Spernyak, J.A.; Foster, B.A.; Gollnick, S.O. Peroxiredoxin 1 controls prostate cancer growth through Toll-like receptor 4-dependent regulation of tumor vasculature. Cancer Res. 2011, 71, 1637-1646. [CrossRef]

139. Shichita, T.; Hasegawa, E.; Kimura, A.; Morita, R.; Sakaguchi, R.; Takada, I.; Sekiya, T.; Ooboshi, H.; Kitazono, T.; Yanagawa, T.; et al. Peroxiredoxin family proteins are key initiators of post-ischemic inflammation in the brain. Nat. Med. 2012, 18, 911-917. [CrossRef]

140. Whitaker, H.C.; Patel, D.; Howat, W.J.; Warren, A.Y.; Kay, J.D.; Sangan, T.; Marioni, J.C.; Mitchell, J.; Aldridge, S.; Luxton, H.J.; et al. Peroxiredoxin-3 is overexpressed in prostate cancer and promotes cancer cell survival by protecting cells from oxidative stress. Br. J. Cancer 2013, 109, 983-993. [CrossRef]

141. Feldman, N.; Rotter-Maskowitz, A.; Okun, E. DAMPs as mediators of sterile inflammation in aging-related pathologies. Ageing Res. Rev. 2015, 24, 29-39. [CrossRef]

142. Du, J.-R.; Kuang, X.; Wang, L.-F.; Yu, L.; Li, Y.-J.; Wang, Y.-N.; He, Q.; Chen, C.; Du, J.-R. Ligustilide ameliorates neuroinflammation and brain injury in focal cerebral ischemia/reperfusion rats: Involvement of inhibition of TLR4/peroxiredoxin 6 signaling. Free Radic. Biol. Med. 2014, 71, 165-175. [CrossRef]

143. Riddell, J.R.; Wang, X.-Y.; Minderman, H.; Gollnick, S.O. Peroxiredoxin 1 stimulates secretion of proinflammatory cytokines by binding to TLR4. J. Immunol. 2010, 184, 1022-1030. [CrossRef] [PubMed]

144. Hellweg, C.E. The Nuclear Factor KB pathway: A link to the immune system in the radiation response. Cancer Lett. 2015, 368, 275-289. [CrossRef]

145. Ishikawa, Y.; Yokoo, T.; Kitamura, M. c-Jun/AP-1, but not NF-kappa B, is a mediator for oxidant-initiated apoptosis in glomerular mesangial cells. Biochem. Biophys. Res. Commun. 1997, 240, 496-501. [CrossRef]

146. Turpaev, K.T. Role of transcription factor AP-1 in integration of cellular signalling systems. Mol. Biol. (Mosk) 2006, 40, 945-961. [CrossRef] [PubMed]

147. Garces de los Fayos Alonso, I.; Liang, H.-C.; Turner, S.; Lagger, S.; Merkel, O.; Kenner, L. The Role of Activator Protein-1 (AP-1) Family Members in CD30-Positive Lymphomas. Cancers (Basel) 2018, 10, 93. [CrossRef]

148. Shaulian, E.; Karin, M. AP-1 as a regulator of cell life and death. Nat. Cell Biol. 2002, 4, E131-E136. [CrossRef]

149. Moreno-Manzano, V.; Ishikawa, Y.; Lucio-Cazana, J.; Kitamura, M. Suppression of Apoptosis by All-trans-Retinoic Acid. J. Biol. Chem. 1999, 274, 20251-20258. [CrossRef]

150. Yokoo, T.; Kitamura, M. Unexpected protection of glomerular mesangial cells from oxidant-triggered apoptosis by bioflavonoid quercetin. Am. J. Physiol. 1997, 273, F206-12. [CrossRef]

151. Park, S. Polyphenol Compound as a Transcription Factor Inhibitor. Nutrients 2015, 7, 8987-9004. [CrossRef] [PubMed]

152. Grigoriev, P.A.; Sharapov, M.G.; Novoselov, V.I. Voltage-dependent cation-selective ion channels formed by peroxiredoxin 6 in a lipid bilayer. Biophysics 2015, 60, 696-699. [CrossRef]

153. Chatterjee, S.; Feinstein, S.I.; Dodia, C.; Sorokina, E.; Lien, Y.C.; Nguyen, S.; Debolt, K.; Speicher, D.; Fisher, A.B. Peroxiredoxin 6 phosphorylation and subsequent phospholipase A2 activity are required for agonist-mediated activation of NADPH oxidase in mouse pulmonary microvascular endothelium and alveolar macrophages. J. Biol. Chem. 2011, 286, 11696-11706. [CrossRef] [PubMed]

154. Manevich, Y.; Shuvaeva, T.; Dodia, C.; Kazi, A.; Feinstein, S.I.; Fisher, A.B. Binding of peroxiredoxin 6 to substrate determines differential phospholipid hydroperoxide peroxidase and phospholipase $\mathrm{A}_{2}$ activities. Arch. Biochem. Biophys. 2009, 485, 139-149. [CrossRef] [PubMed]

155. Hampton, M.B.; Vick, K.A.; Skoko, J.J.; Neumann, C.A. Peroxiredoxin involvement in the initiation and progression of human cancer. Antioxid. Redox Signal. 2017, 28, 591-608. [CrossRef] [PubMed]

156. Kanasty, R.; Dorkin, J.R.; Vegas, A.; Anderson, D. Delivery materials for siRNA therapeutics. Nat. Mater. 2013, 12, 967-977. [CrossRef] [PubMed]

157. Levanova, A.; Poranen, M.M. RNA Interference as a Prospective Tool for the Control of Human Viral Infections. Front. Microbiol. 2018, 9, 2151. [CrossRef] 
158. Zhang, B.; Wang, Y.; Liu, K.; Yang, X.; Song, M.; Wang, Y.; Bai, Y. Adenovirus-mediated transfer of siRNA against peroxiredoxin I enhances the radiosensitivity of human intestinal cancer. Biochem. Pharmacol. 2008, 75, 660-667. [CrossRef]

159. Do Yo, Y.; Chung, Y.M.; Park, J.K.; Ahn, C.M.; Kim, S.K.; Kim, H.J. Synergistic effect of peroxiredoxin II antisense on cisplatin-induced cell death. Exp. Mol. Med. 2002, 34, 273-277. [CrossRef]

160. Guryev, E.L.; Volodina, N.O.; Shilyagina, N.Y.; Gudkov, S.V.; Balalaeva, I.V.; Volovetskiy, A.B.; Lyubeshkin, A.L.; Sen, A.V.; Ermilov, S.A.; Vodeneev, V.A.; et al. Radioactive (90Y) upconversion nanoparticles conjugated with recombinant targeted toxin for synergistic nanotheranostics of cancer. Proc. Natl. Acad. Sci. USA 2018, 115, 9690-9695. [CrossRef]

161. Kłossowski, S.; Muchowicz, A.; Firczuk, M.; Świech, M.; Redzej, A.; Golab, J.; Ostaszewski, R.; Swiech, M.; Redzej, A.; Golab, J.; et al. Studies toward novel peptidomimetic inhibitors of thioredoxin-thioredoxin reductase system. J. Med. Chem. 2012, 55, 55-67. [CrossRef] [PubMed]

162. Trzeciecka, A.; Klossowski, S.; Bajor, M.; Zagozdzon, R.; Gaj, P.; Muchowicz, A.; Malinowska, A.; Czerwoniec, A.; Barankiewicz, J.; Domagala, A.; et al. Dimeric peroxiredoxins are druggable targets in human Burkitt lymphoma. Oncotarget 2016, 7, 1717-1731. [CrossRef] [PubMed]

163. Graczyk-Jarzynka, A.; Zagozdzon, R.; Muchowicz, A.; Siernicka, M.; Juszczynski, P.; Firczuk, M. New insights into redox homeostasis as a therapeutic target in B-cell malignancies. Curr. Opin. Hematol. 2017, 24, 393-401. [CrossRef]

164. Jo, M.; Yun, H.-M.; Park, K.-R.; Park, M.H.; Lee, D.H.; Cho, S.H.; Yoo, H.-S.S.; Lee, Y.-M.; Jeong, H.S.; Kim, Y.; et al. Anti-cancer effect of thiacremonone through down regulation of peroxiredoxin 6. PLoS ONE 2014, 9, e91508. [CrossRef] [PubMed]

165. Lee, H.L.; Park, M.H.; Son, D.J.; Song, H.S.; Kim, J.H.; Ko, S.C.; Song, M.J.; Lee, W.H.; Yoon, J.H.; Ham, Y.W.; et al. Anti-cancer effect of snake venom toxin through down regulation of AP-1 mediated PRDX6 expression. Oncotarget 2015, 6, 22139-22151. [CrossRef] [PubMed]

166. Gudkov, S.V.; Guryev, E.L.; Gapeyev, A.B.; Sharapov, M.G.; Bunkin, N.F.; Shkirin, A.V.; Zabelina, T.S.; Glinushkin, A.P.; Sevost'yanov, M.A.; Belosludtsev, K.N.; et al. Unmodified hydrated C60 fullerene molecules exhibit antioxidant properties, prevent damage to DNA and proteins induced by reactive oxygen species and protect mice against injuries caused by radiation-induced oxidative stress. Nanomedicine 2019, 15, 37-46. [CrossRef] [PubMed]

167. Vasin, M.V.; Semenov, L.F.; Suvorov, N.N.; Antipov, V.V.; Ushakov, I.B.; Ilyin, L.A.; Lapin, B.A. Protective effect and the therapeutic index of indralin in juvenile rhesus monkeys. J. Radiat. Res. 2014, 55, 1048-1055. [CrossRef]

168. Vasin, M.V. Classification of radiation protective agents as a basis of modern radiation pharmacology. Radiat. Biol. Radioecol. 1999, 39, 212-222.

169. Pacifici, F.; Della-Morte, D.; Capuani, B.; Pastore, D.; Bellia, A.; Sbraccia, P.; Di Daniele, N.; Lauro, R.; Lauro, D. Peroxiredoxin6, a Multitask Antioxidant Enzyme Involved in the Pathophysiology of Chronic Non-Communicable Diseases. Antioxid. Redox Signal. 2018, 30, 399-414. [CrossRef]

170. Perkins, A.; Nelson, K.J.; Parsonage, D.; Poole, L.B.; Karplus, P.A. Peroxiredoxins: Guardians against oxidative stress and modulators of peroxide signaling. Trends Biochem. Sci. 2015, 40, 435-445. [CrossRef]

171. Nicolussi, A.; D'inzeo, S.; Capalbo, C.; Giannini, G.; Coppa, A. The role of peroxiredoxins in cancer. Mol. Clin. Oncol. 2017, 6, 139-153. [CrossRef]

(C) 2019 by the authors. Licensee MDPI, Basel, Switzerland. This article is an open access article distributed under the terms and conditions of the Creative Commons Attribution (CC BY) license (http:/ / creativecommons.org/licenses/by/4.0/). 


\title{
Peroxiredoxin 6: The Protector of Male Fertility
}

\author{
Cristian O'Flaherty \\ Departments of Surgery (Urology Division) and Pharmacology and Therapeutics, Faculty of Medicine, \\ McGill University and the Research Institute, McGill University Health Centre, Montréal, QC H4A 3J1, Canada; \\ cristian.oflaherty@mcgill.ca
}

Received: 24 October 2018; Accepted: 21 November 2018; Published: 24 November 2018

check for updates

\begin{abstract}
The spermatozoon is a terminal cell with the unique purpose of delivering the paternal genome to the oocyte during fertilization. Once spermatozoa enter into the female reproductive tract, they count on only the antioxidant protection that they received during spermatogenesis and epididymal maturation. Peroxiredoxins (PRDXs), particularly PRDX6, are important players in the antioxidant protection and regulation of reactive oxygen species (ROS) levels in spermatozoa. PRDX6, through its peroxidase and calcium-independent phospholipase $\mathrm{A}_{2}$ activities, plays a major role in the regulation of ROS to maintain viability and motility and allow the spermatozoon to achieve fertilizing ability during the complex process of capacitation. The absence of PRDX6 is sufficient to promote abnormal reproductive outcomes in mice that resemble what we observe in infertile men. Indeed, Prdx6 $6^{-/}$spermatozoa display low motility and severe DNA damage, which is translated into reduced ability to fertilize oocytes in vitro or produce a low number of pups compared to wild-type controls. This review focuses on the role of PRDX6 as the primary antioxidant enzyme that protects the spermatozoon from oxidative-stress-associated damages to protect the paternal genome and assure fertility.
\end{abstract}

Keywords: spermatozoa; oxidative stress; reactive oxygen species; fertilization; sperm capacitation

\section{Introduction}

The mammalian spermatozoon is a specialized cell with only one purpose: fertilize and deliver the paternal genome to the ovulated oocyte. To accomplish these tasks, the spermatozoon needs to be able to move and to achieve fertilizing capacity to recognize the oocyte. These essential activities for the survival of any species are susceptible to failure. Infertility is a significant human health problem that affects 1 in 6 couples worldwide, and the infertile population has been increasing over the past few decades [1]. The underlying cause in half of these cases can be traced to men [1,2].

Spermatozoa are very sensitive to high levels of reactive oxygen species (ROS), which promote lipid peroxidation [3]. This peroxidative damage is mainly due to the high levels of polyunsaturated fatty acids of their plasma membrane [3,4]. Moreover, the enzymatic antioxidant protection in human spermatozoa is limited. There is relatively little cytoplasm containing superoxide dismutase 1 (SOD1). They do not have catalase [5,6], glutathione peroxidase (GPX) 1, GPX2, GPX3, and GPX5 [7,8], and the mitochondrial mGPX4 is enzymatically inactive in mature spermatozoa [9,10]. Mitochondrial GPX4 is essential during the spermatogenesis to produce normal spermatozoa. This enzyme is needed to build the mitochondrial sheath, an envelope that surrounds the mitochondrial helix in the flagellum, and its absence is associated with male infertility [10,11].

Then, how do healthy spermatozoa control ROS levels and avoid oxidative damage? Spermatozoa contain SOD2, nuclear GPX4, thioredoxin (TRX), TRX reductase (TRD), and the specific sperm TRX1 and $2[6,12,13]$. We found that the six members of the peroxiredoxins (PRDX) family are localized in different sperm compartments (head, mitochondrial sheath, and flagellum), where TRX 
and TRD (enzymes needed for reactivation of PRDX activity) are also found. PRDXs react with different hydrogen peroxides, organic peroxides, and peroxynitrite in spermatozoa $[6,12,13]$. Moreover, we recently reported that reduced levels of PRDXs are associated with male infertility [14]. Thus, PRDXs play an important role in the protection of spermatozoa against oxidative stress. Notably, PRDX6 stands alone as the major player in the protection of spermatozoa against oxidative stress. Indeed, we observed that spermatozoa from infertile patients with either clinical varicocele or idiopathic infertility had lower levels of PRDX6, which correlated with low motility and high levels of lipid peroxidation and DNA damage compared to fertile controls [14]. Animals studies indicated that male mice lacking Prdx6 $6^{-/-}$produced a lower number of pups than the wild-type controls [15]. PRDX6 is a moonlighting enzyme with peroxidase and calcium-independent phospholipase $\mathrm{A}_{2}$ $\left(\mathrm{iPLA} \mathrm{A}_{2}\right)$ activities $[16,17]$. The peroxidase activity is necessary to remove hydrogen peroxide $\left(\mathrm{H}_{2} \mathrm{O}_{2}\right)$, other hydroperoxides, and peroxynitrite $\left(\mathrm{ONOO}^{-}\right)$, and the iPLA $\mathrm{P}_{2}$ activity is essential to repair oxidized membranes [16]. Indeed, PRDX6 PLA $_{2}$ removes the peroxidized phospholipid, and the lysophosphatidylcholine acyl transferase activity (also present in PRDX6) replace it with a nonoxidized phospholipid [17].

\section{PRDX6 and Male Infertility}

Infertility is on the rise, with couples that struggle with infertility increasing from $8 \%$ in the 1980 s to almost $17 \%$ worldwide [1,2]. The prevalence of idiopathic infertility or that associated with clinical varicocele (a dilation of pampiniform plexus veins) is $23 \%$ and $43 \%$, respectively [18]. These are the most common causes of male infertility. We observed that these patients had reduced amounts of PRDXs in seminal plasma and spermatozoa compared to fertile donors [14]. Notably, thiol-oxidized (an inactive) PRDXs levels and the presence of high molecular mass complexes (containing the inactive PRDX6- $\mathrm{SO}_{2}$ ) [12] were also elevated in sperm from infertile men [14]. Due to the low total amount and the oxidation status of PRDXs, very little antioxidant protection (less than 20\%) remains, which explains the impairment of sperm function and poor DNA quality observed in these patients [14]. PRDX6 calcium-independent phospholipase $\mathrm{A}_{2}\left(\mathrm{iPLA}_{2}\right)$ and peroxidase activities are necessary to maintain sperm viability and integrity of the paternal genome [19]. The integrity of the paternal genome is essential to assure fertility.

Spermatozoa from $\operatorname{Prdx}^{-/-}$mice are sensitive to in vitro and in vivo oxidative stress, showing higher levels of lipid peroxidation, S-glutathionylated and oxidized (and non-functional) proteins, abnormal sperm chromatin structure, and a sperm phenotype similar to that of infertile men (abnormal reproductive outcomes, low motility, and oxidative damage in proteins and DNA) [15]. We observed that Prdx6 $6^{-/}$spermatozoa and testes did not have higher levels of other antioxidant enzymes than wild-type (WT) mice (Figure 1). Thus, no compensatory antioxidant enzymes were upregulated in the absence of PRDX6 [15].

Excess of reduced glutathione (GSH) is a cause of reductive stress, which results in an imbalance of the redox status and cytotoxicity [20]. Because spermatozoa contain very little amounts of $\mathrm{GSH}$, this tripeptide is rapidly consumed in cases of oxidative stress, such as the one occurring in the Prdx6 $6^{-/-}$spermatozoa. Indeed, the high levels of S-glutathionylation observed in Prdx6 $6^{-1-}$ spermatozoa accounts for this rapid depletion of GSH [15].

Interestingly, we found that aging worsens the $\operatorname{Prdx} 6^{-/-}$phenotype, with a severe reduction in fertility and greater damage to sperm chromatin compared to age-matched WT controls [21]. These findings are worrisome as some men plan to have children in their $40 \mathrm{~s}$ or beyond due to professional or work priorities. Increasing evidence shows that aging men have increased numbers of abnormal spermatozoa [22]. Thus, this deliberate delay may negatively impact fertility as sperm quality decreases as men age [23-25]. 


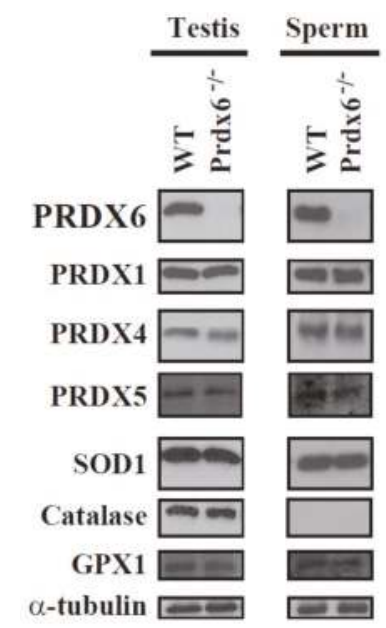

Figure 1. Expression of antioxidant enzymes in wild-type and $\operatorname{Prd} x 6^{-/}$testis and spermatozoa. No compensatory mechanisms by overexpression of other antioxidant enzymes were observed due to the absence of peroxiredoxin 6 (PRDX6) in testes or spermatozoa. Sodium dodecyl sulfate polyacrylamide gel electrophoresis (SDS-PAGE) and immunoblotting of different antioxidant enzymes in C57Bl6J wild-type (WT) or $\operatorname{Prdx} 6^{-/-}$testis and spermatozoa were done as before $[12,15]$. $\alpha$-tubulin was used as loading control $(n=4)$. SOD1: superoxide dismutase 1; GPX1: glutathione peroxidase 1 .

Recently, it was reported that a 50\% reduction in fertilization rate was noted when mouse spermatozoa were treated with conoidin A, a specific inhibitor of 2-Cys PRDXs, compared to untreated controls [26]. Our in vitro studies demonstrated that fertilization rates were reduced by $80 \%$ when using Prdx6 $6^{-/-}$compared to WT spermatozoa, and Prdx6 $6^{-/-}$spermatozoa were unable to produce blastocysts in vitro [27]. Thus, these results indicate that one of the causes of in vitro fertilization failure might also be associated with activity dysfunction of PRDXs, particularly PRDX6, in spermatozoa.

The spermatozoa are unable to move or even fertilize an oocyte when they leave the testis. They must undergo a series of biochemical and morphological transformations to sustain these sperm functions. This process is called sperm maturation and it occurs in the epididymis, an organ composed of a 3-6-meter-long complex and convoluted tubule in humans [28]. During the epididymal transit, the removal of part of the cytoplasm makes the spermatozoa more vulnerable to oxidative stress because it leads to SOD and other cytosolic antioxidant enzymes remaining in low amounts in the maturing spermatozoon [29]. We observed that adult male Sprague-Dawley rats exposed to an in vivo oxidative stress generated by tert-butyl hydroperoxide (tert-BHP) had spermatozoa with decreased motility and increased levels of DNA oxidation and lipid peroxidation along with increased amounts of PRDX1 and PRDX6 compared to control rats [30]. Interestingly, the amount of SOD did not change due to this in vivo treatment. Sperm PRDXs were highly oxidized and therefore inactivated. There was a differential regulation in the expression of PRDX1 and PRDX6 in the epididymis, which suggests a segment-specific role of PRDXs to fight against oxidative stress [30]. These findings are interesting in light of the fact that the spermatozoon is transcriptionally silent; thus, an increase in the protein content should be due to the transfer of proteins from the epididymal epithelium. This increase in the PRDX content in the maturing spermatozoa is a consequence of the response of the epididymis to the in vivo oxidative stress to protect the spermatozoa during their transit through this organ. The epididymis produces epididymosomes, vesicles of different sizes containing proteins with a diverse function from cell adhesion, energy metabolism, and antioxidant protection [31,32]. Through epididymosomes, the epididymis delivers the proteins needed by the 
maturing spermatozoa depending on the stage of maturation and in response to the environmental conditions. Indeed, the fact that PRDX1 and PRDX6 - but not SOD-were increased in sperm from the tert-BHP-treated rats support the specific delivery actions of epididymosomes depending on the type of oxidative stress present in the epididymis [30].

\section{PRDX6 Peroxidase and Phospholipase $A_{2}$ Activities are Important for Sperm Quality}

The spermatozoon is a terminal cell with the unique purpose of delivering the paternal genome to the oocyte during fertilization. They need to survive in the female reproductive tract, move to colonize the oviduct to be capacitated and then to find the oocyte, penetrate the zona pellucida, fuse with the oolemma, and finally form the male pronucleus just before the syngamy. Once the sperm enters into the female genital tract, they leave behind the antioxidant protection that the seminal plasma provides. Then, it is up to the internal antioxidant enzymes the spermatozoon carries to protect the cell during this journey in the female reproductive tract until fertilization occurs.

Sperm motility is severely affected by oxidative stress. The machinery that makes spermatozoon to move is the target of ROS and lipid peroxidation. Enzymes that produce energy and tubulin, the structural protein in the sperm flagellum, are directly oxidized by ROS or modified by ROS-dependent protein modifications and lipid peroxidation. Prdx $6^{-/}$spermatozoa are less viable with lower motility than the WT controls [27]. They have high levels of carbonyl groups and S-glutathionylation than WT controls, indicating the oxidative stress that is going on in the cell, and damage sperm proteins [15]. The significant lower motility observed in Prdx6 $6^{-/}$spermatozoa compared to WT controls can be due to the inhibition of enzymes required to generate energy and the thiol oxidation of tubulin [33-35]. Unsaturated fatty acids are highly susceptible to peroxidation, and lipid peroxidation has been associated with impairment of sperm motility and infertility $[3,36]$.

We observed a lower percentage of WT oocyte with pronuclear formation produced when inseminated with Prdx6 $6^{-/-}$compared to WT spermatozoa during in vitro fertilization [27]. Notably, there was a delay in the formation of pronuclei as a similar number of oocytes with male and female pronuclei were observed at $6 \mathrm{~h}$ or $8-10 \mathrm{~h}$ after in vitro fertilization using WT or Prdx6 $6^{-1-}$ spermatozoa, respectively. This finding indicates damage to the paternal genome. Indeed, Prd $x 6^{-/}$spermatozoa have abnormal chromatin structure, displaying significant higher DNA damage (oxidation and fragmentation) and low levels of protamines (small basic proteins that replaced histones during spermiogenesis to make the sperm nucleus smaller), which result in lower DNA compaction compared to WT controls [15]. This damage of the paternal genome is responsible for the smaller number of pups generated by natural mating with Prdx6 $6^{-/-}$males and WT females [15] or the incapacity to produce healthy embryos in vitro. Certainly, although we obtained a reduced number of zygotes and 2-cell embryos using Prdx6 $6^{-/-}$spermatozoa and WT oocytes, these embryos did not develop to blastocysts (preimplantation embryos) [27]. This phenomenon has been observed when using spermatozoa exposed to radiation $[37,38]$.

Our studies suggest that the PRDX6 iPLA 2 activity is a major factor in the protection of the sperm DNA. We also found lower fertilization rates and percentage of blastocysts when we pretreated WT spermatozoa with 1-hexadecyl-3-(trifluoroethyl)-sn-glycero-2-phosphomethanol lithium (MJ33) [27]. The sperm DNA oxidation levels were higher in human spermatozoa treated with MJ33 compared to nontreated controls or even in spermatozoa treated with conoidin A, an inhibitor of 2-Cys PRDXs, or with ezatiostat, an inhibitor of glutathione-S-transferase $\mathrm{Pi}$, which is an enzyme that participates in the reactivation of the PRDX6 peroxidase activity [19]. Thus, it is possible that failure to achieve fatherhood resides in the inactivation of PRDX6 iPLA 2 in spermatozoa of infertile men.

The origin of the oxidative damage responsible for the reduction of viability, motility, and increased DNA damage is associated with an increase in the production of mitochondrial superoxide anion due to mitochondrial dysfunction in human spermatozoa. The inhibition of both PRDX6 iPLA 2 and peroxidase activities resulted in higher mitochondrial superoxide production compared to those obtained when 2-Cys PRDXs were inhibited [19]. The production 
of 4-hydroxy-2,3-nonenal (4-HNE) was significantly higher in spermatozoa treated with MJ33 or ezatiostat compared to conoidin A, the inhibitor of the 2-Cys PRDXs. These findings indicate that both PRDX6 peroxidase and iPLA 2 activities are essential to control ROS levels and avoid damage associated with lipid peroxidation in the spermatozoa. 4-HNE is a lipid peroxidation product with mutagenic properties that reacts with all four DNA bases, with guanosine the most affected [39]. Thus, ROS promote DNA mutations by directly oxidizing DNA bases (8-hydroxy-2'-deoxyguanosine) or by generating 4 -HNE that will form DNA adducts $[39,40]$ responsible for male infertility.

\section{PRDX6 and Sperm Capacitation}

Ejaculated spermatozoa are unable to fertilize oocytes. They must reside for several hours in the oviduct of the female genital tract to acquire fertilizing ability. Low levels of ROS are necessary for the spermatozoon to acquire fertilizing ability [41,42]. They trigger and regulate phosphorylation events during capacitation to allow the spermatozoon to undergo the acrosome reaction and fertilize the oocyte [42-44]. Sperm capacitation requires a tightly controlled redox signaling [42,45], which is disrupted by inhibition of PRDX activity [46]. The inhibition of 2-Cys PRDXs or PRDX6 iPLA 2 activity promoted a rise in ROS levels, identified by increased lipid peroxidation that did not impair sperm viability, but prevented phosphorylation of protein kinase A (PKA) substrates [47] and residues of tyrosine (a hallmark of sperm capacitation) [48-50], leading to the inhibition of human sperm capacitation [46].

The capacitated spermatozoon needs to undergo the acrosome reaction, an exocytotic event that releases hydrolytic enzymes, to penetrate the glycoprotein-made matrix called zona pellucida, which surrounds the oocyte, fuses with the oolemma, and fertilizes the oocyte [51]. We dissected this process to understand the role of PRDX6 iPLA $_{2}$ activity in fertilization. The percentage of Prdx6 $6^{-/-}$ spermatozoa to undergo acrosome reaction, to bind to the zona pellucida, and to fuse with the oolemma and fertilize the oocyte were lower than in the wild-type controls [15,27,52]. Moreover, wild-type spermatozoa treated with MJ33 during capacitation also had reduced percentages of these parameters compared to untreated controls. Altogether, these results suggest that the PRDX6 iPLA 2 activity is essential for sperm fertility in humans and mice $[15,27,46,52]$.

Different events occur at early, middle, and late stages of sperm capacitation. Under capacitating conditions, spermatozoa produce ROS, particularly superoxide anion, hydrogen peroxide, nitric oxide, and peroxynitrite, at concentrations that do not harm the cell but are necessary to trigger phosphorylation pathways [42,43]. We observed that MJ33 prevented the phosphorylation PKA substrates during human sperm capacitation [46]. This inhibitory effect was prevented when spermatozoa were capacitated with IBMX + dbcAMP, which increased the levels of cAMP bypassing the activation of PKA $[47,49]$. These findings indicate that PRDX6 PLA $_{2}$ activity participates in the early events of human sperm capacitation. Studies are ongoing to elucidate the role of PRDX6 during the early stages of sperm capacitation.

The absence of PRDX6 or pharmacological inhibition of its iPLA 2 activity by MJ33 promotes an increase in lipid peroxidation in the lung [53,54] and spermatozoa [15,27]. It is known that lipid peroxidation products, such as 4 -HNE, can inactivate protein kinase $\mathrm{C}$ and extracellular signal-regulated kinase [55-57]. Because these kinases are needed for sperm capacitation [43,44,58], PRDX6 iPLA $A_{2}$ activity is essential to prevent the formation of products of lipid peroxidation that will produce inactive key enzymes necessary for sperm fertility.

\section{Perspective and Future Research}

There is a need for more research to elucidate whether there are close associations between PRDX6 and other antioxidant enzymes. Although we found that PRDX6 is the primary protector of the paternal genome [19], GPX5 and nuclear GPX4 are also important to protect DNA against oxidation [59,60]. However, contrary to Prdx6 $6^{-/-}$males [15] that show both in vivo and in vitro infertility $[15,27]$, the $\mathrm{nGpx} 4^{-/-}$and $\mathrm{Gpx} 5^{-/-}$and the double GPX4/GPX5 knockout males are fertile [59-61]. 
DNA oxidation is higher in spermatozoa from the double GPX5/nGPX4 double-knockout male mice compared to WT controls, indicating that these enzymes are necessary to avoid DNA damage [61]. The level of other antioxidant enzymes, such as PRDX3, TRX, and GSTpi, are upregulated in the epididymis of the double-knockout males [61]. TRX and GSTpi participate in the reactivation of the peroxidase activity of 2-Cys PRDXs and PRDX6, respectively $[6,13,19]$. The absence of abnormal reproductive outcome (i.e., reduction of litter size, miscarriages, pups with developmental abnormalities) observed in adult males without nGPX4, GPX5, or both enzymes is an indication that other enzymes, such as PRDX6 and 2-Cys PRDXs, and their reactivation systems by TRX and GSTpi are acting to avoid significant oxidative damages, thus maintaining fertility in these modified mice.

Contrary to females, male mice lacking SOD1 are fertile $[62,63]$. It is possible that in $\mathrm{SOD}^{-/-}$ males, there is an upregulation of PRDX6 and/or other antioxidant enzymes to lower the $\mathrm{H}_{2} \mathrm{O}_{2}$ levels produced by the increased levels of superoxide anion. Further studies are necessary to determine whether the absence of other antioxidant enzymes (i.e., GPX4, GPX5, SOD) along with PRDX6 have a greater negative impact on sperm quality.

\section{Conclusions}

The limited protection of spermatozoa against oxidative stress resides in the architecture of this terminal cell. During spermatogenesis and epididymal maturation, part of the large cytoplasm of round and elongated spermatids is removed to generate the characteristic aerodynamic shape. Due to this removal, antioxidant enzymes, such as catalase and SOD, are removed from the forming spermatozoon. The only enzymes with antioxidant capacity are PRDXs, which can be easily thiol-oxidized and therefore inactive. Because ROS are needed for redox signaling associated with the acquisition of fertilizing ability, a delicate balance between ROS production and PRDXs must be established to assure the viability and functionality of the spermatozoon. Deficiencies in PRDX content and activity are plausible causes of male infertility. PRDX6 stands out of the family as the primary protector of the spermatozoon against oxidative stress to protect not only sperm function but the paternal genome, an essential cargo for the preservation of the species.

Funding: This work was supported by Canadian Institutes of Health Research (MOP 133661) to C.O.

Conflicts of Interest: The author declares no conflict of interest. The founding sponsors had no role in the design of the study; in the collection, analyses, or interpretation of data; in the writing of the manuscript, and in the decision to publish the results.

\section{References}

1. Bushnik, T.; Cook, J.L.; Yuzpe, A.; Tough, S.; Collins, J. Estimating the prevalence of infertility in Canada. Hum. Reprod. 2012, 7, 738-746. [CrossRef] [PubMed]

2. World Health Organization. Towards more objectivity in diagnosis and management of male fertility. Int. J. Androl. 1987, 7, 1-53.

3. Alvarez, J.G.; Aitken, R.J. Lipid Peroxidation in Human Spermatozoa. In Studies on Men's Health and Fertility; Agarwal, A., Aitken, R.J., Alvarez, J.G., Eds.; Humana Press: New York, NY, USA, 2012; pp. 119-130.

4. Jones, R.; Mann, T.; Sherins, R. Peroxidative breakdown of phospholipids in human spermatozoa, spermicidal properties of fatty acid peroxides, and protective action of seminal plasma. Fertil. Steril. 1979, 31, 531-537. [CrossRef]

5. Zini, A.; De Lamirande, E.; Gagnon, C. Reactive oxygen species in semen of infertile patients: Levels of superoxide dismutase- and catalase-like activities in seminal plasma and spermatozoa. Int. J. Androl. 1993, 16, 183-188. [CrossRef] [PubMed]

6. O'Flaherty, C. Peroxiredoxins: Hidden players in the antioxidant defence of human spermatozoa. Basic Clin. Androl. 2014, 24, 4. [CrossRef] [PubMed]

7. Chabory, E.; Damon, C.; Lenoir, A.; Henry-Berger, J.; Vernet, P.; Cadet, R.; Saez, F.; Drevet, J.R. Mammalian glutathione peroxidases control acquisition and maintenance of spermatozoa integrity. J. Anim. Sci. 2009, 88, 1321-1331. [CrossRef] [PubMed] 
8. Williams, K.; Frayne, J.; Hall, L. Expression of extracellular glutathione peroxidase type 5 (GPX5) in the rat male reproductive tract. Mol. Hum. Reprod. 1998, 4, 841-848. [CrossRef] [PubMed]

9. Ursini, F.; Heim, S.; Kiess, M.; Maiorino, M.; Roveri, A.; Wissing, J.; Flohe, L. Dual function of the selenoprotein phgpx during sperm maturation. Science 1999, 285, 1393-1396. [CrossRef] [PubMed]

10. Foresta, C.; Flohe, L.; Garolla, A.; Roveri, A.; Ursini, F.; Maiorino, M. Male fertility is linked to the selenoprotein phospholipid hydroperoxide glutathione peroxidase. Biol. Reprod. 2002, 67, 967-971. [CrossRef] [PubMed]

11. Schneider, M.; Forster, H.; Boersma, A.; Seiler, A.; Wehnes, H.; Sinowatz, F.; Neumuller, C.; Deutsch, M.J.; Walch, A.; Hrabe de Angelis, M.; et al. Mitochondrial glutathione peroxidase 4 disruption causes male infertility. FASEB J. 2009, 23, 3233-3242. [CrossRef] [PubMed]

12. O'Flaherty, C.; de Souza, A.R. Hydrogen peroxide modifies human sperm peroxiredoxins in a dose-dependent manner. Biol. Reprod. 2011, 84, 238-247. [CrossRef] [PubMed]

13. O'Flaherty, C. The enzymatic antioxidant system of human spermatozoa. Adv. Androl. 2014, 2014, 1-15.

14. Gong, S.; San Gabriel, M.; Zini, A.; Chan, P.; O'Flaherty, C. Low amounts and high thiol oxidation of peroxiredoxins in spermatozoa from infertile men. J. Androl. 2012, 33, 1342-1351. [CrossRef] [PubMed]

15. Ozkosem, B.; Feinstein, S.I.; Fisher, A.B.; O'Flaherty, C. Absence of peroxiredoxin 6 amplifies the effect of oxidant stress on mobility and SCSA/CMA3 defined chromatin quality and impairs fertilizing ability of mouse spermatozoa. Biol. Reprod. 2016, 94, 1-10. [CrossRef] [PubMed]

16. Fisher, A.B. Peroxiredoxin 6 in the repair of peroxidized cell membranes and cell signaling. Arch. Biochem. Biophys. 2017, 617, 68-83. [CrossRef] [PubMed]

17. Fisher, A.B.; Dodia, C.; Sorokina, E.M.; Li, H.; Zhou, S.; Raabe, T.; Feinstein, S.I. A novel lysophosphatidylcholine acyl transferase activity is expressed by peroxiredoxin 6. J. Lipid Res. 2016, 31, 292-303. [CrossRef] [PubMed]

18. McDougal, W.; Wein, A.; Kavoussi, L.; Novick, A.; Partin, A.; Peters, C.; Ramchandani, P. Campbell-Walsh Urology, 10th ed.; Elsevier Saunders: Philadelphia, PA, USA, 2012.

19. Fernandez, M.C.; O'Flaherty, C. Peroxiredoxin 6 activates maintenance of viability and DNA integrity in human spermatozoa. Hum. Reprod. 2018, 33, 1394-1407. [CrossRef] [PubMed]

20. Zhang, H.; Limphong, P.; Pieper, J.; Liu, Q.; Rodesch, C.K.; Christians, E.; Benjamin, I.J. Glutathione-dependent reductive stress triggers mitochondrial oxidation and cytotoxicity. FASEB J. 2012, 26, 1442-1451. [CrossRef] [PubMed]

21. Ozkosem, B.; Feinstein, S.I.; Fisher, A.B.; O’Flaherty, C. Advancing age increases sperm chromatin damage and impairs fertility in peroxiredoxin 6 null mice. Redox Biol. 2015, 5, 15-23. [CrossRef] [PubMed]

22. Paul, C.; Robaire, B. Ageing of the male germ line. Nat. Rev. Urol. 2013, 10, 227-234. [CrossRef] [PubMed]

23. Kovac, J.R.; Addai, J.; Smith, R.P.; Coward, R.M.; Lamb, D.J.; Lipshultz, L.I. The effects of advanced paternal age on fertility. Asian J. Androl. 2013, 15, 723-728. [CrossRef] [PubMed]

24. Jenkins, T.G.; Aston, K.I.; Meyer, T.; Carrell, D.T. The Sperm Epigenome, Male Aging, and Potential Effects on the Embryo. In The Male Role in Pregnancy Loss and Embryo Implantation Failure; Bronson, R., Ed.; Springer International Publishing: Cham, Switzerland, 2015; pp. 81-93.

25. Conti, S.; Eisenberg, M. Paternal aging and increased risk of congenital disease, psychiatric disorders, and cancer. Asian J. Androl. 2016, 18, 420-424. [PubMed]

26. Ryu, D.-Y.; Kim, K.-U.; Kwon, W.-S.; Rahman, M.S.; Khatun, A.; Pang, M.-G. Peroxiredoxin activity is a major landmark of male fertility. Sci. Rep. 2017, 7, 17174. [CrossRef] [PubMed]

27. Moawad, A.R.; Fernandez, M.C.; Scarlata, E.; Dodia, C.; Feinstein, S.I.; Fisher, A.B.; O’Flaherty, C. Deficiency of peroxiredoxin 6 or inhibition of its phospholipase $A_{2}$ activity impair the in vitro sperm fertilizing competence in mice. Sci. Rep. 2017, 7, 12994. [CrossRef] [PubMed]

28. Robaire, B.; Hinton, B.T.; Orgebin-Crist, M.C. The Epididymis. In Knobil and Neill's Physiology of Reproduction, 3rd ed.; Neill, J.D., Plant, T.M., Pfaff, D.W., Challis, J.R.G., de Kretser, D.M., Richards, J.S., Wassarman, P.M., Eds.; Academic Press: St Louis, MO, USA, 2006; pp. 1071-1148.

29. Aitken, R.J.; Buckingham, D.W.; Carreras, A.; Stewart Irvine, D. Superoxide dismutase in human sperm suspensions: Relationship with cellular composition, oxidative stress, and sperm function. Free Radic. Biol. Med. 1996, 21, 495-504. [CrossRef]

30. Liu, Y.; O'Flaherty, C. In vivo oxidative stress alters thiol redox status of peroxiredoxin 1 and 6 and impairs rat sperm quality. Asian J. Androl. 2017, 19, 73-79. [PubMed] 
31. Sullivan, R.; Frenette, G.; Girouard, J. Epididymosomes are involved in the acquisition of new sperm proteins during epididymal transit. Asian J. Androl. 2007, 9, 483-491. [CrossRef] [PubMed]

32. Thimon, V.; Frenette, G.; Saez, F.; Thabet, M.; Sullivan, R. Protein composition of human epididymosomes collected during surgical vasectomy reversal: A proteomic and genomic approach. Hum. Reprod. 2008, 23, 1698-1707. [CrossRef] [PubMed]

33. Matsushita-Fournier, D.; O'Flaherty, C. Oxidative Stress Induces Redox-Dependent Modifications of Human Sperm and Seminal Plasma Proteins and Damages the Paternal Genome; McGill University: Montreal, QC, Canada, 2015.

34. De Lamirande, E.; Gagnon, C. Reactive oxygen species and human spermatozoa. I. Effects on the motility of intact spermatozoa and on sperm axonemes. J. Androl. 1992, 13, 368-378. [PubMed]

35. De Lamirande, E.; Gagnon, C. Reactive oxygen species and human spermatozoa. II. Depletion of adenosine triphosphate plays an important role in the inhibition of sperm motility. J. Androl. 1992, 13, 379-386. [PubMed]

36. Alvarez, J.G.; Touchstone, J.C.; Blasco, L.; Storey, B.T. Spontaneous lipid peroxidation and production of hydrogen peroxide and superoxide in human spermatozoa. Superoxide dismutase as major enzyme protectant against oxygen toxicity. J. Androl. 1987, 8, 338-348. [CrossRef] [PubMed]

37. Ahmadi, A.; Ng, S.C. Fertilizing ability of DNA-damaged spermatozoa. J. Exp. Zool. 1999, 284, 696-704. [CrossRef]

38. Fatehi, A.N.; Bevers, M.M.; Schoevers, E.; Roelen, B.A.J.; Colenbrander, B.; Gadella, B.M. DNA damage in bovine sperm does not block fertilization and early embryonic development but induces apoptosis after the first cleavages. J. Androl. 2006, 27, 176-188. [CrossRef] [PubMed]

39. Zhong, H.; Yin, H. Role of lipid peroxidation derived 4-hydroxynonenal (4-HNE) in cancer: Focusing on mitochondria. Redox Biol. 2015, 4, 193-199. [CrossRef] [PubMed]

40. Kino, K.; Sugiyama, H. Gc $\rightarrow$ Cg transversion mutation might be caused by 8-oxoguanine oxidation product. Nucleic Acids Symp. Ser. 2000, 44, 139-140. [CrossRef]

41. O'Flaherty, C.; Beorlegui, N.; Beconi, M. Role of Superoxide Anion and Hydrogen Peroxide in Bovine Acrosome Reaction. In Andrology in the 21st Century, Proceedings of the VII International Congress of Andrology, Montreal, QC, Canada, 15-19 June 2001; Robaire, B., Chemes, H., Morales, C., Eds.; Medimond Publications: Englewood, NJ, USA, 2001; pp. 103-108.

42. De Lamirande, E.; O'Flaherty, C. Sperm Capacitation as an Oxidative Event. In Studies on Men's Health and Fertility, Oxidative Stress in Applied Basic Research and Clinical Practice; Aitken, J., Alvarez, J., Agawarl, A., Eds.; Springer Science: Berlin, Germany, 2012; pp. 57-94.

43. O'Flaherty, C.; de Lamirande, E.; Gagnon, C. Positive role of reactive oxygen species in mammalian sperm capacitation: Triggering and modulation of phosphorylation events. Free Radic. Biol. Med. 2006, 41, 528-540. [CrossRef] [PubMed]

44. O'Flaherty, C.; de Lamirande, E.; Gagnon, C. Reactive oxygen species modulate independent protein phosphorylation pathways during human sperm capacitation. Free Radic. Biol. Med. 2006, 40, 1045-1055. [CrossRef] [PubMed]

45. O'Flaherty, C. Redox regulation of mammalian sperm capacitation. Asian J. Androl. 2015, 17, 583-590. [CrossRef] [PubMed]

46. Lee, D.; Moawad, A.; Morielli, T.; Fernandez, M.; O’Flaherty, C. Peroxiredoxins prevent oxidative stress during human sperm capacitation. Mol. Hum. Reprod. 2017, 23, 106-115. [CrossRef] [PubMed]

47. O'Flaherty, C.; de Lamirande, E.; Gagnon, C. Phosphorylation of the Arginine-X-X-(Serine/Threonine) motif in human sperm proteins during capacitation: Modulation and protein kinase A dependency. Mol. Hum. Reprod. 2004, 10, 355-363. [CrossRef] [PubMed]

48. Visconti, P.E.; Bailey, J.L.; Moore, G.D.; Pan, D.; Olds-Clarke, P.; Kopf, G.S. Capacitation of mouse spermatozoa. I. Correlation between the capacitation state and protein tyrosine phosphorylation. Development 1995, 121, 1129-1137. [PubMed]

49. Leclerc, P.; de Lamirande, E.; Gagnon, C. Cyclic adenosine 3',5' monophosphate-dependent regulation of protein tyrosine phosphorylation in relation to human sperm capacitation and motility. Biol. Reprod. 1996, 55, 684-692. [CrossRef] [PubMed]

50. Cormier, N.; Sirard, M.A.; Bailey, J.L. Premature capacitation of bovine spermatozoa is initiated by cryopreservation. J. Androl. 1997, 18, 461-468. [PubMed] 
51. Florman, H.M.; Fissore, R.A. Chapter 4-Fertilization in Mammals. In Knobil and Neill's Physiology of Reproduction, 4th ed.; Plant, T.M., Zeleznik, A.J., Eds.; Academic Press: San Diego, CA, USA, 2015; pp. 149-196.

52. Ozkosem, B.; Moawad, A.; O'Flaherty, C. 228-Peroxiredoxin 6 is involved in the acquisition of fertilizing competence of mouse spermatozoa. Free Radic. Biol. Med. 2015, 87 (Suppl. 1), S104. [CrossRef]

53. Fisher, A.B.; Vasquez-Medina, J.P.; Dodia, C.; Sorokina, E.M.; Tao, J.Q.; Feinstein, S.I. Peroxiredoxin 6 phospholipid hydroperoxidase activity in the repair of peroxidized cell membranes. Redox Biol. 2017, 14, 41-46. [CrossRef] [PubMed]

54. Li, H.; Benipal, B.; Zhou, S.; Dodia, C.; Chatterjee, S.; Tao, J.Q.; Sorokina, E.M.; Raabe, T.; Feinstein, S.I.; Fisher, A.B. Critical role of peroxiredoxin 6 in the repair of peroxidized cell membranes following oxidative stress. Free Radic. Biol. Med. 2015, 87, 356-365. [CrossRef] [PubMed]

55. Chiarpotto, E.; Domenicotti, C.; Paola, D.; Vitali, A.; Nitti, M.; Pronzato, M.A.; Biasi, F.; Cottalasso, D.; Marinari, U.M.; Dragonetti, A.; et al. Regulation of rat hepatocyte protein kinase c beta isoenzymes by the lipid peroxidation product 4-hydroxy-2,3-nonenal: A signaling pathway to modulate vesicular transport of glycoproteins. Hepatology 1999, 29, 1565-1572. [CrossRef] [PubMed]

56. Pronzato, M.A.; Domenicotti, C.; Biasi, F.; Chiarpotto, E.; Cottalasso, D.; Viotti, P.; Melloni, E.; Marinari, U.M.; Poli, G. Inactivation of hepatocyte protein kinase $\mathrm{C}$ by carbon tetrachloride: Involvement of drug's metabolic activation and prooxidant effect. Biochem. Biophys. Res. Commun. 1990, 171, 1353-1360. [CrossRef]

57. Sampey, B.P.; Carbone, D.L.; Doorn, J.A.; Drechsel, D.A.; Petersen, D.R. 4-hydroxy-2-nonenal adduction of extracellular signal-regulated kinase (ERK) and the inhibition of hepatocyte Erk-Est-like protein-1-activating protein-1 signal transduction. Mol. Pharmacol. 2007, 71, 871-883. [CrossRef] [PubMed]

58. De Lamirande, E.; Gagnon, C. The extracellular signal-regulated kinase (ERK) pathway is involved in human sperm function and modulated by the superoxide anion. Mol. Hum. Reprod. 2002, 8, 124-135. [CrossRef] [PubMed]

59. Chabory, E.; Damon, C.; Lenoir, A.; Kauselmann, G.; Kern, H.; Zevnik, B.; Garrel, C.; Saez, F.; Cadet, R.; Henry-Berger, J.; et al. Epididymis seleno-independent glutathione peroxidase 5 maintains sperm DNA integrity in mice. J. Clin. Invest. 2009, 119, 2074-2085. [CrossRef] [PubMed]

60. Conrad, M.; Moreno, S.G.; Sinowatz, F.; Ursini, F.; Kolle, S.; Roveri, A.; Brielmeier, M.; Wurst, W.; Maiorino, M.; Bornkamm, G.W. The nuclear form of phospholipid hydroperoxide glutathione peroxidase is a protein thiol peroxidase contributing to sperm chromatin stability. Mol. Cell Biol. 2005, 25, 7637-7644. [CrossRef] [PubMed]

61. Noblanc, A.; Peltier, M.; Damon-Soubeyrand, C.; Kerchkove, N.; Chabory, E.; Vernet, P.; Saez, F.; Cadet, R.; Janny, L.; Pons-Rejraji, H.; et al. Epididymis response partly compensates for spermatozoa oxidative defects in snGPx4 and GPx5 double mutant mice. PLoS ONE 2012, 7, e38565. [CrossRef]

62. Matzuk, M.M.; Dionne, L.; Guo, Q.; Kumar, T.R.; Lebovitz, R.M. Ovarian function in superoxide dismutase 1 and 2 knockout mice. Endocrinology 1998, 139, 4008-4011. [CrossRef] [PubMed]

63. Ho, Y.S.; Gargano, M.; Cao, J.; Bronson, R.T.; Heimler, I.; Hutz, R.J. Reduced fertility in female mice lacking copper-zinc superoxide dismutase. J. Biol. Chem. 1998, 273, 7765-7769. [CrossRef] [PubMed]

(C) 2018 by the author. Licensee MDPI, Basel, Switzerland. This article is an open access article distributed under the terms and conditions of the Creative Commons Attribution (CC BY) license (http:/ / creativecommons.org/licenses/by/4.0/). 

MDPI

St. Alban-Anlage 66

4052 Basel

Switzerland

Tel. +41616837734

Fax +41 613028918

www.mdpi.com

Antioxidants Editorial Office

E-mail: antioxidants@mdpi.com

www.mdpi.com/journal/antioxidants

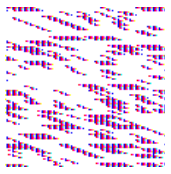



MDPI

St. Alban-Anlage 66

4052 Basel

Switzerland

Tel: +41 616837734

Fax: +41 613028918

www.mdpi.com 